NARIANA MATTOS FIGUEIREDO SOUSA

\title{
Uso da Addenbrooke's Cognitive Examination III (ACE-III) em pacientes com doença de Parkinson idiopática
}

Tese apresentada à Faculdade de Medicina da Universidade de São Paulo para obtenção do título de Doutora em Ciências

Programa de Neurologia

Orientadora: Profa. Dra. Sonia Maria Dozzi Brucki

(Versão corrigida. Resolução CoPGr 6018/11, de 13 de outubro de 2011. A versão original está disponível na Biblioteca da FMUSP)

São Paulo

2021 
Dados Internacionais de Catalogação na Publicação (CIP)

Preparada pela Biblioteca da

Faculdade de Medicina da Universidade de São Paulo

Creproduçāo autorizada pelo autor

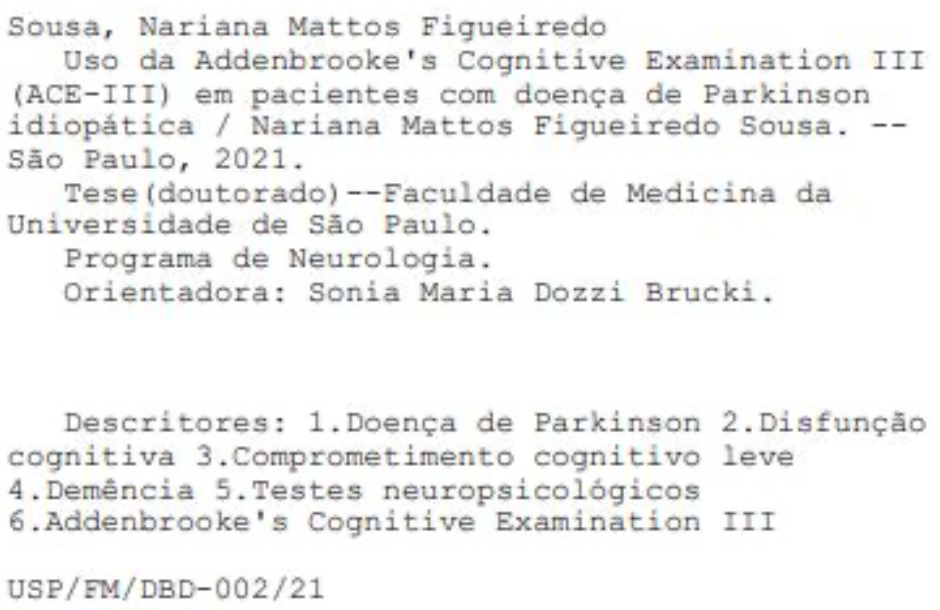

Responsável: Erinalva da Conceição Batista, CRB-8 6755 


\section{DEDICATÓRIA}

Aos pacientes, familiares e voluntários que participaram deste estudo, minha eterna gratidão por contribuir com a ciência. 


\section{AGRADECIMENTOS}

À minha orientadora, Profa. Dra. Sonia Maria Dozzi Brucki, pela oportunidade de aprendizado e enriquecimento nesta área de conhecimento que tenho tanta admiração e encantamento. Minha profunda gratidão.

À Dra. Eneida Mioshi por ter cedido o instrumento para uso nesta pesquisa.

À rede SARAH de Hospitais de Reabilitação, em especial à unidade Salvador, por acreditar e viabilizar esta pesquisa. Sem este apoio não seria possível a execução deste trabalho científico.

À bibliotecária, Marilene Félix, por sempre me ajudar, desde a busca de artigos científicos até a formatação desta tese; além de ser sempre solícita e eficiente. Meu eterno agradecimento.

Às colegas, Adriana Carneiro e à Ana Cristina da Mata Neri, pelo incentivo e ajuda ao longo desse processo. À colega Giovana Serrati, por auxiliar na seleção do grupo controle, com toda organização e presteza das informações. À colega, Juliana Diniz, pelo suporte e amizade. Meu carinho especial às colegas, Márcia Nascimento, Mariângela Cunha Bonfim, Andrea Moura e Ângela Lanzarini.

Aos meus irmãos (Nara Luisa e Josenar), sobrinhos (Mateus e Pedro) e cunhada (Camila), pela compreensão e por terem relevado a minha ausência em alguns momentos durante a minha dedicação a este estudo.

À minha avó (Estela) pelo carinho e amor depositados em mim. 
Ao meu pai que, mesmo não estando mais nesta vida, sempre me incentivou na vida acadêmica. Ao meu tio, Josenar Figueiredo, que sempre valorizou as minhas conquistas.

E, por fim, à minha querida mãe e amiga (Lena Mattos), principal incentivadora, sempre me fez acreditar em minha capacidade de sempre querer mais e nunca parar e/ou desistir. Este mérito também é seu! Te amo! 
"O cientista não é a pessoa que dá as respostas certas, mas quem faz as perguntas certas" (Claude Levi-Strauss). 


\section{NORMALIZAÇÃO ADOTADA}

Esta tese está de acordo com as seguintes normas, em vigor no momento desta publicação:

Referências: adaptado de International Committee of Medical Journals Editors (Vancouver).

Universidade de São Paulo. Faculdade de Medicina. Divisão de Biblioteca e Documentação. Guia de apresentação de dissertações, teses e monografias. Elaborado por Anneliese Carneiro da Cunha, Maria Julia de A. L. Freddi, Maria F. Crestana, Marinalva de Souza Aragão, Suely Campos Cardoso, Valéria Vilhena. 3. ed. São Paulo: Divisão de Biblioteca e Documentação; 2011. Abreviaturas dos títulos dos periódicos de acordo com List of Journals Indexed in Index Medicus. 


\section{SUMÁRIO}

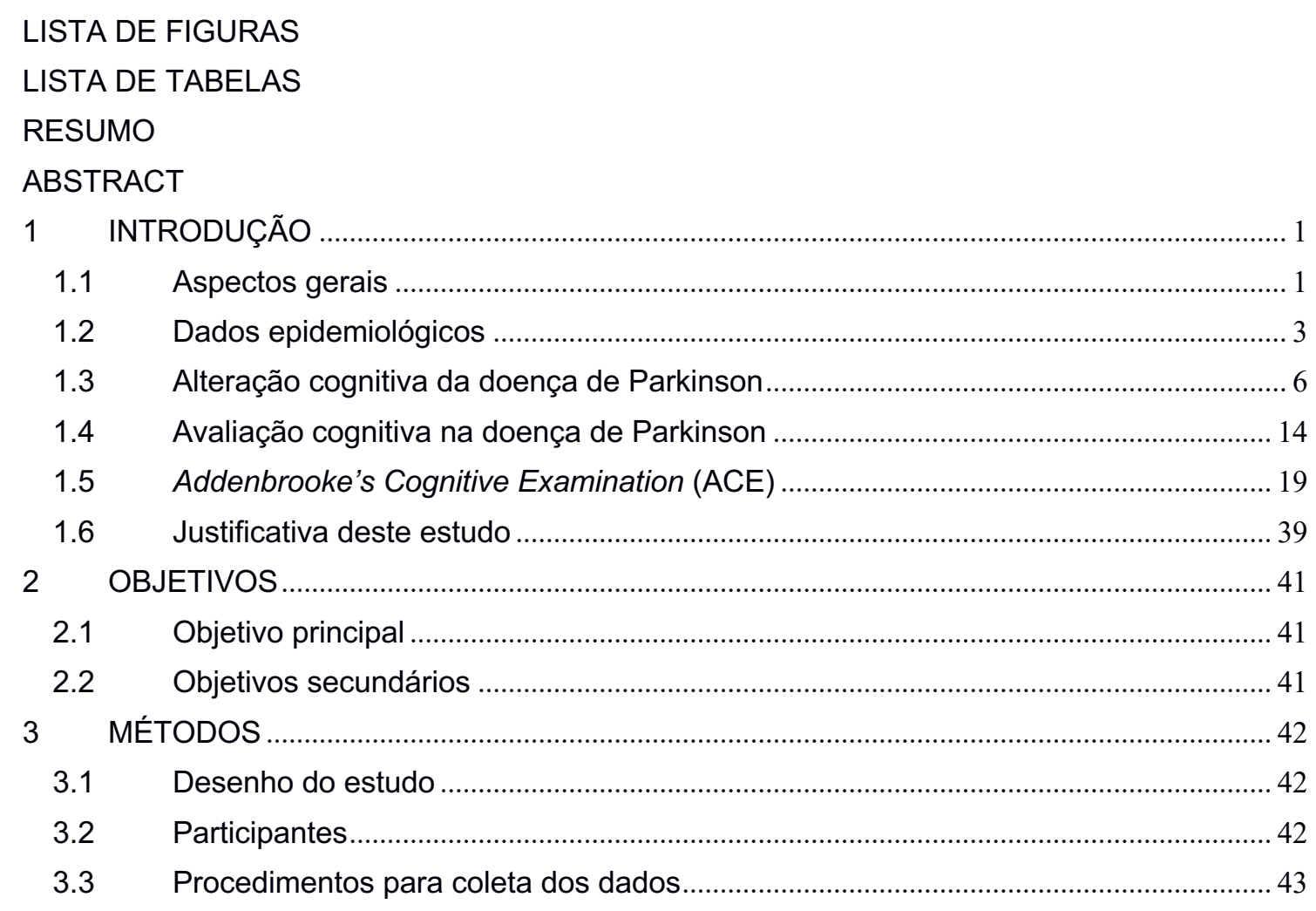

3.3.1 Testes utilizados para avaliação do nível II de comprometimento pela Sociedade de Distúrbios do Movimento (2012) ................................................................................. 46

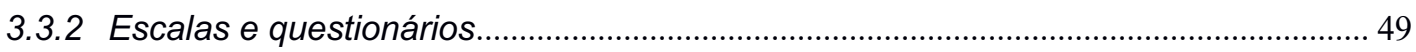

3.4 Procedimentos para análise dos dados...................................................................... 51

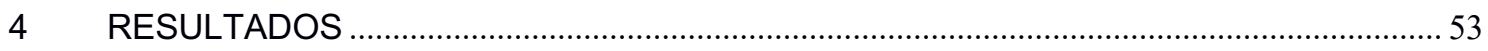

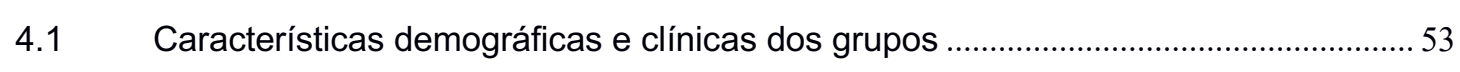

4.2 Comparações entre os subgrupos clínicos e grupo controle .........................................58

4.3 Comparações entre escores da ACE-III, conforme dados demográficos .......................60

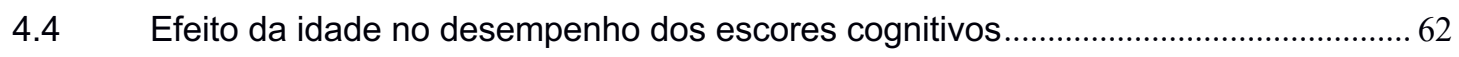

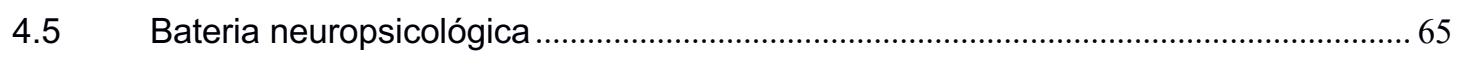

4.6 Notas de corte, sensibilidade e especificidade, da ACE-III, por meio de análises da

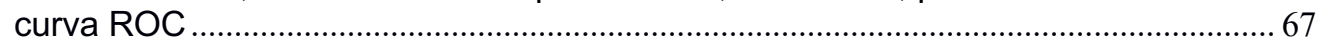

4.7 Notas de corte, sensibilidade e especificidade, da ACE-III, por meio de análises da

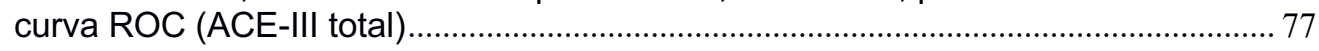

4.8 Notas de corte, sensibilidade e especificidade, da ACE-III, por meio de análises da curva ROC (ACE-III, domínios).

4.9 Notas de corte, sensibilidade e especificidade, da ACE-III, por meio de análises da

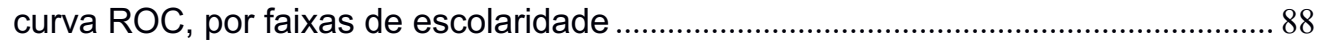

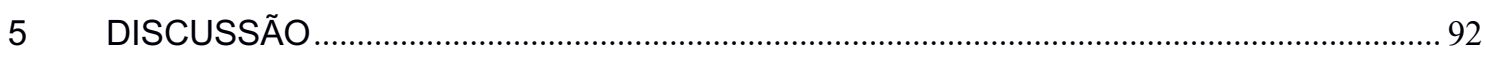

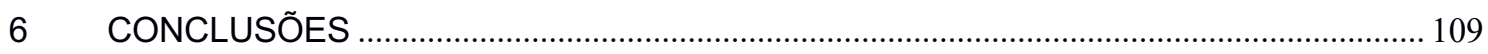

$7 \quad$ ANEXOS 
Anexo A - Addenbrooke's Cognitive Examination (ACE) …….................................................... 112

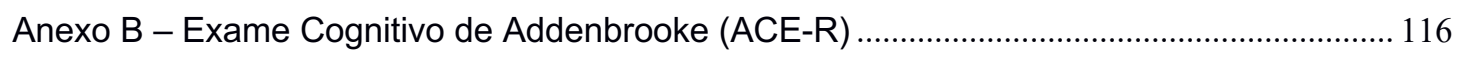

Anexo C - Addenbrooke's Cognitive Examination (ACE-III)...................................................... 122

Anexo D - Addenbrooke's Cognitive Examination (ACE-III) (utilizado neste estudo) .............. 128

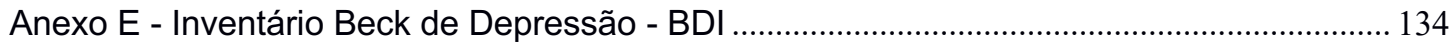

Anexo F - Inventário Beck de Ansiedade - BAI .............................................................................. 136

Anexo G - Questionário de Atividades Funcionais de Pfeffer (QAF) ........................................ 137

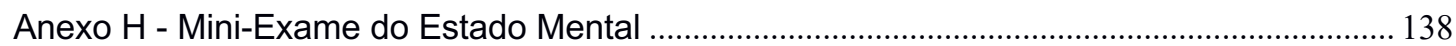

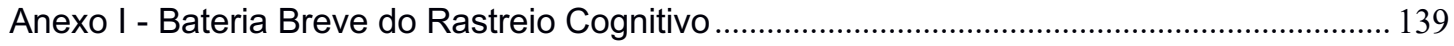

Anexo J - Questionário sobre o Declínio Cognitivo do Idoso (IQCODE) ................................... 141

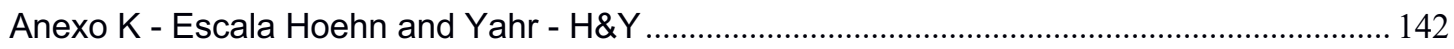

Anexo L - Termo de Consentimento Livre e Esclarecido ................................................................. 143

Anexo M - Aprovação pela Rede SARAH de Hospitais de Reabilitação ..................................... 145

Anexo N - Aprovação pela Faculdade de Medicina da Universidade de São Paulo/FMUSP 148

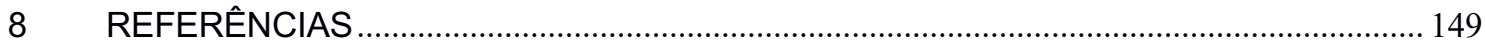

APÊNDICE 


\section{LISTA DE FIGURAS}

Figura 1 - Distribuição da população por sexo, segundo as faixas etárias no Brasil, IBGE 20194

Figura 2 - Fluxograma do protocolo de pesquisa

Figura 3 - Representação gráfica (curva ROC) para discriminar entre controles e pacientes, usando escore total da ACE-III. Área sob a curva ROC foi 0,6192 (95\% IC [0,5395; 0,6990])

Figura 4 - Representação gráfica (curva ROC) para discriminar entre CCL-DP e D-DP, usando escore total da ACE-III. Área sob a curva ROC foi 0,7863 (95\% IC [0,6784; 0,8942])80

Figura 5 - Representação gráfica (curva ROC) para discriminar entre controles saudáveis e CCL-DP, usando escore total da ACE-III. Área sob a curva ROC foi 0,6400 (95\% IC $[0,5535 ; 0,7265])$

Figura 6 - Representação gráfica (curva ROC) para discriminar entre controles saudáveis e DDP, usando escore total da ACE-III. Área sob a curva ROC foi 0,8848 (95\% IC $[0,8003 ; 0,9694])$

Figura 7 - Representação gráfica (curva ROC) para discriminar entre CN-DP e Controle, usando escore total da ACE-III. Área sob a curva ROC foi 0,7142 (95\% IC [0,6004; $0,8281])$

Figura 8 - Representação gráfica (curva ROC) para discriminar controles e pacientes, usando escore total e domínios da ACE-III

Figura 9 - Representação gráfica (curva ROC) para discriminar entre CCL-DP e D-DP, usando escore total e domínios da ACE-III.

Figura 10 - Representação gráfica (curva ROC) para discriminar entre controles saudáveis e CCL-DP, usando escore total e domínios da ACE-III

Figura 11 - Representação gráfica (curva ROC) para discriminar entre controles saudáveis e D-DP, usando escore total e domínios da ACE-III 


\section{LISTA DE TABELAS}

Tabela 1 - Aspectos sociodemográficos dos pacientes atendidos no Hospital SARAH, Salvador-BA......

Tabela 2 - Critérios diagnósticos para avaliação de síndromes demenciais na doença de Parkinson (D-DP). Nível I

Tabela 3 - Avaliação cognitiva proposta pelo Movement Disorder Society, (os testes com padronização/estudos brasileiros estão assinalados - Adaptado de Litvan) (Litvan et al., 2012)

Tabela 4 - Estudos que utilizaram a ACE-III .....

Tabela 5 - Estudo que utilizou a ACE-III na DP

Tabela 6 - Características clínicas e sociodemográficas e comparação entre os grupos clínico e controle.

Tabela 7 - Características clínicas e sociodemográficas e comparação entre os subgrupos clínicos e o grupo controle.

Tabela 8 - Estatística descritiva e inferencial da bateria ACE-III (grupo clínico e controles saudáveis)

Tabela 9 - Estatística descritiva e inferencial da bateria ACE-III

Tabela 10 - Escores na ACE-III (escore total e domínios), por faixas de idade e escolaridade no grupo clínico $(\mathrm{N}=150)$

Tabela 11 - Escores na ACE-III (escore total e domínios), por faixas de idade e escolaridade no grupo controle $(\mathrm{N}=60)$....

Tabela 12 - Dados descritivos da ACE-III (escore total e domínios) do grupo controle, de acordo com a idade (média \pm DP) e comparação entre os subgrupos ..... 63

Tabela 13 - Dados descritivos da ACE-III (escore total e domínios) do grupo CN-DP, de acordo com a idade (média \pm DP) e comparação entre os subgrupos ..... 64

Tabela 14 - Dados descritivos da ACE-III (escore total e domínios) do grupo CCL-DP, de acordo com a idade ((média \pm DP) e comparação entre os subgrupos .... 64

Tabela 15 - Dados descritivos da ACE-III (escore total e domínios) do grupo D-DP, de acordo com a idade (média \pm DP) e comparação entre os subgrupos 65

Tabela 16 - Escores nos testes neuropsicológicos e comparação entre os dois grupos . 66

Tabela 17 - Escores nos testes neuropsicológicos e comparação entre os subgrupos ... 67

Tabela 18 - Coeficientes de correlação e de determinação de escores por idade e escolaridade (ACE-III total e seus domínios)

Tabela 19 - Correlação de Pearson entre variável cognitiva (ACE-III total) e dados clínicos. Grupo clínico.

Tabela 20 - Correlação de Pearson entre variável cognitiva (ACE-III total) e clínicas. Subgrupo CN-DP.

Tabela 21- Correlação de Pearson entre variável cognitiva (ACE-III total) e clínicas. Subgrupo CCL-DP 
Tabela 22 - Correlação de Pearson entre variável cognitiva (ACE-III total) e clínicas. Subgrupo D-DP

Tabela 23 - Correlação entre a ACE-III (escore total) e testes da bateria neuropsicológica (grupo clínico e controles saudáveis)

Tabela 24 - Correlação entre a ACE-III (domínio atenção/orientação) e testes da bateria neuropsicológica (grupo clínico e controles saudáveis)

Tabela 25 - Correlação entre a ACE-III (domínio memória) e testes da bateria neuropsicológica (grupo clínico e controles saudáveis)

Tabela 26 - Correlação entre a ACE-III (domínio fluência verbal) e testes da bateria neuropsicológica (grupo clínico e controles saudáveis)

Tabela 27- Correlação entre a ACE-III (domínio linguagem) e testes da bateria neuropsicológica (grupo clínico e controles saudáveis)

Tabela 28 - Correlação entre a ACE-III (domínio visuoespacial) e testes da bateria neuropsicológica (grupo clínico e controles saudáveis)

Tabela 29 - Notas de corte, sensibilidade e especificidade, para diferenciar controles saudáveis e pacientes, usando escore total da ACE-III

Tabela 30 - Notas de corte, sensibilidade e especificidade, para diferenciar CCL-DP e D-DP, usando escore total da ACE-III

Tabela 31 - Notas de corte, sensibilidade e especificidade, para identificar controles saudáveis e CCL-DP, usando escore total da ACE-III

Tabela 32 - Notas de corte, sensibilidade e especificidade, para identificar controles saudáveis e D-DP, usando escore total da ACE-III...

Tabela 33 - Notas de corte, sensibilidade e especificidade, para diferenciar controles saudáveis e CCL-DP, usando os domínios da ACE-III

Tabela 34 - Notas de corte, sensibilidade e especificidade, para diferenciar controles saudáveis e D-DP, usando os domínios da ACE-III .

Tabela 35 - Notas de corte, sensibilidade e especificidade, para diferenciar CCL-DP e D-DP, usando os domínios da ACE-III

Tabela 36 - Notas de corte, sensibilidade e especificidade, para diferenciar controles saudáveis e pacientes, usando escore total da ACE-III

Tabela 37 - Notas de corte, sensibilidade e especificidade, para diferenciar controles saudáveis e CCL-DP, usando escore total da ACE-III ....

Tabela 38 - Notas de corte, sensibilidade e especificidade, para diferenciar controles saudáveis e D-DP, usando os domínios da ACE-III

Tabela 39 - Comparação entre as propriedades diagnósticas do estudo vigente e anteriores, realizados na DP (ACE e ACE-R)

Tabela 40 - Comparação entre estudo atual e Lucza et al., 2018 


\section{LISTA DE ABREVIATURAS E SIGLAS}

ACE

ACE-R

ACE-III

ANOVA

ACP

APP

AUC/ ROC

BAI

BDI

CCL

CCL-DP

CCSD

CDR

CN-DP

DA

DCB

DCL

D-DP

DFT

DFTve

DP

DM

DPI

DV

ECAS

FAS

FVS

FCR

FTDFRS

$H \& Y$

IBGE

IQCODE

M-ACE

MDRS

MDS

MEEM

MoCA

OMS

PD-CRS

PSP

QAF

RAVLT

SCOPA-COG

SYDBAT
Addenbrooke's Cognitive Examination

Addenbrooke's Cognitive Examination-Revised

Addenbrooke's Cognitive Examination-III

Análise de variância

Atrofia cortical posterior

Afasia progressiva primária

Area under the curve / Receiver Operating Characteristic

Inventário Beck de Ansiedade

Inventário Beck de Depressão

Comprometimento cognitivo leve

Comprometimento cognitivo leve associada a doença de Parkinson

Comprometimento cognitivo sem demência

Clinical Dementia Rating

Cognição normal na doença de Parkinson

Doença de Alzheimer

Degeneração córtico-basal

Demência por corpos de Lewy

Demência associada a doença de Parkinson

Demência frontotemporal

Demência frontotemporal variante comportamental

Desvio-padrão

Demência mista

Doença de Parkinson idiopática

Demência vascular

Edinburgh Cognitive and Behavioural Amyotrophic Lateral Sclerosis

Screen

Fluência verbal fonêmica

Fluência verbal semântica (animais)

Figura Complexa de Rey

Escala Funcional de Demência frontotemporal

Escala Hoehn and Yahr

Instituto Brasileiro de Geografia e Estatistica

Questionário do Informante sobre o Declínio Cognitivo do Idoso

Mini-Exame Cognitivo de Addenbrooke

Escala de Avaliação de Demência desenvolvida por Mattis

Movement Disorder Society

Mini-Exame do Estado Mental

Montreal Cognitive Assessment

Organização Mundial da Saúde

Parkinson's Disease-Cognitive Rating Scale

Paralisia supranuclear progressiva

Questionário de Atividade Funcional

Teste de Aprendizado Auditivo Verbal de Rey

Scales for Outcomes in Parkinson's disease-Cognition

Sydney Language Battery 


\section{LISTA DE SÍMBOLOS}

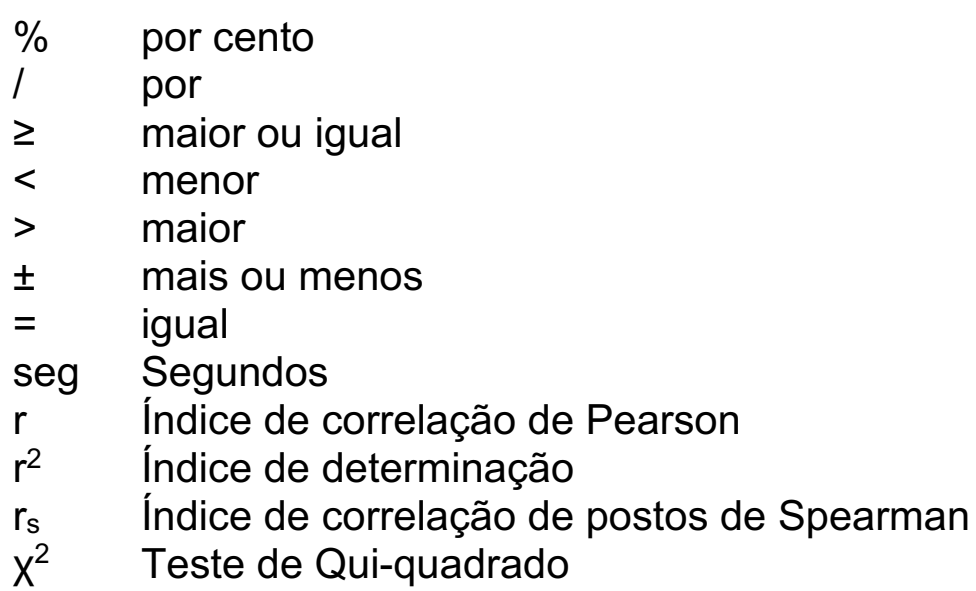




\section{RESUMO}

Sousa NMF. Uso da Addenbrooke's Cognitive Examination III (ACE-III) em pacientes com doença de Parkinson idiopática [tese]. São Paulo: Faculdade de Medicina, Universidade de São Paulo; 2021.

INTRODUÇÃO: A doença de Parkinson idiopática, condição neurodegenerativa progressiva, é caracterizada por sintomas, como tremor, rigidez, bradicinesia e instabilidade postural. As manifestações não motoras, como distúrbios do sistema nervoso autônomo, fadiga, distúrbios do sono, transtornos afetivos, alterações cognitivas e neuropsiquiátricas podem estar presentes ao longo da evolução da doença. $O$ déficit cognitivo na doença de Parkinson idiopática é uma importante causa de incapacidade funcional nestes pacientes e a detecção precoce, com instrumentos sensíveis, pode auxiliar no acompanhamento longitudinal. OBJETIVOS: Investigar a acurácia diagnóstica, sensibilidade e especificidade, do Exame Cognitivo de Addenbrooke, terceira versão, como ferramenta de avaliação cognitiva breve em pacientes com diagnóstico de doença de Parkinson idiopática. MÉTODOS: Estudo de corte transversal, observacional, do tipo caso-controle. Foram selecionados 150 pacientes com Doença de Parkinson Idiopática, conforme os critérios de diagnóstico clínico do Banco de Cérebro da Sociedade Britânica de doença de Parkinson, e 60 controles saudáveis, pareados por idade, sexo e escolaridade. Realizada a aplicação da ACE-III e bateria neuropsicológica, através de testes que avaliam os domínios atencionais, mnemônicos, funções visuoespaciais/visuo-construtivas, funções executivas e linguagem. RESULTADOS: O grupo clínico foi dividido em quatro subgrupos, tais como cognição normal na doença de Parkinson (CN-DP - 24 pacientes - 16\%), comprometimento cognitivo leve devido a doença de Parkinson (CCL-DP - 104 pacientes - 69,33\%), demência devido à doença de Parkinson (D-DP - 22 pacientes - 14,66\%) e indivíduos sem DPI e cognição normal (controles). Obtivemos notas de corte capazes de identificar alterações cognitivas entre os grupos: CCL-DP e D-DP de controles saudáveis, tendo notas de corte de $85 / 100$ (sensibilidade $=58,65 \%$, especificidade $=60 \%, \quad A U C=0,64$ ) e $81 / 100$ pontos (sensibilidade $=81,82 \%$, especificidade $=75 \%, A \cup C=0,88$ ), para detectar CCL-DP e D-DP, respectivamente. A idade foi inversamente associada ao desempenho dos escores (totais e domínios da ACE-III), enquanto os anos de escolaridade exerceram uma correlação significantemente positiva no desempenho destes escores. Houve correlação significante com os testes neuropsicológicos padronizados para esta população. CONCLUSÕES: A detecção precoce de comprometimento cognitivo, através de instrumentos breves e sensíveis para esta população, como a ACE-III facilita a possibilidade de intervenção precoce e ajustes no estilo de vida.

Descritores: Doença de Parkinson; Disfunção cognitiva; Comprometimento Cognitivo Leve; Demência; Testes Neuropsicológicos; Addenbrooke's Cognitive Examination III. 


\begin{abstract}
Sousa NMF. Use of Addenbrooke's Cognitive Examination III (ACE-III) in patients with idiopathic Parkinson's disease [thesis]. São Paulo: "Faculdade de Medicina, Universidade de São Paulo"; 2021.
\end{abstract}

INTRODUCTION: Parkinson's disease, progressive neurodegenerative condition, is characterized by symptoms, such as tremor, stiffness, bradykinesia; and postural instability. Non-motor manifestations, such as disorders of the autonomic nervous system, fatigue, sleep disorders, affective disorders, cognitive and neuropsychiatric disorders may be present throughout the course of the disease. Cognitive deficit in idiopathic Parkinson's disease is an important cause of functional disability in these patients and early detection, with sensitive instruments, can contribute to longitudinal monitoring. OBJECTIVES: To investigate the diagnostic accuracy, sensitivity and specificity of the Addenbrooke Cognitive Examination, third version, as a brief cognitive assessment tool in patients diagnosed with idiopathic Parkinson's disease. METHODS: Cross-sectional, observational, case-control study. 150 patients with IPD were selected, according to the clinical diagnosis criteria of the British Society of Parkinson's Disease Brain Bank, and 60 healthy controls, matched for age, sex and education. The application of ACE-III and neuropsychological battery was carried out, through tests that evaluate the attentional, mnemonic domains, visuospatial/visuoconstructive functions, executive functions and language. RESULTS: A total of 150 patients and 60 healthy controls were recruited for this study. The clinical group was divided into four subgroups, such as normal cognition in Parkinson's disease (NC-DP - 24 patients - 16\%), mild cognitive impairment due to Parkinson's disease (MCl-DP - 104 patients 69.33\%) and dementia due to Parkinson's disease (D-PD - 22 patients $14.66 \%)$. ACE-III was useful to differentiate groups: with cut-off scores of $85 / 100$ (sensibility $=58.65 \%$, specificity $=60 \%, \quad A U C=0.64$ ) e $81 / 100$ pontos (sensibility $=81.82 \%$, specificity $=75 \%, A \cup C=0.88$ ), to detect MCI-PD and D-PD, respectively. Age was inversely associated with the performance of the scores (totals and domains of the ACE-III), while the years of schooling had a significantly positive correlation in the performance of these scores. There was a significant correlation with standardized neuropsychological tests for this population. CONCLUSIONS: The early detection of cognitive impairment, using brief and sensitive instruments for this population, as ACE-III, facilitates the possibility of early intervention and lifestyle adjustments.

Descriptors: Parkinson disease; Cognitive Dysfunction; Mild Cognitive Impairment; Dementia; Neuropsychological Tests; Addenbrooke's Cognitive Examination III. 


\section{INTRODUÇÃO}

\subsection{Aspectos gerais}

O termo doença de Parkinson idiopática (DPI) ou parkinsonismo primário é usado para se referir à síndrome clássica descrita por James Parkinson em 1817, parkinsonismo secundário ou adquirido para se referir ao parkinsonismo resultante de etiologias variadas (vascular, traumática, por uso de medicamentos antipsicóticos) e parkinsonismo atípico para se referir àquelas condições em que uma síndrome parkinsoniana é acompanhada de outros sinais neurológicos adicionais (Merrit, 2007).

A DPI é uma condição neurodegenerativa progressiva descrita inicialmente como um distúrbio do movimento, caracterizado por sintomas, como tremor, rigidez, bradicinesia e instabilidade postural (Goldman e Bennett 2001; Lees et al., 2009). Atualmente, outros sintomas passam a receber igual atenção pela repercussão na qualidade de vida dos pacientes, como: dor, fadiga, disautonomia, distúrbios do sono, transtornos afetivos, declínio cognitivo e sintomas neuropsiquiátricos (Kulisevsky e Pagonabarraga, 2009; Kudlicka et al., 2011; Kaszás et al., 2012; Todorova et al., 2014).

Estudos mencionam que o processo neurodegenerativo apresenta uma progressão ascendente acometendo, inicialmente, as terminações neurais olfatórias, em seguida, tronco encefálico, particularmente, o mesencéfalo. No mesencéfalo, mais precisamente, nos núcleos dorsais do vago, no núcleo do glossofaríngeo, no núcleo olfatório e na área intermédia (Cersosismo et al., 2018; Teive, 2000; Braak et al., 2003). A degeneração dos neurônios produtores de dopamina na substância negra e área tegmentar ventral e, 
consequentemente, a interrupção nas vias estriatais e cortico-límbicas podem justificar como alterações motoras e cognitivo-comportamentais (Janvin et al., 2006; Benazzouz et al., 2014). A DPI é caracterizada pela deposição de agregados intraneuronais de, principalmente, composto de gene alfa-sinucleina como corpos de Lewy na região conhecida como substantia nigra pars compacta do cérebro, levando à morte de neurônios dopaminérgicos (Dinda et al., 2019).

A causa é idiopática. Fatores genéticos, neurotoxinas ambientais, estresse oxidativo, anormalidades mitocondriais (diminuição da atividade do complexo I da cadeia respiratória mitocondrial e da alfacetoglutarato desidrogenase), excitotoxicidade, fatores inflamatórios (estudos sugerem aumento de IL-1 B, INF- $\gamma$ e TNF- $\alpha$ ) são descritos como alguns dos mecanismos etiopatogênicos da doença (Teive 2000; Teive e Meneses 2003).

A partir de cada área acometida pela doença, surgem manifestações clínicas. Para ocorrer repercussão clínica, a perda desses neurônios dos núcleos da base (substância negra) tem que ser superior a 60\% (Wirdefeldt et al., 2011). Além da depleção do neurotransmissor dopamina, outras catecolaminas e serotonina também são acometidas, o que contribui para o aparecimento de sintomas não motores, como disfunções autonômicas (hipotensão, constipação), anosmia, parestesias, ansiedade, depressão, distúrbios do sono (acometimento da substância reticular). Com a evolução da doença, ocorre o acometimento do neocórtex, surgindo os distúrbios cognitivos e demência (Wakabayashi et al., 2007; Irwin et al., 2012; Caspell-Garcia et al., 2017). 
O diagnóstico da DPI é clínico e se caracteriza pelo aparecimento de, pelo menos, dois sinais dos sintomas motores, com exclusão de outras causas de parkinsonismo. A presença do sintoma unilateral e a resposta ao uso de levodopa corroboram para o diagnóstico (Lau et al., 2006).

\subsection{Dados epidemiológicos}

Estudos epidemiológicos confirmam que, com o avançar da idade, há um aumento da prevalência da doença de Parkinson, aumentando progressivamente em até dez vezes por volta dos 50-80 anos. Dados nacionais estimam que a expectativa de vida no Brasil, em 2030, será de 78,6 anos e, em 2060, de 81,2 anos. Ou seja, com o aumento da população idosa também teremos um maior número de pessoas com a doença de Parkinson, visto que há aumento da prevalência com a idade, variando 425 e 428 casos a cada 100.000 pessoas entre 60 e 74 anos de idade, e um discreto predomínio no sexo masculino (Pringsheim et al., 2014). 
Distribuição da População por sexo segundo os grupos de idade (em mil pessoas) - Brasil - 2010
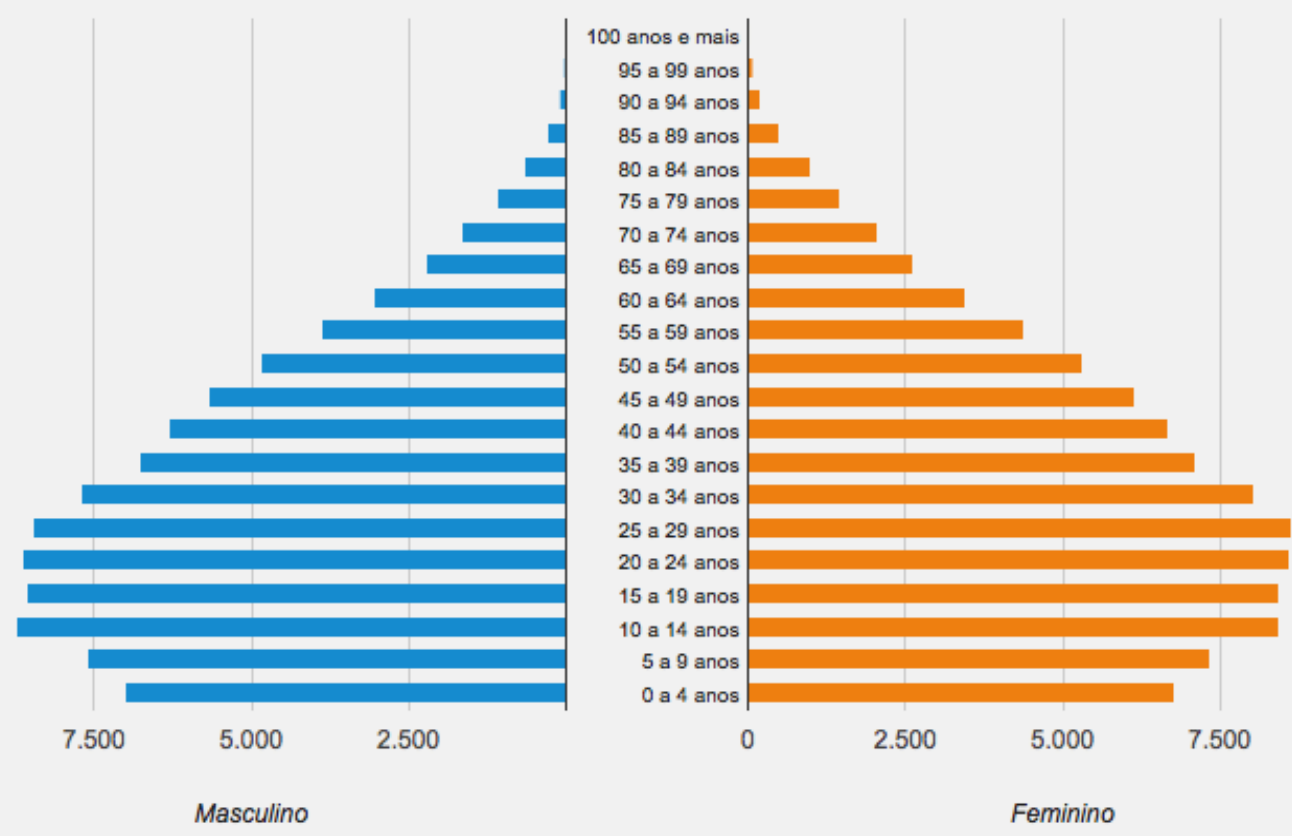

Figura 1 - Distribuição da população por sexo, segundo as faixas etárias no Brasil, IBGE 2019

A Organização Mundial da Saúde (OMS) (Fernandes e Andrade Filho 2018) estima que $1 \%$ da população acima de 65 anos seja acometida por essa doença. Em 2005, mais de 4 milhões de indivíduos com idade superior a 50 anos possuíam a doença. A projeção para 2030 é que esse número duplique. Nos Estados Unidos, surgem cerca de 59 mil casos por ano. No Brasil, os estudos epidemiológicos são escassos, mas estima-se que haja 200 mil portadores da doença e que o número de pacientes com DPI no Brasil dobrará até 2030 (Steidl et al., 2007; Wirdefeldt et al., 2011).

Uma estimativa não oficial sugere que existem 220.000 casos em todo o país (Barbosa et al., 2006), mas um estudo realizado no estado de Minas Gerais encontrou prevalência de $3,3 \%$ entre os idosos com idade acima e igual a 65 anos. Se tomarmos esse valor como referência e os dados populacionais disponíveis, pode-se inferir que o número de casos de DPI em todo o país pode 
alcançar 630.000. Este número, entretanto, não considerou pacientes com idade menor e igual a 64 anos (Bovolenta e Felício, 2017).

No estado da Bahia, um estudo (Fernandes e Andrade Filho, 2018) mostrou que entre 2005 a 2015, houve maior proporção de indivíduos entre as faixas de idade de 60-69 anos, casados, cor parda e do sexo masculino com diagnóstico de doença de Parkinson.

No hospital SARAH, Unidade Salvador, Bahia, podemos observar, na Tabela 1, que nos últimos cinco anos, no momento da admissão médica, houve uma maior proporção de homens $(65 \%)$, casados $(66 \%)$, ensino médio completo (37\%), com uma média de idade de 63,3 anos, sendo a maior parte aposentada e pensionista não especificada (58\%). Dados similares à literatura, principalmente quanto à faixa de idade e maior predominância do sexo masculino. 
Tabela 1 - Aspectos sociodemográficos dos pacientes atendidos no Hospital SARAH, Salvador-BA

\begin{tabular}{lcc}
\hline & Frequência Absoluta & Frequência Relativa \\
\hline Idade & 5 & \\
\hline $27-36$ & 33 & $1 \%$ \\
$37-46$ & 114 & $6 \%$ \\
$47-56$ & 186 & $20 \%$ \\
$57-66$ & 179 & $32 \%$ \\
$67-76$ & 52 & $31 \%$ \\
$77-86$ & 4 & $9 \%$ \\
$87-96$ & & $1 \%$ \\
Escolaridade & 26 & \\
\hline Ensino Médio Incompleto & 213 & $5 \%$ \\
Ensino Médio Completo & 19 & $37 \%$ \\
Superior Incompleto & 100 & $3 \%$ \\
Superior Completo & 18 & $17 \%$ \\
Pós-graduação & 4 & $3 \%$ \\
Mestrado & 1 & $1 \%$ \\
Doutorado & & $0 \%$ \\
Sexo & 371 & $65 \%$ \\
\hline Masculino & 202 & $35 \%$ \\
Feminino & & \\
Ocupação & 332 & \\
\hline Aposentados e pensionistas não & & \\
especificados & & \\
\hline
\end{tabular}

\subsection{Alteração cognitiva da doença de Parkinson}

A disfunção dopaminérgica nesta condição neurológica produz sintomatologia similar a lesões frontais, ocasionando mudanças cognitivas (domínios atencionais e executivos) e comportamentais. Além desta via de transmissão neuroquímica, a perda da inervação colinérgica e noradrenérgica também são mencionadas (Piovezan et al., 2007; Nardone et al., 2017), principalmente, ao longo da evolução da doença e em casos de síndromes demenciais (Jankovic e Tolosa, 2015). 
A DPI foi inicialmente descrita como sendo uma desordem exclusivamente motora, negligenciando-se as alterações cognitivas associadas à doença. Desde os estágios iniciais, em torno de $20-30 \%$ dos pacientes apresentam alguma dificuldade cognitiva e, parte destes evoluem para uma síndrome demencial. As alterações cognitivas são uma importante causa de incapacidade funcional nesses pacientes (Barbosa et al., 2006; Kulisevsky e Pagonabarraga, 2009; Kudlicka et al., 2011; Kaszás et al., 2012; Rolinski et al., 2012; Papagno e Trojano, 2018).

Estudos revelam que o comprometimento cognitivo leve na DPI (CCL-DP) é frequente, inclusive, nos estágios iniciais da doença, porém pode apresentar características heterogêneas, com diferenças na sua progressão para demência e diferenças prováveis na fisiopatologia subjacente (Goldman et al., 2018).

As alterações cognitivas podem estar presentes desde os estágios iniciais da doença, mas tendem a predominar o quadro clínico à medida que a doença progride. Cerca de $40 \%$ dos pacientes com DPI apresentam déficits cognitivos em vários domínios cognitivos, incluindo atenção, memória operacional e funções executivas, linguagem, habilidades visuoespaciais e memória episódica. Em estágios posteriores da doença, declínio cognitivo e distúrbios comportamentais ocorrem para determinar demência clinicamente relevante associada à DPI. Parte dessas alterações é atribuída a uma disfunção dependente de dopamina de vias frontoestriatais, mas há uma heterogeneidade considerável, bem como influência de outros sistemas 
neurotransmissores, como o colinérgico, principalmente responsável pela síndrome demencial na DPI (Papagno e Trojano, 2018).

As alterações na conectividade de rede funcional foram descritas em pacientes com a DPI com comprometimento cognitivo, em um estudo de metaanálise, cujo objetivo foi identificar estudos que utilizaram neuroimagem funcional nestes pacientes. Foram selecionados dezessete estudos, consistindo em 222 pacientes com CCL-DP, 68 D-DP, 289 pacientes com DP com comprometimento cognitivo e 353 controles saudáveis. Pacientes com doença de Parkinson com comprometimento cognitivo mostraram predominantemente uma conectividade reduzida em regiões específicas do cérebro que fazem parte da default mode network. Desta forma, o prejuízo cognitivo estava associado à conectividade reduzida em redes relevantes para a cognição, mais proeminentemente a default mode network. Alterações específicas na conectividade funcional podem contribuir para o declínio cognitivo em pacientes com Parkinson e pode ser um biomarcador futuro promissor (Wolters et al., 2019).

Estudos estruturais de ressonância magnética revelaram mudanças consideráveis na substância cinzenta e branca em pacientes com DPI com disfunção cognitiva, mostrando alterações, tais como atrofia e difusividade acentuadas em pacientes com demência. Os substratos neurais de comprometimento cognitivo leve nesta condição neurológica são mais variáveis (Hall e Lewis, 2019).

Dentre as alterações cognitivas, a disfunção executiva ou síndrome disexecutiva ocorre com mais frequência, principalmente nos estágios iniciais da doença (Chow e Cummings, 1999; Barbosa et al., 2006; Stella et al., 2007; 
Piovezan et al., 2007; Bocanegra et al., 2014; Cerasa et al., 2014; Petrelli et al., 2015; Bovolenta e Felício, 2017; Galtier et al., 2017; Papagno e Trojano, 2018; Wolters et al., 2019; Hall e Lewis, 2019). Este domínio cognitivo está relacionado com a capacidade para antecipar, planejar, iniciar e monitorar o comportamento dirigido a objetivos, que diante de novas informações deve ser flexibilizado e reformulado (Petrelli et al., 2015). Os pacientes com a DPI têm mais dificuldade na formação de conceitos e estabelecimento de regras durante a execução da tarefa. São mais inflexíveis, além de ter reduzido desempenho em atividades de concorrência e manutenção atencional (Chow e Cummings, 1999; Galtier et al., 2017). A síndrome disexecutiva caracteriza-se também por dificuldades para manter a sequência de atividades necessárias para alcançar um objetivo e déficit de julgamento mnemônico de recência, ou seja, da ordem temporal e sequenciamento dos eventos recentes (aspectos da memória episódica e autobiográfica), assim como baixo desempenho em tarefas sujeitas à interferência (Chow e Cummings, 1999; Salazar et al., 2017). Além do prejuízo em domínios relacionados à atenção alternada (flexibilidade mental), planejamento e atenção seletiva, alguns estudos referem que a alteração da função visuoespacial, outra função cognitiva comprometida nesta população, de forma precoce pode representar um fator preditor para o desenvolvimento de demência (Taylor et al., 1988; Stella et al., 2007; Bocanegra et al., 2014).

Em relação ao funcionamento mnemônico, estudos referem prejuízo na evocação das informações, sendo observada preservação da capacidade de retenção/consolidação e reconhecimento do material; configurando alterações durante os processos de manipulação dos dados, que dependem de 
habilidades de atenção e controle executivo, sendo nomeada de "hipótese do déficit de recuperação" (Tedrus et al., 2009a; 2009b).

No comprometimento cognitivo leve (CCL) as alterações cognitivas não repercutem nas atividades de vida diária, entretanto, o paciente pode queixarse de dificuldades em atividades complexas com relativa preservação de sua funcionalidade (Portet et al., 2006). Apesar de ser referido como de domínio único e não amnéstico, os critérios para este diagnóstico ainda não estão bem estabelecidos na literatura, havendo controvérsias em relação à definição e características do comprometimento cognitivo leve na DPI (CCL-DP), devido à diversidade metodológica entre os estudos (Portet et al., 2006; Tedrus et al., 2009a; 2009b).

Os estudos têm mostrado que há dois diferentes subtipos de CCL-DP, o de domínio único e o de múltiplos domínios. Além disso, características cognitivas, tais como prejuízo frontoestriatal e o cortical posterior, estão descritos nesta patologia, e a disfunção cortical posterior pode ser usado como um preditor para estratificar o risco de desenvolver ou evoluir para demência (Janvin et al., 2006; Williams-Gray et al., 2007; 2009). O tipo frontoestriatal caracteriza-se por comprometimento em habilidades atencionais, flexibilidade cognitiva e planejamento e o tipo cortical posterior por predomínio de prejuízo visuoespacial, visuo-construtivo e nomeação (Zgaljardic et al., 2003; Muslimović et al., 2005; 2007). Uma diferenciação clinicamente prática baseiase na importância dos déficits executivos nas fases iniciais do comprometimento cognitivo na DPI e nas evidências que enfatizam o papel 
transitório do comprometimento posterior-cortical na progressão do CCL-DP para a demência (Martinez-Horta et al., 2019).

Janvin e colaboradores (2006) demonstraram que mais de $50 \%$ dos pacientes sem demência têm alguma alteração cognitiva e que destes $20 \%$ exibem disfunção predominantemente mnemônica, 30\% disfunção executiva e $50 \%$ desempenho globalmente prejudicado. Desta forma, o fenótipo cognitivo nesta condição neurológica parece ser heterogêneo, com características corticais e subcorticais, apesar da maior evidência para a disfunção executiva. Novas abordagens multivariadas têm sido usadas para descrever padrões de mudanças subcorticais e corticais iniciais que se relacionam com cursos mais graves de DPI (Krajcovicova et al., 2019).

Estudos têm associado alguns aspectos demográficos e clínicos, como idade de início mais tardio dos sintomas, maior tempo de evolução da doença, presença precoce de alucinações com o tratamento dopaminérgico e manifestações motoras do tipo rígido-acinéticas, com o desenvolvimento de demência na DPI (Emre, 2003; Bonelli e Cummings, 2008; Tedrus et al., 2009a; 2009b). O declínio cognitivo, especialmente das funções executivas, pode estar associado com as alterações da marcha e risco de quedas (Krajcovicova et al., 2019). Foi observado, no estudo de Sousa e Macedo (2019) que os parâmetros motores foram significantemente relacionados com as habilidades cognitivas, principalmente, com aspectos de atenção dividida, sugerindo que as habilidades de equilíbrio e mobilidade funcional podem estar correlacionadas com a mudança atencional entre duas tarefas. 
Outros estudos referem também que a baixa escolaridade, características dos sintomas motores (como fenótipo motor do tipo instabilidade postural e dificuldade de marcha/quedas), hiposmia e transtorno comportamental do sono REM são preditores clínicos e demográficos para o declínio cognitivo na DPI (Hu et al., 2014; Campos et al., 2015). Estes estudos, no entanto, ainda possuem resultados conflitantes e divergentes em função da falta de poder estatístico e diversidade metodológica, como instrumentos utilizados para avaliação e heterogeneidade da amostra (Mader e Anjos, 2003).

Um estudo de meta-análise mostrou que o padrão metabólico na DPI, progressão da doença, sintomas não motores, tais como fadiga, depressão, apatia, distúrbios de controle de impulsos e comprometimento cognitivo; aumentou o risco de progressão para demência foram identificados em estudos com PET-FDG. O hipometabolismo em redes fronto-parietais, que está relacionado à disfunção executiva e mnemônica, é um dos fatores de risco para o desenvolvimento de demência (Peralta et al., 2019). Outro estudo sinalizou a influência do déficit colinérgico para o desenvolvimento de demência, assim como estudos combinando SPECT dopaminérgico com ressonância magnética funcional demonstrarem que a denervação dopaminérgica está associada à atrofia cortical frontal e posterior. Novas abordagens metodológicas possibilitaram estudar as perdas de núcleos colinérgicos no prosencéfalo basal e mostraram que estão presentes no início do curso da doença, provavelmente levando à atrofia das áreas de projeção cortical nas regiões corticais pré-frontal e posterior para a progressão subsequente de déficits cognitivos. Estudos futuros devem verificar esses resultados utilizando biomarcadores colinérgicos combinados na mesma população com DP (Krajcovicova et al., 2019). 
A incidência de demência na DPI é seis vezes maior do que na população geral e é cumulativa com o avançar da idade (Kulisevsky e Pagonabarraga, 2009). Após 3 anos, 25\% dos pacientes com CCL desenvolvem demência devido a doença de Parkinson (Pigott et al., 2015). Em outro estudo, onde participaram 145 pacientes com DPI em uma comunidade no município de Rogaland, na Noruega, durante 1996/1997, mostraram que 62\% desenvolveram D-DP após 4 anos com CCL (Janvin et al., 2006).

Dentre as alterações cognitivas, a D-DP é a manifestação mais grave. Esta condição afeta cerca de $24 \%$ a $31 \%$ dos pacientes, acarreta redução da qualidade de vida dos pacientes, aumento de sobrecarga de seus cuidadores; além de ocasionar um maior risco de institucionalização, morte e custos econômicos (Janvin et al. 2006; Williams-Gray et al., 2009).

A característica deste tipo de demência assemelha-se à demência subcortical, tendo as funções executivas como as principais alterações cognitivas (Reich, 1997; Hughes et al., 2000; Schrag et al., 2007; Tedrus et al., 2009a; Zhu et al., 2014; Hoogland et al., 2017). O declínio cognitivo nas demências fronto-subcorticais, portanto, são distintas daquelas que caracterizam as demências corticais, que têm como modelo a doença de Alzheimer, nas quais o espectro das disfunções cognitivas inclui afasias, apraxias e agnosias. As demências fronto-subcorticais são caracterizadas pelo comprometimento do padrão de evocação de informações, redução da capacidade de abstração, dificuldade para elaborar estratégias de resolução de problemas, déficit de atenção sustentada e dividida, memória operacional, fluência verbal e lentificação do pensamento/bradifrenia (Brønnick, 2015). Com 
o avanço da doença, os pacientes podem apresentar sintomas similares aos da doença de Alzheimer, como déficit de retenção de informação ou aprendizagem, dificuldades visuoespaciais e de linguagem. Isto ocorre devido ao depósito de peptídeos beta-amiloides e aglomerados de proteína TAU no parênquima cerebral, além de alterações metabólicas no córtex cingulado posterior (Kim et al., 2018; Winer et al., 2018). Estudos mostram que biomarcadores da DA, como presença do alelo APOE e $\beta$-amiloide 42, além de mutações no gene GBA e SCNA estão associados a uma pior cognição em pacientes com a doença de Parkinson (Aarsland et al., 2017).

\subsection{Avaliação cognitiva na doença de Parkinson}

A avaliação cognitiva deve ser feita, inicialmente, com baterias breves ou de rastreio, o que permitirá a conceptualização clínica e delineamento de hipóteses diagnósticas. Os quadros de demência leve ou aqueles que necessitam de uma maior investigação devem ser encaminhados para avaliação neuropsicológica complementar e abrangente, com a finalidade de confirmação diagnóstica.

A avaliação breve é realizada para rastrear possíveis déficits cognitivos. 0 Mini-Exame do Estado Mental (MEEM) (Brucki et al., 2003) é o mais amplamente utilizado e estudado no Brasil, apesar da baixa sensibilidade para detectar prejuízo cognitivo em que predominam disfunções executivas. A escala de avaliação de Montreal (MoCA) parece ter maior sensibilidade e especificidade para tal finalidade (Matías-Guiu et al., 2017). Outras baterias, tais como Parkinson's Disease-Cognitive Rating Scale (PD-CRS) (Kulisevsky e 
Pagonabarraga, 2009), Escala de Avaliação de Demência desenvolvida por Mattis (MDRS) (Porto et al., 2003) e Scale for Outcomes in Parkinson's disease-Cognition (SCOPA-COG) têm mostrado uma maior sensibilidade em detectar alterações cognitivas precoces associadas à DPI (Kulisevsky e Pagonabarraga, 2009). As avaliações neuropsicológicas, com aplicação de testes padronizados, são mais sensíveis e específicas para detectar alterações sutis da cognição ou em pacientes com maior reserva cognitiva.

Estudos recentes têm mostrado a importância da combinação de avaliação neuropsicológica abrangente/completa com o uso de baterias breves, através da obtenção de escore cognitivo global para detectar quadros de alterações cognitivas leves, como CCL e demência em estágio inicial e de intensidade leve. A utilização de testes de rastreio cognitivo, portanto, não é suficiente para discriminar pacientes com CCL e D-DP, exceto naqueles pacientes com síndromes demenciais já estabelecidas e de intensidade grave.

Emre (2003) estabeleceram critérios diagnósticos para avaliação de síndromes demenciais. A Tabela 2 fornece a relação dos testes de nível I recomendados com a pontuação sugerida para qualificar os pacientes com D-DP. 


\section{Tabela 2 - Critérios diagnósticos para avaliação de síndromes demenciais na doença de Parkinson (D-DP). Nível I}

\begin{tabular}{|c|c|}
\hline \multicolumn{2}{|l|}{ Características Principais } \\
\hline Diagnóstico de DPI & \\
\hline $\begin{array}{l}\text { Sintomas motores antes dos sintomas cognitivos } \\
\text { (demência) }\end{array}$ & Diferenciar D-DP de CCL \\
\hline Declínio abaixo do esperado quando comparado & MEEM $<26$ \\
\hline Prejuízo funcional & $\begin{array}{l}\text { Entrevistas com familiares/cuidadores, a } \\
\text { fim de obter dados sobre as alterações } \\
\text { nas atividades básicas e instrumentais } \\
\text { de vida diária }\end{array}$ \\
\hline Prejuízo em mais de um domínio cognitivo & $\begin{array}{l}\text { Atenção, funções executivas, funções } \\
\text { visuo-construtivas e memória }\end{array}$ \\
\hline \multicolumn{2}{|l|}{$\begin{array}{l}\text { Características clínicas associadas } \\
\text { Cognição (supracitado) }\end{array}$} \\
\hline Comportamento & $\begin{array}{l}\text { Apatia, alucinações, delírios, depressão, } \\
\text { hipersonolência diurna }\end{array}$ \\
\hline \multicolumn{2}{|l|}{ Elimar fatores de incerteza } \\
\hline $\begin{array}{l}\text { Presença de patologia vascular } \\
\text { Incerteza sobre o início da demência } \\
\text { Excluir antes de considerar D-DP }\end{array}$ & $\begin{array}{l}\text { Exames de neuroimagem (RNM, TC) } \\
\text { Entrevistas e prontuários médicos }\end{array}$ \\
\hline $\begin{array}{l}\text { Intoxicação ou exposição a medicamentos que } \\
\text { podem influenciar negativamente na memória }\end{array}$ & Medicamentos com ação anticolinérgica \\
\hline $\begin{array}{l}\text { Distúrbios metabólicos (deficiência de vitaminas } \\
\text { ou disfunção hormonal), infecciosos ou outro fator } \\
\text { clínico que possa levar à demência ou delirium }\end{array}$ & Avaliação clínica geral \\
\hline Transtorno do humor depressivo & $\begin{array}{l}\text { Avaliação com escalas e necessidade de } \\
\text { tratamento antes de realizar diagnóstico } \\
\text { cognitivo }\end{array}$ \\
\hline $\begin{array}{l}\text { Características compatíveis com demência } \\
\text { vascular provável, de acordo com o Instituto } \\
\text { Nacional de Doenças Neurológicas e AVC-AIREN }\end{array}$ & $\begin{array}{l}\text { Imagem, história clínica e achados } \\
\text { neurológicos }\end{array}$ \\
\hline
\end{tabular}

Nível I = Avaliação que pode ser realizada por um clínico, sem necessidade de expertise em testes de avaliação neuropsicológica

Recentemente critérios para melhor caracterizar o $C C L$ e seus subtipos foram estabelecidos pela Movement Disorder Society (MDS) em 2012 (Geurtsen et al., 2014; Goldman e Weintraub, 2015). Esses critérios compreendem duas operacionalizações: Nível I (avaliação breve) e Nível II (avaliação neuropsicológica abrangente), permitindo caracterizar subtipos de $\mathrm{CCL}$, como de domínio único e múltiplos domínios, através de, pelo menos, dois testes para cada das cinco funções cognitivas (atenção e memória operacional, funções executivas, linguagem, memória e função visuoespacial). Os resultados (escores) em testes neuropsicológicos com desvios-padrão de 1 
a 2 abaixo ou acima da média (a depender do teste), por faixas de idade e escolaridade, indicam CCL. Este guideline também fornece os testes mais sensíveis na DPI, tanto em relação às baterias globais quanto testes por domínios cognitivos, como pode ser visto na Tabela 3 (Litvan et al., 2012).

Tabela 3 - Avaliação cognitiva proposta pela Movement Disorder Society (adaptado de Litvan et al., 2012)

\begin{tabular}{llc}
\hline \multicolumn{1}{c}{ Avaliação } & \multicolumn{1}{c}{ Instrumentos } & No Brasil \\
\hline Global & MoCA & Sim \\
& PD-CRS & Sim \\
& SCOPA-COG & Sim \\
Inteligência pré-mórbida & MDRS & Sim \\
& NART & Não \\
Domínios cognitivos & WTAR & Não \\
\hline Atenção e Memória Operacional & Sequência de Números e letras (WAIS-IV) & Sim \\
& $\begin{array}{l}\text { Códigos } \\
\text { Teste de Trilhas }\end{array}$ & \\
& Teste de Amplitude de Dígitos & \\
Funções Executivas & Teste de Stroop & Sim \\
Linguagem & Teste Wisconsin & Sim \\
& Torre de Londres & \\
Memória & Fluência Verbal (fonológica e semântica) & Sim \\
& Similitudes (WAIS-IV) & \\
& Teste de nomeação de Boston & \\
Lista de palavras de Rey, Califórnia, & Hopkins e Reminding Test \\
Memória lógica, Teste de memória & \\
visuoespacial breve-revisada (BVMT-R) & \\
& Teste Hooper \\
Desenho do Relógio & Sim
\end{tabular}

No Brasil, alguns estudos avaliaram a capacidade de avaliação de algumas baterias breves na DPI, tais como a Escala de Consequências da Doença de Parkinson-SCOPA-COG (Carod-Artal et al., 2008) e Montreal Cognitive Assessment - MoCA (Sobreira et al., 2015). Estudo, utilizando o MEEM mostrou baixa sensibilidade para detectar alteração cognitiva nesta condição neurológica (Breder et al., 2017). 
Apesar da importância da avaliação cognitiva, observa-se um número relativamente reduzido de instrumentos específicos e validados no Brasil.

Há, então, um aumento da necessidade de testes de screening cognitivo, de fácil administração, sensibilidade e especificidade, suficientes para detectar as alterações cognitivas (heterogêneas) precoces e/ou iniciais na DPI. A identificação de fatores confundidores, durante a avaliação, também é importante, pois podem enviesar os resultados cognitivos. Desta forma, sintomas como alterações afetivas (humor e/ou ansiedade), fadiga, distúrbios do sono, alterações motoras (flutuações, rigidez, tremor, disartria) e efeitos adversos de medicamentos (sonolência, alterações de memória, alucinações, agitação, transtorno de controle do impulso) devem ser considerados e manejados antes de realizar a testagem, a fim de obter resultados mais precisos e confiáveis. Dentre estes fatores, a alteração afetiva (especialmente o transtorno de humor depressivo) pode ser de difícil diagnóstico e manejo, pois pode ocorrer sobreposição de sintomas (como dores e outros sintomas somáticos); além do curso da doença ser diferente, devido a farmacocinética específica do idoso, caracterizada por pior resposta ao tratamento medicamentoso e maior cronicidade (Lees et al., 2009).

Além dos aspectos afetivos, as alterações executivas podem ser confundidas nestes pacientes, com as dificuldades motoras e a baixa velocidade de processamento mental (Benge et al., 2014); bem como as tarefas visuoespaciais dependem do controle atencional, executivo e habilidade motora fina, sendo, em alguns momentos, difícil a interpretação dos resultados 
cognitivos, havendo necessidade de adaptações e adequações no momento da testagem (Dujardin et al., 2007).

\subsection{Addenbrooke's Cognitive Examination (ACE)}

A ACE é uma bateria de avaliação cognitiva breve, com elevada sensibilidade e especificidade para detecção de demência, em estágio leve, que não requer equipamento especializado. Foi desenvolvida, em 2000, por uma equipe conduzida por John R. Hodges e Germán E. Berríos no Hospital de Addenbrooke, Cambridge, no Reino Unido (Mathuranath et al., 2000), como uma ferramenta para avaliar estágios precoces e diferenciar subtipos de demência, como Demência de Alzheimer (DA) e Demência Frontotemporal (DFT), Demência Vascular (DV), Paralisia Supranuclear Progressiva (PSP) e outras síndromes parkinsonianas (Newman, 2005; Mioshi et al., 2006; Stokholm et al., 2009; Crawford et al., 2012).

Esta bateria (ANEXO A) inclui itens do MEEM, além de itens de habilidades visuoespaciais e executivas, avaliando, assim, domínios como atenção, orientação, fluência verbal, linguagem, função visuoespacial e memória. Escores são fornecidos para cada função cognitiva. É constituído por seis domínios cognitivos, totalizando 100 pontos: orientação (10 pontos), atenção (8 pontos), memória (35 pontos), fluência verbal (14 pontos), linguagem (28 pontos) e habilidades visuoespaciais (5 pontos). Os pontos referentes aos seis domínios podem ser calculados separadamente. A soma de todos equivale ao escore total. Neste escore total, estão inseridos os 30 pontos relativos ao MEEM, que também podem ser calculados em separado. $\mathrm{Na}$ 
avaliação da orientação e da atenção, são utilizados os mesmos itens do MEEM. A memória é avaliada em seus aspectos episódicos (recordação das três palavras do MEEM, aprendizado e recordação tardia de nome e endereço) e semântico. A linguagem é avaliada pela nomeação de 12 figuras, além de tarefas de compreensão, repetição, leitura e escrita. A habilidade visuoespacial é avaliada pela cópia dos retângulos sobrepostos (MEEM), do cubo e do desenho do relógio. A capacidade de fluência verbal é dividida por categoria fonêmica (palavras iniciadas com a letra "P") e semântica (nomes de animais). Os escores brutos são utilizados para a pontuação final em todos os itens, com exceção do item de fluência verbal, o qual exige uma conversão do número de palavras geradas em uma pontuação preestabelecida. A duração média de administração da ACE é de 15 a 20 minutos.

Mathuranath e colaboradores (2000) demonstraram a utilidade diagnóstica deste instrumento para o diagnóstico de demência em estágios iniciais. Em uma amostra de 115 pacientes com demência leve comparada a 127 controles, foram obtidos altos valores de sensibilidade e especificidade com a nota de corte $83 / 100$ (82\% e 96\%, respectivamente). Para a nota 88/100, a sensibilidade encontrada foi de $93 \%$ e especificidade de $71 \%$. A acurácia do instrumento foi quase três vezes maior do que o MEEM para a mesma amostra.

Este estudo demonstrou a utilidade no diagnóstico diferencial entre DA e DFT. Os pacientes com DA apresentaram melhor desempenho nos domínios de fluência verbal e linguagem quando comparados aos pacientes com DFT. Com estes resultados, surgiu a fórmula $(\mathrm{V}+\mathrm{L}) /(\mathrm{O}+\mathrm{M})$, à qual deram o nome de 
razão VLOM. Ele é calculado usando a seguinte fórmula: VLOM ratio = (fluência verbal + linguagem): (orientação + evocação tardia). Esse valor tende a ser maior nos pacientes com DA (> 3,2: sensibilidade $75 \%$ e especificidade $84 \%$ ) e menor naqueles com DFT ( $<2,2$ : sensibilidade $58 \%$ e especificidade $97 \%$ ). O valor entre 2,2 e 3,2 pode indicar tanto DFT como DA, ou qualquer outra forma de demência.

Estudo no qual utilizou a ACE foi capaz de detectar a presença de comprometimento cognitivo em pacientes com DPI ( $<83$ pontos e $<88$ pontos). Neste estudo participaram 77 pacientes com demência precoce (53 com doença de Alzheimer e 24 com demência frontotemporal), 22 pacientes com doença de Parkinson e 53 controles saudáveis, totalizando 152 participantes. Uma idade média de 71 anos e escolaridade média de 11 anos. Os pacientes com a doença de Parkinson diferiram significantemente dos controles saudáveis e dos pacientes com demência precoce no escore total da ACE (Chade et al., 2008).

Estudo realizado apenas em pacientes com DPI sem demência $(n=31$, idade média de 68,6 e escolaridade média de 14,3) e com demência ( $n=13$, idade média de 71,9 anos, escolaridade média de 11 anos e tempo médio de doença de 8,2 anos), mostrou que a ACE parece ser uma ferramenta válida para detecção de demência, com notas de corte de 83 pontos (sensibilidade 92\% e especificidade 91\%, AUC = 0,97), sinalizando correlação forte e significante com baterias breves, como SCOPA-COG $(r=0,93, p<0,0001)$, MDRS $(r=0,91, p<0,0001$, e MEEM ( $r=0,84, p<0,0001)$ (Reyes et al., 2009). 
Em 2006, um estudo de revisão da ACE, conduzido por Mioshi, apresentou dados de validação desse instrumento em uma amostra de 241 sujeitos (DA=67; $\mathrm{DFT}=55 ; \mathrm{DCL}=20 ; \mathrm{CCL}=36$; Controles=63), tendo estes grupos uma média de 65 anos de idade e 12 anos de escolaridade (Mioshi et al., 2006). Duas notas de corte foram estabelecidas para diferenciação entre indivíduos controles e pacientes com demência em geral: 82/100 com sensibilidade de $84 \%$ e especificidade de $100 \%$, e $88 / 100$ com $94 \%$ e $89 \%$ respectivamente. As análises da razão VLOM da ACE-R replicaram os resultados originais (Mathuranath et al., 2000), uma vez que os elementos que contribuem para a razão foram pouco alterados na versão revisada. Embora alguns estudos tenham relatado achados muito semelhantes (Sarasola et al., 2005; García-Caballero et al., 2006), outros não apoiaram o uso da razão VLOM (Bier et al., 2004; Larner, 2005). É provável que essa variação ocorra em função do uso de diferentes critérios entre os estudos (número de pacientes, nível de comprometimento de acordo com a escala CDR e critérios de corte da ACE-R) (Mioshi et al., 2006).

A ACE-R (ANEXO B) apresenta algumas modificações em relação à versão anterior, com objetivo de facilitar a sua aplicação. Foi desenvolvido um guia de instruções com informações sobre a pontuação e ordem de aplicação dos itens, com a finalidade de aumentar a confiabilidade entre os examinadores. Nesta versão, a pontuação dos seis domínios cognitivos, avaliados na bateria, apresenta a seguinte distribuição: orientação e atenção (18), memória (26), fluência verbal (14), linguagem (26) e habilidade visuoespacial (16). A avaliação da orientação e da atenção foi mantida como na versão original. O escore do item de memória anterógrada/episódica foi 
reduzido de 21 para 7 pontos e os restantes foram atribuídos a novos itens da bateria. Também foi adicionado um item de reconhecimento com três opções para cada parte. No subteste de memória retrógrada, as questões foram modificadas devido à dificuldade da versão anterior (Mioshi et al., 2006).

Diferentemente da versão original, a avaliação da cópia do cubo aumentou para 2 pontos, o escore do desenho do relógio foi modificado para possibilitar uma análise mais detalhada de cada parte de sua construção, e duas novas tarefas perceptivas foram incluídas (contagem de pontos e identificação de letras). Nos itens da linguagem, foram excluídos dois comandos simples e um comando complexo; houve acréscimo de novas questões que avaliam o aspecto semântico da linguagem e substituição de palavras e sentenças; substituição de seis figuras no item de nomeação e as palavras comuns foram excluídas do item de repetição. Como na primeira versão do instrumento, a ACE-R é administrado em média em torno de 15 minutos e nesta há três formas alternativas ( $A, B$ e $C)$, onde são oferecidas diferentes versões do nome e endereço na memória episódica/recordação, para minimizar os efeitos de prática e aprendizagem. Esta bateria apresenta uma boa sensibilidade para detecção de demência (Larner, 2007; Hsieh et al., 2008; Komadina et al., 2011; Terpening et al., 2011).

Komadina e colaboradores (2011) mostraram que a nota de corte igual ou menor que 93 pontos ofereceu sensibilidade (61\%) e especificidade (64\%) para detectar CCL-DP para os indivíduos com escolaridade acima de 12 anos (61\% de sensibilidade e $64 \%$ de especificidade). Para aqueles com escolaridade inferior ou igual a 12 anos, a nota de corte foi de 85 pontos (sensibilidade de 
44\% e especificidade de 100\%). Neste estudo participaram 101 pacientes com CCL (idade média de 65,3 anos e escolaridade média de 14 anos, tempo médio de doença de 6 anos), conforme diretrizes da MDS. Os instrumentos de comparação foram amplitude de dígitos, teste de trilhas, fluência verbal semântica e memória lógica (WMS). O teste foi superior ao MEEM em detectar CCL-DP. O domínio de fluência verbal foi o que mais influenciou neste resultado e apresentou uma maior capacidade discriminatória em indivíduos com escolaridade igual ou inferior a 12 anos, com a pontuação de 10 (sensibilidade de $92 \%$ e especificidade de $48 \%$, AUC $=0,656$ ).

Em outro estudo (Berankova et al., 2015), também com indivíduos com a DPI, diagnosticados de acordo com os critérios da MDS foram examinados três grupos (cognição normal-CN-DP, CCL-DP e D-DP). Diferenças, estatisticamente significantes entre os grupos foram demonstradas nos escores globais e domínios da ACE-R, exceto na linguagem. A pontuação de corte de 88,5 pontos discriminou melhor entre CCL-DP e CN-DP (sensibilidade de 68\% e especificidade de $91 \%$ ); A ACE-R de 82,5 pontos distinguiu melhor entre CCL-DP e D-DP (sensibilidade de 70\% e especificidade de $73 \%$ ). O domínio de fluência verbal da ACE-R demonstrou a melhor discriminação entre CN-DP e CCL-DP (pontuação de corte 11,5; sensibilidade de $70 \%$ e especificidade de 73\%) enquanto a pontuação do domínio atenção/orientação foi melhor entre CCL-DP e D-DP (pontuação de corte 15,5; sensibilidade de $90 \%$ e especificidade 97\%). Os escores da ACE-R, exceto para a linguagem, da ACE-R, correlacionaram-se com testes cognitivos específicos.

Uma revisão sistemática da ACE-R (Crawford et al., 2012), cujo objetivo foi avaliar a acurácia diagnóstica e a utilidade clínica do Exame Cognitivo de 
Addenbrooke (ACE) e sua versão atualizada, o Exame Cognitivo de Addenbrooke - Revisado (ACE-R) em relação ao diagnóstico de demência; mostrou que o escore de 88 pontos demonstrou maior capacidade de distinguir entre aqueles com e sem comprometimento cognitivo; não ficando claro nos estudos a discriminação entre comprometimento cognitivo leve e demência. $O$ processo de busca sistemática identificou nove estudos para revisão (sete relativos à ACE e dois à ACE-R). Pontos fortes e fracos em todos os estudos foram considerados, e medidas de precisão diagnóstica foram apresentadas para seis dos nove estudos.

Estudo sobre investigação da validade diagnóstica e confiabilidade da versão japonesa do Exame Cognitivo de Addenbrooke (ACE-R) para identificar comprometimento cognitivo leve e demência (Yoshida et al., 2012) mostrou que escores de corte para a detecção de CCL e demência foram 88/89 (sensibilidade 0,87, especificidade 0,92) e 82/83 (sensibilidade 0,99, especificidade 0,99 ), respectivamente. Um total de 242 indivíduos (controles $=$ 73, $\mathrm{CCL}=39$, demência $=130)$ participaram deste estudo. $\mathrm{O}$ grupo demência teve menor escore na pontuação total e em todos os domínios, enquanto o grupo CCL obteve menor pontuação no escore total e nos domínios de memória e fluência verbal.

Larner e Mitchell (2014) fizeram uma revisão sistemática de estudos de acurácia diagnóstica, da ACE e ACE-R. Foram incluídos estudos que examinaram a validade diagnóstica da ACE ou ACE-R em comparação com um padrão de diagnóstico validado de demência ou CCL. A ACE-R apresentou uma precisão diagnóstica um pouco superior ao MEEM, enquanto a ACE houve uma precisão inferior. 
Foi realizada também a validação da versão francesa (Bastide et al., 2012), em indivíduos com demência (DA, DFT, DCL, DV, demência mista-DM, APP, PSP, DCB), CCL e sem alteração cognitiva. A pontuação de 83/100 teve $92,2 \%$ de sensibilidade e $68,6 \%$ de especificidade para o diagnóstico de demência e de $83 / 100$ (72\% de sensibilidade e 73,6\% de especificidade) a 89/100 (98,4\% de sensibilidade e 99,4\% de especificidade) para o diagnóstico de CCL.

No Brasil, Amaral-Carvalho e Caramelli, (2012), avaliaram 144 voluntários cognitivamente saudáveis (50\% homens, $50 \%$ mulheres), com idades entre 50 e 93 anos, e 4 a 24 anos de escolaridade. Os participantes foram divididos em 4 faixas etárias, cada uma foi estratificada em 3 grupos de acordo com os anos de escolaridade formal. Foram avaliados com a ACE-R, a escala de classificação de demência de Mattis (MDRS) e a escala Cornell para avaliação de depressão em demência. Os resultados mostraram que os anos de escolaridade influenciaram em todos os subscores e pontuação total da ACE-R. A idade, entretanto, influenciou no escore de fluência verbal $(p<0,001)$ e na pontuação total da ACE-R $(p<0,05)$.

Estudos usando ACE-R para detecção de demência em pacientes com DP encontraram pontuações de corte variáveis, mas apresentaram uma boa acurácia diagnóstica (Rocha et al., 2014; Berankova et al., 2015; Sobreira et al., 2015). Em geral, a acurácia foi julgada superior àquela encontrada com a aplicação do MEEM. Embora alguns estudos tenham mostrado que a ACE-R pode ser útil para detectar CCL, estudos em pacientes com DP encontraram achados controversos, porém houve heterogeneidade metodológica entre eles, 
em função, por exemplo, da escolaridade, idade e testes utilizados para o diagnóstico de CCL (McColgan et al., 2012; Ozdilek e Kenangil, 2014).

A validação da versão chinesa, na qual participaram 151 sujeitos (DA=25, CCL amnéstico=75 e cognição normal=51), mostrou que a nota de corte de 85/86 mostrou ser superior ao MEEM, com sensibilidade de 1,000 e especificidade de 0,937 (Fang et al., 2014).

Um estudo, realizado no Brasil, na cidade de Tremembé, São Paulo, com 630 participantes, incluindo iletrados e pessoas com menos de quatro anos de escolaridade, 385 foram classificados como cognitivamente normais (CN), 135 foram classificados como comprometimento cognitivo sem demência (CCSD) e 110 indivíduos foram diagnosticados com demência (César et al., 2017). As pontuações totais da ACE-R variaram significantemente de acordo com a idade, escolaridade e sexo. A pontuação que distinguiu demência de controles saudáveis (cognição normal) foi 64 pontos (sensibilidade de $91 \%$ e especificidade de $76 \%$ ) e para distinguir controles saudáveis de CCSD foi 69 pontos (sensibilidade de $73 \%$ e especificidade de $65 \%$ ).

Outro estudo realizado no Brasil, porém constituído por 79 pacientes com DPI (32 com CCL e 17 com D-DP), utilizou a ACE-R e a bateria MoCA (Sobreira et al., 2015). A nota de corte capaz de identificar indivíduos com DDP foi $=<76$ pontos (sensibilidade de $88 \%$ e especificidade de $68 \%$, AUC $=0,84$ ) e para distinguir CN-DP e CCL-DP, foi obtida a pontuação de 89 (sensibilidade de $84 \%$ e especificidade de $20 \%$, AUC=0,53). Os escores do MoCA e da ACE-R correlacionaram-se significantemente com a escolaridade e a idade dos pacientes, sugerindo que esses fatores podem desempenhar um papel significativo no desempenho dos sujeitos avaliados por esses instrumentos. Os 
escores do MoCA e da ACE-R também se correlacionaram com outras medidas globais de cognição (MoCA) e funcionalidade (Schwab and England functional scale), indicando que as versões brasileiras dessas escalas tiveram boa validade concordante.

Em um estudo de Rocha et al., (2014) foram estudados 70 pacientes com DPI, avaliados de acordo com os procedimentos diagnósticos recomendados pela MDS como padrão-ouro para o diagnóstico de D-DP, com idade média de $64,1(9,3)$ anos, duração da doença média de $7,7(5,3)$ anos e escolaridade de 5,9 anos, pareados por idade e escolaridade a controles. A melhor nota de corte foi de $\leq 72$ pontos (sensibilidade de $90 \%$ e especificidade de $85 \%$; concordância kappa (K) 0,79, AUC=0,93). Os resultados demonstraram que a ACE-R foi um instrumento válido para avaliação de demência em pacientes com DPI de níveis educacionais heterogêneos (média de 5,9 anos), mostrando boa correlação com o critério clínico e procedimentos diagnósticos da MDS.

A ACE-R, portanto, demonstrou, através dos estudos realizados em pacientes com DPI, a sua propriedade diagnóstica para detectar demência, sendo poucos os estudos que buscaram avaliar a sua acurácia para identificar CCL-DP. Estes também utilizaram critérios metodológicos diferentes, não sendo possível a sua comparação.

A ACE-III (ANEXO C) foi desenvolvida em 2013 (Hsieh et al., 2013), tendo diferentes versões validadas em vários países, como Espanha, China, Malásia, Japão, Portugal, Egito, Argentina e Chile (Matias-Guiu et al., 2015, 2017; Wang et al., 2017; Peixoto et al., 2018; Kan et al., 2019; Li et al., 2019; Takenoshita et al., 2019; Bruno et al., 2020; Qassem et al., 2020). Há evidência de propriedade psicométrica e habilidade diagnóstica para discriminar pessoas 
saudáveis de pacientes com demência. Como na versão anterior (ACE-R), a ACE-III centra-se em cinco domínios cognitivos (atenção/orientação, memória, fluência verbal, habilidade visuoespacial e linguagem). As alterações foram feitas em domínios, como linguagem (mudanças de duas figuras do item nomeação, alteração dos comandos do item compreensão e escrita) e visuoespacial, sendo substituído o desenho dos pentágonos sobrepostos pelo desenho dos infinitos sobrepostos. Os domínios de memória e fluência verbal não foram modificados. A pontuação total continuou sendo 100 .

Estudo evidenciou alta sensibilidade e especificidade desta terceira versão, obtendo notas de corte para demência de 88 (sensibilidade = 1,0; especificidade $=0,96)$ e 82 (sensibilidade $=0,93$ e especificidade $=1,0) . A$ consistência interna, medida pelo coeficiente de alfa de Cronbach's foi de 0,88 (Noone, 2015).

A validação da versão inglesa (Hsieh et al., 2013), tendo um total de 61 pacientes com demência (DFT=33 e DA=28) e 25 controles saudáveis, mostrou que os domínios cognitivos da ACE-III se correlacionaram significantemente com os testes neuropsicológicos padronizados, utilizados para avaliação da atenção, linguagem, memória verbal e função visuoespacial, como amplitude/spam de dígitos (WAIS-DS), teste de aprendizado auditivo verbal de Rey (RAVLT), Sydney Language Battery (SYDBAT), Teste da Figura Complexa de Rey (ROCFT) e escala funcional de demência frontotemporal (FTDFRS). A ACE-III também se comparou muito favoravelmente ao seu antecessor, a ACE$R$, com níveis semelhantes de sensibilidade e especificidade. Os pacientes tenderam a marcar 1 a 2 pontos a menos na ACE-III, que alcançou 
significância apenas no grupo DA. A ACE-III também continuou apresentando alta sensibilidade e especificidade nos pontos de corte, previamente recomendados: (1) 88 (sensibilidade $=1,0$; especificidade $=0,96$ ) e (2) 82 ( sensibilidade $=0,93$; especificidade $=1,0)$. A confiabilidade interna do ACE-III, medida pelo coeficiente $\alpha$ de Cronbach, foi de 0,88 (Hsieh et al., 2013).

A validação da versão espanhola também encontrou altos níveis de acurácia em distinguir controles saudáveis de pacientes com demência. Este estudo foi realizado em pacientes com DPI, porém tendo outros subgrupos, ou seja, com demais condições neurológicas, não sendo uma amostra homogênea do grupo clínico. Foram observadas variações na capacidade de diagnóstico da ACE-III de acordo com a escolaridade do paciente. Dessa forma, o grupo com 10 anos ou mais de escolaridade apresentou área na curva ROC abaixo de 0,982 para a ACE-III e de 0,934 para o MEEM. Para este grupo, o ponto de corte ideal foi de 73,5 , com sensibilidade de $90,5 \%$ e especificidade de $96,7 \%$. No grupo com menos de 10 anos de escolaridade, a área abaixo da curva ROC foi de 0,922 para a ACE-III e de 0,908 para o MEEM. Nesse caso, o ponto de corte foi de 61,5 , com sensibilidade de $82,3 \%$ e especificidade de $83,9 \%$. A capacidade diagnóstica da ACE-III excedeu a do MEEM para sujeitos com, pelo menos, o ensino fundamental, mas o MEEM foi mais útil para o grupo com pouca ou nenhuma escolaridade. A precisão, entretanto, do diagnóstico da ACE-III foi semelhante à do MEEM para todas as faixas etárias (Matias-Guiu et al., 2015).

A detecção de demência em estágio inicial em pacientes entre 75 anos e 84 anos de idade, com tamanho amostral de 59 indivíduos, tendo 33 com diagnóstico de demência ( $D A=56,3 \%, D M=31,3 \%, D V=12,5 \%$ ) e 26 sem 
demência. O estudo indicou que a nota de corte de 81/100 mostrou melhor sensibilidade e especificidade (0,79 e 0,96 respectivamente), além de apresentar valor preditivo positivo de 0,96. A escolaridade teve correlação positiva com o escore total da ACE-III no grupo sem demência (Jubb e Evans, 2015).

Estudos em pacientes com a DA, DV, DM, DDP, DCL, DFT e demência alcoólica ( $n=217)$ mostrou a utilidade diagnóstica da ACE-III na detecção de alterações cognitivas, em estágios iniciais, bem como houve correlação significante com testes neuropsicológicos padronizados para esta população (Matias-Guiu et al., 2015).

Na demência de início precoce, antes dos 65 anos de idade $(n=71)$, a pontuação 88/100 foi capaz de distinguir pacientes com demência de início precoce (DA, DFT-variante comportamental e APP, ACP), de controles saudáveis (sensibilidade de $91,5 \%$ e especificidade de $96,4 \%$ ), demonstrando ser uma ferramenta efetiva para o screening de demência (Elamin et al., 2016).

O estudo de Peixoto e colaboradores (2018) abrangeu uma amostra de 90 participantes, distribuída em 3 grupos: Controle $(n=30)$, CCL $(n=30)$ e Demência $(n=30)$. Além da ACE-III, também foram usados o Clinical Dementia Rating (CDR) e o Montreal Cognitive Assessment (MoCA). A confiabilidade da ACE-III foi muito boa $(\alpha=0,914)$. ACE-III diferenciou significantemente os 3 grupos. As curvas de características de operação do receptor, receiver operator characteristic curve (ROC) favoreceram significantemente a ACE-III em comparação a outro teste de triagem - MoCA. ACE-III apresentou níveis mais elevados de sensibilidade e especificidade. Seu escore total correlacionou-se 
positivamente com os resultados do MoCA $(\rho=0,912 ; p<0,001)$ e negativamente com a escala de depressão (Geriatric Depression Scale) $(\rho=-0,505 ; p<0,001)$. A versão em português da ACE-III teve uma confiabilidade muito boa e alta capacidade diagnóstica no contexto de CCL e demência.

Para a validação da versão chinesa, foram recrutados 177 pacientes com demência (diagnosticados com demência vascular ou DA) e 180 controles saudáveis. A pontuação de 83 obteve maior sensibilidade $(91,1 \%)$ e especificidade $(83,1 \%)$. Ocorreu também correlação significante e negativa com o escore da CDR e o escore total da ACE-III, bem como correlação positiva entre o MEEM e o escore total da ACE-III total. A idade demonstrou efeito significativo na pontuação total, nos escores de memória e linguagem (Wang et al., 2017).

Em amostras com pacientes com queixa subjetiva de memória, CCL amnéstico (CCL-A), DA leve e outras desordens neurodegenerativas $(n=175)$; Matias-Guiu et al., (2017) mostraram que os subescores de memória e linguagem foram altamente correlacionados com testes neuropsicológicos específicos para estes domínios ( $r=0,806$ para recordação tardia total no teste de evocação livre e com dicas; 0,744 com teste de Boston) (Matias-Guiu et al., 2017). O ponto de corte da ACE-III para a detecção de DA leve (CDR 1) foi 63/64, o que é semelhante ao ponto de corte estabelecido por um estudo de validação anterior; 73/74 foi o ponto de corte para o CCL-A. Estas notas de corte foram inferiores aos demais estudos, realizados com a ACE-R e ACE-III, podendo estar ligadas às diferenças de idade e escolaridade entre os 
pacientes, o que justificaria a maior utilidade dos dados normativos do que os pontos de corte (Matias-Guiu et al., 2015).

Em relação à versão italiana, um estudo de normatização, com 574 participantes saudáveis (idade média de 68,70 \pm 9,65; escolaridade média de $9,15 \pm 4,04)$, mostrou que a idade e a escolaridade exerceram um efeito significativo nos escores totais e domínios da ACE-III, enquanto o sexo influenciou no escore de atenção/orientação, linguagem e habilidade visuoespacial (Pigliautile et al., 2019).

Para discriminar CCL de controles saudáveis, Wang et al. (2019) mostraram que não houve diferenças significantes na precisão do diagnóstico entre os instrumentos ACE-III e MoCA. Um total de 120 pacientes com CCL e 136 controles saudáveis foram avaliados nesta versão chinesa da ACE-III, MoCA e MEEM; sendo evidenciada correlação significantemente positiva entre a pontuação total da ACE-III e a pontuação do MoCA e correlação significantemente positiva entre o escore total da ACE-III e o escore do MEEM. Para a pontuação total do ACE-III, um ponto de corte de 85 produziu uma sensibilidade de $97,3 \%$ e uma especificidade de 90,7\%. A AUC para a pontuação total do ACE-III foi de 0,978. Para o MoCA, um ponto de corte de 23 produziu uma sensibilidade de $86,5 \%$ e uma especificidade de $97,7 \%$. A AUC para MoCA foi de 0,961 .

Outro estudo, também na população chinesa (Li et al., 2019), mostrou que os participantes com $\geq 12$ anos de escolaridade, a AUC foi significantemente maior para a ACE-III do que para o MEEM ao detectar CCL $(0,90$ vs. 0,68; $p$ $<0,05)$ e demência leve $(0,97$ vs. 0,90; $p<0,05)$. Participaram 176 indivíduos divididos em 3 grupos: grupo demência leve, grupo CCL e grupo controle 
saudável. MEEM, MoCA e ACE-III foram administrados em todos os participantes por pesquisadores cegos para o agrupamento clínico. A ACE-III exibiu boa consistência interna e validade convergente. A idade e o nível de escolaridade influenciaram significantemente nos escores totais da ACE-III. Na triagem do $\mathrm{CCL}$, a área sob a curva ROC (AUC) foi significantemente maior para a ACE-III do que para o MEEM $(0,88$ vs. 0,$72 ; p<0,05)$ e MoCA $(0,88$ vs. 0,76; $p<0,05)$. A ACE-III mostrou maior sensibilidade $(0,75)$ e especificidade $(0,89)$ do que o MEEM $(0,64$ e 0,63 , respectivamente) e o MoCA $(0,67$ e 0,77$)$ no ponto de corte ideal de 88/89. Para detectar demência leve, a ACE-III produziu sensibilidade satisfatória $(0,94)$ e especificidade $(0,83)$, com o ponto de corte ideal de 74/75. A AUC do ACE-III foi de 0,95, comparável à do MEEM $(0,95)$ e $\operatorname{MoCA}(0,91)$.

Na população japonesa, as melhores pontuações de corte da ACE-III para detectar CCL e demência foram 88/89 (sensibilidade de 0,77 e especificidade de 0,92) e 75/76 (sensibilidade de 0,82 e especificidade de 0,90), respectivamente. A ACE-III foi superior ao HDS-R (Hasegawa Dementia Scalerevised) e MEEM na detecção de CCL ou demência. A consistência interna, a confiabilidade teste-reteste e a confiabilidade entre avaliadores da ACE-III foram excelentes (Senda et al., 2020).

A versão em espanhol da ACE-III continua sendo uma ferramenta eficaz para detectar disfunção cognitiva em pacientes com demência (Bruno et al., 2020). Foram encontradas diferenças significantes nos escores totais da ACE-III entre pacientes com doença de Alzheimer e controles $(p<0,05)$ e entre pacientes com doença de Alzheimer e DFT-vc $(p<0,05)$. Com um ponto de corte de $86,98,6 \%$ dos pacientes com DA, $83,9 \%$ dos pacientes com demência 
frontotemporal variante comportamental e $84,2 \%$ dos controles foram classificados corretamente.

Um estudo, realizado na Índia (Bajpai et al., 2020), o qual objetivou validar o Exame Cognitivo de Addenbrooke (ACE-III) em idosos indianos e comparar a sua validade diagnóstica com o MEEM. Para isso foram recrutados 412 idosos, categorizados em três grupos: controles saudáveis $(n=222), \operatorname{CLL}(n=70)$ e demência $(n=120)$. Os resultados mostraram que os valores de corte para detectar CCL e demência com o instrumento ACE-III foram 71 e 62 (AUC: 0,849 e 0,884), respectivamente, um pouco mais altos que com o MEEM (AUC: 0,822 e 0,861).

A ACE-III foi também padronizada para uso em sete idiomas, na Índia (Mekala et al., 2020). No total, 757 controles, 242 demências e 204 pacientes com CCL foram recrutados em cinco cidades da Índia para o estudo de validação. As propriedades psicométricas das versões adaptadas foram examinadas e sua sensibilidade e especificidade foram estabelecidas. A escolaridade teve um efeito independente nos escores da ACE-III. As pontuações de corte foram estabelecidas separadamente para os grupos de baixa escolaridade ( $\leq 10$ anos de educação), 82 para discriminar demência (0,97 de sensibilidade e 0,92 de especificidade) e 86 CCL (0,96 de sensibilidade e 0,82 de especificidade) e alta escolaridade (> 10 anos de educação), 84 para discriminar demência (0,98 de sensibilidade e 0,96 de especificidade) e $89 \operatorname{CCL}(0,92$ de sensibilidade e 0,81 de especificidade).

Estudo de Kourtesis et al., (2020) teve como objetivo adaptar o Exame Cognitivo de Addenbrooke-III (ACE-III) e o Mini-Exame Cognitivo de Addenbrooke (M-ACE) para o grego e, em seguida, examinar a validade 
convergente em comparação com o Exame Cognitivo de Addenbrooke revisado (ACE-R) e Mini Exame do Estado Mental (MEEM) em uma população grega. Além disso, o objetivo principal era avaliar a utilidade de cada triagem, conduzindo uma comparação das propriedades psicométricas de ACE-III, M-ACE, ACE-R, MEEM e a triagem de esclerose lateral amiotrófica cognitiva e comportamental de Edimburgo na detecção da doença de Alzheimer (DA). Um total de 40 pacientes com DA foi recrutado e pareado com 38 controles. A análise de correlação de Pearson Bayesian foi conduzida para examinar a validade convergente. A análise da curva, característica de operação do receptor, foi implementada para avaliar a sensibilidade e especificidade dos testes na detecção de DA. As pontuações da ACE-III, M-ACE e Edinburgh Cognitive and Behavioural Amyotrophic Lateral Sclerosis Screen (ECAS) se correlacionaram fortemente com ACE-R e MEEM. O ACE-III e o escore ECAS-ALS não específico foram as ferramentas mais sensíveis e específicas na detecção de DA, seguidos de perto pelo escore total ECAS-ALS e M-ACE. Apenas a pontuação total ECAS-ALS se correlacionou com a duração da doença. O ACE-III grego e o M-ACE foram adaptados com sucesso e mostraram boa validade convergente contra seus predecessores.

Os dados dos estudos supracitados, que utilizaram a ACE-III, estão sumarizados na Tabela 4 . Os resultados foram bem satisfatórios com uma sensibilidade que variou de 63,2 a 97,3\% na diferenciação de controles e CCL, de 79 a 100\% para diferenciar demência; especificidade de 57,14 a $92 \%$ e 78,7 a $100 \%$; respectivamente. 


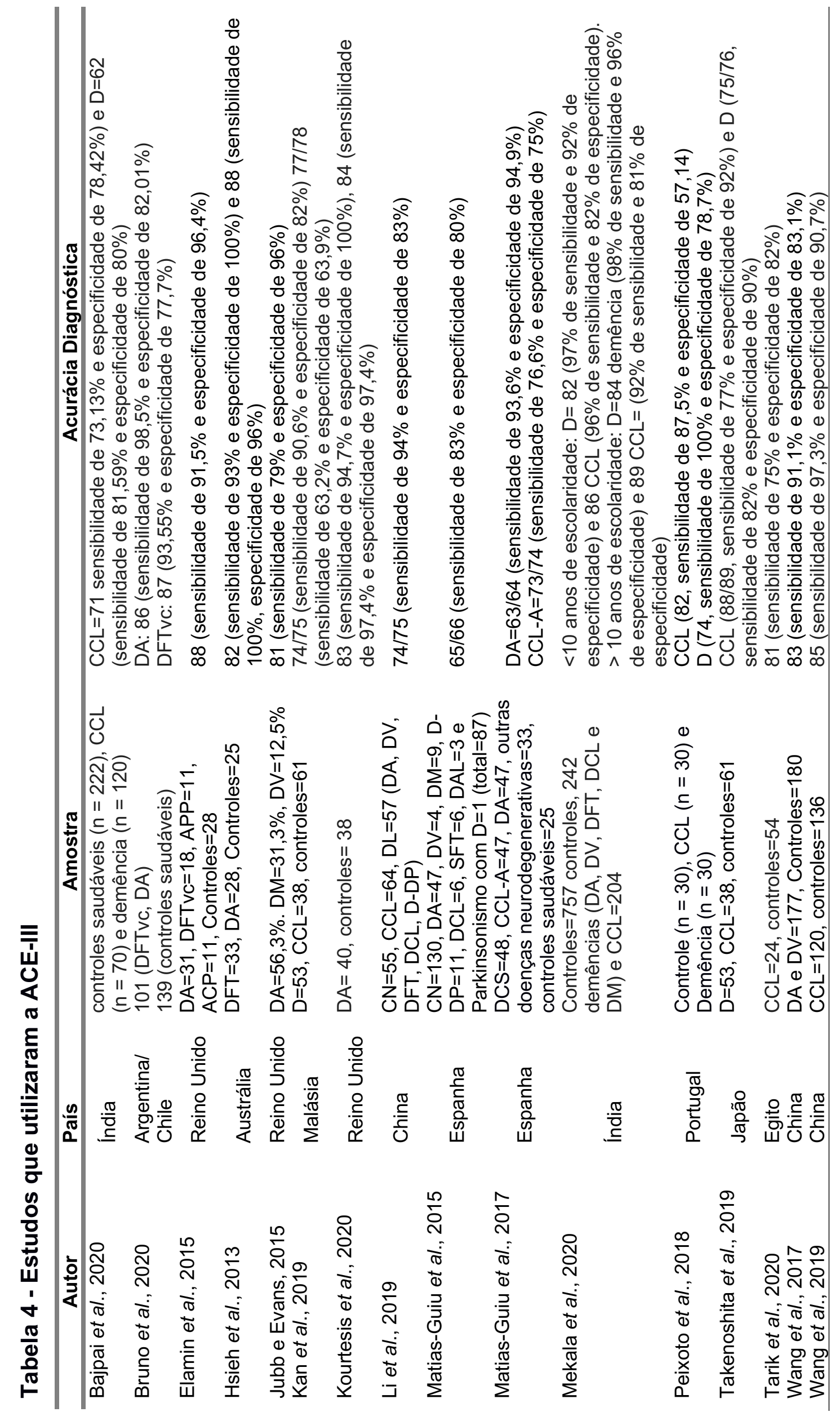


$\mathrm{Na}$ DPI, entretanto, ainda não há estudos de validação e padronização da ACE-III, exceto um estudo realizado por Lucza e colaboradores (2018), no qual foi comparada a sensibilidade e especificidade de algumas versões do exame cognitivo de Addenbrooke (ACE, ACE-III e M-ACE) em 552 indivíduos com DPI (Lucza et al., 2018). Cognição normal, comprometimento cognitivo menor e comprometimento cognitivo maior foram julgados de acordo com os respectivos critérios do Manual Diagnóstico e Estatístico de Transtornos Mentais (American Psychiatric Association, 2014). Para indivíduos com escolaridade de 0 a 8 e 9 a 12 anos, a ACE-III apresentou as melhores capacidades de discriminação para comprometimento cognitivo menor (pontuação de corte: 83,5 e 85,5 pontos, respectivamente), enquanto a M-ACE foi melhor para indivíduos com escolaridade > 12 anos (pontuação de corte: 25,5 pontos). Para detectar comprometimento cognitivo maior, a ACE-III apresentou a melhor precisão diagnóstica em todas as faixas de escolaridade (pontuações de corte: 70,5 , 77,5 e 78,5 pontos para indivíduos com escolaridade formal de 0 a 8,9 a 12 e $>12$ anos, respectivamente).

Tabela 5 - Estudo que utilizou a ACE-III na DP

\begin{tabular}{|c|c|c|c|c|}
\hline Autor & País & Amostra & $\begin{array}{c}\text { Acurácia Diagnóstica } \\
\text { CCL-DP }\end{array}$ & $\begin{array}{c}\text { Acurácia Diagnóstica } \\
\text { D-DP }\end{array}$ \\
\hline $\begin{array}{l}\text { Lucza et al., } \\
2018\end{array}$ & Hungria & $D P=552$ & $\begin{array}{l}\mathbf{8 3 , 5} \text { (escolaridade:0-8 } \\
\text { anos, sensibilidade de } \\
93 \% \text { e especificidade de } \\
64 \% \text {, AUC=0,733). } \\
\mathbf{8 5 , 5} \text { (escolaridade } 9-12 \\
\text { anos, sensibilidade de } \\
80 \% \text { e especificidade d } \\
78 \% \text {, AUC }=0,771 \text { ). } \\
\mathbf{8 8 , 5} \text { (escolaridade }>12 \\
\text { anos, sensibilidade de } \\
76 \% \text { e especificidade de } \\
74 \%, \text { AUC }=0.838 \text { ) }\end{array}$ & $\begin{array}{l}\mathbf{7 0 , 5} \text { (escolaridade:0-8 } \\
\text { anos, sensibilidade de } \\
80 \% \text { e especificidade de } \\
90 \% \text {, AUC=0,895). } \\
\mathbf{7 7 , 5} \text { (escolaridade } 9-12 \\
\text { anos, sensibilidade de } \\
90 \% \text { e especificidade de } \\
74 \% \text { ), AUC=0,926. } \\
\mathbf{7 8 , 5} \text { (escolaridade }>12 \\
\text { anos, sensibilidade de } \\
95 \% \text { e especificidade de } \\
\text { 92\%, AUC }=0,972 \text { ) }\end{array}$ \\
\hline
\end{tabular}


Desta forma, os estudos com a ACE-III estão mais voltados para condições neurológicas como DA, DFT, DV e parkinsonismos atípicos, ou até mesmo para condições psiquiátricas, como esquizofrenia (Charernboon e Chompookard, 2019). A avaliação cognitiva é uma importante ferramenta para detecção do funcionamento cerebral, sendo essencial a utilização de instrumentos/baterias breves, com sensibilidade e especificidade para diagnóstico de CCL e quadros demenciais na prática clínica e hospitalar do dia a dia; levando-se em conta as características demográficas, como idade e escolaridade e, se possível, aspectos culturais.

Este é o primeiro estudo realizado no Brasil, com a terceira versão da ACE, e o primeiro a ser estudado exclusivamente em pacientes com DPI. Representa, portanto, uma possibilidade de avaliação cognitiva breve do paciente com suspeita de alteração cognitiva. A ACE-III foi disponibilizada pela autora, Eneida Mioshi.

\subsection{Justificativa deste estudo}

A partir de resultados de pesquisas recentes, os quais demonstraram a utilidade da ACE para o auxílio no diagnóstico de demência inicial e diagnóstico diferencial de quadros demenciais, faz-se importante utilizar a terceira versão desta bateria com objetivo de avaliar a aplicabilidade desta ferramenta como um instrumento de avaliação cognitiva em pacientes com DPI. Esta condição neurológica apresenta características diversas/heterogêneas e trabalhos com amostras maiores e controladas, são importantes para esclarecer a relação entre a doença e as alterações neuropsicológicas observadas, uma vez que a 
alteração cognitiva, seja CCL ou demência, é frequente nesta condição neurológica. O conhecimento e identificação do funcionamento cognitivo em estágios precoces são fundamentais para compreender e favorecer intervenções clínicas, de reabilitação e manejo/orientação ao paciente e à família. 


\section{OBJETIVOS}

\subsection{Objetivo principal}

Investigar a acurácia diagnóstica, sensibilidade e especificidade, do Exame Cognitivo de Addenbrooke, terceira versão (ACE-III), como ferramenta de avaliação cognitiva breve em pacientes com diagnóstico de DPI.

\subsection{Objetivos secundários}

Avaliar a adequação do uso da referida bateria breve para auxílio no diagnóstico de comprometimento cognitivo leve e síndrome demencial na DPI.

Estabelecer as notas de corte para CCL-DP e D-DP.

Correlacionar o desempenho dos pacientes na ACE-III (escore total e domínios) com instrumentos neuropsicológicos padronizados, utilizados nesta população, recomendados pelas diretrizes da Movement Disorder Society (MDS).

Correlacionar escore total da ACE-III com dados clínicos (tempo de evolução e gravidade da doença) e habilidades funcionais. 


\section{MÉTODOS}

\subsection{Desenho do estudo}

Corte transversal, observacional, do tipo caso-controle.

\subsection{Participantes}

Participaram desta pesquisa 150 pacientes com DPI e 60 controles saudáveis. O diagnóstico de DPI foi realizado por neurologistas, de acordo com os critérios de diagnóstico clínico do Banco de Cérebro da Sociedade Britânica de doença de Parkinson (Litvan et al., 2003). Estes pacientes eram provenientes do programa de reabilitação neurológica da Rede SARAH de Hospitais de Reabilitação, Unidade Salvador/BA. Os controles saudáveis foram pareados por idade, sexo e escolaridade. O período de recrutamento ocorreu entre agosto de 2017 e janeiro de 2020. Foi uma amostragem de conveniência, porém os participantes pertenciam a diferentes localidades/regiões brasileiras.

O grupo clínico deveria ter idade superior a 40 anos, escolaridade $\geq$ 4 anos, sem transtornos psiquiátricos ou história de uso e/ou abuso de substância, doença cerebrovascular e/ou outras condições clínicas que pudessem prejudicar o estado mental e interferir no desempenho cognitivo.

Cada paciente possuía o exame de ressonância magnética cerebral de rotina (ou tomografia computadorizada do encéfalo, se o exame de ressonância magnética fosse contraindicado). Aqueles com anormalidades focais na neuroimagem, alterações nos níveis de hormônio tireoidiano ou doenças sistêmicas não compensadas (ou seja, diabetes, hipertensão e insuficiência 
cardíaca) também foram excluídos. Além destes critérios, a avaliação neuropsicológica foi realizada na fase "ON", naqueles com flutuação motora, sem alterações sensoriais que pudessem interferir durante a execução dos instrumentos de avaliação. Em relação aos aspectos afetivos, foram incluídos pacientes com escores nos Inventários Beck de Depressão-BDI e AnsiedadeBAI (ANEXOS E e F), de intensidade mínimo a leve (menor e igual a 16 no BDI e menor e igual a 15 no BAI) (Cunha, 2001).

Os controles saudáveis foram recrutados, através de convite aos acompanhantes dos pacientes atendidos no Hospital SARAH, porém sem vínculo com o paciente participante; bem como pacientes do setor de ortopedia do referido SARAH, conforme os seguintes critérios de inclusão: escolaridade $\geq 4$ anos, Questionário de Atividades Funcionais de Pfeffer, QAF (ANEXO G) (Pfeffer et al., 1982) de 0 ou 1, MEEM, medianas por escolaridade (ANEXO H) (Brucki et al., 2003), evocação de figuras da bateria breve de rastreio cognitivo (ANEXO I) maior ou igual a sete (Nitrini et al., 1994; 2004). Foram excluídos os indivíduos com distúrbios neurológicos e/ou psiquiátricos que pudessem afetar no funcionamento cognitivo.

\subsection{Procedimentos para coleta dos dados}

Após explicar sobre os objetivos do estudo e obter a assinatura do Termo de Consentimento Livre e Esclarecido (TCLE), foram aplicadas as escalas de humor e ansiedade (Inventários Beck de Depressão e Ansiedade), os Questionário do Informante sobre o Declínio Cognitivo do Idoso - IQCODE 
(ANEXO J) (Sanchez e Lourenço, 2009) e o Questionário de Atividades Funcionais de Pfeffer - QAF aos familiares ou cuidadores.

Em seguida foram coletados os dados clínicos, como tempo de evolução e gravidade da doença, através da escala Hoehn and Yahr - H\&Y (ANEXO K) (Hoehn and Yahr, 1967; Camargos et al., 2004) pelo mesmo examinador (avaliados no período "ON" e colhidos em obtidos em prontuário eletrônico). Esta avaliação motora foi realizada por um fisioterapeuta, pertencente ao programa de reabilitação neurológica do Hospital SARAH, treinado e com experiência em doença de Parkinson. As duas avaliações (motora e cognitiva) ocorreram na mesma época (até três meses entre elas), a fim de evitar vieses nos resultados em função do tempo.

Os pacientes foram avaliados individualmente em duas sessões de aproximadamente uma hora e meia cada. Para a avaliação de nível I, foi utilizado o Exame Cognitivo de Addenbrooke, terceira versão. Como há poucas mudanças entre as versões revisadas e a terceira, foram aplicados itens da versão revisada e itens da terceira versão que foram modificados, tais como a parte visuoespacial, na qual o desenho dos pentágonos foi substituído pela intersecção do símbolo do infinito e na parte de nomeação, as figuras colher e livro no lugar de caneta e relógio (ANEXO D). A avaliação nível II foi feita mediante bateria neuropsicológica abrangente, composta por testes padronizados para esta população, recomendados pela MDS, de forma randomizada. Os resultados destes testes foram comparados/correlacionados com os obtidos através da ACE-III (escore total e por domínios cognitivos). 
Após a avaliação neuropsicológica, os pacientes foram distribuídos em três subgrupos (cognição normal na doença de Parkinson / CN-DP, comprometimento cognitivo leve devido a doença de Parkinson / CCL-DP, demência devido a doença de Parkinson / D-DP), conforme diretrizes da MDS (Emre, 2003; Litvan et al., 2012). Os dados brutos foram convertidos para Z-escore e aqueles com pontuação de 1,5 desvios-padrão abaixo ou acima da média (dependendo do teste) para sua idade e escolaridade, em testes da bateria neuropsicológica foram diagnosticados como CCL-DP.

Todos os participantes foram avaliados por um neuropsicólogo especializado e treinado para esta condição neurológica, que foi a autora deste estudo.

Para auxílio na classificação de demência foram utilizados o Questionário Pfeffer de Atividade Funcional (QAF) maior do que cinco pontos e/ou IQCODE (maior que 3,41). Os indivíduos foram classificados por profissional com experiência em neurologia cognitiva e cego em relação ao paciente.

Desta forma, após a avaliação neuropsicológica e funcional, os indivíduos foram classificados nos grupos normal (CN-DP), CCL-DP e D-DP.

Após uma descrição completa do estudo para os participantes e/ou seus familiares/cuidadores, foi obtido o Termo de Consentimento Livre e Esclarecido (ANEXO L), aprovado pelo Comitê de Ética da Rede SARAH de Hospitais de Reabilitação (número do CAAE 57521316.8.0000.0022 - ANEXO M) e da Faculdade de Medicina da Universidade de São Paulo/FMUSP (número do CAAE 57521316.8.3001.0065 - ANEXO N). 
3.3.1 Testes utilizados para avaliação do nível II de comprometimento pela Sociedade de Distúrbios do Movimento (2012)

Amplitude de Dígitos (WMS-R) (Weschsler, 1987). Esta tarefa é subdividida em duas partes - ordem direta e ordem inversa. Na ordem direta, o experimentador lê uma sequência de dígitos na razão de um número por segundo. Após a apresentação de cada sequência o sujeito deve repetir os números na ordem em que foram lidos. Quando ocorrem erros, o sujeito tem a oportunidade de realizar o teste com outra sequência de mesmo número de dígitos. O escore é o número de dígitos na sequência máxima repetida corretamente. $\mathrm{Na}$ ordem inversa, o formato do teste é o mesmo, porém o sujeito deverá recordar os números de trás para frente. Os objetivos do teste na ordem direta e inversa são avaliar a capacidade de armazenamento e reverberação na memória imediata verbal (alça fonológica) e a capacidade de manter e manipular informações (executivo central), respectivamente.

Blocos de Corsi (Lezak et al., 2004). Avalia a amplitude ou capacidade (spam) visuoespacial atencional, memória de curto prazo (ordem direta) e a capacidade de manipular conteúdos visuoespaciais, memória operacional (ordem inversa). É composto de um tabuleiro com nove blocos numerados dispostos aleatoriamente. O examinador tocará uma sequência de blocos e esta mesma sequência deverá ser repetida pelo examinando na ordem direta e depois é a apresentada uma nova sequência que deverá ser repetida na ordem inversa.

Controle mental (WMS-R) (Weschsler, 1987). Avalia componentes da função executiva, como controle mental, atenção e concentração. Consiste em 
três tarefas, na primeira pede-se ao sujeito contar números na ordem decrescente (20-1); na segunda, o examinando fala o alfabeto completo (A-Z) e na terceira solicita-se que ele conte de três em três iniciando do número um (1-40). Estas tarefas devem ser realizadas o mais rápido possível, o tempo limite para primeira é de 30 segundos e para segunda e terceira é de 45 segundos cada. O escore para cada tarefa é de dois pontos para toda sequência correta e tempo limite, um ponto para um erro em cada sequência e tempo limite correto e zero para dois erros ou mais em cada sequência ou tempo limite ultrapassado.

Teste de aprendizagem auditivo-verbal de Rey - RAVLT (Malloy-Diniz et al., 2007): O RAVLT consiste em uma lista de 15 substantivos (lista A) que é lida em voz alta para o sujeito com um intervalo de um segundo entre as palavras, por cinco vezes consecutivas (A1 a A5). Cada uma das tentativas é seguida por um teste de evocação espontânea. Depois da quinta tentativa, uma lista de interferência, também composta por 15 substantivos (lista B), é lida para o sujeito, sendo seguida da evocação da mesma (tentativa B1). Logo após a tentativa B1, é pedido ao sujeito que recorde as palavras da lista $A$, sem que ela seja, nesse momento, reapresentada (tentativa A6). Após um intervalo de 20 minutos, que deve ser preenchido com outras atividades que não demandem raciocínio verbal, pede-se ao sujeito que se lembre das palavras da lista A (tentativa A7) sem que a lista seja lida para ele. Após a tentativa A7 é feito o teste de memória de reconhecimento, quando uma lista contendo 15 palavras da lista A, 15 palavras da lista B e 20 distratores (semelhantes às palavras de lista A e B em termos fonológicos ou semânticos) são lidas para o 
sujeito. A cada palavra lida, o sujeito deve indicar se ela pertence (ou não) à lista A.

Figura Complexa de Rey - FCR (Lezak et al., 2004). Consiste em uma figura geométrica complexa composta por um retângulo grande, bissetores horizontais e verticais, duas diagonais, e detalhes geométricos adicionais interna e externamente ao retângulo grande. O sujeito é solicitado a copiar a figura a partir do modelo oferecido, atentando aos detalhes. Em seguida, é solicitado que ele desenhe a figura a partir de sua recordação imediata. Após trinta minutos, novamente é solicitada a recordação do desenho. A cópia avalia planejamento executivo e habilidades visuo-construtivas, ao passo que as recordações imediatas e tardias avaliam memória episódica para conteúdos visuais.

Teste de Trilhas, partes A e B - TMT-A e TMT-B (Straus et al., 2006). Ambas as partes requerem habilidades visuais e motoras, porém a parte $B$ recruta aspectos das funções executivas. Requer o uso de lápis para fazer as linhas que ligarão 25 números em ordem crescente, os quais estão arranjados aleatoriamente na parte A e na parte B é o mesmo procedimento, porém, nesta última o sujeito terá que alternar números e letras correspondentes (1-A, 2-B, 3-C...). Ambas as aplicações são precedidas de um treino, os erros são apontados e devem ser corrigidos pelo próprio testando, o teste é encerrado após três erros ou 5 minutos do início da tarefa. O escore é o tempo para a realização da tarefa. Foi obtida tanto a pontuação em cada parte quanto a subtração da B-A, a fim de obter um resultado mais preciso das funções executivas. 
Fluência verbal fonêmica - FAS (Straus et al., 2006). Neste teste solicita-se ao sujeito a produção espontânea de palavras iniciadas com as letras "F", "A" e "S", num tempo estipulado de um minuto para cada letra, não podendo, porém, repetir as palavras, formar nomes próprios e derivados. $\mathrm{O}$ escore total do teste é a soma das palavras admissíveis.

\subsubsection{Escalas e questionários}

Inventário de Depressão de Beck - BDI (Cunha, 2001). Questionário de autorrelato, constituído por 21 itens de múltipla escolha, que mede a intensidade de sintomas depressivos. É composto por diversos itens relacionados aos sintomas depressivos como desesperança, irritabilidade e cognições como culpa ou sentimentos de ser punido; assim como sintomas físicos como fadiga, perda de peso e diminuição da libido. A gravidade da depressão será medida através de escores: mínimo (0-9), leve (10-16), moderado (17-29) e grave (30-63).

Inventário de Ansiedade de Beck - BAI (Cunha, 2001). Consiste em 21 questões sobre como o indivíduo tem se sentido na última semana, expressas em sintomas comuns de ansiedade (como sudorese e sentimentos de angústia). Cada questão apresenta quatro possíveis respostas, e a que se assemelha mais com o estado mental do indivíduo deve ser sinalizada. A gravidade da ansiedade será medida através de escores: mínimo (0-7), leve (8$15)$, moderado (16-25) e grave (26-63).

\section{Avaliação Funcional - Questionário de Atividades Funcionais - QAF} (Pfeffer et al., 1982): É composta por dez itens e avalia a funcionalidade 
através do grau de independência para realização das atividades instrumentais de vida diária. O escore mínimo é 0 e o máximo é 30 . Quanto maior a pontuação, maior é a dependência do paciente, sendo considerada a presença de prejuízo funcional a partir de um escore $>5$ pontos.

\section{Questionário do Informante sobre o Declínio Cognitivo do Idoso -} IQCODE (Sanchez e Lourenço, 2009): É um instrumento de rastreio que se baseia nas informações fornecidas por familiares ou cuidadores acerca de um possível declínio cognitivo do paciente. O informante é questionado a respeito da funcionalidade e capacidades cognitivas do familiar, com perguntas simples de memória e atividades de vida diária, comparando o seu desempenho atual com o dos últimos dez anos. O resultado final é obtido pela soma ponderada dos itens, dividindo-os pelo total de itens da escala. O escore varia de um a cinco. Os escores menores ou iguais a 3,41 indicam que não há alteração, igual a quatro indica uma considerável alteração e igual a 5 muita alteração.

A aplicação do protocolo de pesquisa durou duas sessões de, aproximadamente, uma hora e meia cada. Na Figura 2 pode ser visualizado o fluxograma para melhor entendimento das etapas supracitadas. 


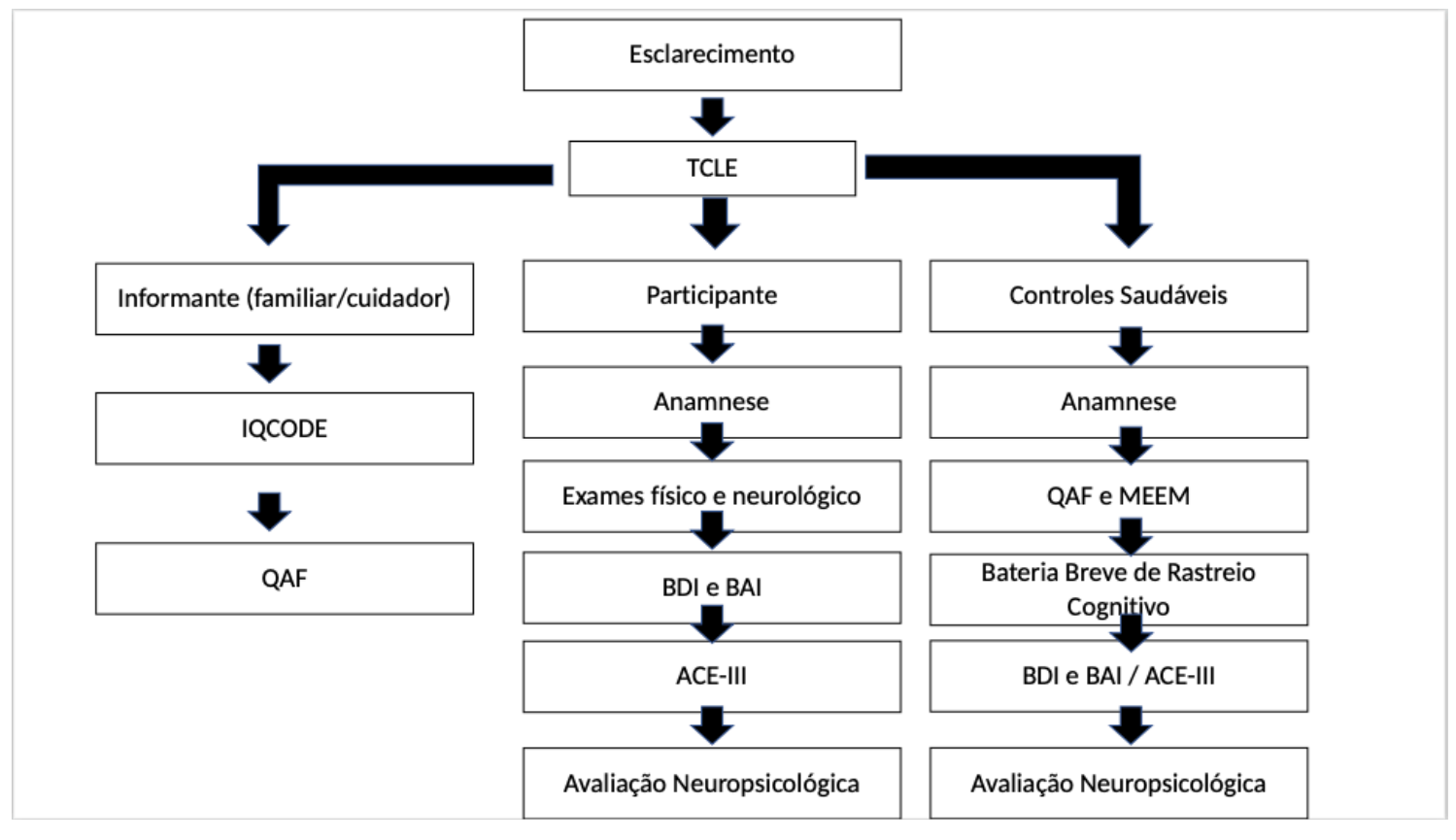

Figura 2 - Fluxograma do protocolo de pesquisa

IQCODE = Questionário do Informante sobre o Declínio Cognitivo do Idoso, QAFP = Questionário de Atividade Funcional de Pfeffer, BBRC = Bateria Breve do Rastreio Cognitivo, ACE-III = Addenbrooke's Cognitive Examination-terceira versão.

\subsection{Procedimentos para análise dos dados}

Os dados foram analisados através de técnica estatística com o auxílio do programa STATA SE 12.0. As variáveis foram analisadas pelos testes Qui-quadrado, $t$ de Student, correlação de Pearson, correlação de Spearman, conforme o tipo de dado (categórico ou contínuo) e distribuição do mesmo.

Os dados demográficos (idade, escolaridade e duração da doença) e as pontuações na ACE-III, bem como os testes neuropsicológicos foram comparados por Análise de Variância (ANOVA), de uma via, com comparações post hoc de Bonferroni.

Os coeficientes de correlação de Pearson foram utilizados entre as variáveis contínuas, como desempenho na ACE-III com os demais testes cognitivos, bem como entre os escores da ACE-III e os dados clínicos 
(evolução e gravidade da doença) e habilidades funcionais (escores das escalas QAF e IQCODE). O coeficiente de correlação de Spearman, correlação não paramétrica, foi utilizado para variáveis ordinais, como a escala H\&Y.

A acurácia diagnóstica da bateria foi investigada pela análise das áreas sob as curvas ROC (Receiver Operating Characteristic), para verificação da sensibilidade e especificidade dos pontos de corte. A Curva ROC Permite evidenciar os valores para os quais existe maior otimização da sensibilidade em função da especificidade que corresponde ao ponto em que se encontra mais próxima do canto superior esquerdo do diagrama, uma vez que o índice de positivo-verdadeiros é 1 e o de falso-positivos é zero. Como o ponto de corte ideal é aquele que seleciona uma quantidade maior de doença (alta sensibilidade), mas com muito poucos falsos positivos (alta especificidade) foi escolhido o melhor ponto de corte para equilibrar a sensibilidade e a especificidade, identificando o ponto na curva mais próxima do ponto $(0,1)$. A área sob a curva (AUC) foi usada como uma medida da capacidade de cada teste para distinguir entre os grupos de participantes.

Foi considerado um nível de significância de $5 \%$ para os resultados das análises estatísticas, isto é, quando o valor de significância $p$ foi menor de 0,05 , as diferenças foram consideradas estatisticamente significantes. 


\section{RESULTADOS}

\subsection{Características demográficas e clínicas dos grupos}

Um total de 150 pacientes e 60 controles saudáveis foram recrutados para este estudo. O grupo clínico foi dividido em três subgrupos: cognição normal na doença de Parkinson (CN-DP - 24 pacientes - 16\%), comprometimento cognitivo leve devido a doença de Parkinson (CCL-DP - 104 pacientes - 69,33\%) e demência devido à doença de Parkinson (D-DP - 22 pacientes - 14,66\%). Este grupo clínico, conforme explicado nos métodos, foi pareado, por idade e escolaridade, ao grupo controle.

Como pode ser observado na Tabela 6 , não houve diferença estatisticamente significante, entre os grupos (clínico total e controle), em relação à idade $(t=0,1942, p=0,84)$, anos de escolaridade $(t=1,1003$, $p=0,2725)$ e sexo $(x 2=0.7046, p=0,401)$. Nas medidas clínicas, de humor e ansiedade, bem como funcionais foi observada maior pontuação, ou seja, pior resultado, no grupo clínico. Em relação à gravidade dos sintomas motores, houve uma maior proporção de pacientes nos estágios I e II da escala H\&Y, ou seja, com menor gravidade da doença. Esta tabela também ilustra a comparação de escores totais da ACE-III e seus escores por domínios cognitivos entre esses dois grupos. Foram observadas diferenças estatisticamente significantes nos escores médios da pontuação total da ACE-III ( $t=-3,186, p=0,002)$, e seus domínios atenção/orientação $(t=-3,188$, $p=0,002)$, memória $(t=-2,992, p=0,003)$ e componente visuoespacial $(t=-2,518, p=0,012)$. 
Tabela 6 - Características clínicas e sociodemográficas e comparação entre os grupos clínico e controle

\begin{tabular}{|c|c|c|c|}
\hline$N=210$ & $\begin{array}{l}\text { Grupo Clínico } \\
(n=150)\end{array}$ & $\begin{array}{l}\text { Grupo Controle } \\
\qquad(n=60)\end{array}$ & Valor de $p$ \\
\hline \multicolumn{4}{|l|}{ Sexo $(\%)$} \\
\hline Masculino & 104 & $38(63,33 \%)$ & $0,401^{\mathrm{b}}$ \\
\hline Idade, anos & $63,58(8,81)$ & $63,32(9,04)$ & $0,8462^{\mathrm{a}}$ \\
\hline Escolaridade, anos & $11,03(4,00)$ & $10,38(3,51)$ & $0,2725^{a}$ \\
\hline Duração da doença (anos) & $6,61(4,69)$ & - & - \\
\hline \multicolumn{4}{|l|}{ Escala Hoehn \& Yahr (\%) } \\
\hline Estágios I-II & $86(57,33 \%)$ & - & - \\
\hline Estágio III & $64(42,67 \%)$ & - & - \\
\hline $\mathrm{BDI}$ & $5,92(4,37)$ & $0,68(1,63)$ & $<0,0001^{* * * a}$ \\
\hline BAI & $3,13(3,04)$ & $0,20(0,51)$ & $<0,0001^{* \star * a}$ \\
\hline QAF & $2,59(3,12)$ & $0,27(0,48)$ & $<0,0001^{* * * a}$ \\
\hline IQCODE & $3,44(0,63)$ & $3,13(0,23)$ & $0,0003^{\star \star \star a}$ \\
\hline ACE-III (escore total/máx.100) & $81,83(11,61)$ & $87,02(7,70)$ & $0,0017^{* * a}$ \\
\hline Atenção/Orientação (máx.18) & $15,97(1,99)$ & $16,88(1,52)$ & $0,0017^{* * a}$ \\
\hline Memória (máx. 26) & $18,28(4,81)$ & $20,37(3,89)$ & $0,0031^{* * a}$ \\
\hline Fluência Verbal (máx.14) & $9,29(2,91)$ & $9,93(2,68)$ & $0,1430^{a}$ \\
\hline Linquagem (máx.26) & $24,54(2,35)$ & $25,13(1,29)$ & $0,0662^{a}$ \\
\hline Visuoespacial (máx.16) & $13,75(2,76)$ & $14,70(1,57)$ & $0,0125^{* a}$ \\
\hline
\end{tabular}

$\mathrm{BDI}=$ Inventário Beck de Depressão; $\mathrm{BAI}=$ Inventário Beck de Ansiedade; $\mathrm{QAF}=$ Questionário de Atividades Funcionais; IQCODE=Questionário do Informante sobre o Declínio Cognitivo do Idoso. (a) Teste $t$ para amostras independentes (b) Qui-quadrado.

${ }^{*} p<0,01,{ }^{* *} p<0,001,{ }^{* * *} p<0,0001$.

$\mathrm{Na}$ Tabela 7 mostra a mesma análise estatística supracitada, após a estratificação do grupo clínico, em função do status cognitivo. Foram observadas diferenças em relação à idade entre os subgrupos CN-DP e D-DP, gravidade da doença entre os subgrupos D-DP e CCL-DP, CN-DP e CCL-DP, bem como quanto aos subgrupos CN-DP e D-DP. Quanto à gravidade da doença, avaliada através da escala H\&Y, foi observada diferença entre os grupos, principalmente entre o CN-DP e D-DP $\left(\chi^{2}=12,564, p=<0,0001\right)$. A análise post hoc (teste de Bonferroni) revelou que o grupo D-DP apresentou escores médios significantemente mais baixos para o escore total da ACE-III e em todos os seus cinco domínios quando comparados aos grupos CN-DP, CCL-DP e controles saudáveis. A comparação entre os grupos CCL-DP e controles saudáveis mostrou que o grupo CCL-DP teve apenas escores médios 
significantemente mais baixos no total da ACE-III e domínio de memória. A comparação entre D-DP e CCL-DP, D-DP e controles saudáveis, D-DP e CN-DP apresentou diferenças estatisticamente significantes em todas as medidas (escore total da ACE-III e os seus cinco domínios cognitivos). 


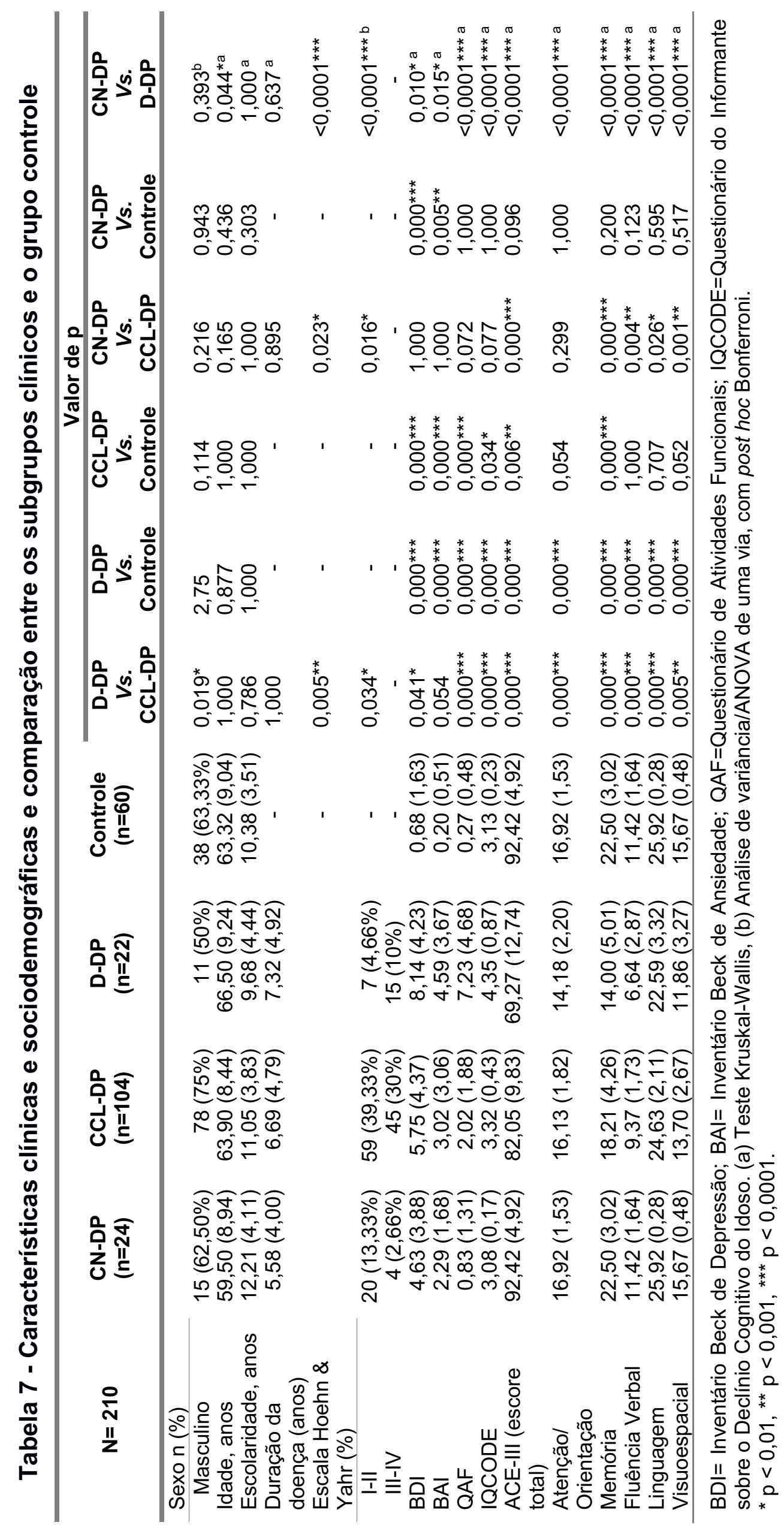


Em relação aos itens que compõem cada domínio da bateria ACE-III, quando comparado com o grupo controle, o grupo clínico apresentou uma pontuação total média significantemente menor, bem como em aspectos da atenção/orientação, atenção (controle mental), memória (nome e endereço / evocação imediata), leitura, visuoespacial (desenho do relógio) e memória (nome e endereço / evocação tardia). Apesar do desempenho ser inferior em relação às outras medidas, não houve diferença estatisticamente significante entre estes grupos (Tabela 8).

Tabela 8 - Estatística descritiva e inferencial da bateria ACE-III (grupo clínico e controles saudáveis)

\begin{tabular}{lrrr}
\hline \multicolumn{1}{c}{ ACE-III } & $\begin{array}{c}\text { Grupo Controle } \\
\text { Média (DP) } \\
\mathbf{n = 6 0}\end{array}$ & $\begin{array}{c}\text { Grupo } \\
\text { Clínico } \\
\mathbf{n = 1 5 0}\end{array}$ & $\begin{array}{c}\text { Valor } \\
\text { de } \mathbf{p}\end{array}$ \\
\hline Escore Total & $87,02(7,70)$ & $81,83(11,61)$ & $0,0017^{* *}$ \\
Atenção/Orientação & $9,97(0,18)$ & $9,77(0,58)$ & $0,0100^{*}$ \\
Atenção (registro 3 palavras) & $3,00(0,00)$ & $2,99(0,12)$ & 0,3712 \\
Atenção (controle mental) & $3,92(1,46)$ & $3,22(1,80)$ & $0,0084^{* *}$ \\
Memória (evocação 3 palavras) & $1,98(0,81)$ & $1,79(0,85)$ & 0,1413 \\
Fluência (p) & $4,92(1,72)$ & $4,57(1,64)$ & 0,1787 \\
Fluência (animais) & $5,02(1,31)$ & $4,72(1,70)$ & 0,2265 \\
Memória (nome e endereço - imediata) & $6,25(1,21)$ & $6,73(0,76)$ & $0,0042^{* *}$ \\
Memória (informação) & $3,12(1,06)$ & $2,82(1,17)$ & 0,0899 \\
Linguagem (compreensão) & $3,00(0,00)$ & $2,93(0,28)$ & 0,0629 \\
Linguagem (2 sentenças) & $2,00(0,00)$ & $1,96(0,20)$ & 0,1171 \\
Linguagem (repetição/palavras) & $2,00(0,00)$ & $1,95(0,25)$ & 0,1052 \\
Linguagem (repetição/frase) & $1,00(0,00)$ & $1,00(0,00)$ & - \\
Linguagem (repetição/frase) & $1,00(0,00)$ & $1,00(0,00)$ & - \\
Linguagem (nomeação) & $11,22(1,08)$ & $10,94(1,64)$ & 0,2279 \\
Compreensão (figuras) & $3,92(0,38)$ & $3,83(0,56)$ & 0,2578 \\
Leitura & $1,00(0,00)$ & $0,93(0,25)$ & $0,0406^{*}$ \\
Visuoespacial (diagrama) & $0,78(0,42)$ & $0,71(0,45)$ & 0,3023 \\
Visuoespacial (cubo) & $1,37(0,78)$ & $1,30(0,85)$ & 0,5749 \\
Visuoespacial (relógio) & $4,58(0,94)$ & $3,97(1,58)$ & $0,0053^{* *}$ \\
Visuoespacial (pontos) & $3,97(0,18)$ & $3,91(0,39)$ & 0,2516 \\
Visuoespacial (letras) & $4,00(0,00)$ & $3,95(0,27)$ & 0,1789 \\
Memória (evocação tardia/nome e endereço) & $3,93(2,27)$ & $3,15(2,34)$ & $0,0274^{*}$ \\
Reconhecimento (nome e endereço) & $4,60(0,74)$ & $4,27(1,04)$ & $0,0272^{*}$ \\
\hline
\end{tabular}

Teste $t$ para amostras independentes. ${ }^{*} p<0,01,{ }^{* *} p<0,001,{ }^{* * *} p<0,0001$. 


\subsection{Comparações entre os subgrupos clínicos e grupo controle}

Após estratificar a amostra clínica, pelo comprometimento cognitivo, pode-se observar que o subgrupo D-DP apresentou uma pontuação total média significantemente menor para todos os itens que compõem os domínios da ACE-III, exceto atenção (controle mental), fluência verbal fonêmica (letra p), linguagem (compreensão, leitura de duas sentenças), visuoespacial (diagrama e letras), evocação tardia (nome e endereço). A pontuação média foi inferior nestes itens para o subgrupo D-DP e, em seguida, para o subgrupo CCL-DP, porém não sendo observada diferença estatisticamente significante entre os subgrupos (Tabela 9). 


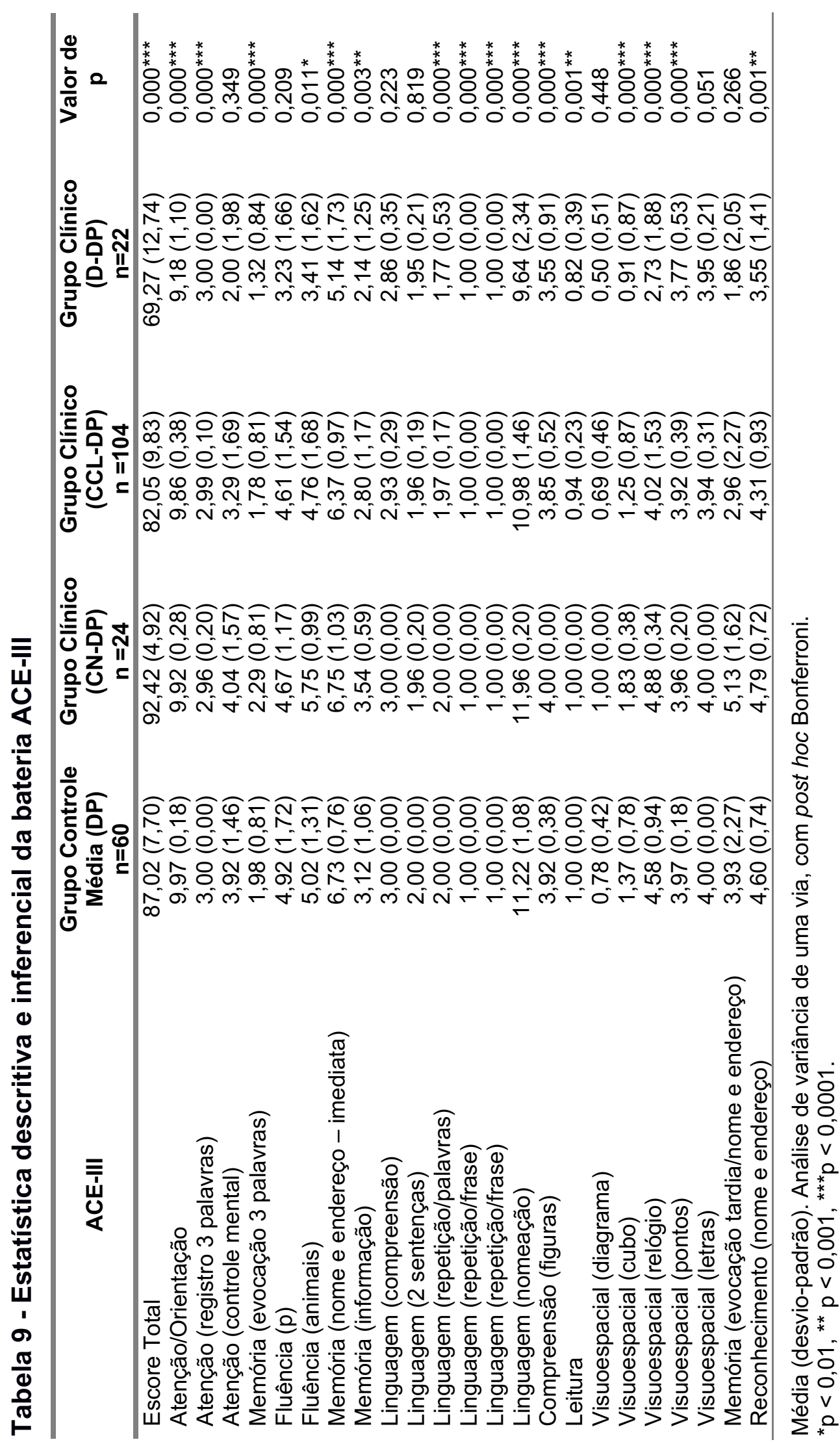




\subsection{Comparações entre escores da ACE-III, conforme dados demográficos}

Ao analisar os escores da ACE-III (pontuação total e seus domínios), por idade e escolaridade, ou seja, nas faixas de idade de 40 - 59, 60 - 69 anos e maior e igual a 70 anos; e faixas de escolaridade de 4 - 9 anos, 10 - 12 anos e maior e igual a 13 anos; o subgrupo >= 13 anos de escolaridade apresentou maior média no escore total e em todos os índices, evidenciando a interferência da escolaridade nas medidas cognitivas desta bateria. Quanto à faixa de idade, também houve influência nos escores cognitivos, como pode ser observado nas Tabelas 10 e 11. 
Tabela 10 - Escores na ACE-III (escore total e domínios), por faixas de idade e escolaridade no grupo clínico $(\mathrm{N}=150)$

\begin{tabular}{|c|c|c|c|c|c|c|c|c|c|}
\hline \multirow{2}{*}{$\begin{array}{l}\text { Idade (anos) } \\
\text { Escolaridade (anos) }\end{array}$} & \multicolumn{3}{|c|}{$40-59$} & \multicolumn{3}{|c|}{$60-69$} & \multicolumn{3}{|c|}{$>=70$} \\
\hline & $\begin{array}{c}4-9 \\
(n=30)\end{array}$ & $\begin{array}{c}10-12 \\
(n=33)\end{array}$ & $\begin{array}{c}>=13 \\
(n=16)\end{array}$ & $\begin{array}{c}4-9 \\
(n=24)\end{array}$ & $\begin{array}{c}10-12 \\
(n=37)\end{array}$ & $\begin{array}{c}>=13 \\
(n=18)\end{array}$ & $\begin{array}{c}4-9 \\
(n=21)\end{array}$ & $\begin{array}{c}10-12 \\
(n=17)\end{array}$ & $\begin{array}{c}>=13 \\
(n=14)\end{array}$ \\
\hline \multicolumn{10}{|l|}{ Escore Total } \\
\hline Média & 79,2 & 88,1 & 89,1 & 72,0 & 81,6 & 89,6 & 77,1 & 74,2 & 86,8 \\
\hline Mediana & 79,0 & 89,0 & 93,0 & 74,0 & 81,0 & 91,0 & 80,0 & 74,5 & 90,0 \\
\hline Desvio-Padrão & 10,8 & 5,1 & 9,8 & 13,1 & 11,1 & 6,1 & 11,4 & 11,5 & 10,2 \\
\hline Mínimo & 59,0 & 80,0 & 63,0 & 43,0 & 58,0 & 77,0 & 59,0 & 58,0 & 59,0 \\
\hline Máximo & 95,0 & 98,0 & 99,0 & 88,0 & 95,0 & 98,0 & 92,0 & 92,0 & 96,0 \\
\hline \multicolumn{10}{|l|}{ Atenção/Orientação } \\
\hline Média & 15,7 & 16,7 & 16,0 & 14,8 & 15,6 & 17,2 & 15,7 & 15,8 & 16,9 \\
\hline Mediana & 15,0 & 17,0 & 17,0 & 15,0 & 15,0 & 18,0 & 16,0 & 16,5 & 17,0 \\
\hline Desvio-Padrão & 2,0 & 1,6 & 2,3 & 2,2 & 2,0 & 1,2 & 1,9 & 2,3 & 1,4 \\
\hline Mínimo & 13,0 & 13,0 & 12,0 & 9,0 & 12,0 & 14,0 & 13,0 & 12,0 & 13,0 \\
\hline Máximo & 18,0 & 18,0 & 18,0 & 18,0 & 18,0 & 18,0 & 18,0 & 18,0 & 18,0 \\
\hline \multicolumn{10}{|l|}{ Memória } \\
\hline Média & 17,0 & 20,1 & 20,9 & 13,4 & 18,7 & 21,2 & 16,9 & 16,3 & 20,8 \\
\hline Mediana & 17,0 & 20,0 & 22,0 & 13,0 & 20,0 & 22,0 & 17,0 & 15,0 & 22,0 \\
\hline Desvio-Padrão & 4,9 & 3,2 & 4,4 & 4,9 & 4,6 & 3,3 & 4,3 & 4,0 & 4,3 \\
\hline Mínimo & 8,0 & 14,0 & 12,0 & 4,0 & 10,0 & 15,0 & 8,0 & 11,0 & 13,0 \\
\hline Máximo & 25,0 & 25,0 & 26,0 & 22,0 & 25,0 & 26,0 & 22,0 & 24,0 & 26,0 \\
\hline \multicolumn{10}{|l|}{ Fluência Verbal } \\
\hline Média & 8,6 & 11,3 & 11,2 & 7,9 & 9,3 & 10,9 & 8,1 & 6,7 & 9,3 \\
\hline Mediana & 9,0 & 11,0 & 11,5 & 9,0 & 9,0 & 11,0 & 8,0 & 7,5 & 10,0 \\
\hline Desvio-Padrão & 2,7 & 1,4 & 2,1 & 2,9 & 2,7 & 1,8 & 2,9 & 3,3 & 3,3 \\
\hline Mínimo & 4,0 & 8,0 & 6,0 & 2,0 & 4,0 & 8,0 & 5,0 & 1,0 & 1,0 \\
\hline Máximo & 13,0 & 14,0 & 14,0 & 13,0 & 14,0 & 14,0 & 14,0 & 11,0 & 13,0 \\
\hline \multicolumn{10}{|l|}{ Linguagem } \\
\hline Média & 24,6 & 25,3 & 25,4 & 23,4 & 24,4 & 25,7 & 23,5 & 23,0 & 25,6 \\
\hline Mediana & 25,5 & 26,0 & 26,0 & 23,5 & 26,0 & 26,0 & 25,0 & 24,0 & 26,0 \\
\hline Desvio-Padrão & 1,9 & 0,9 & 1,3 & 2,6 & 2,5 & 1,1 & 2,8 & 4,0 & 0,7 \\
\hline Mínimo & 19,0 & 23,0 & 21,0 & 17,0 & 15,0 & 22,0 & 18,0 & 12,0 & 24,0 \\
\hline Máximo & 26,0 & 26,0 & 26,0 & 26,0 & 26,0 & 26,0 & 26,0 & 26,0 & 26,0 \\
\hline \multicolumn{10}{|l|}{ Visuoespacial } \\
\hline Média & 13,3 & 14,8 & 15,6 & 12,6 & 13,7 & 14,5 & 12,8 & 12,3 & 14,3 \\
\hline Mediana & 14,5 & 15,0 & 16,0 & 13,5 & 15,0 & 15,0 & 14,0 & 12,0 & 15,5 \\
\hline Desvio-Padrão & 3,1 & 1,4 & 1,1 & 3,0 & 2,8 & 1,6 & 2,9 & 3,4 & 3,3 \\
\hline Mínimo & 7,0 & 11,0 & 12,0 & 8,0 & 7,0 & 12,0 & 7,0 & 6,0 & 6,0 \\
\hline Máximo & 16,0 & 16,0 & 16,0 & 16,0 & 16,0 & 16,0 & 16,0 & 16,0 & 18,0 \\
\hline
\end{tabular}


Tabela 11 - Escores na ACE-III (escore total e domínios), por faixas de idade e escolaridade no grupo controle $(\mathrm{N}=60)$

\begin{tabular}{|c|c|c|c|c|c|c|c|c|c|}
\hline \multirow{2}{*}{$\begin{array}{l}\text { Idade (anos) } \\
\text { Escolaridade } \\
\text { (anos) }\end{array}$} & \multicolumn{3}{|c|}{$40-59$} & \multicolumn{3}{|c|}{$60-69$} & \multicolumn{3}{|c|}{$>=70$} \\
\hline & $\begin{array}{c}4-9 \\
(n=30)\end{array}$ & $\begin{array}{c}10-12 \\
(n=33)\end{array}$ & $\begin{array}{c}>=13 \\
(n=16)\end{array}$ & $\begin{array}{c}4-9 \\
(n=24)\end{array}$ & $\begin{array}{c}10-12 \\
(n=37)\end{array}$ & $\begin{array}{c}>=13 \\
(n=18)\end{array}$ & $\begin{array}{c}4-9 \\
(n=21)\end{array}$ & $\begin{array}{c}10-12 \\
(n=17)\end{array}$ & $\begin{aligned}> & =13 \\
(n & =14)\end{aligned}$ \\
\hline \multicolumn{10}{|l|}{ Escore Total } \\
\hline Média & 81,6 & 86,4 & 98,0 & 78,1 & 92,6 & 94,8 & 86,2 & 92,0 & 91,5 \\
\hline Mediana & 82,5 & 85,5 & 98,0 & 78,5 & 93,0 & 95,0 & 88,0 & 92,0 & 91,5 \\
\hline Desvio-Padrão & 7,7 & 4,8 & 1,4 & 4,0 & 5,2 & 4,4 & 8,2 & 3,4 & 0,7 \\
\hline Mínimo & 72,0 & 80,0 & 97,0 & 71,0 & 86,0 & 88,0 & 72,0 & 88,0 & 91,0 \\
\hline Máximo & 92,0 & 95,0 & 99,0 & 84,0 & 99,0 & 100,0 & 95,0 & 97,0 & 92,0 \\
\hline \multicolumn{10}{|c|}{ Atenção/Orientação } \\
\hline Média & 16,7 & 17,1 & 18,0 & 15,0 & 17,9 & 17,6 & 16,2 & 17,4 & 17,5 \\
\hline Mediana & 17,0 & 18,0 & 18,0 & 14,5 & 18,0 & 18,0 & 16,5 & 17,0 & 17,5 \\
\hline Desvio-Padrão & 1,6 & 1,6 & 0,0 & 1,6 & 0,4 & 0,9 & 1,5 & 0,5 & 0,7 \\
\hline Mínin & 14,0 & 14,0 & 18,0 & 13,0 & 17,0 & 16,0 & 14,0 & 17,0 & 17,0 \\
\hline Máximo & 18,0 & 18,0 & 18,0 & 18,0 & 18,0 & 18,0 & 18,0 & 18,0 & 18,0 \\
\hline \multicolumn{10}{|l|}{ Memória } \\
\hline Média & 17,5 & 19,8 & 24,5 & 17,3 & 22,0 & 25,0 & 21,3 & 22,2 & 21,5 \\
\hline Med & 18,0 & 19,5 & 24,5 & 16,5 & 21,5 & 25,0 & 22,0 & 23,0 & 21,5 \\
\hline -Padrão & 4,4 & 3,4 & 0,7 & 3,0 & 3,2 & 1,0 & 2,1 & 3,8 & 0,7 \\
\hline Mínin & 12,0 & 15,0 & 24,0 & 14,0 & 17,0 & 24,0 & 18,0 & 16,0 & 21,0 \\
\hline Máximo & 24,0 & 25,0 & 25,0 & 23,0 & 26,0 & 26,0 & 23,0 & 26,0 & 22,0 \\
\hline \multicolumn{10}{|l|}{ Fluência Verbal } \\
\hline Média & 8,4 & 9,1 & 13,5 & 8,1 & 11,6 & 11,0 & 10,0 & 11,8 & 12,5 \\
\hline Mediana & 8,5 & 9,0 & 13,5 & 7,5 & 12,0 & 11,0 & 11,0 & 12,0 & 12,5 \\
\hline Sadrão & 2,5 & 2,8 & 0,7 & 2,0 & 1,8 & 2,1 & 3,0 & 1,6 & 0,7 \\
\hline Mínir & 3,0 & 4,0 & 13,0 & 6,0 & 9,0 & 8,0 & 5,0 & 9,0 & 1,20 \\
\hline Máximo & 12,0 & 14,0 & 14,0 & 11,0 & 14,0 & 14,0 & 13,0 & 13,0 & 13,0 \\
\hline \multicolumn{10}{|l|}{ Linguagem } \\
\hline Média & 24,0 & 25,3 & 26,0 & 25,0 & 25,9 & 25,8 & 24,8 & 25,4 & 25,5 \\
\hline Media & 25,0 & 25,5 & 26,0 & 25,0 & 26,0 & 26,0 & 25,0 & 26,0 & 25,5 \\
\hline -Padrão & 2,3 & 0,9 & 0,0 & 0,9 & 0,4 & 0,4 & 1,3 & 0,9 & 0,7 \\
\hline Mínin & 21,0 & 24,0 & 26,0 & 24,0 & 25,0 & 25,0 & 23,0 & 24,0 & 25,0 \\
\hline Máximo & & & & 26,0 & & & 26,0 & 26,0 & 26,0 \\
\hline \multicolumn{10}{|l|}{ Visuoespacial } \\
\hline Média & 15,0 & 15,1 & 16,0 & 12,8 & 15,3 & 15,4 & 13,8 & 15,2 & 14,5 \\
\hline M & 15,0 & 15,0 & 16,0 & 12,5 & 16,0 & 16,0 & 14,0 & 16,0 & 14,5 \\
\hline -Padrão & 0,9 & 1,0 & 0,0 & 1,9 & 1,4 & 0,9 & 2,1 & 1,3 & 2,1 \\
\hline Mínim & 14,0 & 13,0 & 16,0 & 11,0 & 12,0 & 14,0 & 11,0 & 13,0 & 13,0 \\
\hline Máximo & 16,0 & 16,0 & 16,0 & 16,0 & 16,0 & 16,0 & 16,0 & 16,0 & 16,0 \\
\hline
\end{tabular}

\subsection{Efeito da idade no desempenho dos escores cognitivos}

Para investigar o efeito da idade no desempenho dos escores cognitivos, os controles saudáveis foram divididos em três grupos, de acordo com a mesma faixa de idade da análise anterior (40 - 59, 60 - 69 e iguais e acima de 70 anos). A Tabela 12 mostra os escores médios gerados a partir de controles saudáveis para o total da ACE-III e seus escores dos domínios de acordo com diferentes faixas etárias. Entre esses subgrupos, não foram observadas diferenças estatisticamente significante nos anos de escolaridade. A pontuação 
média total da ACE-III $[F(2,57)=1,16, p=0,3195]$, atenção $[F(2,57)=0,26, p$ $=0,7699]$, memória $[F(2,57=2,06, p=0,1363]$, fluência verbal $[F(2,57)=$ 2,34, $p=0,1051]$, linguagem $[F(2,57)=1,83, p=0,1700]$ e subescores visuoespaciais $[F(2,57)=1,68, p=0,1955]$ não apresentaram diferenças significantes entre os subgrupos.

Tabela 12 - Dados descritivos da ACE-III (escore total e domínios) do grupo controle, de acordo com a idade (média \pm DP) e comparação entre os subgrupos

\begin{tabular}{|c|c|c|c|c|c|c|}
\hline \multirow{2}{*}{$\begin{array}{l}\text { Grupo Controle } \\
\qquad(n=60)\end{array}$} & \multicolumn{3}{|c|}{ Subgrupos por idade } & \multicolumn{3}{|c|}{ Valor de $p$} \\
\hline & $\begin{array}{c}40-59(1) \\
(n=26)\end{array}$ & $\begin{array}{c}60-69(2) \\
(n=21)\end{array}$ & $\begin{array}{c}>=70(3) \\
(n=13)\end{array}$ & (1)vs.(2) & (1)vs.(3) & (2)vs.(3) \\
\hline Escolaridade, anos & $10,2 \pm 3,2$ & $10,7 \pm 3,8$ & $10,2 \pm 3,8$ & 1,000 & 1,000 & 1,000 \\
\hline ACE-III (total) & $85,4 \pm 7,3$ & $87,6 \pm 8,8$ & $89,2 \pm 6,4$ & 1,000 & 0,450 & 1,000 \\
\hline Atenção/Orientação & $17,0 \pm 1,5$ & $16,7 \pm 1,7$ & $16,8 \pm 1,2$ & 1,000 & 1,000 & 1,000 \\
\hline Memória & $19,3 \pm 4,1$ & $20,9 \pm 4,1$ & $21,7 \pm 2,6$ & 0,450 & 0,201 & 1,000 \\
\hline Fluência Verbal & $9,2 \pm 2,8$ & $10,1 \pm 2,5$ & $11,1 \pm 2,4$ & 0,664 & 0,116 & 0,950 \\
\hline Linguagem & $24,8 \pm 1,6$ & $25,5 \pm 0,7$ & $25,2 \pm 1,1$ & 0,183 & 1,000 & 1,000 \\
\hline Visuoespacial & $15,1 \pm 1,0$ & $14,3 \pm 1,9$ & $14,5 \pm 1,8$ & 0,271 & 0,656 & 1,000 \\
\hline
\end{tabular}

Análise de variância de uma via, com post hoc Bonferroni. ${ }^{*} p<0,01,{ }^{* *} p<0,001,{ }^{* * *} p<0,0001$. DP=Desvio-padrão.

Em relação à mesma análise, porém aplicada no grupo CN-DP, também não foram identificadas diferenças estatisticamente significantes quanto aos anos de escolaridade. A pontuação média do total da ACE-III $[F(2,21)=0,13$, $p=0,8821]$, atenção $[F(2,21)=0,34, p=0,7175]$, memória $[F(2,21)=0,06, p$ $=0,9428]$, fluência verbal $[F(2,21)=1,79, p=0,1908]$, linguagem $[F(2,21)=$ $0,12, p=0,8842]$ e subescores visuoespaciais $[F(2,21)=0,63, p=0,5406]$ não apresentaram diferenças significantes entre os subgrupos. Cabe referir que o tamanho amostral do grupo >= 70 anos foi apenas de dois pacientes, com resultados do escore total da ACE-III e escolaridade muito semelhantes aos demais grupos (Tabela 13). 
Tabela 13 - Dados descritivos da ACE-III (escore total e domínios) do grupo CN-DP, de acordo com a idade (média \pm DP) e comparação entre os subgrupos

\begin{tabular}{|c|c|c|c|c|c|c|}
\hline \multirow{2}{*}{$\begin{array}{l}\text { CN-DP } \\
(n=24)\end{array}$} & \multicolumn{3}{|c|}{ Subgrupos por idade } & \multicolumn{3}{|c|}{ Valor de $p$} \\
\hline & $\begin{array}{c}40-59(1) \\
(n=13)\end{array}$ & $\begin{array}{c}60-69(2) \\
(n=9)\end{array}$ & $\begin{array}{c}>=70(3) \\
(n=2)\end{array}$ & (1)vs.(2) & (1)vs.(3) & (2)vs.(3) \\
\hline Escolaridade, anos & $12,2 \pm 5,0$ & $12,1 \pm 2,9$ & $12,5 \pm 4,9$ & 1,000 & 1,000 & 1,000 \\
\hline ACE-III (total) & $92,5 \pm 5,7$ & $92,0 \pm 4,4$ & $94,0 \pm 2,8$ & 1,000 & 1,000 & 1,000 \\
\hline Atenção/Orientação & $16,7 \pm 1,8$ & $17,1 \pm 1,4$ & $17,5 \pm 0,7$ & 1,000 & 1,000 & 1,000 \\
\hline Memória & $22,3 \pm 3,8$ & $22,8 \pm 2,2$ & $22,5 \pm 0,7$ & 1,000 & 1,000 & 1,000 \\
\hline Fluência Verbal & $11,8 \pm 1,5$ & $10,7 \pm 25,9$ & $12,5 \pm 0,7$ & 0,371 & 1,000 & 0,462 \\
\hline Linguagem & $25,9 \pm 0,3$ & $25,9 \pm 0,3$ & $26,0 \pm 0,0$ & 1,000 & 1,000 & 1,000 \\
\hline Visuoespacial & $15,8 \pm 0,4$ & $15,6 \pm 0,5$ & $15,5 \pm 0,7$ & 0,976 & 1,000 & 1,000 \\
\hline
\end{tabular}

Análise de variância de uma via, com post hoc Bonferroni.

${ }^{*} p<0,01,{ }^{* *} p<0,001,{ }^{* * *} p<0,0001$. DP=Desvio-padrão.

Em relação ao grupo CCL-DP (Tabela 14), houve diferença entre os subgrupos 1 (40-59 anos de idade) versus 3 ( $>=70$ anos de idade), 2 (60 -69 anos de idade) versus 3 (>= 70 anos de idade), na pontuação média do índice de fluência verbal. No grupo D-DP (Tabela 15) foi observada diferença estatisticamente significante do domínio de habilidades visuoespaciais entre os subgrupos 1 (40 - 59 anos de idade) versus 2 (60 - 69 anos de idade) e uma tendência para o domínio linguagem entre os subgrupos 1 (40 - 59 anos de idade) versus 2 (60 - 69 anos de idade).

Tabela 14 - Dados descritivos da ACE-III (escore total e domínios) do grupo CCL-DP, de acordo com a idade ((média \pm DP) e comparação entre os subgrupos

\begin{tabular}{|c|c|c|c|c|c|c|}
\hline \multirow[b]{2}{*}{ CCL-DP } & \multicolumn{3}{|c|}{ Subgrupos por idade } & \multicolumn{3}{|c|}{ Valor de $p$} \\
\hline & $\begin{array}{c}40-59(1) \\
(n=35)\end{array}$ & $\begin{array}{c}60-69(2) \\
(n=40)\end{array}$ & $\begin{array}{c}>=70(3) \\
(n=29)\end{array}$ & (1)vs.(2) & (1)vs.(3) & (2)vs.(3) \\
\hline Escolaridade, anos & $10,6 \pm 4,0$ & $11,6 \pm 3,3$ & $10,8 \pm 4,2$ & 0,789 & 1,000 & 1,000 \\
\hline ACE-III (total) & $83,4 \pm 9,5$ & $82,4 \pm 8,7$ & $79,9 \pm 11,5$ & 1,000 & 0,454 & 0,862 \\
\hline Atenção/Orientação & $16,3 \pm 1,9$ & $15,8 \pm 1,9$ & $16,4 \pm 1,6$ & 0,751 & 1,000 & 0,506 \\
\hline Memória & $18,3 \pm 3,9$ & $18,1 \pm 4,3$ & $18,2 \pm 4,7$ & 1,000 & 1,000 & 1,000 \\
\hline Fluência Verbal & $10,2 \pm 2,3$ & $9,7 \pm 2,4$ & $7,9 \pm 3,1$ & 1,000 & $0,003^{* *}$ & $0,019^{*}$ \\
\hline Linguagem & $24,7 \pm 1,7$ & $24,9 \pm 1,5$ & $24,2 \pm 3,1$ & 1,000 & 0,852 & 0,525 \\
\hline Visuoespacial & $13,9 \pm 2,5$ & $13,9 \pm 2,3$ & $13,1 \pm 3,3$ & 1,000 & 0,689 & 0,591 \\
\hline
\end{tabular}

Análise de variância de uma via, com post hoc Bonferroni.

${ }^{*} p<0,01,{ }^{* *} p<0,001,{ }^{* * *} p<0,0001$. DP=Desvio-padrão. 
Tabela 15 - Dados descritivos da ACE-III (escore total e domínios) do grupo D-DP, de acordo com a idade (média \pm DP) e comparação entre os subgrupos

\begin{tabular}{|c|c|c|c|c|c|c|}
\hline \multirow[b]{2}{*}{ D-DP } & \multicolumn{3}{|c|}{ Subgrupos por idade } & \multicolumn{3}{|c|}{ Valor de $p$} \\
\hline & $\begin{array}{c}40-59(1) \\
(n=5)\end{array}$ & $\begin{array}{c}60-69(2) \\
(n=9)\end{array}$ & $\begin{array}{c}>=70(3) \\
(n=8)\end{array}$ & (1)vs.(2) & (1)vs.(3) & (2)vs.(3) \\
\hline Escolaridade, anos & $8,4 \pm 4,9$ & $9,1 \pm 4,3$ & $11,1 \pm 4,5$ & 1,000 & 0,908 & 1,000 \\
\hline ACE-III (total) & $76,6 \pm 10,2$ & $62,0 \pm 12,2$ & $72,9 \pm 11,8$ & 0,109 & 1,000 & 0,207 \\
\hline Atenção/Orientação & $13,6 \pm 1,1$ & $14,0 \pm 2,4$ & $14,8 \pm 2,5$ & 1,000 & 1,000 & 1,000 \\
\hline Memória & $16,4 \pm 6,4$ & $11,3 \pm 4,7$ & $15,5 \pm 3,2$ & 0,203 & 1,000 & 0,249 \\
\hline Fluência Verbal & $7,0 \pm 2,7$ & $5,9 \pm 2,5$ & $7,3 \pm 3,5$ & 1,000 & 1,000 & 1,000 \\
\hline Linguagem & $25,2 \pm 0,8$ & $20,9 \pm 3,7$ & $22,9 \pm 2,9$ & 0,055 & 0,568 & 0,565 \\
\hline Visuoespacial & $14,4 \pm 3,0$ & $9,9 \pm 2,5$ & $12,5 \pm 3,1$ & $0,031^{*}$ & 0,769 & 0,224 \\
\hline
\end{tabular}

Análise de variância de uma via, com post hoc Bonferroni. ${ }^{*} p<0,01,{ }^{* *} p<0,001,{ }^{* * *} p<0,0001$. DP=Desvio-padrão.

Os escores totais da ACE-III, portanto, não sofreram influência da idade nos grupos controle e de DPI. Os escores totais foram influenciados pela escolaridade dentro de cada grupo. Foram realizadas comparações, usando ANOVA, e deu diferença pela escolaridade no grupo controle em todos os domínios (ACE-III total, $p<0,00$; atenção/orientação, $p=0,0005$; memória, $p=002$; fluência verbal, $p=0,0037$; linguagem, $p=0,010$; visuoespacial, $p=0,0086)$. No grupo CN-DP deu diferença no escore total $(p=0,011)$ e memória da ACE-III $(p=0,031)$. No grupo CCL-DP deu diferença no escore total $(p=0,002)$ e memória $(p=0,0006)$. No grupo D-DP houve diferença no escore total $(p=0,017)$, fluência verbal $(p=0,017)$ e visuoespacial $(p=0,033)$.

\subsection{Bateria neuropsicológica}

Quanto aos testes cognitivos da bateria neuropsicológica (avaliação nível II da MDS), como pode ser observada na Tabela 16, ocorreu diferença estatisticamente significante entre os grupos clínico e controle quanto às medidas controle mental, FCR (cópia, evocação imediata, evocação tardia), 
RAVLT (aprendizagem, lista A; lista B; A após interferência, tardia e reconhecimento), fluência verbal fonêmica (FAS), amplitude de dígitos (ordem inversa), blocos de Corsi (ordem direta e inversa), teste de trilhas (tempo de execução, partes A e B).

Tabela 16 - Escores nos testes neuropsicológicos e comparação entre os dois grupos

\begin{tabular}{lrrc}
\hline \multicolumn{1}{c}{$\mathbf{N = 2 1 0}$} & $\begin{array}{c}\text { Grupo Controle } \\
\text { (n=60) }\end{array}$ & $\begin{array}{c}\text { Grupo Clínico } \\
(\mathbf{n = 1 5 0 )}\end{array}$ & Valor de $\mathbf{p}$ \\
\hline Controle Mental & $5,67 \pm 0,57$ & $5,13 \pm 1,14$ & \multicolumn{1}{c}{$0,0007^{\star * *}$} \\
Figura Complexa de Rey (cópia) & $30,58 \pm 6,49$ & $27,01 \pm 9,22$ & $0,0066^{* *}$ \\
Figura Complexa de Rey (tempo) & $307,13 \pm 144,44$ & $365,99 \pm 239,07$ & 0,0766 \\
Figura Complexa de Rey (evocação & $16,54 \pm 8,40$ & $13,72 \pm 7,59$ & $0,0193^{*}$ \\
imediata) & & & \\
Figura Complexa de Rey (evocação & $16,22 \pm 7,75$ & $13,21 \pm 7,75$ & $0,0095^{\star *}$ \\
tardia) & & & \\
RAVLT - Total A & $42,28 \pm 8,21$ & $35,68 \pm 10,00$ & $<0,0001^{* * *}$ \\
RAVLT - B & $5,35 \pm 2,23$ & $4,29 \pm 1,68$ & $0,0002^{\star * *}$ \\
RAVLT - A após interferência & $8,13 \pm 2,76$ & $6,91 \pm 2,88$ & $0,0055^{\star *}$ \\
RAVLT - tardia & $7,90 \pm 2,73$ & $6,91 \pm 2,98$ & $0,0275^{*}$ \\
RAVLT - reconhecimento & $13,82 \pm 1,33$ & $12,17 \pm 2,55$ & $<0,0001^{* * *}$ \\
Fluência Verbal (FAS) & $33,60 \pm 11,64$ & $27,41 \pm 11,08$ & $0,0004^{* * *}$ \\
Fluência Verbal (animais) & $15,48 \pm 4,27$ & $14,74 \pm 5,24$ & 0,3299 \\
Dígitos Spam (ordem direta) & $5,32 \pm 0,98$ & $5,03 \pm 0,96$ & 0,0500 \\
Dígitos Spam (ordem inversa) & $3,93 \pm 1,01$ & $3,62 \pm 0,88$ & $0,0264^{*}$ \\
Blocos de Corsi (ordem direta) & $5,08 \pm 0,93$ & $4,69 \pm 1,02$ & $0,0095^{\star *}$ \\
Blocos de Corsi (ordem inversa) & $4,28 \pm 0,78$ & $3,99 \pm 1,01$ & $0,0431^{*}$ \\
Trail Making Test - Forma A (tempo) & $67,42 \pm 31,18$ & $86,59 \pm 59,74$ & $0,0192^{*}$ \\
Trail Making Test - Forma B (tempo) & $197,87 \pm 111,76$ & $319,70 \pm 121,37$ & $0,0012^{\star *}$ \\
Trail Making Test (B - A) & $132,35 \pm 98,80$ & $132,12 \pm 92,13$ & 0,9872 \\
\hline
\end{tabular}

Teste $t$ para amostras independentes. ${ }^{*} p<0,01,{ }^{* *} p<0,001,{ }^{* * *} p<0,0001$.

Quando estratificado o grupo clínico por subgrupos em função do comprometimento cognitivo, ocorreu diferença estatisticamente significante em testes cognitivos, tais como controle mental, figura complexa de Rey (cópia e tempo de execução), RAVLT (evocação lista B e reconhecimento), teste de trilhas (tempo de execução das partes A e B e B-A). O subgrupo D-DP apresentou desempenho inferior em todas estas variáveis (Tabela 17). 
Tabela 17 - Escores nos testes neuropsicológicos e comparação entre os subgrupos

\begin{tabular}{|c|c|c|c|c|c|}
\hline $\mathrm{N}=\mathbf{2 1 0}$ & $\begin{array}{l}\text { Controles } \\
(n=60)\end{array}$ & $\begin{array}{l}\text { CN-DP } \\
(n=24)\end{array}$ & $\begin{array}{l}\text { CCL-DP } \\
(n=104)\end{array}$ & $\begin{array}{l}\text { D-DP } \\
(n=22)\end{array}$ & $\begin{array}{c}\text { Valor de } \\
\text { p }\end{array}$ \\
\hline Controle Mental & $5,7 \pm 0,6$ & $5,6 \pm 0,6$ & $5,2 \pm 1,0$ & $4,2 \pm 1,6$ & $<0,0001^{* * *}$ \\
\hline FCR (cópia) & $30,6 \pm 6,5$ & $34,7 \pm 2,0$ & $26,6 \pm 8,7$ & $20,6 \pm 10,8$ & $<0,0001^{* * *}$ \\
\hline FCR (tempo) & $307,1 \pm 144,4$ & $286,0 \pm 157,8$ & $377,0 \pm 251,3$ & $401,2 \pm 243,3$ & $<0,0001^{* * *}$ \\
\hline $\begin{array}{l}\text { FCR (evocação } \\
\text { imediata) }\end{array}$ & $16,5 \pm 8,4$ & $22,4 \pm 6,9$ & $12,8 \pm 6,6$ & $8,9 \pm 5,3$ & 0,051 \\
\hline $\begin{array}{l}\text { FCR (evocação } \\
\text { tardia) }\end{array}$ & $16,2 \pm 7,8$ & $22,9 \pm 5,4$ & $12,0 \pm 6,3$ & $8,4 \pm 5,2$ & 0,058 \\
\hline RAVLT - Total A & $42,3 \pm 8,2$ & $46,5 \pm 6,5$ & $34,7 \pm 8,5$ & $28,6 \pm 10,9$ & 0,107 \\
\hline RAVLT - B & $5,3 \pm 2,2$ & $5,4 \pm 1,7$ & $4,3 \pm 1,6$ & $3,1 \pm 1,3$ & $0,004^{* *}$ \\
\hline $\begin{array}{l}\text { RAVLT - A após } \\
\text { interferência }\end{array}$ & $8,1 \pm 2,8$ & $10,2 \pm 1,9$ & $6,4 \pm 2,6$ & $5,7 \pm 2,5$ & 0,225 \\
\hline RAVLT - tardia & $7,9 \pm 2,7$ & $9,8 \pm 2,2$ & $6,6 \pm 2,8$ & $5,4 \pm 2,7$ & 0,575 \\
\hline $\begin{array}{l}\text { RAVLT - } \\
\text { reconhecimento }\end{array}$ & $13,8 \pm 1,3$ & $14,2 \pm 1,3$ & $11,9 \pm 2,6$ & $11,4 \pm 2,3$ & $<0,0001^{* * *}$ \\
\hline FV (FAS) & $33,6 \pm 11,6$ & $37,0 \pm 11,3$ & $26,09 \pm 9,9$ & $19,2 \pm 8,6$ & 0,288 \\
\hline FV (animais) & $15,5 \pm 4,3$ & $18,4 \pm 4,9$ & $14,8 \pm 4,9$ & $10,7 \pm 4,3$ & 0,636 \\
\hline $\begin{array}{l}\text { Span Dígitos (ordem } \\
\text { direta) }\end{array}$ & $5,3 \pm 1,0$ & $5,5 \pm 0,6$ & $5,0 \pm 0,9$ & $4,4 \pm 0,8$ & 0,844 \\
\hline $\begin{array}{l}\text { Span Dígitos (ordem } \\
\text { inversa) }\end{array}$ & $3,9 \pm 1,0$ & $4,4 \pm 1,0$ & $3,5 \pm 0,7$ & $3,1 \pm 0,8$ & 0,057 \\
\hline $\begin{array}{l}\text { Blocos de Corsi } \\
\text { (ordem direta) }\end{array}$ & $5,1 \pm 0,9$ & $5,5 \pm 0,9$ & $4,7 \pm 0,9$ & $3,9 \pm 1,1$ & 0,581 \\
\hline $\begin{array}{l}\text { Blocos de Corsi } \\
\text { (ordem inversa) }\end{array}$ & $4,3 \pm 0,8$ & $5,1 \pm 0,9$ & $3,9 \pm 0,9$ & $3,2 \pm 0,7$ & 0,576 \\
\hline TMT- A (tempo) & $67,4 \pm 31,1$ & $56,3 \pm 26,3$ & $88,3 \pm 61,7$ & $111,4 \pm 64,4$ & $<0,0001^{* * *}$ \\
\hline TMT -B (tempo) & $197,9 \pm 111,8$ & $131,5 \pm 65,3$ & $233,5 \pm 115,5$ & $250,9 \pm 84,0$ & $<0,0001^{* * *}$ \\
\hline TMT $(B-A)$ & $132,3 \pm 98,8$ & $75,2 \pm 50,5$ & $145,8 \pm 96,5$ & $129,7 \pm 84,6$ & $0,005^{* *}$ \\
\hline
\end{tabular}

RAVLT = Teste de Aprendizado Auditivo Verbal de Rey, FCR=Figura Complexa de Rey, FV= fluência verbal, TMT=

Trail Making Test. Análise de variância de uma via, com post hoc Bonferroni.

${ }^{*} p<0,01,{ }^{* *} p<0,001,{ }^{* * *} p<0,0001$.

\subsection{Notas de corte, sensibilidade e especificidade, da ACE-III, por meio de análises da curva ROC}

A Tabela 18 mostra que o sexo e os anos de escolaridade exerceram associação significante com os escores da ACE-III. A idade foi inversamente associada aos escores total da ACE-III e a todos os seus domínios cognitivos, ou seja, o desempenho diminuiu com o aumento da idade. Por outro lado, o desempenho no escore total da ACE-III foi associado positivamente aos anos de escolaridade. Quanto maior o nível de escolaridade, melhor foi o seu 
desempenho na pontuação cognitiva. Não houve associação significante entre a idade e o escore total da ACE-III e domínios de atenção/orientação e memória.

Tabela 18 - Coeficientes de correlação e de determinação de escores por idade e escolaridade (ACE-III total e seus domínios)

\begin{tabular}{lcccc} 
& \multicolumn{2}{c}{ Idade (anos) } & \multicolumn{2}{c}{ Escolaridade (anos) } \\
\cline { 2 - 5 } & $\mathbf{r}$ & $\mathbf{r}^{\mathbf{2}}$ & $\mathbf{r}$ & $\mathbf{r}^{\mathbf{2}}$ \\
ACE-III (total) & $-0,1296$ & 0,0167 & $0,4373^{\star * *}$ & 0,0191 \\
Atenção/Orientação & $-0,0336$ & 0,0011 & $0,2685^{\star * *}$ & 0,0720 \\
Memória & $-0,0339$ & 0,0011 & $0.4257^{* * *}$ & 0,1812 \\
Fluência Verbal & $-0,1373^{*}$ & 0,0188 & $0,3368^{* * *}$ & 0,1134 \\
Linguagem & $-0,1428^{*}$ & 0,0203 & $0,2693^{\star * *}$ & 0,0725 \\
Visuoespacial & $-0,1970^{* *}$ & 0,0388 & $0,2925^{\star * *}$ & 0,0855 \\
\hline
\end{tabular}

Correlação de Pearson (r). Coeficiente de determinação $\left(r^{2}\right)$. ${ }^{*} p<0,05,{ }^{* *} p<0,01, p<0,001$. Coeficiente de correlação: $(=1)$ perfeita, $(>0,75)$ forte, $(>0,5)$ média, $(<0,5)$ fraca, $(=0)$ inexistente.

Através da correlação de Pearson, após verificar distribuição normal/simétrica dos dados, foi observado que o grupo clínico apresentou correlação significante e de magnitude média entre a variável ACE-III (pontuação total) e a funcionalidade (medida pelo questionário QAF). Nas medidas de gravidade da doença (medida pela escala H\&Y), escolaridade, idade, humor, ansiedade e questionário do informante de queixas cognitivas; houve correlação significante; principalmente com a escala H\&Y, escolaridade, QAF e IQCODE $(p<0,001)$; porém com magnitude fraca do coeficiente, ou seja, menor que 0,5, exceto entre a ACE-III e QAF (Tabela 19). 
Tabela 19 - Correlação de Pearson entre variável cognitiva (ACE-III total) e dados clínicos. Grupo clínico

\begin{tabular}{lcc}
\hline \multicolumn{1}{c}{ Variáveis } & $\mathbf{r}$ & Valor de $\mathbf{p}$ \\
\hline ACE-III (total) e H\&Y & $-0,3878\left(\mathrm{r}_{\mathrm{s}}\right)$ & $<0,0001^{* * *}$ \\
ACE-III e escolaridade (anos) & 0,4297 & $<0,0001^{* * *}$ \\
ACE-III e idade (anos) & $-0,2419$ & $0,0029^{* *}$ \\
ACE-III e tempo de doença (anos) & 0,0107 & 0,8961 \\
ACE-III e BDI & $-0,2429$ & $0,0027^{* *}$ \\
ACE-III e BAI & $-0,0651$ & 0,4287 \\
ACE-III e QAF & $-0,5621$ & $<0,0001^{* * *}$ \\
ACE-III e IQCODE & $-0,4604$ & $<0,0001^{\text {***}}$ \\
\hline
\end{tabular}

ACE-III (Escore total) = Addenbrooke's Cognitive Examination; H\&Y=Escala Hoehn \& Yahr; $\mathrm{BDI}=$ Inventário Beck de Depressão; $\mathrm{BAI}=$ Inventário Beck de Ansiedade; $\mathrm{QAF}=$ Questionário de Atividades Funcionais; IQCODE=Questionário do Informante sobre o Declínio Cognitivo do Idoso.

Correlação de Pearson (r). Correlação de postos de Spearman $\left(r_{s}\right)$.

Coeficiente de correlação: $(=1)$ perfeita, $(>0,75)$ forte, $(>0,5)$ média, $(<0,5)$ fraca, $(=0)$ inexistente.

* Nível de significância $<0,05$.

** Nível de significância $<0,01$.

*** Nível de significância $<0,001$.

Ao estratificar o grupo clínico, pôde-se observar que no subgrupo CN-DP houve correlação média e significante entre ACE-III total e anos de escolaridade (Tabela 20). No subgrupo CCL-DP apresentou uma quantidade maior de correlação entre as variáveis, destacando a gravidade da doença, escolaridade, medidas funcionais e questionário do informante de queixas cognitivas (IQCODE); porém os coeficientes de correlação mostraram magnitudes fracas (Tabela 21). No subgrupo D-DP, houve correlação média e significante entre pontuação total da ACE-III e escolaridade (Tabela 22). 
Tabela 20 - Correlação de Pearson entre variável cognitiva (ACE-III total) e clínicas. Subgrupo CN-DP

\begin{tabular}{lcc}
\hline \multicolumn{1}{c}{ Variáveis } & $\mathbf{r}$ & Valor de $\mathbf{p}$ \\
\hline ACE-III e H\&Y & $-0,0366$ & 0,8651 \\
ACE-III e escolaridade (anos) & 0,6480 & $0,0006^{* * *}$ \\
ACE-III e idade (anos) & $-0,0346$ & 0,8724 \\
ACE-III e tempo de doença (anos) & $-0,1102$ & 0,6082 \\
ACE-III e BDI & 0,1226 & 0,5681 \\
ACE-III e BAI & $-0,3101$ & 0,1403 \\
ACE-III e QAF & $-0,2525$ & 0,2339 \\
ACE-III e IQCODE & $-0,1479$ & 0,4905 \\
\hline
\end{tabular}

ACE-III (Escore total) = Addenbrooke's Cognitive Examination; H\&Y=Escala Hoehn \& Yahr; $\mathrm{BDI}=$ Inventário Beck de Depressão; $\mathrm{BAI}=$ Inventário Beck de Ansiedade; QAF=Questionário de Atividades Funcionais; IQCODE=Questionário do Informante sobre o Declínio Cognitivo do Idoso.

Correlação de Pearson ( $r)$. Correlação de postos de Spearman $\left(r_{s}\right)$.

Coeficiente de correlação: $(=1)$ perfeita, $(>0,75)$ forte, $(>0,5)$ média, $(<0,5)$ fraca, $(=0)$ inexistente.

* Nível de significância $<0,05$.

** Nível de significância $<0,01$.

*** Nível de significância $<0,001$.

Tabela 21- Correlação de Pearson entre variável cognitiva (ACE-III total) e clínicas. Subgrupo CCL-DP

\begin{tabular}{lcc}
\hline \multicolumn{1}{c}{ Variáveis } & $\mathbf{r}$ & Valor de $\mathbf{p}$ \\
\hline ACE-III e H\&Y & $-0,2463$ & $0,0117^{*}$ \\
ACE-III e escolaridade (anos) & 0,3512 & $0,0003^{* * *}$ \\
ACE-III e idade (anos) & $-0,1626$ & 0,0992 \\
ACE-III e tempo de doença (anos) & 0,0335 & 0,7355 \\
ACE-III e BDI & $-0,1495$ & 0,1299 \\
ACE-III e BAI & 0,0612 & 0,5370 \\
ACE-III e QAF & $-0,3928$ & $<0,0001^{* * *}$ \\
ACE-III e IQCODE & $-0,3752$ & $0,0001^{* * *}$ \\
\hline
\end{tabular}

ACE-III $($ Escore total $)=$ Addenbrooke's Cognitive Examination; H\&Y=Escala Hoehn \& Yahr; $\mathrm{BDI}=$ Inventário Beck de Depressão; BAI=Inventário Beck de Ansiedade; QAF=Questionário de Atividades Funcionais; IQCODE=Questionário do Informante sobre o Declínio Cognitivo do Idoso.

Correlação de Pearson (r). Correlação de postos de Spearman $\left(r_{s}\right)$.

Coeficiente de correlação: $(=1)$ perfeita, $(>0,75)$ forte, $(>0,5)$ média, $(<0,5)$ fraca, $(=0)$ inexistente.

* Nível de significância $<0,05$.

** Nível de significância < 0,01.

*** Nível de significância $<0,001$. 
Tabela 22 - Correlação de Pearson entre variável cognitiva (ACE-III total) e clínicas. Subgrupo D-DP

\begin{tabular}{lcc}
\hline \multicolumn{1}{c}{ Variáveis } & $\mathbf{r}$ & Valor de $\mathbf{p}$ \\
\hline ACE-III e H\&Y & $-0,3310$ & 0,1324 \\
\hline ACE-III e escolaridade (anos) & 0,5380 & $0,0098^{\text {** }}$ \\
ACE-III e idade (anos) & $-0,1731$ & 0,4412 \\
ACE-III e tempo de doença (anos) & 0,3258 & 0,1390 \\
ACE-III e BDI & $-0,2487$ & 0,2644 \\
ACE-III e BAI & 0,1480 & 0,5111 \\
ACE-III e QAF & $-0,4011$ & 0,0643 \\
ACE-III e IQCODE & 0,0606 & 0,7887 \\
\hline
\end{tabular}

ACE-III (Escore total) $=$ Addenbrooke's Cognitive Examination; H\&Y=Escala Hoehn \& Yahr; $\mathrm{BDI}=$ Inventário Beck de Depressão; $\mathrm{BAI}=$ Inventário Beck de Ansiedade; QAF=Questionário de Atividades Funcionais; IQCODE=Questionário do Informante sobre o Declínio Cognitivo do Idoso.

Correlação de Pearson (r). Correlação de postos de Spearman $\left(r_{s}\right)$.

Coeficiente de correlação: $(=1)$ perfeita, $(>0,75)$ forte, $(>0,5)$ média, $(<0,5)$ fraca, $(=0)$ inexistente.

* Nível de significância $<0,05$.

** Nível de significância $<0,01$.

*** Nível de significância <0,001.

Em resumo, levando-se em consideração as correlações entre a ACE-III e as variáveis clínicas, podemos observar que a escolaridade se apresentou associada aos escores totais em todos os grupos. Enquanto, no grupo CCL também o declínio cognitivo (visto pelo IQCODE) e a funcionalidade se associaram aos escores da ACE-III.

Quando realizada a correlação entre os escores da ACE-III (total e seus domínios) e testes da bateria neuropsicológica, pôde-se observar que houve associação significante e de intensidade média entre as análises, exceto entre o tempo de cópia da figura complexa de Rey e escore total da ACE-III, além dos domínios linguagem e visuoespacial. A diferença (delta) no teste de trilhas (B-A) também não se correlacionou ao domínio linguagem.

Desta forma, praticamente todos os domínios se correlacionaram de forma significante com os testes da avaliação neuropsicológica, como pode ser visualizado nas Tabelas 23-28. 
Tabela 23 - Correlação entre a ACE-III (escore total) e testes da bateria neuropsicológica (grupo clínico e controles saudáveis)

\begin{tabular}{|c|c|c|}
\hline Variáveis & $\mathbf{r}$ & Valor de p \\
\hline ACE-III e Controle Mental & 0,5238 & $<0,0001^{* * *}$ \\
\hline ACE-III e Figura Complexa de Rey (cópia) & 0,6953 & $<0,0001^{* * *}$ \\
\hline ACE-III e Figura Complexa de Rey (tempo) & $-0,2115$ & $0,0021^{* *}$ \\
\hline ACE-III e Figura Complexa de Rey (imediata) & 0,6165 & $<0,0001^{* * *}$ \\
\hline ACE-III e Figura Complexa de Rey (tardia) & 0,5912 & $<0,0001^{* * *}$ \\
\hline ACE-III e RAVLT (Total A) & 0,6214 & $<0,0001^{* * *}$ \\
\hline ACE-III e RAVLT (B) & 0,4999 & $<0,0001^{* * *}$ \\
\hline ACE-III e RAVLT (A após interferência) & $-0,5015$ & $<0,0001^{* * *}$ \\
\hline ACE-III e RAVLT (tardia) & 0,4758 & $<0,0001^{* * *}$ \\
\hline ACE-III e RAVLT (reconhecimento) & 0,4702 & $<0,0001^{* * *}$ \\
\hline ACE-III e Fluência Verbal (FAS) & 0,6447 & $<0,0001^{* * *}$ \\
\hline ACE-III e Fluência Verbal (animais) & 0,6607 & $<0,0001^{* * *}$ \\
\hline ACE-III e Dígitos Spam (ordem direta) & 0,4552 & $<0,0001^{* * *}$ \\
\hline ACE-III e Dígitos Spam (ordem inversa) & 0,5209 & $<0,0001^{* * *}$ \\
\hline ACE-III e Blocos de Corsi (ordem direta) & 0,4882 & $<0,0001^{* * *}$ \\
\hline ACE-III e Blocos de Corsi (ordem inversa) & 0,4844 & $<0,0001^{* * *}$ \\
\hline ACE-III e Trail Making Test (A tempo) & $-0,4891$ & $<0,0001^{* * *}$ \\
\hline ACE-III e Trail Making Test (B tempo) & $-0,5352$ & $<0,0001^{* * *}$ \\
\hline ACE-III e Trail Making Test (B-A) & $-0,3354$ & $<0,0001^{* * *}$ \\
\hline
\end{tabular}

ACE-III $($ Escore total $)=$ Addenbrooke's Cognitive Examination; RAVLT = Teste de Aprendizado Auditivo Verbal de Rey Coeficiente de correlação: $(=1)$ perfeita, $(>0,75)$ forte, $(>0,5)$ média, $(<0,5)$ fraca, $(=0)$ inexistente.

* Nível de significância $<0,05$.

** Nível de significância $<0,01$.

*** Nível de significância $<0,001$. 
Tabela 24 - Correlação entre a ACE-III (domínio atenção/orientação) e testes da bateria neuropsicológica (grupo clínico e controles saudáveis)

\begin{tabular}{lrc}
\hline \multicolumn{1}{c}{ Variáveis } & $\mathbf{r}$ & Valor de p \\
\hline Atenção/Orientação e Controle Mental & 0,5702 & $<0,0001^{* * *}$ \\
Atenção/Orientação e Figura Complexa de Rey (cópia) & 0,4454 & $<0,0001^{* * *}$ \\
Atenção/Orientção e Figura Complexa de Rey (tempo) & $-0,1856$ & $<0,0001^{* * *}$ \\
Atenção/Orientação e Figura Complexa de Rey (imediata) & 0,4142 & $<0,0001^{* * *}$ \\
Atenção/Orientação e Figura Complexa de Rey (tardia) & 0,4068 & $<0,0001^{* * *}$ \\
Atenção/Orientação e RAVLT (Total A) & 0,4294 & $<0,0001^{* * *}$ \\
Atenção/Orientação e RAVLT (B) & 0,3819 & $<0,0001^{* * *}$ \\
Atenção/Orientção e RAVLT (A após interferência) & 0,2643 & $<0,0001^{* * *}$ \\
Atenção/Orientação e RAVLT (tardia) & 0,2820 & $<0,0001^{* * *}$ \\
Atenção/Orientação e RAVLT (reconhecimento) & 0,2635 & $<0,0001^{* * *}$ \\
Atenção/Orientação e Fluência Verbal (FAS) & 0,4739 & $<0,0001^{* * *}$ \\
Atenção/Orientçãa e Fluência Verbal (animais) & 0,3569 & $<0,0001^{* * *}$ \\
Atenção/Orientçãão e Dígitos Spam (ordem direta) & 0,3661 & $<0,0001^{* * *}$ \\
Atenção/Orientação e Dígitos Spam (ordem inversa) & 0,4093 & $<0,0001^{* * *}$ \\
Atenção/Orientação e Blocos de Corsi (ordem direta) & 0,3507 & $<0,0001^{* * *}$ \\
Atenção/Orientação e Blocos de Corsi (ordem inversa) & 0,4067 & $<0,0001^{* * *}$ \\
Atenção/Orientçãa e Trail Making Test (A tempo) & $-0,3019$ & $<0,0001^{* * *}$ \\
Atenção/Orientação e Trail Making Test (B tempo) & $-0,4056$ & $<0,0001^{* * *}$ \\
Atenção/Orientação e Trail Making Test (B-A) & $-0,2998$ & $<0,0001^{* * *}$ \\
\end{tabular}

Coeficiente de correlação: $(=1)$ perfeita, $(>0,75)$ forte, $(>0,5)$ média, $(<0,5)$ fraca, $(=0)$ inexistente.

* Nível de significância $<0,05$.

** Nível de significância $<0,01$.

*** Nível de significância < 0,001. 
Tabela 25 - Correlação entre a ACE-III (domínio memória) e testes da bateria neuropsicológica (grupo clínico e controles saudáveis)

\begin{tabular}{|c|c|c|}
\hline Variáveis & $\mathbf{r}$ & Valor de $p$ \\
\hline Memória e Controle Mental & 0,3806 & $<0,0001^{* * *}$ \\
\hline Memória e Figura Complexa de Rey (cópia) & 0,5322 & $<0,0001^{* * *}$ \\
\hline Memória e Figura Complexa de Rey (tempo) & $-0,2369$ & $0,0005^{\star * *}$ \\
\hline Memória e Figura Complexa de Rey (imediata) & 0,5318 & $<0,0001^{* * *}$ \\
\hline Memória e Figura Complexa de Rey (tardia) & 0,4841 & $<0,0001^{* * *}$ \\
\hline Memória e RAVLT (Total A) & 0,5502 & $<0,0001^{* * *}$ \\
\hline Memória e RAVLT (B) & 0,4628 & $<0,0001^{* * *}$ \\
\hline Memória e RAVLT (A após interferência) & 0,4880 & $<0,0001^{* \star *}$ \\
\hline Memória e RAVLT (tardia) & 0,4522 & $<0,0001^{* * *}$ \\
\hline Memória e RAVLT (reconhecimento) & 0,4308 & $<0,0001^{* * *}$ \\
\hline Memória e Fluência Verbal (FAS) & 0,5222 & $<0,0001^{* * *}$ \\
\hline Memória e Fluência Verbal (animais) & 0,4865 & $<0,0001^{* * *}$ \\
\hline Memória e Dígitos Spam (ordem direta) & 0,3935 & $<0,0001^{* * *}$ \\
\hline Memória e Dígitos Spam (ordem inversa) & 0,4748 & $<0,0001^{* * *}$ \\
\hline Memória e Blocos de Corsi (ordem direta) & 0,4098 & $<0,0001^{* * *}$ \\
\hline Memória e Blocos de Corsi (ordem inversa) & 0,4468 & $<0,0001^{* * *}$ \\
\hline Memória e Trail Making Test (A tempo) & $-0,3377$ & $<0,0001^{* * *}$ \\
\hline Memória e Trail Making Test (B tempo) & $-0,4585$ & $<0,0001^{* * *}$ \\
\hline Memória e Trail Making Test (B-A) & $-0,3313$ & $<0,0001^{* * *}$ \\
\hline
\end{tabular}

Coeficiente de correlação: $(=1)$ perfeita, $(>0,75)$ forte, $(>0,5)$ média, $(<0,5)$ fraca, $(=0)$ inexistente.

* Nível de significância $<0,05$.

** Nível de significância $<0,01$.

*** Nível de significância $<0,001$. 
Tabela 26 - Correlação entre a ACE-III (domínio fluência verbal) e testes da bateria neuropsicológica (grupo clínico e controles saudáveis)

\begin{tabular}{|c|c|c|}
\hline Variáveis & $\mathbf{r}$ & Valor de $p$ \\
\hline Fluência Verbal e Controle Mental & 0,3511 & $<0,0001^{* \star *}$ \\
\hline Fluência Verbal e Figura Complexa de Rey (cópia) & 0,5383 & $<0,0001^{* * *}$ \\
\hline Fluência Verbal e Figura Complexa de Rey (tempo) & $-0,1535$ & $0,0261^{*}$ \\
\hline Fluência Verbal e Figura Complexa de Rey (imediata) & 0,4989 & $<0,0001^{* * *}$ \\
\hline Fluência Verbal e Figura Complexa de Rey (tardia) & 0,4876 & $<0,0001^{* * *}$ \\
\hline Fluência Verbal e RAVLT (Total A) & 0,4594 & $<0,0001^{* * *}$ \\
\hline Fluência Verbal e RAVLT (B) & 0,3541 & $<0,0001^{* * *}$ \\
\hline Fluência Verbal e RAVLT (A após interferência) & 0,3748 & $<0,0001^{* * *}$ \\
\hline Fluência Verbal e RAVLT (tardia) & 0,3423 & $<0,0001^{* * *}$ \\
\hline Fluência Verbal e RAVLT (reconhecimento) & 0,3014 & $<0,0001^{* * *}$ \\
\hline Fluência Verbal e Fluência Verbal (FAS) & 0,6686 & $<0,0001^{* * *}$ \\
\hline Fluência Verbal e Fluência Verbal (animais) & 0,8348 & $<0,0001^{* * *}$ \\
\hline Fluência Verbal e Dígitos Spam (ordem direta) & 0,3386 & $<0,0001^{* * *}$ \\
\hline Fluência Verbal e Dígitos Spam (ordem inversa) & 0,3997 & $<0,0001^{* * *}$ \\
\hline Fluência Verbal e Blocos de Corsi (ordem direta) & 0,3045 & $<0,0001^{* * *}$ \\
\hline Fluência Verbal e Blocos de Corsi (ordem inversa) & 0,2837 & $<0,0001^{* * *}$ \\
\hline Fluência Verbal e Trail Making Test (A tempo) & $-0,4524$ & $<0,0001^{* * *}$ \\
\hline Fluência Verbal e Trail Making Test (B tempo) & $-0,4412$ & $<0,0001^{* * *}$ \\
\hline Fluência Verbal e Trail Making Test (B-A) & $-0,2579$ & $0,0002^{* * *}$ \\
\hline
\end{tabular}

Coeficiente de correlação: $(=1)$ perfeita, $(>0,75)$ forte, $(>0,5)$ média, $(<0,5)$ fraca, $(=0)$ inexistente.

* Nível de significância < 0,05.

** Nível de significância $<0,01$.

*** Nível de significância $<0,001$. 
Tabela 27- Correlação entre a ACE-III (domínio linguagem) e testes da bateria neuropsicológica (grupo clínico e controles saudáveis)

\begin{tabular}{lcc}
\hline \multicolumn{1}{c}{ Variáveis } & $\mathbf{r}$ & Valor de $\mathbf{p}$ \\
\hline Linguagem e Controle Mental & 0,3505 & $<0,0001^{* * *}$ \\
Linguagem e Figura Complexa de Rey (cópia) & 0,5012 & $<0,0001^{* * *}$ \\
Linguagem e Figura Complexa de Rey (tempo) & $-0,0417$ & 0,5476 \\
Linguagem e Figura Complexa de Rey (imediata) & 0,4042 & $<0,0001^{* * *}$ \\
Linguagem e Figura Complexa de Rey (tardia) & 0,3818 & $<0,0001^{* * *}$ \\
Linguagem e RAVLT (Total A) & 0,3939 & $<0,0001^{* * *}$ \\
Linguagem e RAVLT (B) & 0,3232 & $<0,0001^{* * *}$ \\
Linguagem e RAVLT (A após interferência) & 0,3071 & $<0,0001^{* * *}$ \\
Linguagem e RAVLT (tardia) & 0,3049 & $<0,0001^{* * *}$ \\
Linguagem e RAVLT (reconhecimento) & 0,3053 & $<0,0001^{* * *}$ \\
Linguagem e Fluência Verbal (FAS) & 0,3845 & $<0,0001^{* * *}$ \\
Linguagem e Fluência Verbal (animais) & 0,4109 & $<0,0001^{* * *}$ \\
Linguagem e Dígitos Spam (ordem direta) & 0,2908 & $<0,0001^{* * *}$ \\
Linguagem e Dígitos Spam (ordem inversa) & 0,2620 & $0,0001^{* * *}$ \\
Linguagem e Blocos de Corsi (ordem direta) & 0,3525 & $<0,0001^{* * *}$ \\
Linguagem e Blocos de Corsi (ordem inversa) & 0,2751 & $0,0001^{* * *}$ \\
Linguagem e Trail Making Test (A tempo) & $-0,3729$ & $<0,0001^{* * *}$ \\
Linguagem e Trail Making Test (B tempo) & $-0,2537$ & $0,0002^{* * *}$ \\
Linguagem e Trail Making Test (B-A) & $-0,0756$ & 0,2756 \\
\end{tabular}

Coeficiente de correlação: $(=1)$ perfeita, $(>0,75)$ forte, $(>0,5)$ média, $(<0,5)$ fraca, $(=0)$ inexistente.

* Nível de significância $<0,05$.

** Nível de significância $<0,01$.

*** Nível de significância $<0,001$. 
Tabela 28 - Correlação entre a ACE-III (domínio visuoespacial) e testes da bateria neuropsicológica (grupo clínico e controles saudáveis)

\begin{tabular}{lcc}
\hline \multicolumn{1}{c}{ Variáveis } & $\mathbf{r}$ & Valor de $\mathbf{p}$ \\
\hline Visuoespacial e Controle Mental & 0,4372 & $<0,0001^{* * *}$ \\
Visuoespacial e Figura Complexa de Rey (cópia) & 0,6542 & $<0,0001^{* * *}$ \\
Visuoespacial e Figura Complexa de Rey (tempo) & $-0,1268$ & 0,0666 \\
Visuoespacial e Figura Complexa de Rey (imediata) & 0,4639 & $<0,0001^{* * *}$ \\
Visuoespacial e Figura Complexa de Rey (tardia) & 0,4800 & $<0,0001^{* * *}$ \\
Visuoespacial e RAVLT (Total A) & 0,4930 & $<0,0001^{* * *}$ \\
Visuoespacial e RAVLT (B) & 0,3440 & $<0,0001^{* * *}$ \\
Visuoespacial e RAVLT (A após interferência) & 0,3834 & $<0,0001^{* * *}$ \\
Visuoespacial e RAVLT (tardia) & 0,3637 & $<0,0001^{* * *}$ \\
Visuoespacial e RAVLT (reconhecimento) & 0,4394 & $<0,0001^{* * *}$ \\
Visuoespacial e Fluência Verbal (FAS) & 0,3818 & $<0,0001^{* * *}$ \\
Visuoespacial e Fluência Verbal (animais) & 0,3947 & $<0,0001^{* * *}$ \\
Visuoespacial e Dígitos Spam (ordem direta) & 0,3354 & $<0,0001^{* * *}$ \\
Visuoespacial e Dígitos Spam (ordem inversa) & 0,3915 & $<0,0001^{* * *}$ \\
Visuoespacial e Blocos de Corsi (ordem direta) & 0,4469 & $<0,0001^{* * *}$ \\
Visuoespacial e Blocos de Corsi (ordem inversa) & 0,4076 & $<0,0001^{* * *}$ \\
Visuoespacial e Trail Making Test (A tempo) & $-0,4359$ & $<0,0001^{* * *}$ \\
Visuoespacial e Trail Making Test (B tempo) & $-0,4463$ & $<0,0001^{* * *}$ \\
Visuoespacial e Trail Making Test (B-A) & $-0,2550$ & $0,0002^{* * *}$
\end{tabular}

Coeficiente de correlação: $(=1)$ perfeita, $(>0,75)$ forte, $(>0,5)$ média, $(<0,5)$ fraca, $(=0)$ inexistente.

${ }^{*}$ Nível de significância $<0,05$.

** Nível de significância $<0,01$.

*** Nível de significância $<0,001$.

\subsection{Notas de corte, sensibilidade e especificidade, da ACE-III, por meio} de análises da curva ROC (ACE-III total)

A Tabela 29 revela as notas de corte, sensibilidade e especificidade, da ACE-III, por meio de análises ROC. O ponto de corte ideal da ACE-III para discriminar controles saudáveis do grupo clínico foi 86/100, o que produziu uma sensibilidade de $58 \%$ e uma especificidade de $55 \%$. A AUC da ACE-III foi de 0,6192 (Figura 4). Para discriminar entre D-DP e o subgrupo CCL-DP (Tabela 30), o ponto de corte ideal da ACE-III observado foi de 78/100 (sensibilidade $=$ $72,73 \%$, especificidade $=68,27 \%$ ). A AUC para a ACE-III foi de 0,7863 (Figura 5). Para discriminar entre controles saudáveis e o subgrupo CCL-DP (Tabela 31), o ponto de corte ideal da ACE-III observado foi de $85 / 100$ (sensibilidade $=$ 
$58,65 \%$, especificidade $=60 \%$ ). A AUC para a ACE-III foi de 0,6400 (Figura 6) . Para discriminar entre controles saudáveis e o subgrupo D-DP (Tabela 32), o ponto de corte ideal da ACE-III observado foi de 81/100 (sensibilidade = $81,82 \%$, especificidade $=75,00 \%$ ). A AUC para a ACE-III foi de 0,8848 (Figura $6)$.

Tabela 29 - Notas de corte, sensibilidade e especificidade, para diferenciar controles saudáveis e pacientes, usando escore total da ACEIII

\begin{tabular}{|c|c|c|}
\hline ACE-III & & \\
\hline $\begin{array}{c}\text { Notas de Corte } \\
84\end{array}$ & $\begin{array}{c}\text { Sensibilidade } \\
52,00 \%\end{array}$ & $\begin{array}{c}\text { Especificidade } \\
66,67 \%\end{array}$ \\
\hline 85 & $56,00 \%$ & $60,00 \%$ \\
\hline 86 & $58,00 \%$ & $55,00 \%$ \\
\hline 87 & $59,33 \%$ & $51,67 \%$ \\
\hline 88 & $62,67 \%$ & $41,67 \%$ \\
\hline
\end{tabular}

Tabela 30 - Notas de corte, sensibilidade e especificidade, para diferenciar CCL-DP e D-DP, usando escore total da ACE-III

\begin{tabular}{ccc}
\hline ACE-III & D-DP & \\
\hline Notas de Corte & Sensibilidade & Especificidade \\
76 & $63,64 \%$ & $74,04 \%$ \\
77 & $63,64 \%$ & $70,19 \%$ \\
$\mathbf{7 8}$ & $\mathbf{7 2 , 7 3 \%}$ & $\mathbf{6 8 , 2 7 \%}$ \\
79 & $72,73 \%$ & $66,35 \%$ \\
80 & $\mathbf{7 7 , 2 7 \%}$ & $61,54 \%$ \\
\hline Dados destacados & representam nota de corte ótima (baseado na sensibilidade e \\
especificidade) & &
\end{tabular}

Tabela 31 - Notas de corte, sensibilidade e especificidade, para identificar controles saudáveis e CCL-DP, usando escore total da ACE-III

\begin{tabular}{ccc}
\hline ACE-III & CCL-DP & \\
\hline Notas de Corte & Sensibilidade & Especificidade \\
83 & $50,96 \%$ & $71,67 \%$ \\
84 & $54,81 \%$ & $66,67 \%$ \\
$\mathbf{8 5}$ & $\mathbf{5 8 , 6 5 \%}$ & $\mathbf{6 0 , 0 0 \%}$ \\
86 & $60,58 \%$ & $55,00 \%$ \\
87 & $61,54 \%$ & $51,67 \%$ \\
\hline Dados destacados & representam nota de corte ótima (baseado na sensibilidade e \\
especificidade) & &
\end{tabular}


Tabela 32 - Notas de corte, sensibilidade e especificidade, para identificar controles saudáveis e D-DP, usando escore total da ACE-III

\begin{tabular}{ccc}
\hline ACE-III & D-DP \\
\hline Notas de Corte & Sensibilidade & Especificidade \\
78 & $72,73 \%$ & $85,00 \%$ \\
79 & $72,73 \%$ & $81,67 \%$ \\
80 & $77,27 \%$ & $78,33 \%$ \\
81 & $\mathbf{8 1 , 8 2} \%$ & $\mathbf{7 5 , 0 0 \%}$ \\
82 & $81,82 \%$ & $71,67 \%$ \\
\hline
\end{tabular}

Dados destacados representam nota de corte ótima (baseado na sensibilidade e especificidade)

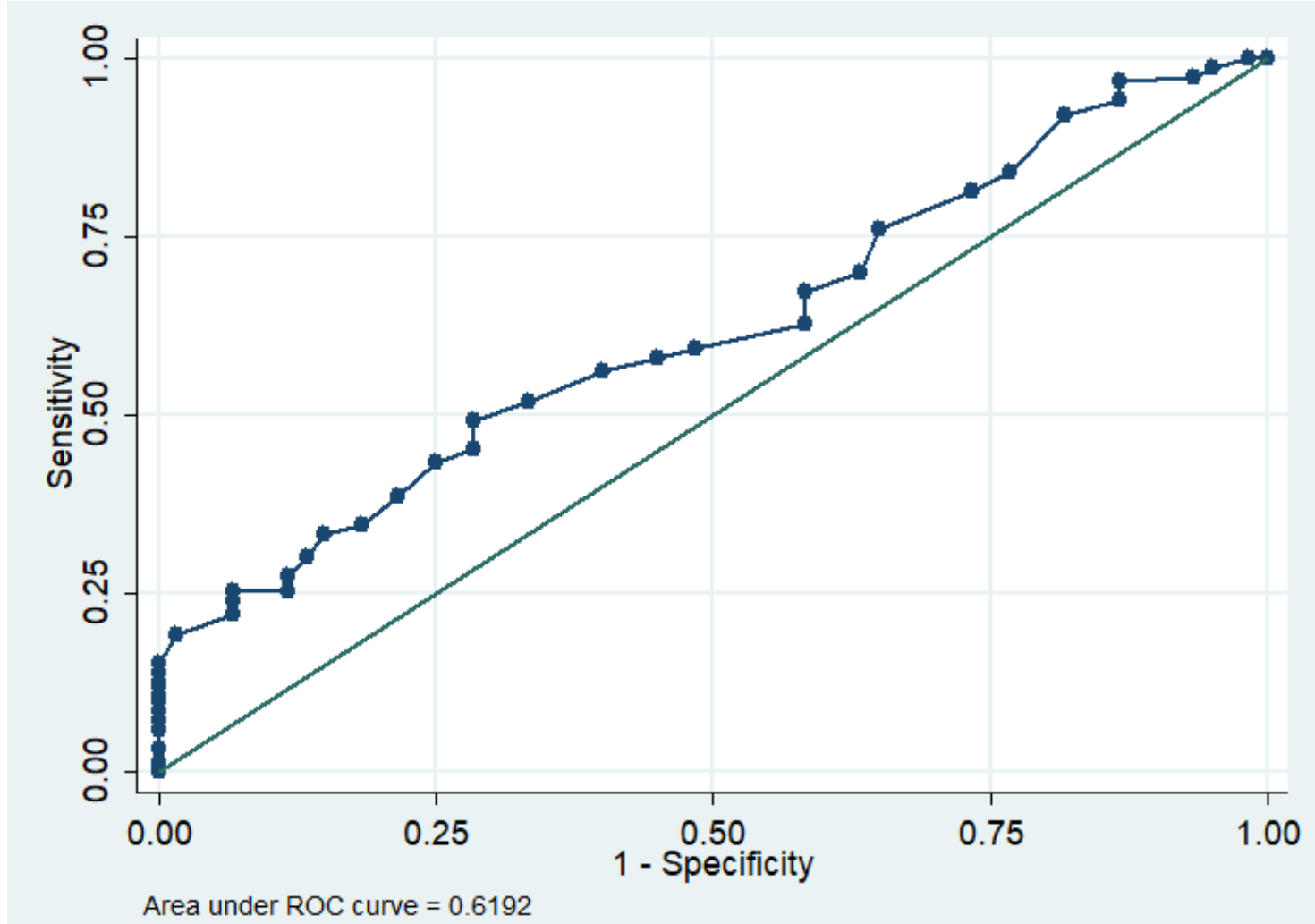

Figura 3 - Representação gráfica (curva ROC) para discriminar entre controles e pacientes, usando escore total da ACE-III. Área sob a curva ROC foi $0,6192(95 \%$ IC $[0,5395 ; 0,6990])$ 


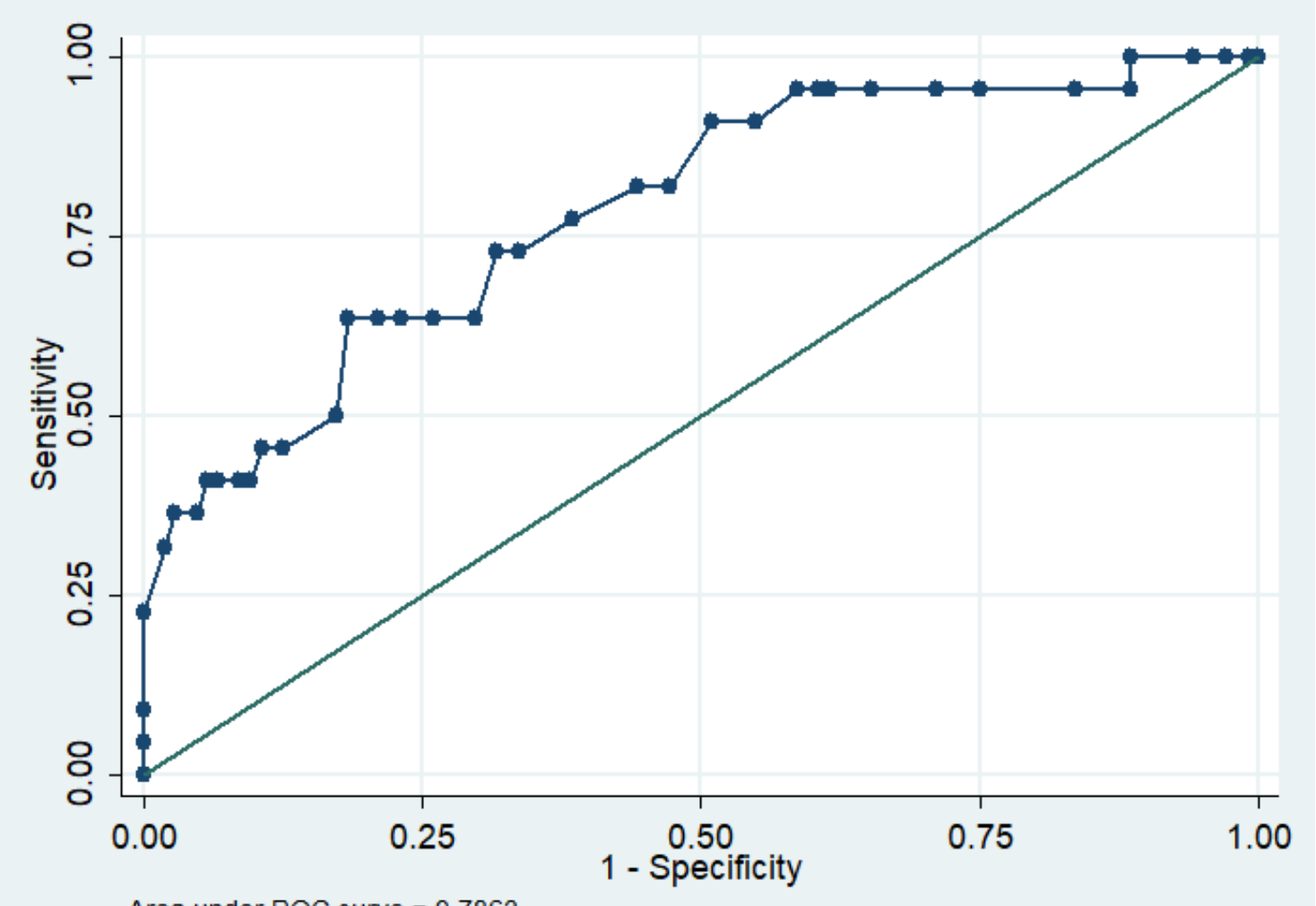

Area under ROC curve $=0.7863$

Figura 4 - Representação gráfica (curva ROC) para discriminar entre CCL-DP e D-DP, usando escore total da ACE-III. Área sob a curva ROC foi 0,7863 (95\% IC $[0,6784 ; 0,8942])$ 


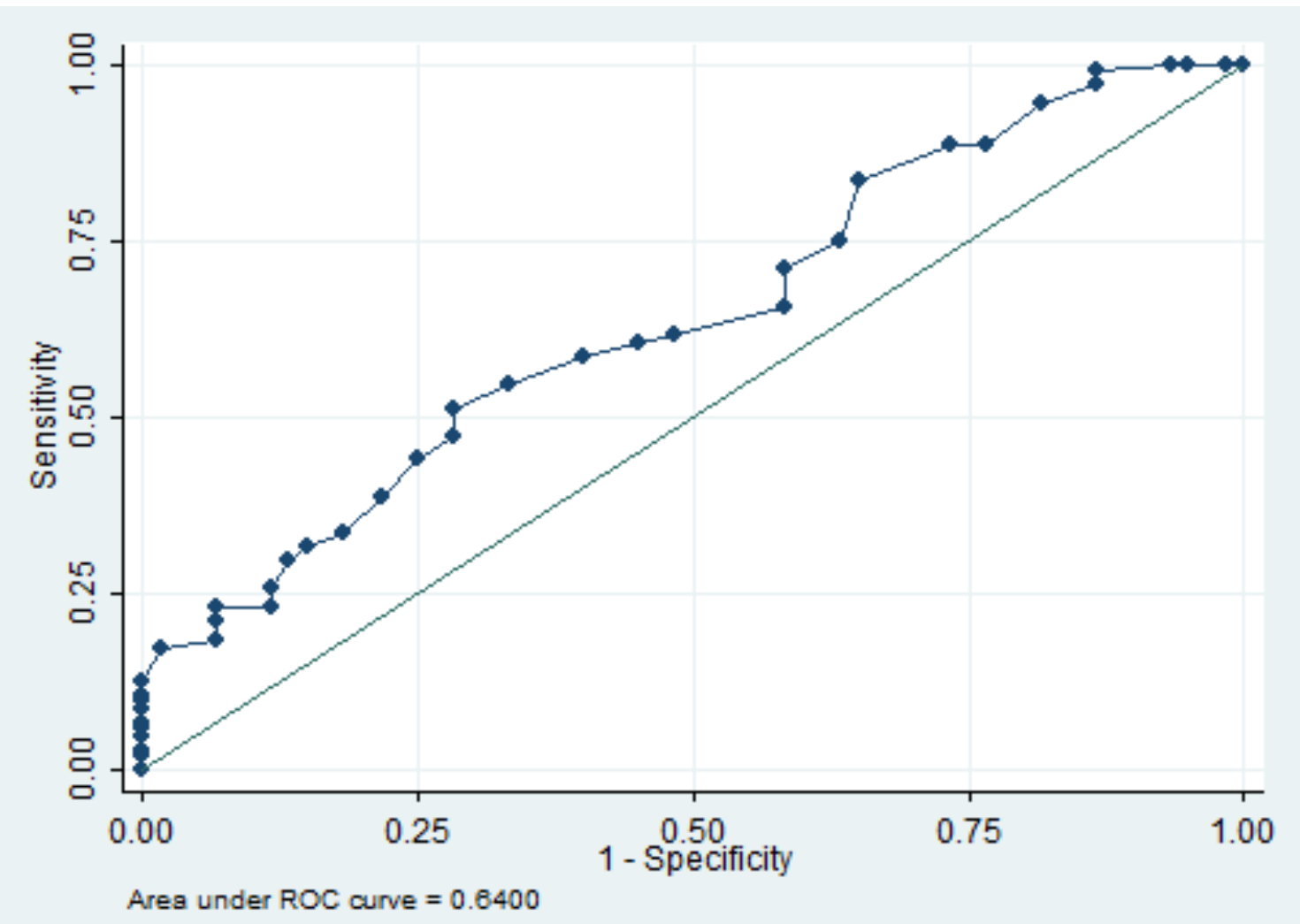

Figura 5 - Representação gráfica (curva ROC) para discriminar entre controles saudáveis e CCL-DP, usando escore total da ACE-III. Área sob a curva ROC foi 0,6400 (95\% IC [0,5535; 0,7265]) 


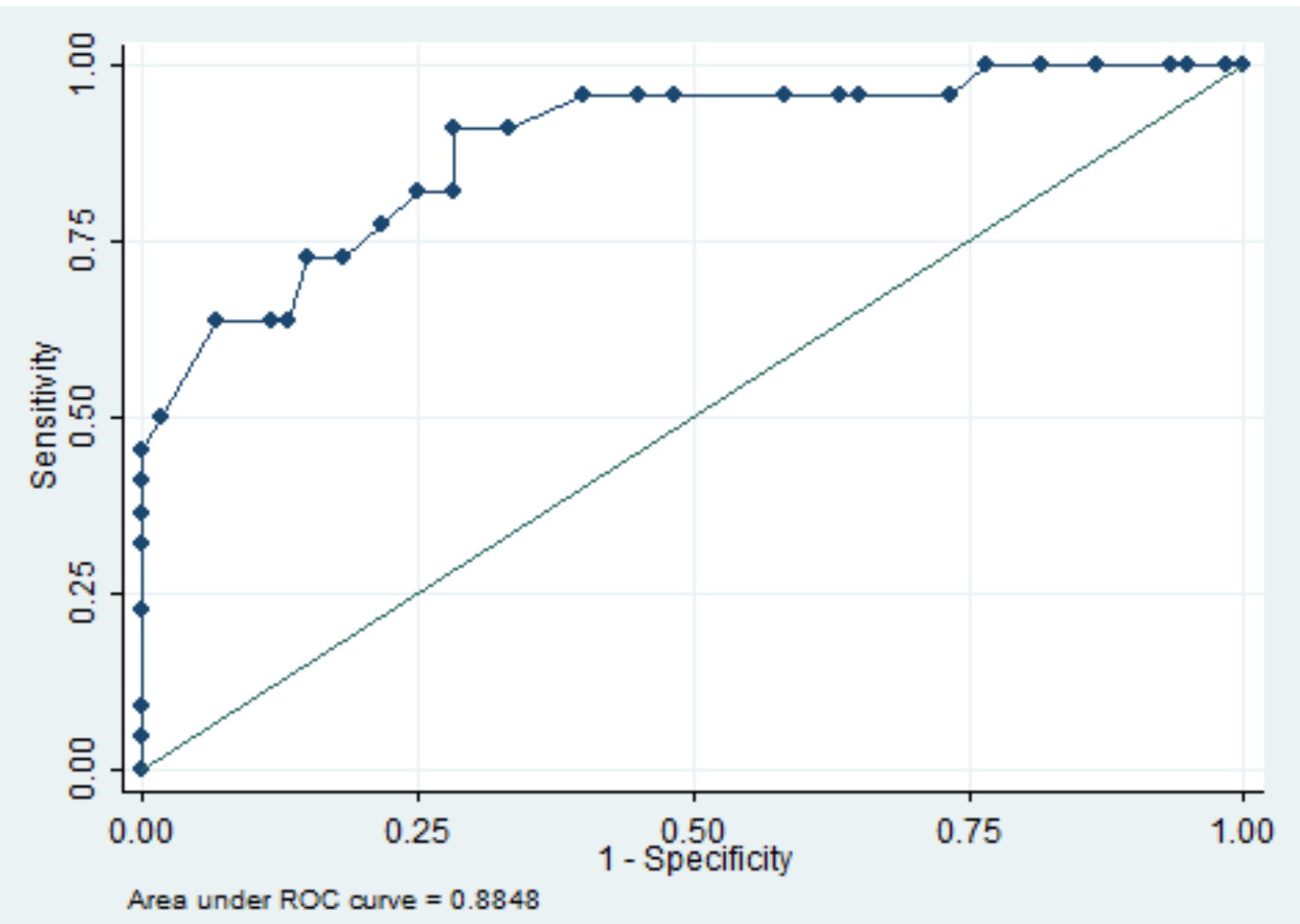

Figura 6 - Representação gráfica (curva ROC) para discriminar entre controles saudáveis e D-DP, usando escore total da ACE-III. Área sob a curva ROC foi 0,8848 (95\% IC [0,8003; 0,9694]) 


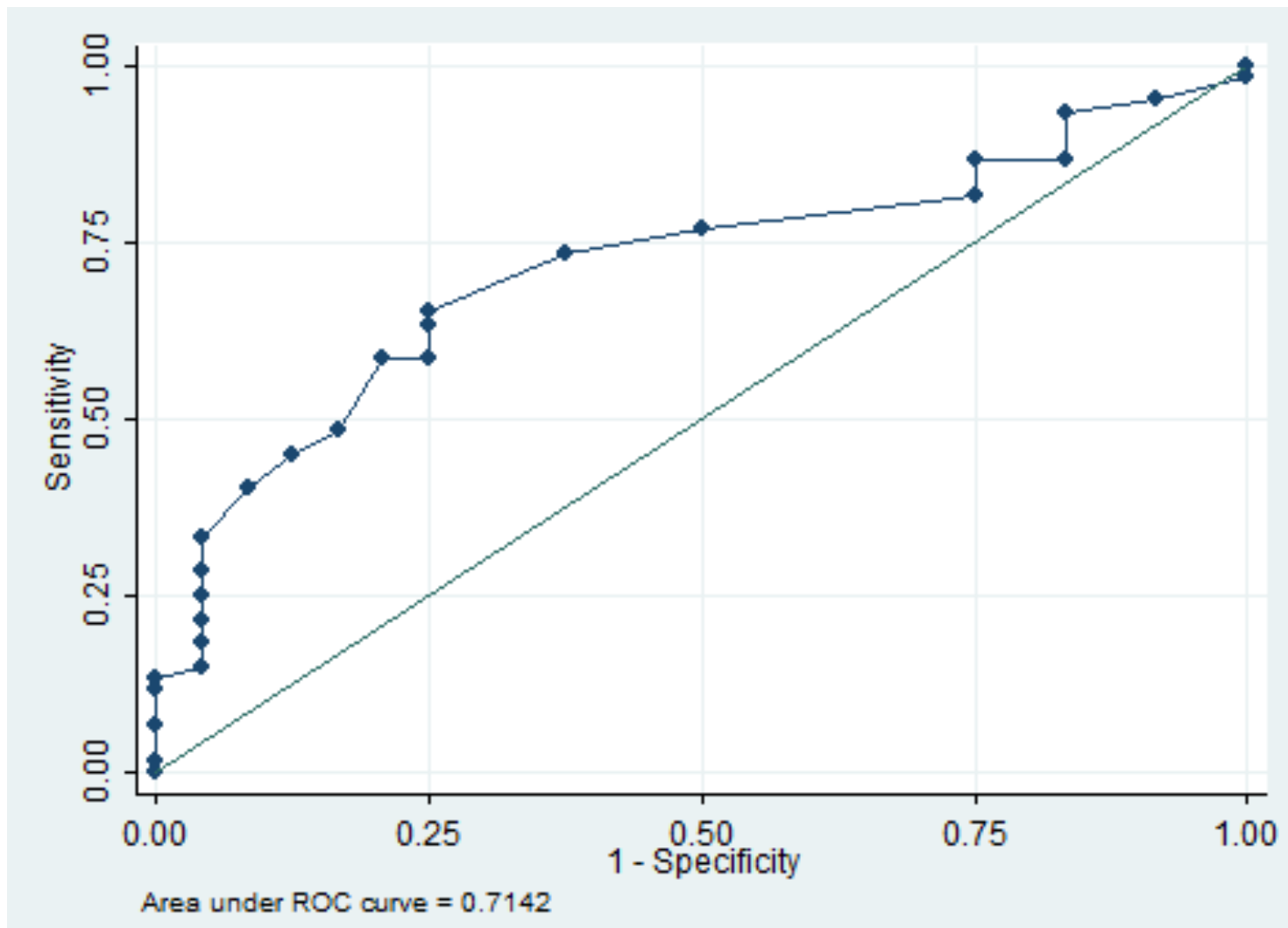

Figura 7 - Representação gráfica (curva ROC) para discriminar entre CN-DP e Controle, usando escore total da ACE-III. Área sob a curva ROC foi $0,7142(95 \%$ IC $[0,6004 ; 0,8281])$

4.8 Notas de corte, sensibilidade e especificidade, da ACE-III, por meio de análises da curva ROC (ACE-III, domínios)

Para o domínio da atenção/orientação, os valores de corte, com melhor sensibilidade e especificidade, para diferenciar controles saudáveis e CCL-DP, controles saudáveis e D-DP e CCL-DP e D-DP foram 17, 15 e 14/15, como pode ser visto nas Tabelas 33-35 e Figuras 8-11. Para o domínio memória os valores de corte foram 19, 17 e 16. Para o domínio fluência verbal os valores de corte foram 9, 8 e 8 . Para o domínio linguagem os valores foram 25,24 e 24. Para o domínio visuoespacial os valores foram 14, 14 e 13. 
Tabela 33 - Notas de corte, sensibilidade e especificidade, para diferenciar controles saudáveis e CCL-DP, usando os domínios da ACE-III

\begin{tabular}{lccc}
\hline \multicolumn{1}{c}{ Domínios } & Notas de Corte & Sensibilidade & Especificidade \\
\hline Atenção/Orientação & 17 & 68,27 & 53,33 \\
Memória & 19 & 52,88 & 60,00 \\
Fluência Verbal & 9 & 44,23 & 58,33 \\
Linguagem & 25 & 49,04 & 58,33 \\
Visuoespacial & 14 & 48,08 & 65,00 \\
\hline
\end{tabular}

Tabela 34 - Notas de corte, sensibilidade e especificidade, para diferenciar controles saudáveis e D-DP, usando os domínios da ACE-III

\begin{tabular}{lccc}
\hline \multicolumn{1}{c}{ Domínios } & Notas de Corte & Sensibilidade & Especificidade \\
\hline Atenção/Orientação & 15 & 72,73 & 80,00 \\
Memória & 17 & 77,27 & 73,33 \\
Fluência Verbal & 8 & 68,18 & 71,67 \\
Linguagem & 24 & 59,09 & 73,33 \\
Visuoespacial & 14 & 63,64 & 65,00 \\
\hline
\end{tabular}

Tabela 35 - Notas de corte, sensibilidade e especificidade, para diferenciar CCL-DP e D-DP, usando os domínios da ACE-III

\begin{tabular}{lccc}
\hline \multicolumn{1}{c}{ Domínios } & Notas de Corte & Sensibilidade & Especificidade \\
\hline Atenção/Orientação & $14 / 15$ & $63,64 / 73$ & $75 / 63,46$ \\
Memória & 16 & 68,18 & 62,50 \\
Fluência Verbal & 8 & 68,18 & 70,19 \\
Linguagem & 24 & 59,09 & 68,27 \\
Visuoespacial & 13 & 59,09 & 65,38 \\
\hline
\end{tabular}




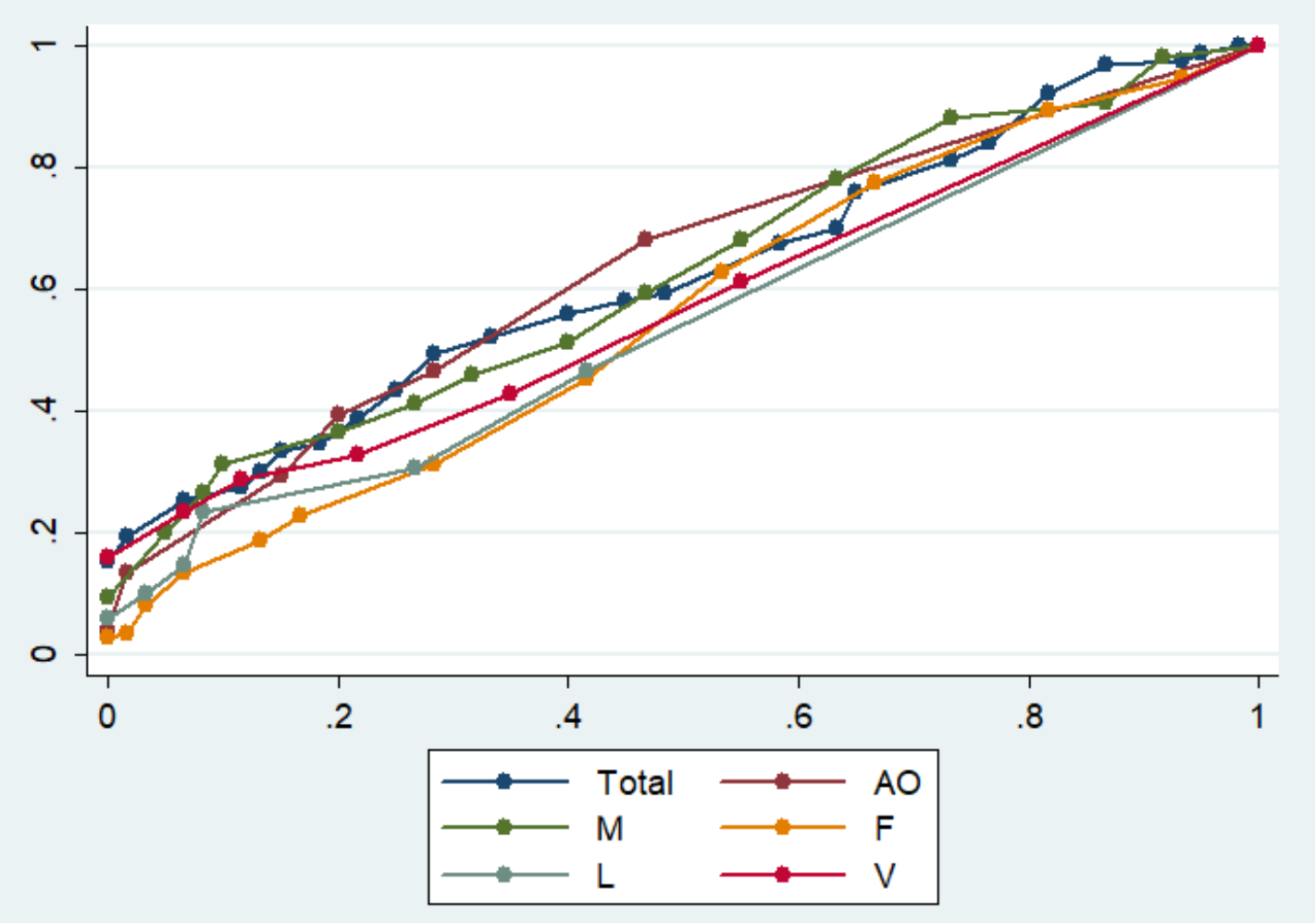

Figura 8 - Representação gráfica (curva ROC) para discriminar controles e pacientes, usando escore total e domínios da ACE-III

Total=ACE-III Total, AO= ACE-III Atenção/Orientação, M= ACE-III Memória, F= ACE-III Fluência verbal, L= ACE-III Linguagem, V= ACE-III Visuoespacial. 


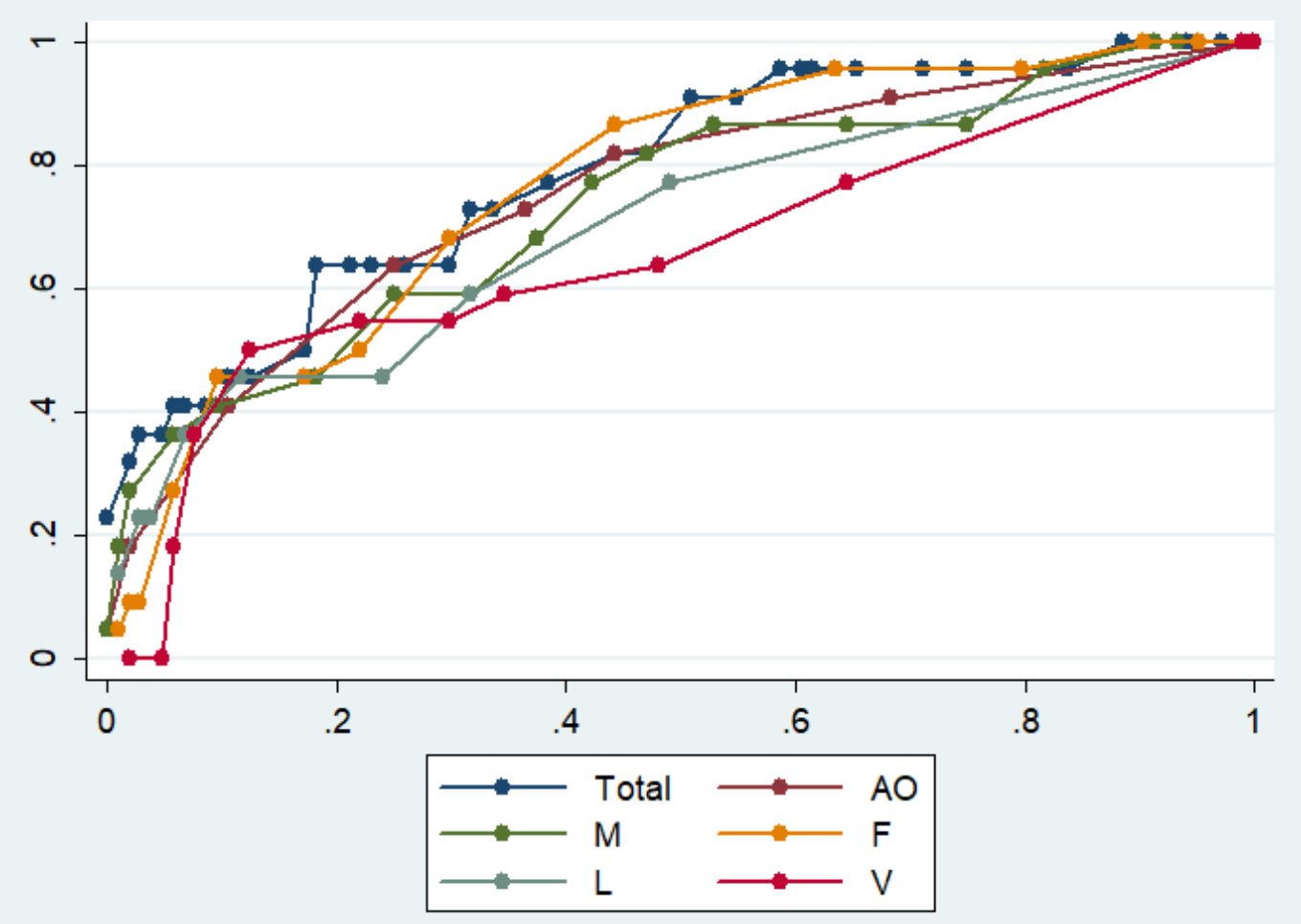

Figura 9 - Representação gráfica (curva ROC) para discriminar entre CCL-DP e D-DP, usando escore total e domínios da ACE-III

Total=ACE-III Total, AO= ACE-III Atenção/Orientação, M= ACE-III Memória, F= ACE-III Fluência verbal, L= ACE-III Linguagem, $V=$ ACE-III Visuoespacial. 


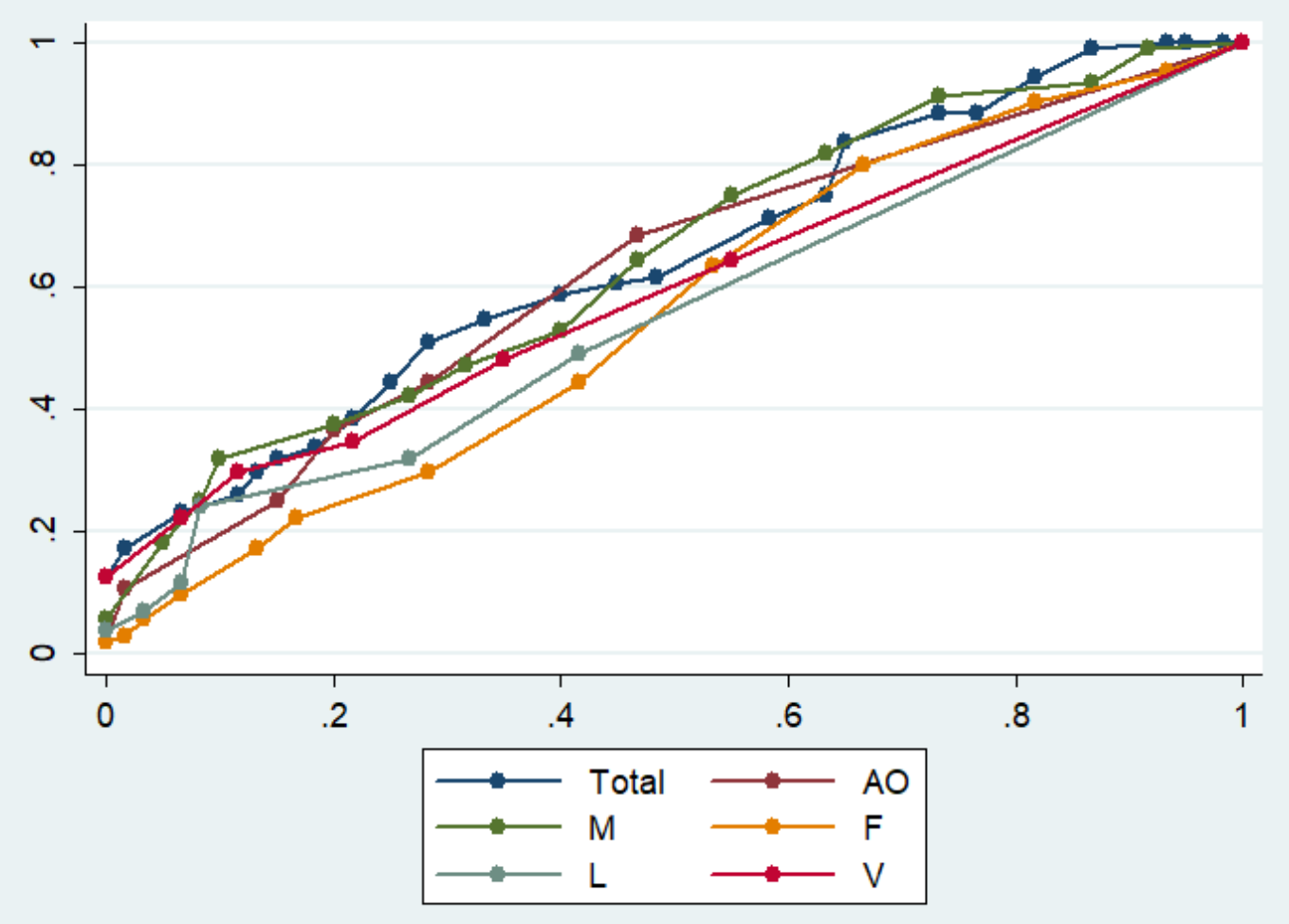

Figura 10 - Representação gráfica (curva ROC) para discriminar entre controles saudáveis e CCL-DP, usando escore total e domínios da ACE-III

Total=ACE-III Total, AO= ACE-III Atenção/Orientação, $M=$ ACE-III Memória, F= ACE-III Fluência verbal, L= ACE-III Linguagem, $V=A C E-$ III Visuoespacial. 


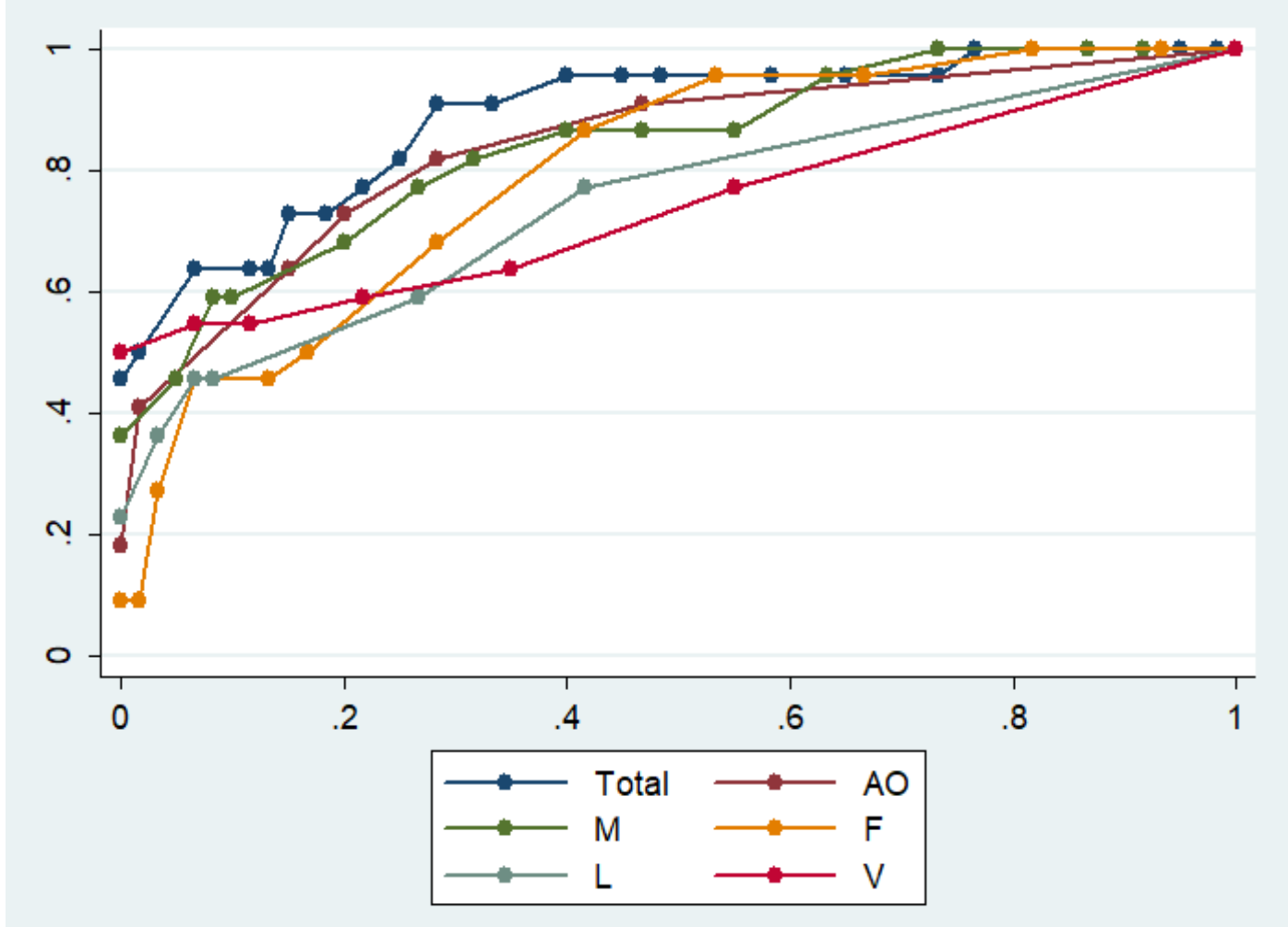

Figura 11 - Representação gráfica (curva ROC) para discriminar entre controles saudáveis e D-DP, usando escore total e domínios da ACE-III

Total=ACE-III Total, AO= ACE-III Atenção/Orientação, M= ACE-III Memória, F= ACE-III Fluência verbal, L= ACE-III Linguagem, V= ACE-III Visuoespacial.

4.9 Notas de corte, sensibilidade e especificidade, da ACE-III, por meio de análises da curva ROC, por faixas de escolaridade

As Tabelas 36-38 mostram que, por faixa de escolaridade, quanto maior foi os anos de estudo formal, maior foi a pontuação nos escores totais e domínios da ACE-III. As notas de corte foram melhores para discriminar controles saudáveis de D-DP, principalmente, na faixa de escolaridade acima de 10-12, 78 pontos, $100 \%$ de sensibilidade e $100 \%$ de especificidade, AUC $=1(95 \%$ $\mathrm{Cl}[1 ; 1])$, em seguida no subgrupo $>=13$ anos de escolaridade, obtendo a pontuação de $83,75 \%$ de sensibilidade e $100 \%$ de especificidade, AUC $=$ 
0,9167 $95 \% \mathrm{Cl}[0,73 ; 1])$ e, por último, $4-9$ anos de escolaridade, com a pontuação de 78 , sensibilidade de $81,82 \%$ e especificidade de $62,50 \%$, AUC = $0,8504(95 \% \mathrm{Cl}[0,69 ; 1])$

Para discriminar controles saudáveis de CCL-DP, as notas de corte também foram melhores no subgrupo com maior escolaridade, ou seja, maior e igual que 13 anos obteve pontuação de 91 , sensibilidade de $73,08 \%$ e especificidade de $77,78 \%, A U C=0,8312$ (95\% CI $[0,67 ; 0,98])$. Em seguida, o subgrupo 1-12 anos, com pontuação de 85 , sensibilidade de 0,47 e especificidade de $74,07 \%, \mathrm{AUC}=0,7089(95 \% \mathrm{Cl}[0,60 ; 0,83])$. E por último o subgrupo 4-9 anos, com pontuação de 81 , sensibilidade de $60 \%$ e especificidade de $50 \%, A U C=0,6110(95 \% \mathrm{Cl}[0,46 ; 0,75])$.

Para distinguir pacientes de controles saudáveis, as notas de corte foram melhores para o subgrupo >= 13 anos, com 93 pontos, sensibilidade de $66,67 \%$ e especificidade de $66,67 \%$, AUC $=0,750$ (95\% Cl $[0,57 ; 0,92])$. Para o subgrupo 10-12 anos, 86 pontos (sensibilidade de 58,33\% e especificidade de $62,96 \%, A \cup C=0,6861, I C: 0,57-0,79)$. Para o subrupo 4-9 anos, a pontuação de 81 , sensibilidade de $62,75 \%$ e especificidade de $50,00 \%$, AUC $=0,6242$ $(95 \% \mathrm{Cl}[0,40 ; 0,75])$.

Em relação aos domínios da ACE-III, por faixas de escolaridade, pôde-se observar que no subgrupo >=13 anos, para distinguir controles saudáveis de DDP, todos os domínios apresentaram uma boa acurácia diagnóstica, principalmente, fluência verbal e memória. 
Tabela 36 - Notas de corte, sensibilidade e especificidade, para diferenciar controles saudáveis e pacientes, usando escore total da ACE-III

\begin{tabular}{|c|c|c|c|c|c|c|}
\hline Escolaridade & ACE-III & $\begin{array}{c}\text { Nota de } \\
\text { Corte }\end{array}$ & Sensibilidade & Especificidade & AUC & $95 \%$ IC \\
\hline \multirow[t]{6}{*}{ 4-9 anos } & Total & 81 & $62,75 \%$ & $50,00 \%$ & 0,6242 & $0,49-0,75$ \\
\hline & Atenção/Orientação & 15 & $54,90 \%$ & $62,50 \%$ & 0,5788 & $0,44-0,71$ \\
\hline & Memória & 17 & $60,78 \%$ & $62,50 \%$ & 0,6250 & $0,52-0,77$ \\
\hline & Fluência Verbal & 8 & $45,10 \%$ & $50,00 \%$ & 0,5458 & $0,40-0,68$ \\
\hline & Linguagem & 25 & $62,75 \%$ & $45,83 \%$ & 0,5580 & $0,42-0,69$ \\
\hline & Visuoespacial & 14 & $58,82 \%$ & $45,83 \%$ & 0,5760 & $0,44-0,70$ \\
\hline \multirow[t]{6}{*}{$10-12$ anos } & Total & 86 & $58,33 \%$ & $62,96 \%$ & 0,6861 & $0,57-0,79$ \\
\hline & Atenção/Orientação & 17 & $66,67 \%$ & $70,37 \%$ & 0,7210 & $0,61-0,82$ \\
\hline & Memória & 20 & $63,33 \%$ & $55,56 \%$ & 0,603 & $0,52-0,77$ \\
\hline & Fluência Verbal & 10 & $56,67 \%$ & $48,15 \%$ & 0,5991 & $0,46-0,73$ \\
\hline & Linguagem & 25 & $48,33 \%$ & $62,96 \%$ & 0,5580 & $0,42-0,69$ \\
\hline & Visuoespacial & 15 & $63,33 \%$ & $58,85 \%$ & 0,6306 & $0,51-0,74$ \\
\hline \multirow[t]{6}{*}{$>=13$ anos } & Total & 93 & $66,67 \%$ & $66,67 \%$ & 0,7507 & $0,57-0,92$ \\
\hline & Atenção/Orientação & 17 & $56,41 \%$ & $77,78 \%$ & 0,6781 & $0,51-0,83$ \\
\hline & Memória & 23 & $76,92 \%$ & $77,78 \%$ & 0,7550 & $0,59-0,91$ \\
\hline & Fluência Verbal & 11 & $66,67 \%$ & $55,56 \%$ & 0,6852 & $0,48-0,88$ \\
\hline & Linguagem & 25 & $23,08 \%$ & $77,78 \%$ & 0,5128 & $0,36-0,66$ \\
\hline & Visuoespacial & 15 & $43,59 \%$ & $66,67 \%$ & 0,5513 & $0,37-0,72$ \\
\hline
\end{tabular}

Tabela 37 - Notas de corte, sensibilidade e especificidade, para diferenciar controles saudáveis e CCL-DP, usando escore total da ACE-III

\begin{tabular}{|c|c|c|c|c|c|c|}
\hline Escolaridade & ACE-III & $\begin{array}{l}\text { Nota de } \\
\text { Corte }\end{array}$ & Sensibilidade & Especificidade & AUC & $95 \%$ IC \\
\hline \multirow[t]{6}{*}{ 4-9 anos } & Total & 81 & $60,00 \%$ & $50,00 \%$ & 0,6101 & $0,46-0,75$ \\
\hline & Atenção/Orientação & 16 & $54,29 \%$ & $45,83 \%$ & 0,5232 & $0,37-0,67$ \\
\hline & Memória & 17 & $60,00 \%$ & $62,05 \%$ & 0,6512 & $0,50-0,79$ \\
\hline & Fluência Verbal & 9 & $60,00 \%$ & $41,67 \%$ & 0,4881 & $0,33-0,64$ \\
\hline & Linguagem & 25 & $60,00 \%$ & $45,83 \%$ & 0,5387 & $0,39-0,68$ \\
\hline & Visuoespacial & 14 & $62,86 \%$ & $45,83 \%$ & 0,5863 & $0,44-0,73$ \\
\hline \multirow[t]{6}{*}{ 10-12 anos } & Total & 85 & $60,47 \%$ & $74,07 \%$ & 0,7089 & $0,58-0,82$ \\
\hline & Atenção/Orientação & 17 & $67,44 \%$ & $70,37 \%$ & 0,7192 & $0,60-0,83$ \\
\hline & Memória & 20 & $67,44 \%$ & $55,56 \%$ & 0,6628 & $0,53-0,79$ \\
\hline & Fluência Verbal & 11 & $76,74 \%$ & $44,44 \%$ & 0,5973 & $0,45-0,73$ \\
\hline & Linguagem & 25 & $51,16 \%$ & $62,96 \%$ & 0,6137 & $0,49-0,73$ \\
\hline & Visuoespacial & 15 & $60,47 \%$ & $51,85 \%$ & 0,6197 & $0,49-0,74$ \\
\hline \multirow[t]{6}{*}{$>=13$ anos } & Total & 91 & $73,08 \%$ & $77,78 \%$ & 0,8312 & $0,67-0,98$ \\
\hline & Atenção/Orientação & 17 & $61,54 \%$ & $77,78 \%$ & 0,7030 & $0,53-0,87$ \\
\hline & Memória & 13 & $84,62 \%$ & $77,78 \%$ & 0,8162 & $0,66-0,96$ \\
\hline & Fluência Verbal & 11 & $76,92 \%$ & $55,56 \%$ & 0,7479 & $0,55-0,94$ \\
\hline & Linguagem & 25 & $30,77 \%$ & $77,78 \%$ & 0,5513 & $0,38-0,71$ \\
\hline & Visuoespacial & 15 & $53,85 \%$ & $66,67 \%$ & 0,6154 & $0,43-0,79$ \\
\hline
\end{tabular}


Tabela 38 - Notas de corte, sensibilidade e especificidade, para diferenciar controles saudáveis e D-DP, usando os domínios da ACE-III

\begin{tabular}{|c|c|c|c|c|c|c|}
\hline Escolaridade & ACE-III & $\begin{array}{c}\text { Nota de } \\
\text { Corte }\end{array}$ & Sensibilidade & Especificidade & AUC & $95 \%$ IC \\
\hline \multirow[t]{6}{*}{ 4-9 anos } & Total & 78 & $81,82 \%$ & $62,50 \%$ & 0,8504 & $0,69-1$ \\
\hline & Atenção/Orientação & 15 & $90,91 \%$ & $62,50 \%$ & 0,8277 & $0,68-0,97$ \\
\hline & Memória & 17 & $81,82 \%$ & $62,50 \%$ & 0,7860 & $0,58-0,98$ \\
\hline & Fluência Verbal & 7 & $81,82 \%$ & $70,83 \%$ & 0,8466 & $0,70-0,99$ \\
\hline & Linguagem & 22 & $54,55 \%$ & $83,33 \%$ & 0,7443 & $0,56-0,92$ \\
\hline & Visuoespacial & 13 & $64,64 \%$ & $62,50 \%$ & 0,7178 & $0,49-0,93$ \\
\hline \multirow[t]{6}{*}{ 10-12 anos } & Total & 78 & $100 \%$ & $100 \%$ & 1,000 & $1-1$ \\
\hline & Atenção/Orientação & 16 & $85,71 \%$ & $88,89 \%$ & 0,8810 & $0,70-1$ \\
\hline & Memória & 19 & $100 \%$ & $62,96 \%$ & 0,9418 & $0,84-1$ \\
\hline & Fluência Verbal & 9 & $85,71 \%$ & $62,96 \%$ & 0,8360 & $0,69-0,98$ \\
\hline & Linguagem & 25 & $85,71 \%$ & $62,96 \%$ & 0,8492 & $0,65-1$ \\
\hline & Visuoespacial & 11 & $85,71 \%$ & $100 \%$ & 0,8942 & $0,68-1$ \\
\hline \multirow[t]{6}{*}{$>=13$ anos } & Total & 83 & $75,00 \%$ & $100 \%$ & 0,9167 & $0,73-1$ \\
\hline & Atenção/Orientação & 17 & $75,00 \%$ & $77,78 \%$ & 0,7917 & $0,49-1$ \\
\hline & Memória & 22 & $100 \%$ & $77,78 \%$ & 0,9583 & $0,85-1$ \\
\hline & Fluência Verbal & 10 & $75,00 \%$ & $88.89 \%$ & 0,8056 & $0,53-1$ \\
\hline & Linguagem & 24 & $25,00 \%$ & $100 \%$ & 0,5417 & $0,22-0,86$ \\
\hline & Visuoespacial & 15 & $50,00 \%$ & $66,67 \%$ & 0,5278 & $0,21-0,84$ \\
\hline
\end{tabular}




\section{DISCUSSÃO}

A necessidade de instrumentos breves, com boa propriedade psicométrica, para detectar alterações cognitivas leves na DPI e iniciar opções de tratamento e orientações ao paciente e familiares/cuidadores, faz-se importante na prática clínica, visto que prejuízos cognitivos e o seu declínio podem influenciar na qualidade de vida e na funcionalidade destes indivíduos. A frequência de CCL-PD e D-DP pode ser de $30 \%$ a depender da idade, tempo de evolução da doença e comorbidades (Lucza et al., 2018)

Desta forma, o objetivo deste estudo foi estabelecer a acurácia diagnóstica da ACE-III para detecção de CCL-DP e D-DP.

A ACE-III leva de 20 a 30 minutos e fornece informações sobre o nível global das funções cognitivas e déficits cognitivos específicos em pacientes com DPI. É um instrumento que, desde a primeira versão, é capaz de distinguir entre tipos de demência, tais como DA, DFT, PSP, DCB e AMS (Bier et al., 2004; Mathuranath et al., 2004; Bak et al., 2005; Dudas, 2005; Galton et al., 2005; Larner, 2005), diferentemente de outros instrumentos que são mais sensíveis para determinada condição neurológica e/ou estágios mais avançados de demência.

Estudos anteriores têm demonstrado a propriedade psicométrica da bateria ACE-III, para o diagnóstico de quadros de CCL e demência em diversas condições neurológicas, tais como DA, APP, DFT variante comportamental, ACP (Elamin et al., 2016), DA, DFT (Hsieh et al., 2013), indivíduos com queixas subjetivas de memória, CCL, DA, DFT variante comportamental, APP e parkinsonismo atípico (Matías-Guiu et al., 2017), DA, DA com DCV e DV (Jubb 
e Evans, 2015), DA e DV (Wang et al., 2017). Na maior parte destes estudos, a nota de corte ficou entre $80-88 / 100$ pontos, poucos tiveram uma nota de corte de 68/100 pontos (García-Caballero et al., 2006), 67/68/100 pontos (Fang et al., 2014) e 63/64/100 pontos (Matías-Guiu et al., 2017). Cabe referir que nestes estudos, a média de escolaridade formal foi menor (=<12 anos) ou apresentou média de idade maior ( $>=70$ anos).

A nossa amostra foi constituída por 60 controles saudáveis, 24 CN-DP, 104 CCL-DP e 22 D-DP. Em comparação com estudos anteriores, com esta condição neurológica, às características demográficas e clínicas, independente da versão utilizada da ACE, a média de idade, escolaridade, duração e gravidade da doença foram similares ao nosso estudo; exceto a idade, que foi menor aos demais estudos. Consistente com a literatura, o prejuízo ocorreu em mais de um domínio cognitivo (Janvin et al., 2006; Caviness et al., 2007; Aarsland e Kurz, 2010b; 2010a; Sollinger et al., 2010) evidenciando déficits em aspectos da atenção, memória e fluência verbal, o que é consistente com a hipótese de alterações fronto-subcorticais nesta condição neurológica (Papagno e Trojano, 2018); porém também pode ocorrer déficit relacionado à estruturas posteriores, como visuoespaciais e visuo-construtivas.

O presente estudo mostrou que a ACE-III é uma ferramenta de avaliação breve da cognição, sendo capaz de diferenciar indivíduos de CCL-DP e D-DP de controles saudáveis, tendo notas de corte de 81/100 (sensibilidade de $81,82 \%$ e especificidade de $75,00 \%$ ) e $85 / 100$ pontos (sensibilidade de $58,65 \%$ e especificidade de 60,00\%), para detectar CCL-DP e D-DP, respectivamente.

Na doença de Parkinson, há estudos com a primeira versão (Reyes et al., 2009; Lucza et al., 2015) e a revisada (Komadina et al., 2011; Berankova et al., 
2015), porém, com a terceira versão são poucos os estudos, sendo a maioria constituída por amostras heterogêneas, ou seja, indivíduos com diagnóstico de CCL, DA, DV, DFT, DCL e D-DP (Li et al., 2019), DA, DV, demência degenerativa com componente vascular, D-DP, DCL, DFT e demência alcoólica (Matias-Guiu et al., 2015). Um estudo avaliou uma amostra heterogênea, constituída por pacientes com demência leve (DA e DFT), DP e controles saudáveis, utilizando a ACE, que incluiu indivíduos com DPI (Chade et al., 2008).

As análises de correlação entre os escores totais e aspectos demográficos e clínicos, mostraram que houve associação entre o escore total da ACE-III e escolaridade, sendo a idade inversamente associada aos escores do total da ACE-III e a todos os seus domínios cognitivos, ou seja, o desempenho da pontuação diminuiu quando a idade aumentou. Por outro lado, o desempenho dos escores cognitivos foi associado positivamente aos anos de escolaridade. Isso se observou em outros estudos com DPI, sinalizando a influência da escolaridade no desempenho nos escores totais e por domínios cognitivos da $A C E$, tanto na versão revisada, quanto na terceira versão No estudo de Rocha et al. (2014) participaram 70 pacientes com DPI, pareados por idade e escolaridade a controles, com média de idade de $64,1(9,3)$ anos, tempo médio de doença de $7,7(5,3)$ anos e escolaridade de 5,9 anos. E no estudo de Matías-Guiu et al. (2016), a amostra foi heterogênea em relação ao diagnóstico clínico, constituída não apenas por indivíduos com DPI.

Em relação à associação com questionários de avaliação funcional, QAF e IQCODE, mesmo com a estratificação do grupo clínico por comprometimento cognitivo, o grupo clínico apresentou correlação significante e de magnitude 
média entre a variável ACE-III (pontuação total) e a funcionalidade (medida através do questionário QAF). Nas medidas de gravidade da doença (avaliada pela escala $\mathrm{H} \& Y$ ), escolaridade, idade, humor, ansiedade e questionário do informante sobre queixas cognitivas; houve correlação significante com escore total da ACE-III, principalmente com a escala H\&Y, escolaridade, QAF e IQCODE; porém com magnitude fraca, exceto entre a ACE-III e o QAF.

Os coeficientes de correlação obtidos entre os domínios da ACE-III e testes neuropsicológicos convencionais, específicos para aqueles domínios cognitivos e amplamente utilizados nesta condição neurológica, sugerem que a ACE-III é um instrumento de screening útil para detecção de alterações cognitivas.

O domínio atenção/orientação foi correlacionado, moderadamente, com o teste de controle mental $(r=0,570)$. O domínio da memória foi correlacionado moderadamente com a FCR-evocação imediata $(r=0,531)$, RAVLT, total A $(r=$ $0,550)$ e FAS $(r=0,522)$. Essa correlação confirma o achado de Hsieh et al., (2013) que observaram uma forte correlação entre o domínio da memória e o Teste de Aprendizagem Verbal Auditiva de Rey $(r=0,59)$, porém em indivíduos com DA e DFT. O domínio de fluência verbal foi moderadamente correlacionado com FAS $(r=0,668)$ e fortemente com FVS $(r=0,834)$. O domínio visuoespacial apresentou correlação significante com a FCR-cópia $(r=0,654)$.

Cabe referir que o domínio da linguagem, obteve correlação moderada apenas com a FCR-cópia $(r=0,501)$, porém neste estudo não incluímos testes específicos para avaliação da linguagem, exceto fluência verbal fonêmica (FAS) e semântica (animais). Este aspecto pode ter interferido nas análises 
supracitadas. Os estudos prévios, porém, mostraram poucos déficits no domínio da linguagem nesta população (Litvan et al., 2003; Biundo et al., 2013).

Desta forma, a ACE-III avaliou adequadamente as funções atenção, memória, fluência verbal e aspectos visuoespaciais.

Em relação à baixa sensibilidade e especificidade em detectar CCL-DP (58,65\% e $60 \%$, respectivamente), pode ser justificado pela diferença entre o tamanho amostral deste subgrupo $(n=104)$ com o grupo controle $(n=60)$; o que não ocorreu para diferenciar controles saudáveis de D-DP $(n=22)$, apresentando melhor acurácia diagnóstica (81,82\% e 75\%, respectivamente).

Além de serem analisadas as propriedades diagnósticas, através do escore total da ACE-III, também verificamos por domínios cognitivos, sendo um ponto forte deste estudo; bem como a utilização de bateria de testes neuropsicológicos como medida de comparação.

A maior parte destes estudos teve como método de comparação, baterias breves (MEEM, MoCA ou MDRS). As baterias abrangentes, através de testes neuropsicológicos, foram utilizadas naqueles estudos que tiveram como objetivo discriminar CCL-DP de D-DP (Komadina et al., 2011; Berankova et al., 2015). Nestes estudos, também foram utilizados os testes spam de dígitos, fluência verbal fonêmica, fluência verbal semântica, trail making test; sendo identificadas notas de corte $=<93$ pontos para detectar CCL-DP, com média de idade de 65 anos, escolaridade de 13 anos e tempo de evolução da doença de 5,9 anos (Komadina et al., 2011). No estudo de Berankova e colaboradores a nota de corte de 82,5 pontos foi capaz de detectar D-DP e 88,5 pontos CCL-DP (Berankova et al., 2015). A média de idade foi de 65-70 anos, escolaridade de 
12-13 anos e duração da doença de 7 anos. Cabe referir que o critério para diagnosticar CCL-DP foi diferente do estudo de Komadina et al., (2011), não sendo possível a comparação entre os mesmos. O critério para CCL-DP, no estudo vigente, foi similar ao de Komadina e colaboradores, ou seja, 1,5 desvios-padrão abaixo da média para considerar um prejuízo em domínio cognitivo.

Para uma melhor comparação, na Tabela 39 constam os valores de corte do estudo vigente, sensibilidade e especificidade e áreas sob a curva ROC, em relação aos estudos anteriores.

Tabela 39 - Comparação entre as propriedades diagnósticas do estudo vigente e anteriores, realizados na DP (ACE e ACE-R)

\begin{tabular}{|c|c|c|c|c|}
\hline Estudos & $\begin{array}{l}\text { Pontos de } \\
\text { Corte }\end{array}$ & Sensibilidade & Especificidade & $\begin{array}{c}\text { Área Curva } \\
\text { ROC }\end{array}$ \\
\hline \multirow{2}{*}{ Estudo Vigente } & CCL-DP=85 & $58,65 \%$ & $60,00 \%$ & 0,64 \\
\hline & $\mathrm{D}-\mathrm{DP}=81$ & $81,82 \%$ & $75,00 \%$ & 0,88 \\
\hline Reyes et al., 2009 & \multirow{3}{*}{$\begin{array}{l}\text { D-DP=83 } \\
\text { CCL-DP=93 (>12 anos } \\
\text { de escolaridade) } \\
\text { CCL-DP=85 ( }<12 \text { anos } \\
\text { de escolaridade) }\end{array}$} & $92 \%$ & $91 \%$ & 0,97 \\
\hline Komadina et al., 2011 & & $49 \%$ & $67 \%$ & 0,57 \\
\hline & & $44 \%$ & $100 \%$ & 0,75 \\
\hline Berankova et al., 2015 & $\begin{array}{l}\text { CCL-DP=88,5 } \\
D-D P=82,5\end{array}$ & $\begin{array}{l}68 \% \\
70 \%\end{array}$ & $\begin{array}{l}91 \% \\
73 \%\end{array}$ & $\begin{array}{l}0,78 \\
0,78\end{array}$ \\
\hline
\end{tabular}

A terceira versão (ACE-III) foi apenas realizada na população de DPI por Lucza e colaboradores, o qual teve como objetivo comparar a sensibilidade e a especificidade das diferentes versões da ACE disponíveis em húngaro (ACE-I, ACE-III e M-ACE) (Lucza et al., 2018), para detectar as desordens neurocognitivas maiores e menores, de acordo com os critérios do DSM-5. A ACE-III e sua versão abreviada (M-ACE) tiveram sensibilidade para detectar estas desordens na DPI. Para os indivíduos com faixas de escolaridade de 0-8 
e 9-12 anos, a ACE-III teve as melhores capacidades de discriminação entre D-DP e CCL-DP (pontuações de corte: 83,5 e 85,5 pontos, respectivamente), enquanto O M-ACE foi melhor para indivíduos com escolaridade $>12$ anos (nota de corte: 25,5 pontos). A ACE-III teve a melhor precisão diagnóstica em todos os níveis de escolaridade (notas de corte: $70,5,77,5$ e 78,5 pontos para indivíduos com nível de escolaridade 0-8, 9-12 e > 12 anos, respectivamente). Este estudo, portanto, demonstrou que a ACE-III e sua versão abreviada apresentaram as melhores habilidades de triagem para detecção de CCL-DP e D-DP. Na Tabela 40, comparamos o estudo atual em relação ao de Lucza et al., (2018). 


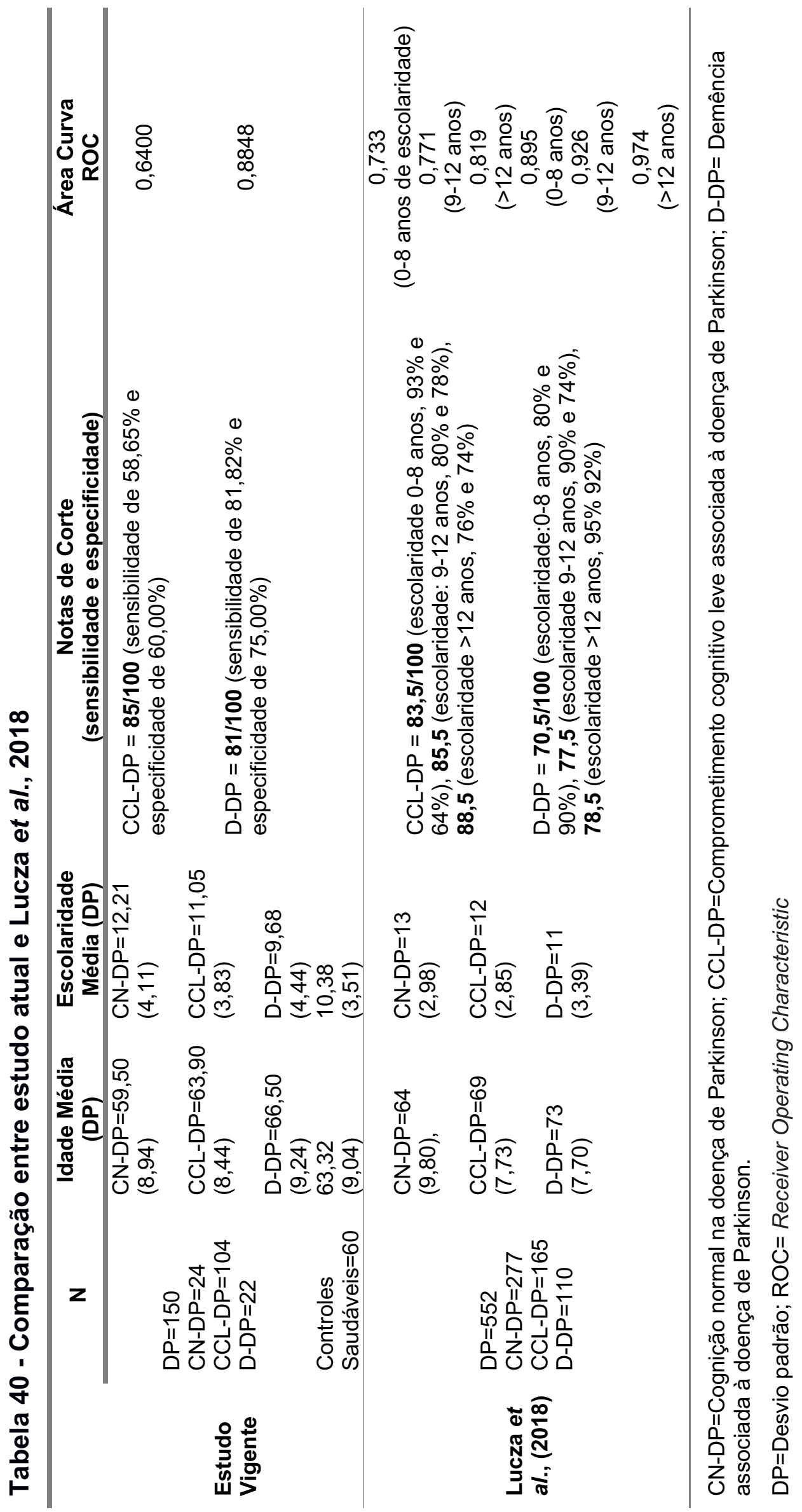


Os resultados mostraram, portanto, que a $\mathrm{ACE}$-III é uma ferramenta útil que pode ser utilizada no diagnóstico de CCL-DP e D-DP, além de apresentar propriedade diagnóstica para diferenciar condições neurológicas (Matias-Guiu et al., 2015), sendo superior ao MEEM e MoCA para detectar CCL-DP (88/89, sensibilidade de 0,75 e especificidade de 0,89, AUC=0,88). Para CCL obteve nota de corte de 28/29 no MEEM (sensibilidade de 0,64 e especificidade de 0,63, $A \cup C=0,72$ ), MoCA 24/25 (sensibilidade de 0,67 e especificidade de 0,77, AUC = 0,76). Para detectar demência, a nota de corte no MEEM foi de 28/29 (sensibilidade de 0,68 e especificidade de 0,59, AUC =0,68) e MoCA 24/25 (sensibilidade de 0,77 e especificidade de 0,76, AUC =0,81) (Li et al., 2019). Neste estudo, demonstrou esta propriedade diagnóstica, para detectar CCL e demência associada à doença de Parkinson, tendo correlação significante com os testes neuropsicológicos padronizados para esta população.

Uma das propriedades desejáveis de uma ferramenta de avaliação cognitiva é a sensibilidade aos prejuízos cognitivos. A inclusão de "verdadeiros positivos" e a exclusão de "verdadeiros negativos" pode acelerar o processo diagnóstico através da identificação de casos para testes adicionais. No entanto, como uma avaliação mais aprofundada ou abrangente requer mais tempo e esforço, também é preciso observar a especificidade. Assim, as pontuações de corte sugeridas para a ACE-III foram baseadas no equilíbrio dessa razão (sensibilidade/especificidade).

Estudos anteriores, então, mostraram que, na doença de Parkinson, as notas de corte entre $78,5-83 / 100$ pontos foram as mais sensíveis para os casos de demência ou de comprometimento cognitivo maior em indíduos com 
escolaridade acima de 12 anos. Outros, com amostras constituídas por outras condições neurológicas, entretanto, obtiveram a nota de corte entre 65/66 pontos, tendo uma média de escolaridade mais baixa nestes estudos (MatiasGuiu et al., 2015; 2017).

Cabe referir que os estudos supracitados, utilizaram como método de comparação baterias de rastreio cognitivo ou breves, como MEEM, MoCA e MADRS, sendo poucos os estudos com inclusão de baterias neuropsicológicas abrangentes.

A nossas notas de corte, portanto, foram inferiores aos estudos com a ACE (Reyes et al., 2009) e ACE-R (Berankova et al., 2015). Neste foi utilizado o instrumento pra distinguir os subtipos cognitivos na DP (CN-DP, CCL-DP, D-DP=69), sendo identificada a nota de corte de 88,5 como capaz de diferenciar CN-DP de CCL-DP (com 0,68 de sensibilidade e 0,91 de especificidade) e 82,5 pontos (com 0,70 de sensibilidade e 0,73 de especificidade) para diferenciar entre CCL-DP de D-DP, tendo AUC de 0,78 $(95 \% \mathrm{Cl}$ 0,63-0,93). Este resultado foi similar ao estudo de prévio de McColgan et al., (2012), onde os autores utilizaram o mesmo critério diagnóstico para CCL-DP e demonstraram sensibilidade de 0,69 e especificidade de 0,84 com o mesmo escore de corte na ACE-R, bem como ao de Biundo et al., (2013) com uma nota de corte inferior de 80 pontos, porém superior aos estudos com a ACE-R no Brasil (Rocha et al., 2014; Sobreira et al., 2015).

Desta forma, os estudos foram diferentes, ao vigente, em relação à escolaridade, tendo o atual maior média. A idade e anos de evolução da doença foram similares, com diferença mínima. A escolaridade influenciou na pontuação total da ACE-III, independente da estratificação da amostra clínica. 
A nota de corte da ACE-III para a detecção de CCL-DP foi 85/100 pontos, sendo semelhante à nota de corte estabelecida por um estudo de validação anterior, considerando a faixa de escolaridade (Lucza et al., 2018). Essa nota de corte foi inferior aos relatados por outro estudo anterior (Komadina et al., 2011).

Essas diferenças nas notas de corte podem ser atribuídas aos efeitos da idade e anos de escolaridade, amplamente divulgados nas baterias de testes cognitivos (Hsieh et al., 2013; Matias-Guiu et al., 2015; 2017), como quanto às características clínicas da amostra, tais como duração e gravidade da doença. Foram poucos os estudos que mostraram a utilidade diagnóstica da ACE para CCL-DP, além de seus resultados serem contraditórios em função também dos critérios utilizados para este diagnóstico cognitivo (Hoops et al., 2009; Dalrymple-Alford et al., 2010; Komadina et al., 2011; McColgan et al., 2012; Ozdilek e Kenangil, 2014).

Efeitos significativos do sexo, idade e anos de escolaridade no escore total da ACE-R foram demonstrados em estudos anteriores (Mioshi et al., 2006; Carvalho et al., 2010; Kwak et al., 2010). Os resultados do nosso estudo também sugerem os efeitos da escolaridade e sexo no escore total e domínios da ACE-III. Ao interpretar as pontuações da ACE-III, esses fatores devem ser levados em consideração.

Comparando-se as características demográficas da população dos estudos sobre a ACE, ACE-R e ACE-III, em relação ao nosso estudo, com ponto de corte acima de 80 para discriminar demência ou desordem neurocognitiva maior, a idade média foi constituída por indivíduos mais jovens (65 a 70 anos) e média de escolaridade mais alta (acima de 10 anos) (Reyes et 
al.; 2009; Berankova et al., 2015; Lucza et al., 2015; 2018). Características demográficas como idade mais alta e/ou menor escolaridade determinaram ponto de corte abaixo de 70 nos estudos entre controles saudáveis e pacientes com demência (Rocha et al., 2014; Sobreira et al., 2015).

O subgrupo D-DP teve pontuações significantemente mais baixas no escore total da ACE-III e em todos os domínios cognitivos. O grupo CCL-DP teve uma pontuação menor do que o grupo controle na pontuação total e em todos os domínios cognitivos, porém sem diferença estatisticamente significante quanto aos domínios atenção/orientação, fluência, linguagem e visuoespacial. Em relação aos subgrupos CN-DP e CCL-DP apenas não houve diferença estatisticamente significante quanto ao domínio atenção/orientação. Por outro lado, não houve diferença entre os subgrupos CN-DP e CCL-DP. Este resultado sugere a maior sensibilidade da bateria para detectar pacientes com comprometimento cognitivo, ressaltando que estes subgrupos foram equivalentes quanto aos aspectos demográficos (idade e escolaridade) e clínicos (duração da doença).

A estratificação da amostra clínica por faixas de idade (40-59, 60-69 anos e maior e igual a 70 anos), e escolaridade (4-9 anos, 10-12 anos e maior e igual a 13 anos), evidenciou que 0 subgrupo >= 13 anos de escolaridade apresentou maior média no escore total e em todos os índices, evidenciando a interferência da escolaridade nas medidas cognitivas desta bateria.

Os resultados da ACE-III foram significantemente diferentes entre os três subgrupos clínicos. O subgrupo CCL-DP obteve resultados mais baixos em comparação ao subgrupo controles saudáveis e CN-DP, no escore total e 
domínios cognitivos. O subgrupo D-DP, entretanto, obteve pontuações inferiores aos demais subgrupos.

O domínio atenção/orientação, da ACE-R, foi capaz de predizer D-DP no estudo de Berankova et al., (2015) e no estudo de Komadina et al., (2011) o domínio de fluência verbal da ACE-R pareceu ser efetivo, além do escore total para detectar CCL-DP.

Através da área sob a curca ROC (AUC) observamos que os melhores testes que diferenciaram entre controles e CCL-DP foram atenção/orientação e memória. Este domínio foi similar ao estudo anterior, com a versão revisada da ACE-III, de Berankova et al., (2015). No entanto, não foi similar quanto ao domínio fluência verbal, que no estudo mostrou uma alta sensibilidade e especificidade para difenrenciar CCL-DP e controles saudáveis (Komadina et al., 2011). No estudo vigente o domínio fluência verbal, além do domínio memória, demonstrou uma boa propriedade diagnóstica para diferenciar CCL-DP de D-DP.

Desta forma, este estudo apresentou pontuações de corte de domínios ACE-III cognitivos individuais para prever CCL-DP e D-DP. Também demonstramos, pela primeira vez, que subtotais de domínios da ACE-III, em participantes com DPI, se correlacionaram com pontuações de testes relevantes, sensíveis e padronizados para esta condição neurológica; derivados de bateria neuropsicológica abrangente; visto que os estudos anteriores, com a ACE-III, nesta condição neurológica, tendem a utilizar baterias breves.

A ACE-III dura em média de 15 a 30 minutos para sua realização (dependendo da velocidade das respostas do paciente), porém avalia uma 
ampla variedade de habilidades cognitivas, especialmente memória, linguagem e componentes visuoespaciais. Além disso, inclui tarefas para medir a fluência verbal, que é considerada associada à função do lobo frontal.

Em resumo, a ACE-III é uma bateria cognitiva amplamente utilizada, com capacidade para detectar alterações cognitivas precoces/leves. Este instrumento fornece um perfil cognitivo multicomponente, ou seja, não apenas uma pontuação total, mais também escores em cinco domínios cognitivos (atenção/orientação, memória, linguagem, fluência verbal e habilidade visuoespacial), permitindo também uma análise qualitativa do perfil de domínios acometidos.

Apesar do tamanho menor do grupo controle, foi observado que este apresentou desempenho médio superior em todos os índices e pontuação total da ACE-III, quando comparado ao grupo clínico, principalmente, nos indivíduos com CCL-DP e D-DP. Este dado evidenciou o principal comprometimento cognitivo na DPI (Bernadotte e Aarsland, 2015; Jankovic e Tolosa, 2015; Petrelli et al., 2015), a síndrome disexecutiva, ainda mais que neste estudo a maior parte do grupo clínico foi composta por pacientes com CCL-DP.

A idade e, principalmente, a escolaridade influenciaram nos escores totais da ACE-III, devendo ser consideradas como variáveis importantes durante a interpretação das notas de corte, para melhorar a precisão do desempenho cognitivo e realização do diagnóstico.

As correlações mostraram que pacientes com menor escolaridade e maior gravidade da doença, foram os que apresentaram pior desempenho cognitivo; assim como aqueles com maior pontuação em escalas de avaliação afetiva e 
dados funcionais. Efeitos significativos destes fatores foram evidenciados na pontuação total da ACE-III (Mioshi et al., 2006; Carvalho et al., 2010; Kwak et al., 2010).

Este estudo, portanto, sugere que a ACE-III foi capaz de detectar a presença de comprometimento cognitivo em pacientes com DPI. Esta bateria pode, portanto, ser usada como uma ferramenta rápida e eficiente na avaliação de déficits cognitivos associados à DP, ou seja, pode ser amplamente útil na prática clínica, ainda mais em contextos hospitalares, no qual se faz necessária a aplicação de instrumentos sensíveis e breves. Há necessidade de combinação com instrumentos neuropsicológicos, principalmente, naqueles indivíduos com maior escolaridade e/ou déficits mais leves/iniciais, a fim de evitar falsos negativos. Apesar do tempo de aplicação da ACE-III ser mais longo do que outras baterias, como o MoCA, ela possui melhor acurácia nesta população para o diagnóstico de prejuízo cognitivo.

A heterogeneidade das características clínicas e demográficas, (idade e escolaridade) entre os pacientes, interferiu nos resultados das comparações entre este estudo com os anteriores, nesta população. Além disso, os diferentes instrumentos utilizados para avaliar a cognição, comportamento e atividades de vida diária, entre os estudos, limitaram a possibilidade de comparação e generalização dos resultados.

O estudo vigente teve como pontos fortes: (1) Tamanho e homogeneidade da amostra, constituída apenas por indivíduos com o diagnóstico de doença de Parkinson idiopática. (2) Utilização de instrumentos neuropsicológicos abrangentes e padronizados para esta condição clínica, como método de comparação. (3) Pareamento do grupo clínico com o grupo 
controle saudável quanto à idade, escolaridade e sexo, contribuiu nos resultados deste estudo, fortalecendo as análises estatísticas. (4) Apesar da diferença entre os grupos em função de questões afetivas (depressão e ansiedade), a média de pontuação nas escalas foi indicativa de depressão e ansiedade de intensidade mínima-leve, principalmente mínima.

A formação de subgrupos (estratificação do grupo clínico) pode ter diminuído o nível de evidência das análises dos dados. Este, porém, foi o primeiro estudo, com objetivo de verificar a acurácia diagnóstica desta bateria breve, ACE-III, e bateria neuropsicológica, apenas em pacientes com DPI, a fim de auxiliar no diagnóstico de CCL-DP e D-DP.

Há algumas limitações no presente estudo. (1) Os participantes foram recrutados em um hospital de reabilitação, portanto, o resultado está sujeito ao viés de referência e pode não ser aplicável a populações comunitárias. (2) O tamanho da amostra dos subgrupos foi relativamente pequeno, principalmente em relação aos subgrupos CN-DP e D-DP. Este aspecto pode ter diminuído a magnitude de diferença entre o grupo clínico e o controle. (3) Aspectos não motores (fadiga, insônia, bradipsiquismo, por exemplo), podem ter influenciado nos resultados cognitivos e funcionais, pois não foram utilizadas escalas para tal finalidade, porém quando observada qualquer interferência destes aspectos a avaliação foi interrompida e/ou continuada em momento posterior. (4) 0 grupo controle, apesar de sua participação ocorrer após uma triagem cognitiva e funcional, apresentou desempenho inferior nos testes neuropsicológicos, podendo ser justificado por outros fatores, como cansaço e sobrecarga física e 
emocional, pois parte deles eram acompanhantes de pacientes acompanhados no Hospital.

A detecção em fase inicial do comprometimento cognitivo, através de instrumentos breves e sensíveis para esta população, facilita a possibilidade de intervenção precoce, com opções terapêuticas (não farmacológicas e/ou farmacológicas), orientações ao paciente e sua família, ajustes no estilo de vida e estratégias psicoeducativas. Este instrumento, além de fornecer uma pontuação total, possibilita a obtenção de dados por domínios cognitivos, auxiliando em uma compreensão mais ampla do potencial e comprometimento cognitivo dos pacientes com DPI, inclusive, auxílio na caracterização do CCL-DP.

Pesquisas futuras, em um cenário comunitário de larga escala, são necessárias para fornecer dados normativos e capacidade discriminatória da ACE-III nas diferentes gravidades de demência e validação com outros testes neuropsicológicos deve ser conduzido. 


\section{CONCLUSÕES}

A acurácia diagnóstica, sensibilidade e especificidade, do Exame Cognitivo de Addenbrooke, terceira versão (ACE-III), como ferramenta de avaliação cognitiva breve em pacientes com diagnóstico de DPI foi demonstrada neste estudo. Esta bateria fornece pontuação total e por domínios cognitivos, o que favorece no diagnóstico e classificação do comprometimento cognitivo nesta população. Apesar de ser uma bateria um pouco mais longa, no tempo de aplicação, do que o MoCA, estudos têm mostrado que a sua acurácia é superior, principalmente, para o diagnóstico de CCL-DP.

É uma ferramenta útil para a detecção de CCL e demência em indivíduos com DPI, sendo evidenciadas notas de corte, com boa sensibilidade e especificidade para detecção destes diagnósticos. As pontuações com melhor capacidade discriminatória foram 85/100 (sensibilidade $=58,65 \%$, especificidade $=60 \%, A \cup C=0,64)$ e $81 / 100$ pontos $($ sensibilidade $=81,82 \%$, especificidade $=75 \%$, AUC $=0,88$ ) para CCL-DP e D-DP, respectivamente.

Comparado com estudos anteriores, estas notas de corte estão similares, principalmente para CCL-DP quando consideradas as faixas de escolaridade. Comparando as notas de corte por faixas de escolaridade, pôde-se observar que o subgrupo maior e igual que 10 anos, apresentou uma pontuação com melhor acurácia para discriminar D-DP de controles saudáveis. Para o diagnóstico de D-DP, a nota de corte do estudo vigente ficou superior ao estudo que utilizou a ACE-III em DPI, porém este não foi um estudo controlado, 
bem como não foi realizada avaliação neuropsicológica abrangente, não sendo possível compará-los por estas diferenças metodológicas. O estudo atual, além de ser controlado por aspectos demográficos, também analisou as notas de corte das pontuações fornecidas pelos domínios cognitivos, possibilitando uma maior capacidade de interpretação dos resultados da ACE-III.

Não existiam estudos que avaliassem a acurácia da ACE-III no diagnóstico de CCL-DP e D-DP, na população brasileira, com uso de notas de corte para a pontuação total e domínios cognitivos, sendo um dos principais benefícios desta pesquisa.

A ACE-III mostrou-se uma boa correlação com testes da bateria neuropsicológica abrangente, principalmente com testes específicos para o domínio cognitivo, fortalecendo ainda mais a propriedade diagnóstica desta bateria.

Em relação aos aspectos clínicos e demográficos, o escore total da ACE-III teve correlação significante com todos os dados, exceto anos de evolução da doença e medida de avaliação da intensidade da ansiedade (BAI). No entanto, a correlação foi significante e de magnitude média com o questionário de atividade funcional (QAF) e em seguida com o instrumento IQCODE e anos de escolaridade.

Desta forma, a ACE-III é uma bateria útil para a prática clínica e hospitalar, para o diagnóstico de CCL e DDP em pacientes com DPI. Este instrumento pode contribuir em medidas de intervenção (farmacológicas e não farmacológicas), acompanhamento longitudinal (reavaliação cognitiva), bem 
como para indicação a tratamentos cirúrgicos (estimulação cerebral profunda) que requerem avaliação eficiente e sensível. 


\section{ANEXOS}

\section{Anexo A - Addenbrooke's Cognitive Examination (ACE)}

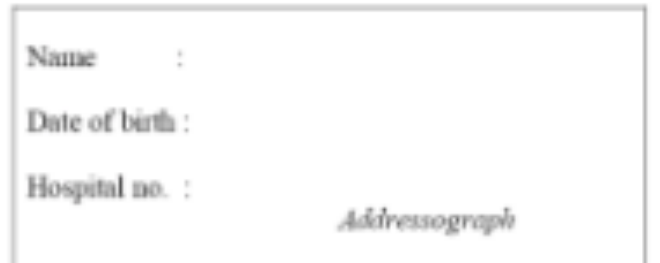

Age at leaving education heliool lowliger ete)

Date of testing

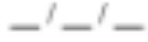

Tester's name

\section{ORIEVTATION}

a) What is the Yeat

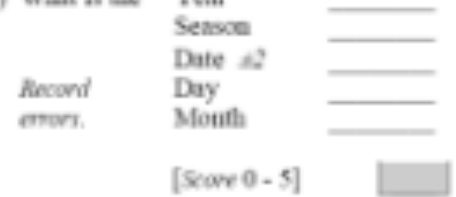

b) Whate ate we

$\begin{array}{ll} & \text { County } \\ & \text { Tous } \\ \text { Reord } & \text { Hospital beilding } \\ \text { erors. } & \text { Floor Allow if aimost comst }\end{array}$

[sove - 5]

\section{REGISTRTION}

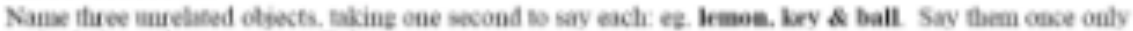

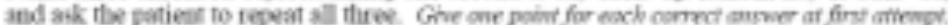

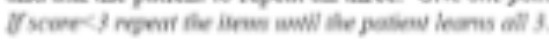

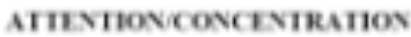

Aak the patient to begie will 100 and sularact 7 , and kerp uhberting 7.

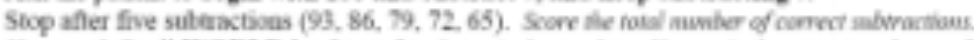

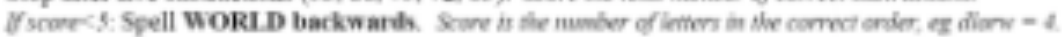

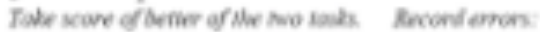

RE.CAL.L. Adk for the umes of the 3 dejocts learned in custion 3.

Ous pohur ber eash anow.

\section{MEMORY}

a) Aaferegrade Mrmary

Read the nanse and abless and ask the potient to repent in cece you huve fanisbed. Regundless of the score

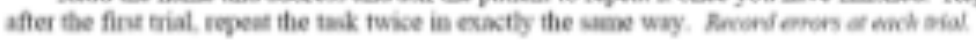

\begin{tabular}{|c|c|c|c|c|c|}
\hline & 1st trial & 2ad & 3rd & 5 min delay & \\
\hline Peter MLuslull & -- & $-\ldots$ & -- & $-\ldots$ & \\
\hline 42 Minket Street & $-\ldots$ & $-\ldots$ & $-\ldots$ & - - - & \\
\hline $\begin{array}{l}\text { Chetrmbond } \\
\text { Fuser }\end{array}$ & - & - & - & - & \\
\hline Estex & $\pi$ & $-n$ & $n$ & -7 & $\begin{array}{l}\text { Thial } 1-3 \quad[0-21] \\
5 \text { min ikles }[0,7]\end{array}$ \\
\hline
\end{tabular}

b) Retrograle Memery: Nime of PS

Rerand

Lat PM!

move.

Oprositice Lesket

us Presider

[0-4] 
VERBAL FLUENCY

a) Letters Ask tbe patient to generate as many words as possible beginning with the letter $P$ in cee mimute; proper nours (people and places etc) are not allowed.

b) Animals In the same way ask the patient to geverate the names of as many animals as possible in one minute, begining with any letter of the alphabet.

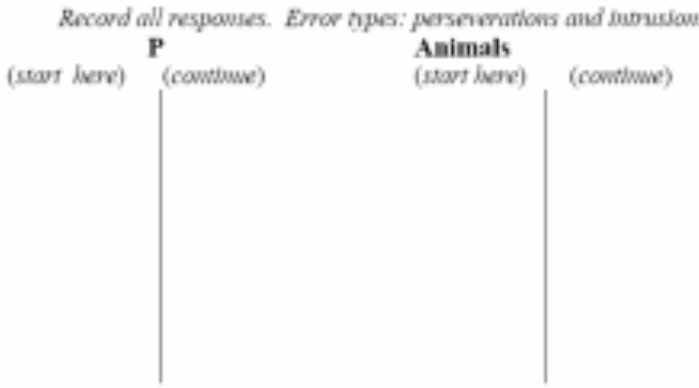

$\mathrm{P}$

P : Toral

Animals : $\quad$ Toca!
No. correct

No. correct

\begin{tabular}{|c|c|c|}
\hline Animal & $P$ & Score \\
\hline$>21$ & $>17$ & 7 \\
\hline $17-21$ & $14-17$ & 6 \\
\hline $14-16$ & $11-13$ & 5 \\
\hline $11-13$ & $8-10$ & 4 \\
\hline $9-10$ & $6-7$ & 3 \\
\hline $7-8$ & $4-5$ & 2 \\
\hline$<7$ & $<4$ & 1 \\
\hline
\end{tabular}

$[0-7]$

\section{LANGUAGE}

a) Spontaneous speech

Describe anty

Do NOT scand

- fluency (plarases $>5$ words)

- paraphasic encors (phonemic or semantic)

- word finding difficulties

b) Naming

Ask the patient to name the following pictures. fiecorf errars.
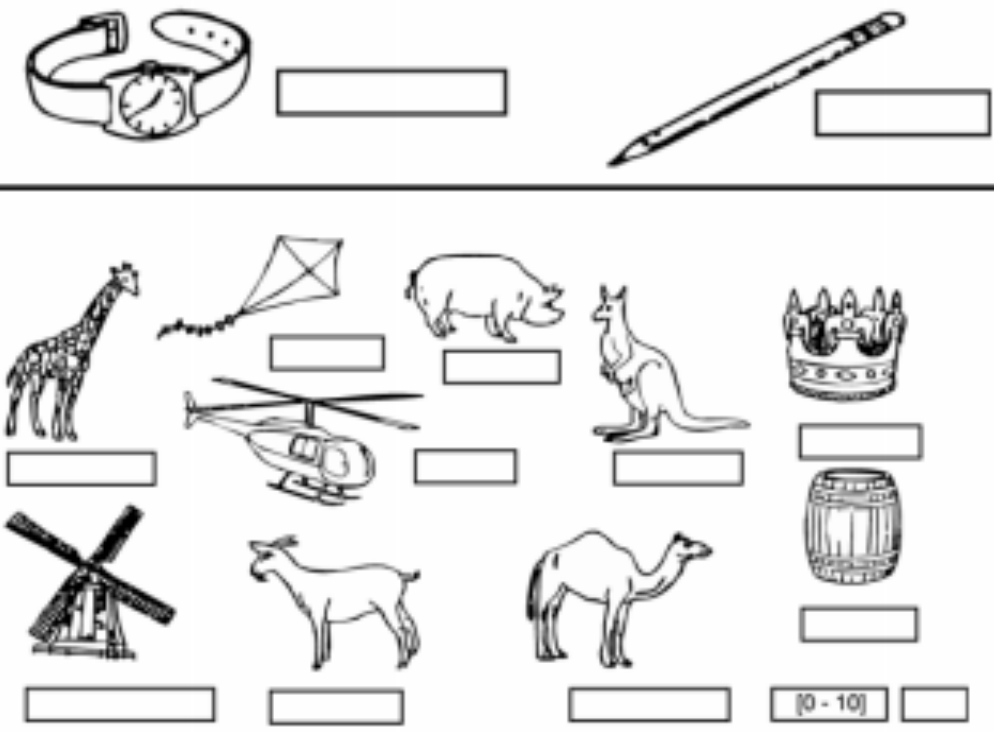
c) Comprehension

single-step commands

- "point to the door"

- "point to the ceiling"

- show written instruction:

$[0-2]$

$[0-1]$

\section{CLOSE YOUR EYES}

3-stage commund

- "Take the paper in your hand. Fold the paper

in balf. Put the paper on the floce."

Scane 1 for ench carnety performed siep

complex granmar

- "point to the ceiling then the door"

- "point to the door after touching the bed/desk' score I for eacti correctily performed coummand.

d) Repetition

single words

- "brown"

- "conversation"

- "articulate"

$[0-3]$

phrases

- "No ifs, ands, or buts."

[0-1]

- "The orchestra played and the audience applauded."

$[0-1]$

- shed

- wipe

- board

- flame

- bridge Score I jo ali mgulur wands carect.

[0-1]

- sew

- pint

- soos

- dough

- beight

Score I tf all inregular wards cancet.

[0 - 1]

Ask the pacient to make up a seutence and write it down in the space below. If stuck, suggest a topic eg. weather, journey to bospital. Score Ifor a correct smbject and werb is a mevaningfinl sesilence.

$[0-1]$

NOW CHECE delaged recall of nawe and address. Recand crrors an page $I$ and enter resalt into box. 
VISUOSPATIAL ABIL.ITIES

a) Overbpping peutagoas Ask the patient to copy this diagram:

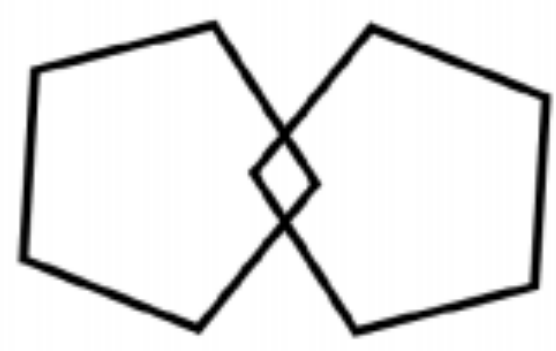

Score I if bow figures hore 5 sides and oweriap

$[0=1]$

b) Wire cube

Ask the patient to copy this drawing:

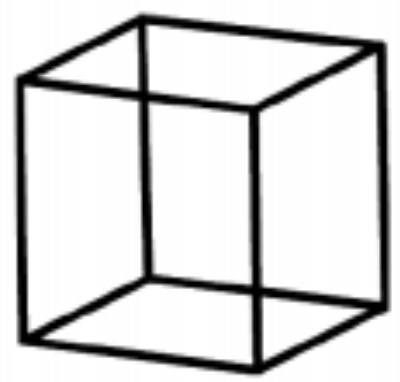

Score I if comect.

$$
[0-1]
$$

c) Clock

Ask the patient to draw a clockface with numbers and the hands at ten past five.

Score I each far convect civcile, numbers and hamts.

[0 - 3]

CHECK: Have you tested and recorded the delayed recall of name and address (page 1)?

\section{OVERALI. SCORES}

MMSE:
TOTAL:

1100

Nornatine vahues based ce 127 ecutrok aged $90-50$.

Mean $93.8+3.5$ Cut off $<58$ gives $93 \%$ semidivity $71 \%$ specificify for denertia

Cut off $<83$ gives $82 \%$ semitiviry $90 \%$ specificity for denewiak

Coesrialn 02000 , John R. Holges 


\section{Anexo B - Exame Cognitivo de Addenbrooke (ACE-R)}

\section{EXAME COGNITIVO DE ADDENBROOKE - VERSÃO REVISADA}

Titule original: Addenbrooke's Cognitive Examination - Revised (ACE-R)

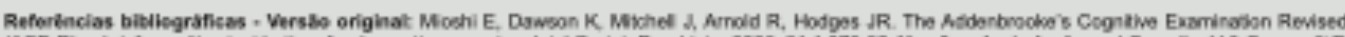

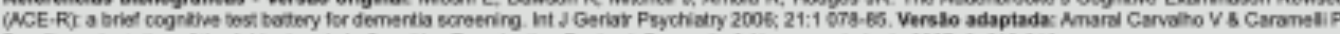

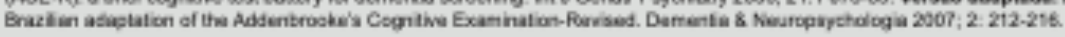

Nome:

Data de nascimento:

Nome do Hospital:

Data da avaliaçås:_.....l..._.

Nome do examinador:

Escolaridade:

Profissão:

Dominâneia manual:

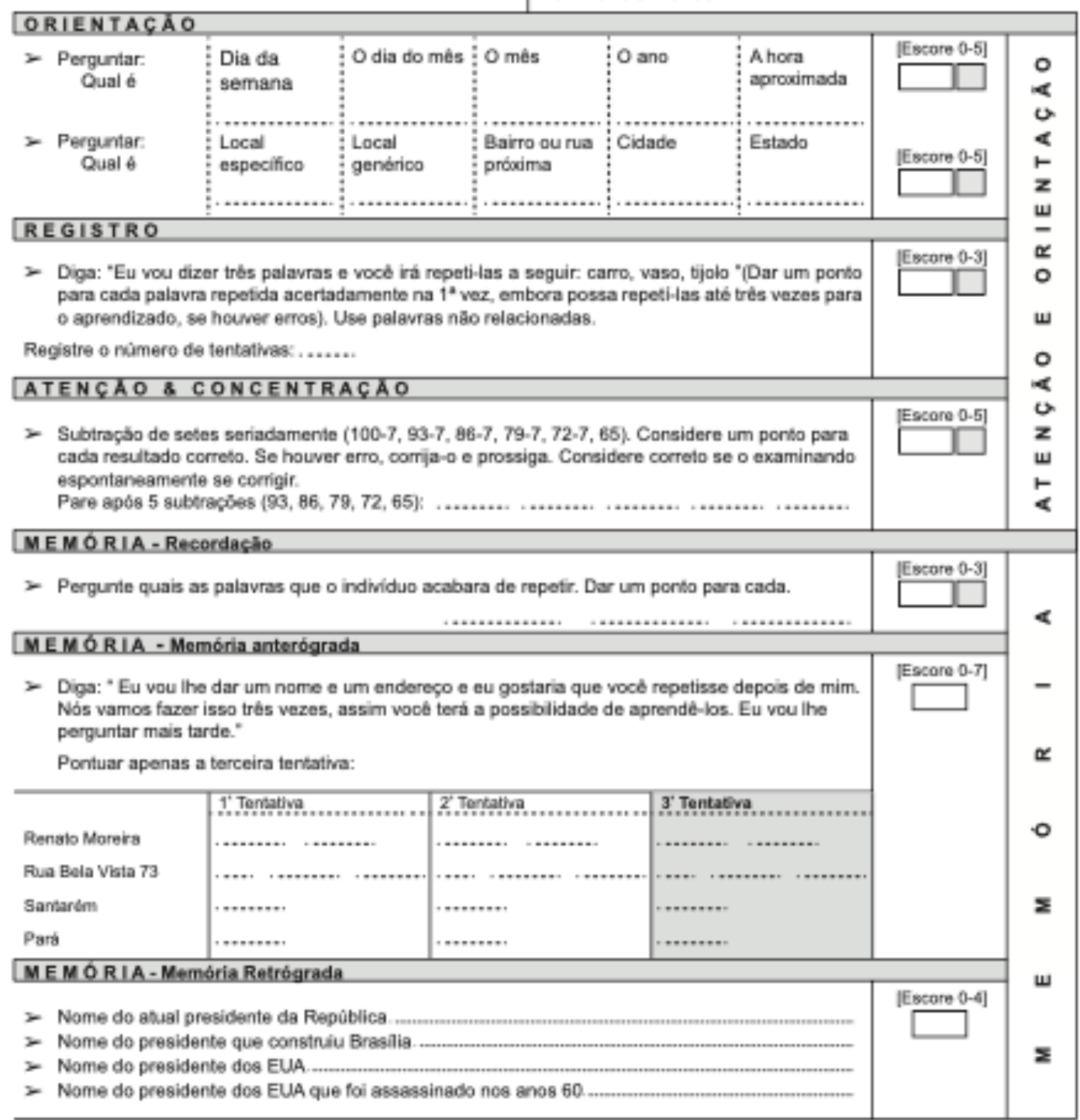




\section{FLUENCIA VERBAL-Lotra "P" Animais}

- Letras

Diga: " Eu vou the dizer uma letra do alfabelo e eu gostaria que wock dissesse o maior

numero de palavras que puder comecande com a letra, mas nāo diga nomes de pessoas

ou lugares. Wocê esta pronto(a) ? Woch tem um minuto e a letra a "P"
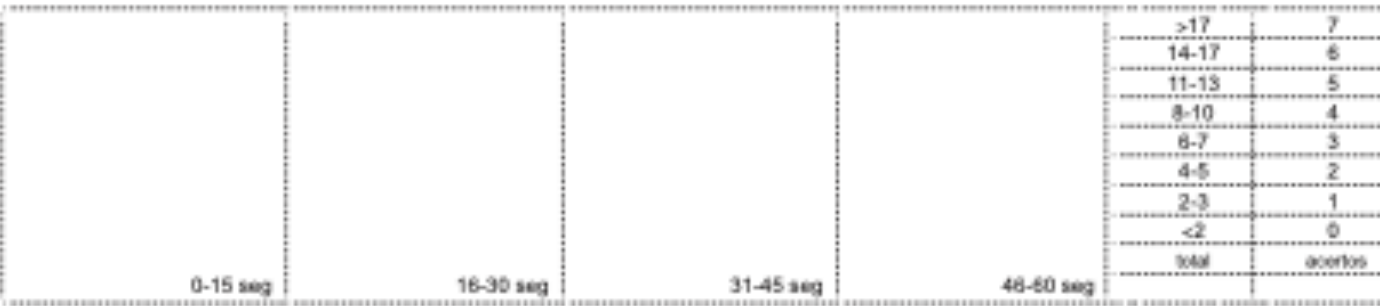

Animais

Diga: "Agura você poderia dizer o maior número de animais que consoguir, começando com qualquer letra?

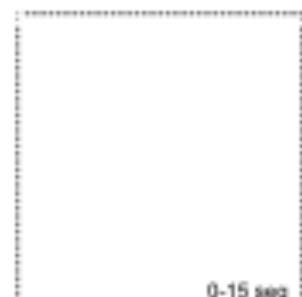

$0.15 \operatorname{seg}$
$16-95 \operatorname{seg}$
$31-45$ ang

46-60 $\operatorname{sen}$
[Escore 0-7]

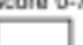

LINGUAGEM - Compreensäo

- Mostrar a instrucbo escrita e pedir ao individux para fazer o que esta sendo mandado (nāe auxilie se ele pedir ajuda ou $8 \theta$ so ler a frase sem reaizar o comande):

Comando :

"Pegue este papel com a mào dirsita, dobre-o ao meio e coloque -o no chão." Dar um panto para cada acerto. Se o individuo pedir ajuda no meio da tarefa năo de dicas.

\section{LINGUAGEM-Escrita}

- Peça ao individuo para escrever uma frase: Se năo compreender o significado, ajude com: alguna frase que fenha começo, meio o fim; aigums coisa que aconfeces hoje:

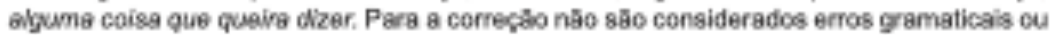
ertegrafices. Dar um panto 
EXAME COCNITIVO DE ADDENBROOKE - VERSAO REVISADA

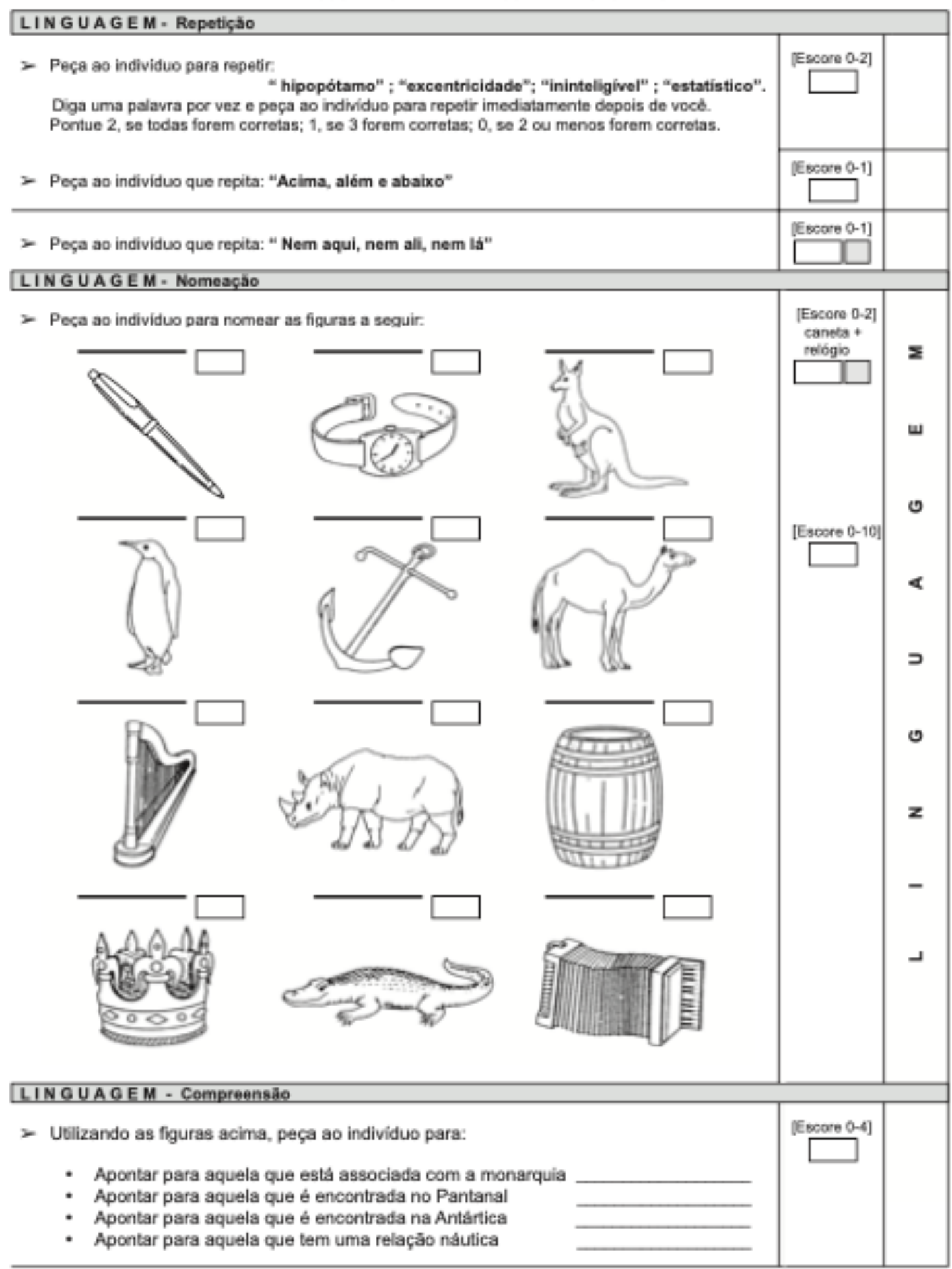


EXAME COCNITIVO DE ADDENBROOKE - VERSAOO REVISADA

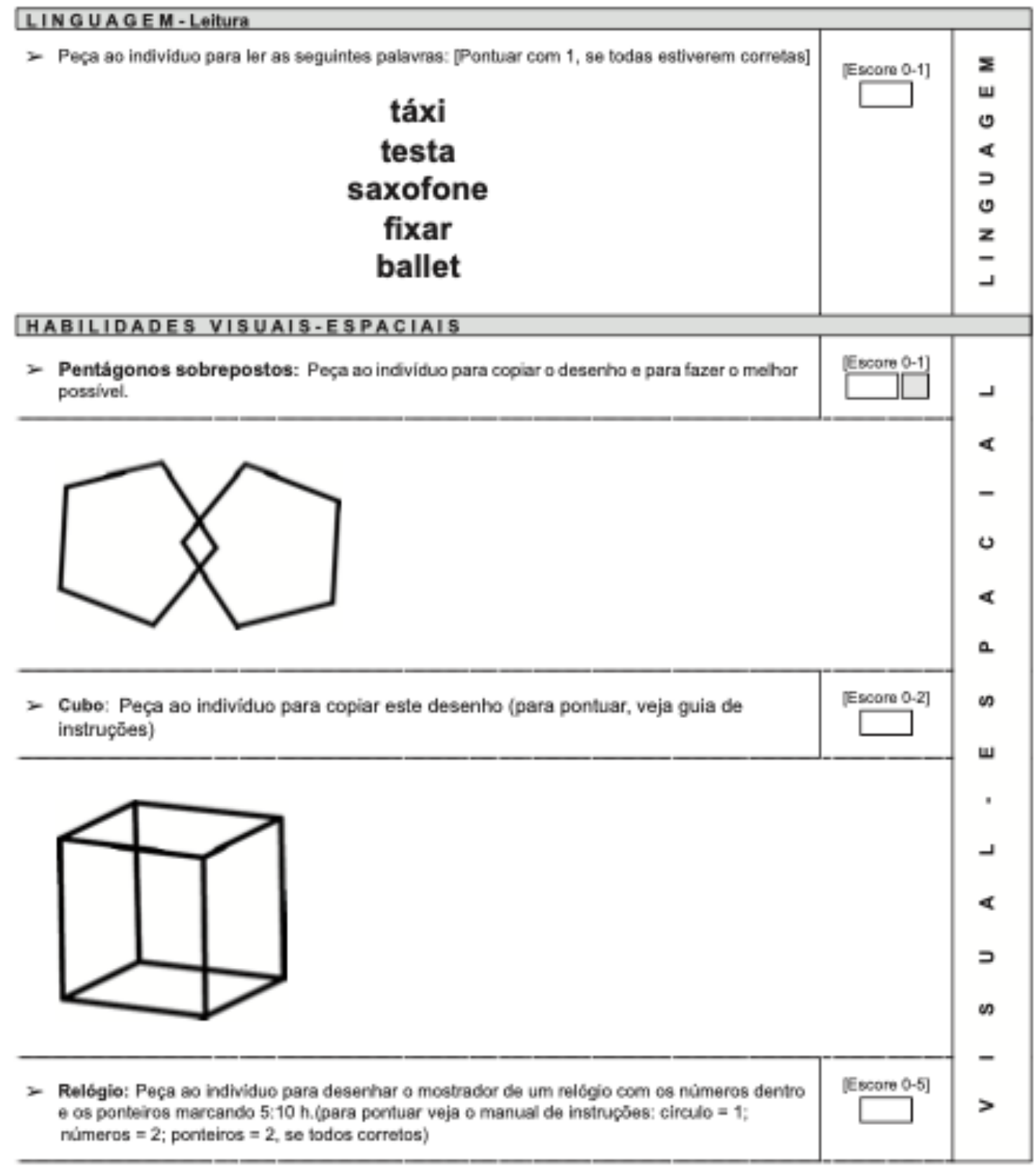


EXAME COGNITIVO DE ADDENBROOKE - VERSAO REVISADA.

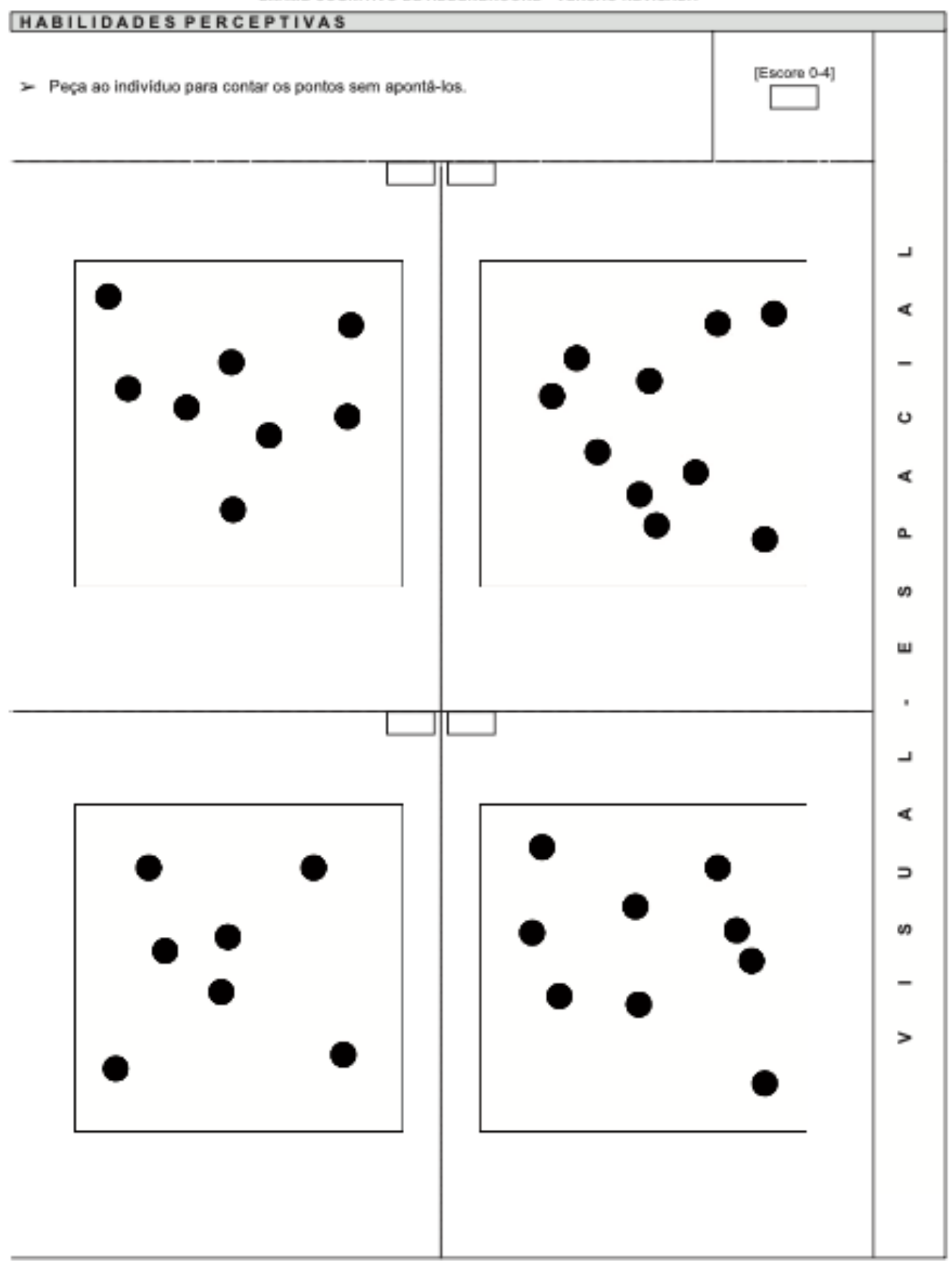


EXAME COONITIVO DE ADDENBROOKE - VERSAO REVISADA

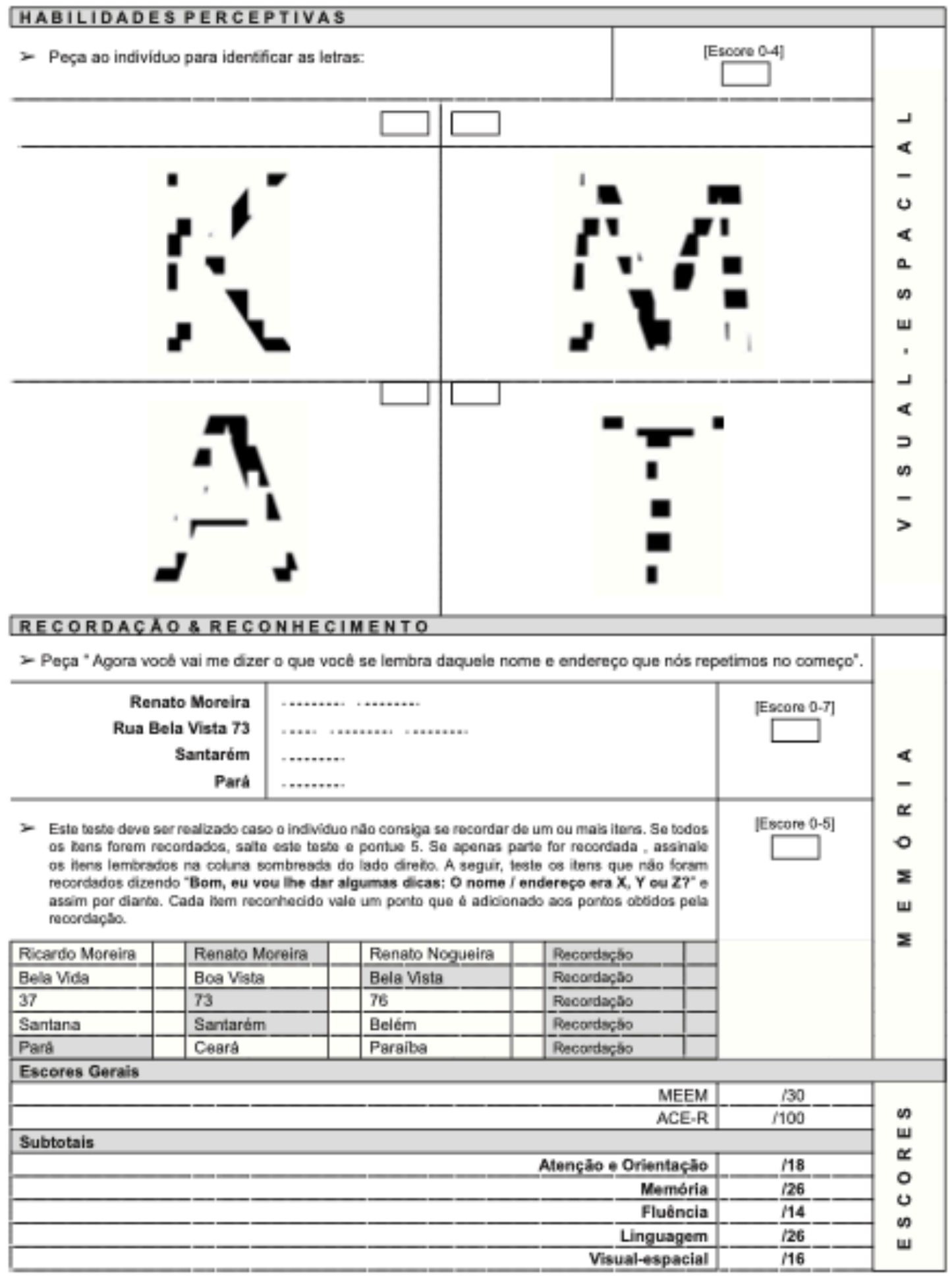




\begin{tabular}{|c|c|c|c|c|c|c|c|}
\hline \multicolumn{8}{|c|}{$\begin{array}{l}\text { ADDENBROOKE'S COGNITIVE EXAMINATION - } \\
\text { ACE-III } \\
\text { UK Version A (2012) }\end{array}$} \\
\hline \multicolumn{2}{|c|}{$\begin{array}{l}\text { Name: } \\
\text { Date of Birth: } \\
\text { Hospital No. or } \\
\text { Address: }\end{array}$} & \multicolumn{4}{|c|}{$\begin{array}{l}\text { Date of testing: } \\
\text { Tester's name: } \\
\text { Age at leaving full-time education: } \\
\text { Occupation: } \\
\text { Handedness: }\end{array}$} & & \\
\hline \multicolumn{8}{|c|}{ A T TENTION } \\
\hline $\begin{array}{c}\text { Ask: } \\
\text { What is } \\
\text { the }\end{array}$ & Day & Date & Month & Year & Season & \multicolumn{2}{|c|}{$\begin{array}{c}\text { Attention } \\
\text { [Score 0-5] }\end{array}$} \\
\hline$>\quad \begin{array}{c}\text { Ask: } \\
\text { Which }\end{array}$ & $\overline{\text { No./Floor }}$ & Street/Hospital & Town & County & Country & \multicolumn{2}{|c|}{$\begin{array}{l}\text { Attention } \\
\text { [Score 0-5] } \\
\end{array}$} \\
\hline \multicolumn{8}{|c|}{ ATTENTION } \\
\hline \multirow{2}{*}{\multicolumn{6}{|c|}{$\begin{array}{l}\text { Tell: "l'm going to give you three words and l'd like you to repeat them after me: } \\
\text { lemon, key and ball." } \\
\begin{array}{c}\text { After subject repeats, say "Try to remember them because l'm going to ask you later". } \\
\text { Score only the first trial (repeat } 3 \text { times if necessary). } \\
\text { Register number of trials: }\end{array}\end{array}$}} & \multicolumn{2}{|c|}{$\begin{array}{l}\text { Attention } \\
\text { [Score 0-3] } \\
\end{array}$} \\
\hline & & & & & & \multicolumn{2}{|c|}{ ATTENTION } \\
\hline \multicolumn{6}{|c|}{$\begin{array}{c}\text { Ask the subject: "Could you take } 7 \text { away from } 100 \text { ? l'd like you to keep taking } 7 \text { away } \\
\text { from each new number until I tell you to stop." } \\
\text { If subject makes a mistake, do not stop them. Let the subject carry on and check } \\
\text { subsequent answers (e.g., 93, 84, 77, 70, 63 - score 4). } \\
\text { S }\end{array}$} & \multicolumn{2}{|c|}{$\begin{array}{l}\text { Attention } \\
\text { [Score 0-5] } \\
\end{array}$} \\
\hline \multicolumn{8}{|c|}{ MEMORY } \\
\hline \multicolumn{6}{|c|}{ > Ask: 'Which 3 words did I ask you to repeat and remember?' } & \multicolumn{2}{|c|}{$\begin{array}{c}\text { Memory } \\
\text { [Score 0-3] }\end{array}$} \\
\hline \multicolumn{6}{|c|}{$\begin{array}{l}\text { Letters } \\
\text { Say: "I'm going to give you a letter of the alphabet and l'd like you to generate as many } \\
\text { words as you can beginning with that letter, but not names of people or places. For } \\
\text { example, if I give you the letter "C", you could give me words like "cat, cry, clock" and so } \\
\text { on. But, you can't give me words like Catherine or Canada. Do you understand? Are you } \\
\text { ready? You have one minute. The letter I want you to use is the letter "P". }\end{array}$} & \multicolumn{2}{|c|}{$\begin{array}{l}\text { Fluency } \\
{[\text { Score } 0-7]} \\
\end{array}$} \\
\hline & & & & & & \begin{tabular}{|c|}
$\geq 18$ \\
$14-17$ \\
$11-13$ \\
$6-10$ \\
$4-5$ \\
$2-3$ \\
$0-1$ \\
total \\
\end{tabular} & $\begin{array}{c}7 \\
6 \\
5 \\
4 \\
3 \\
2 \\
1 \\
0 \\
\text { correc }\end{array}$ \\
\hline
\end{tabular}




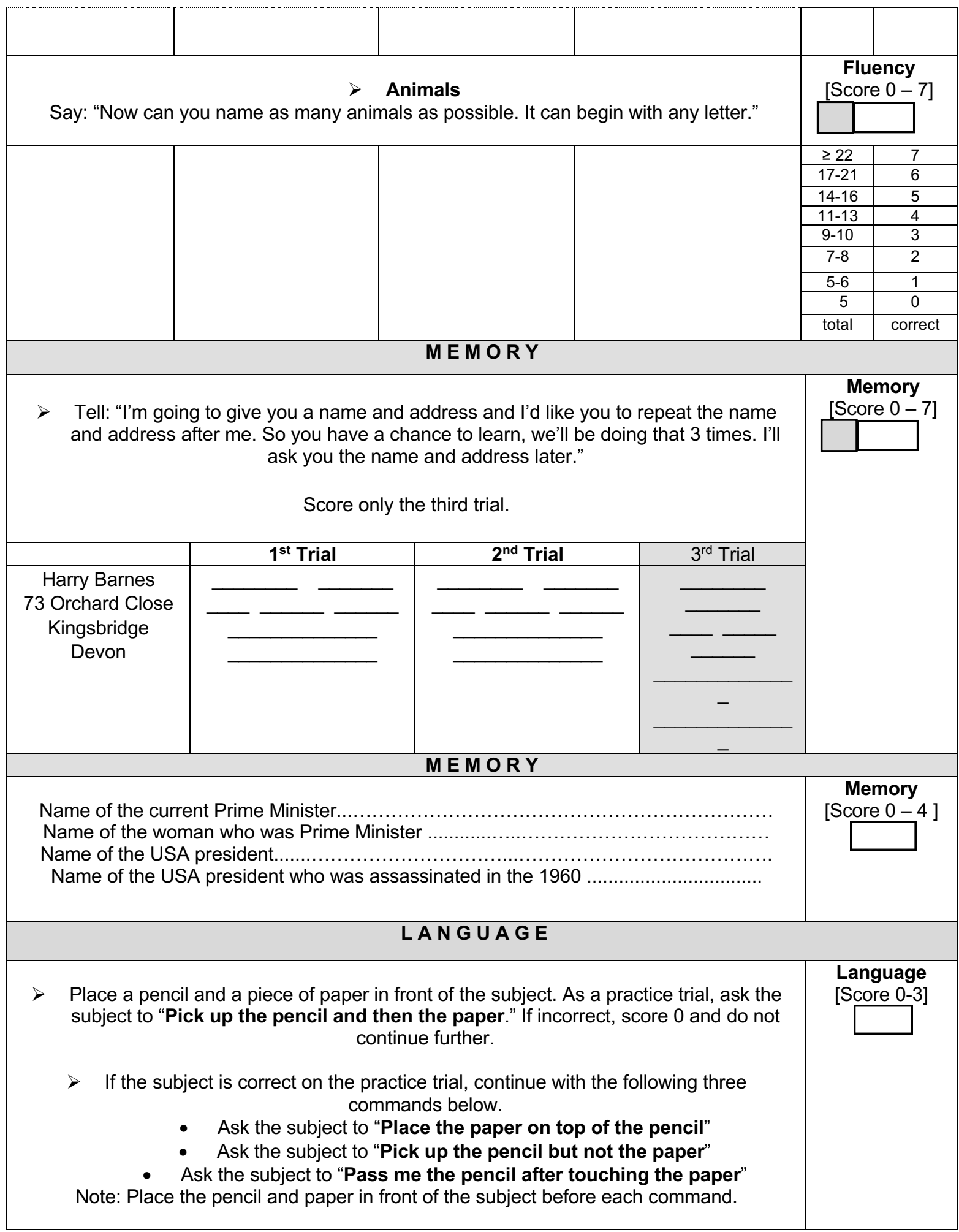




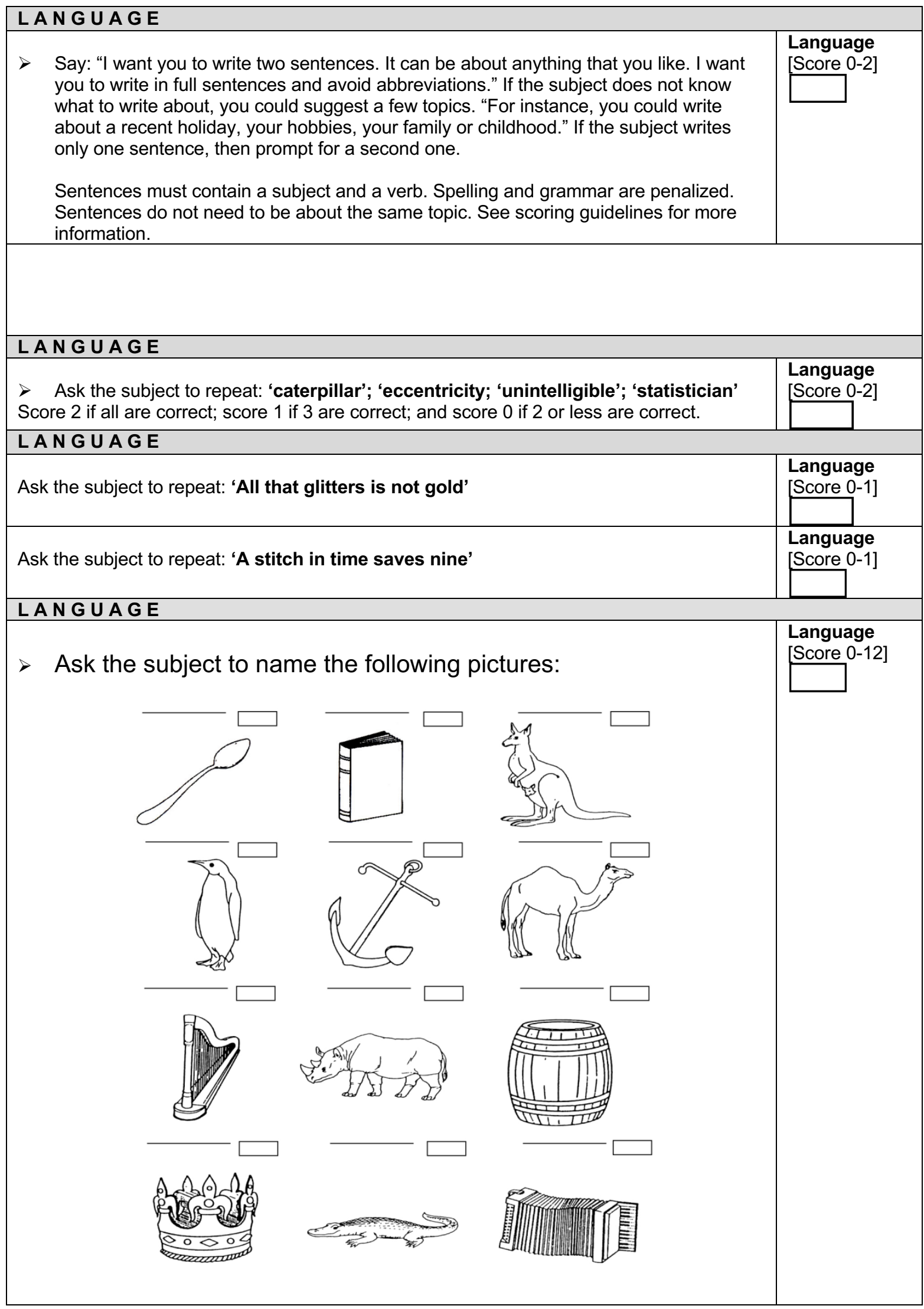




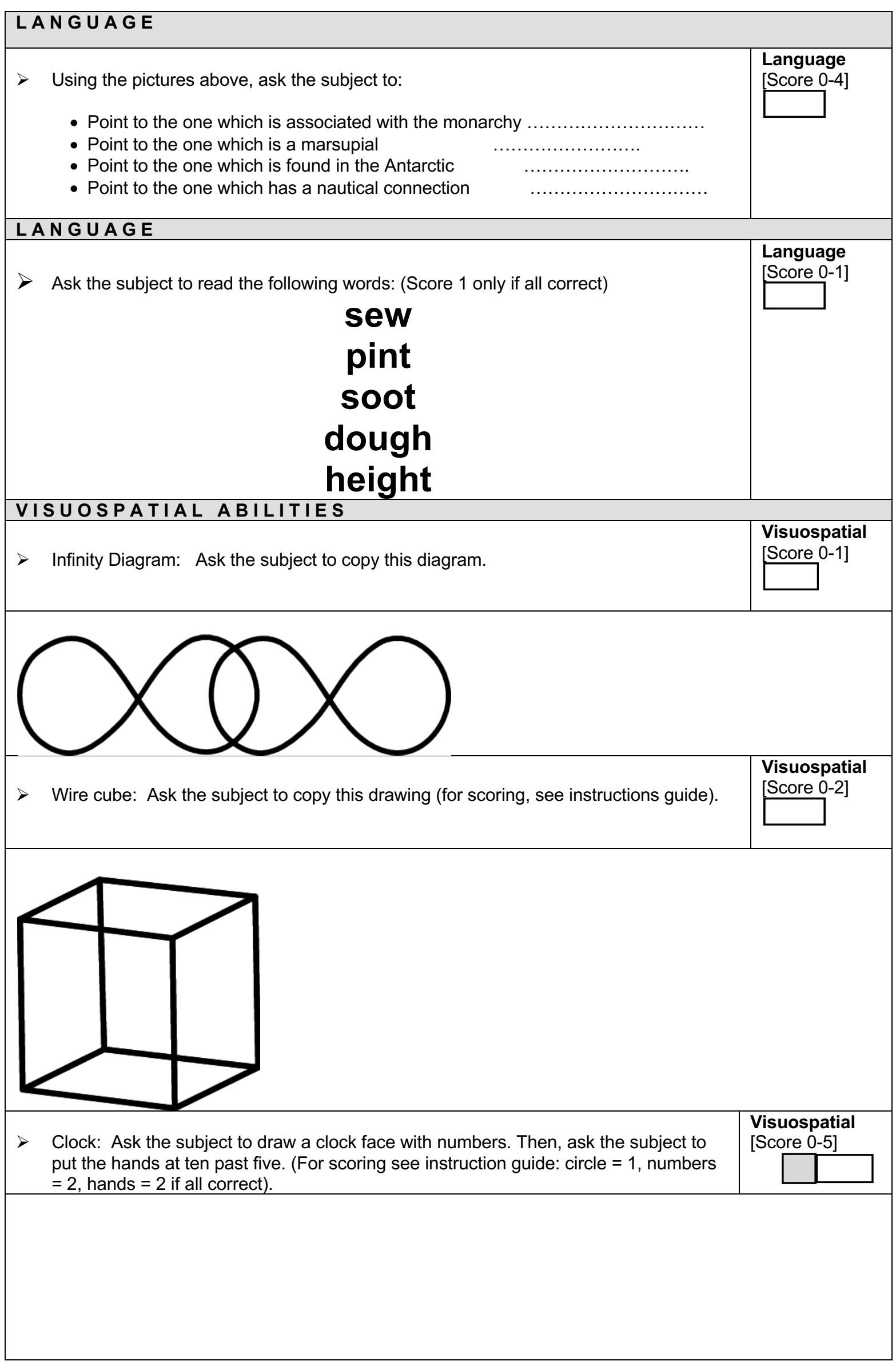




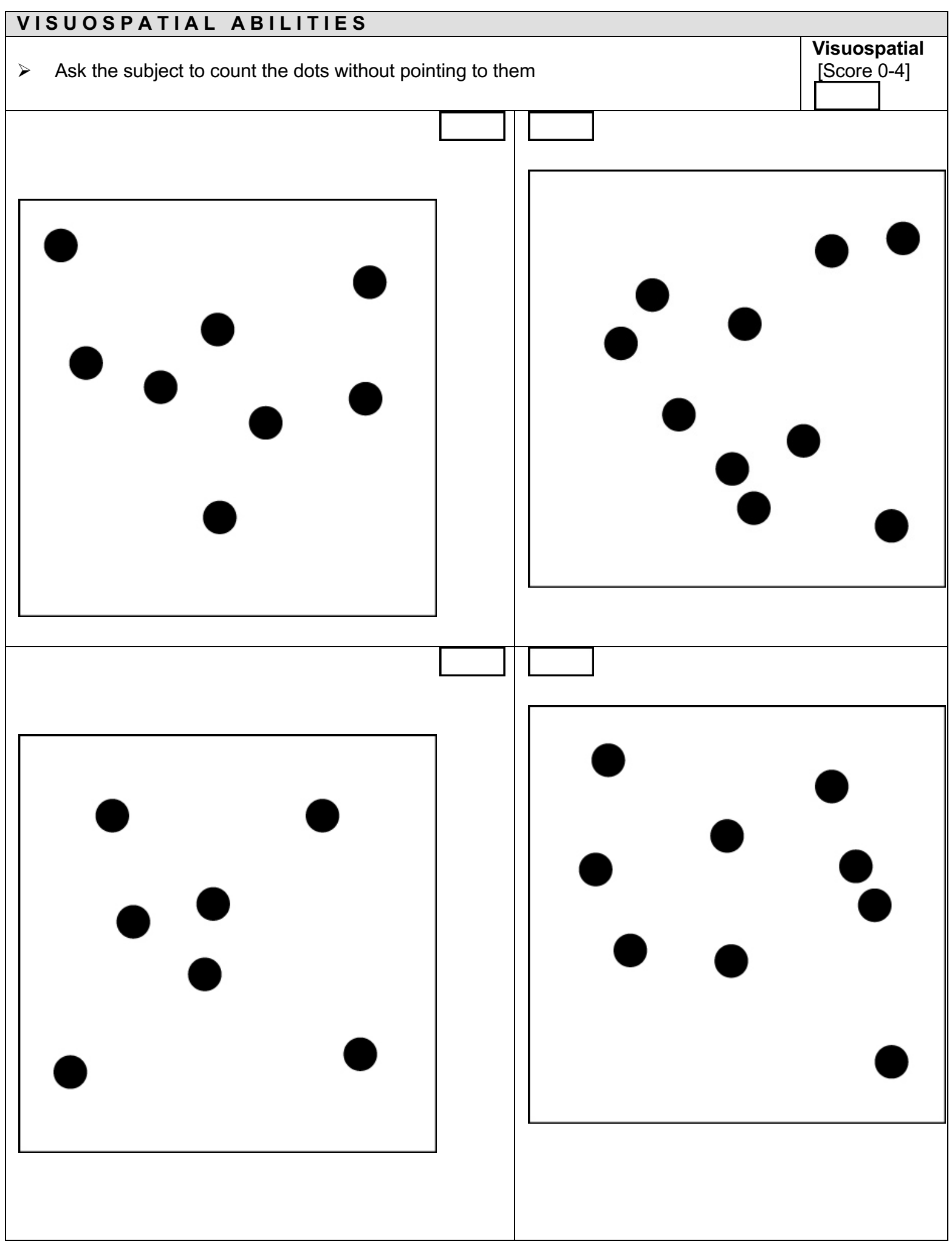




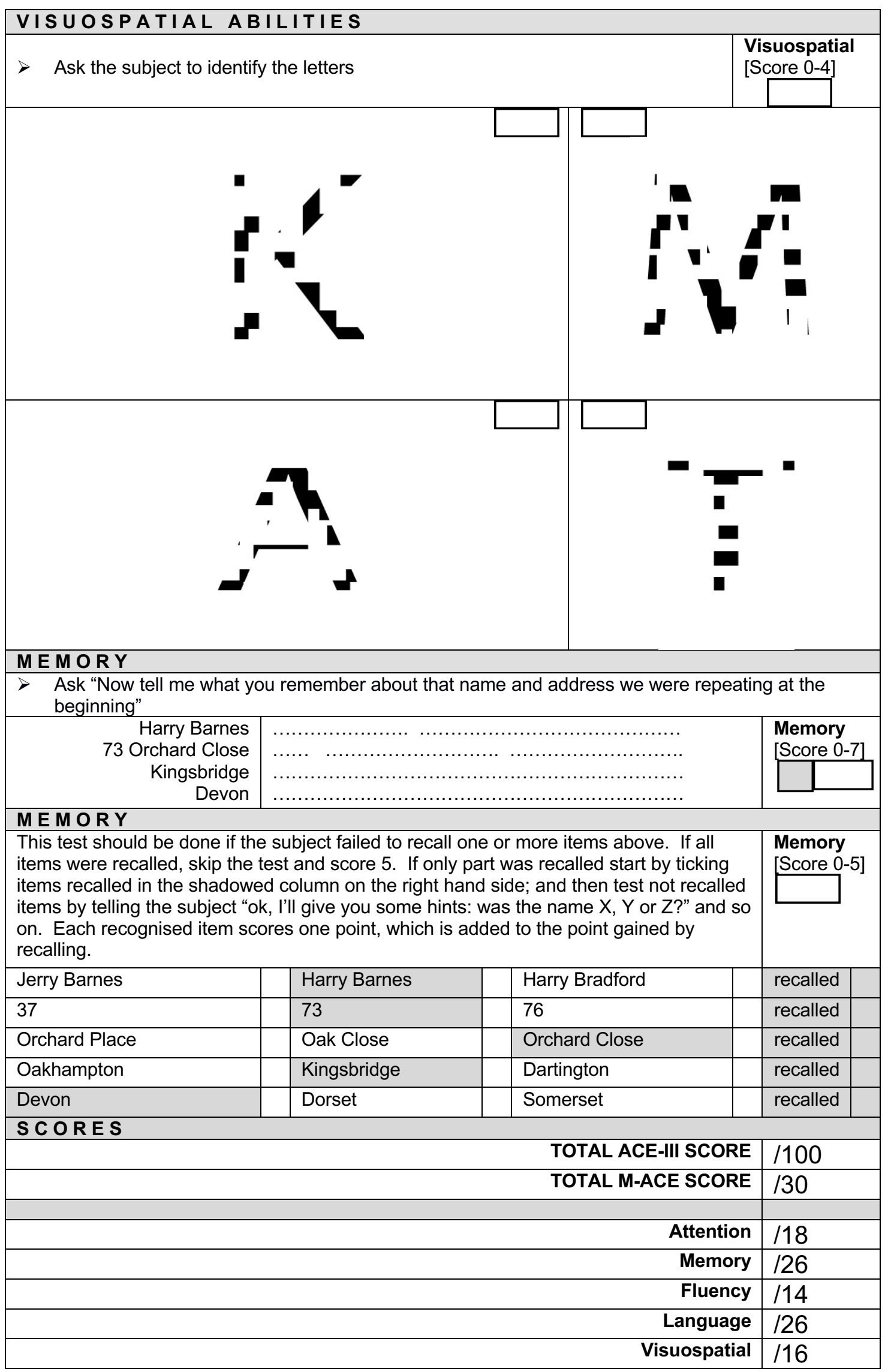




\section{Anexo D - Addenbrooke's Cognitive Examination (ACE-III) (utilizado neste estudo)}

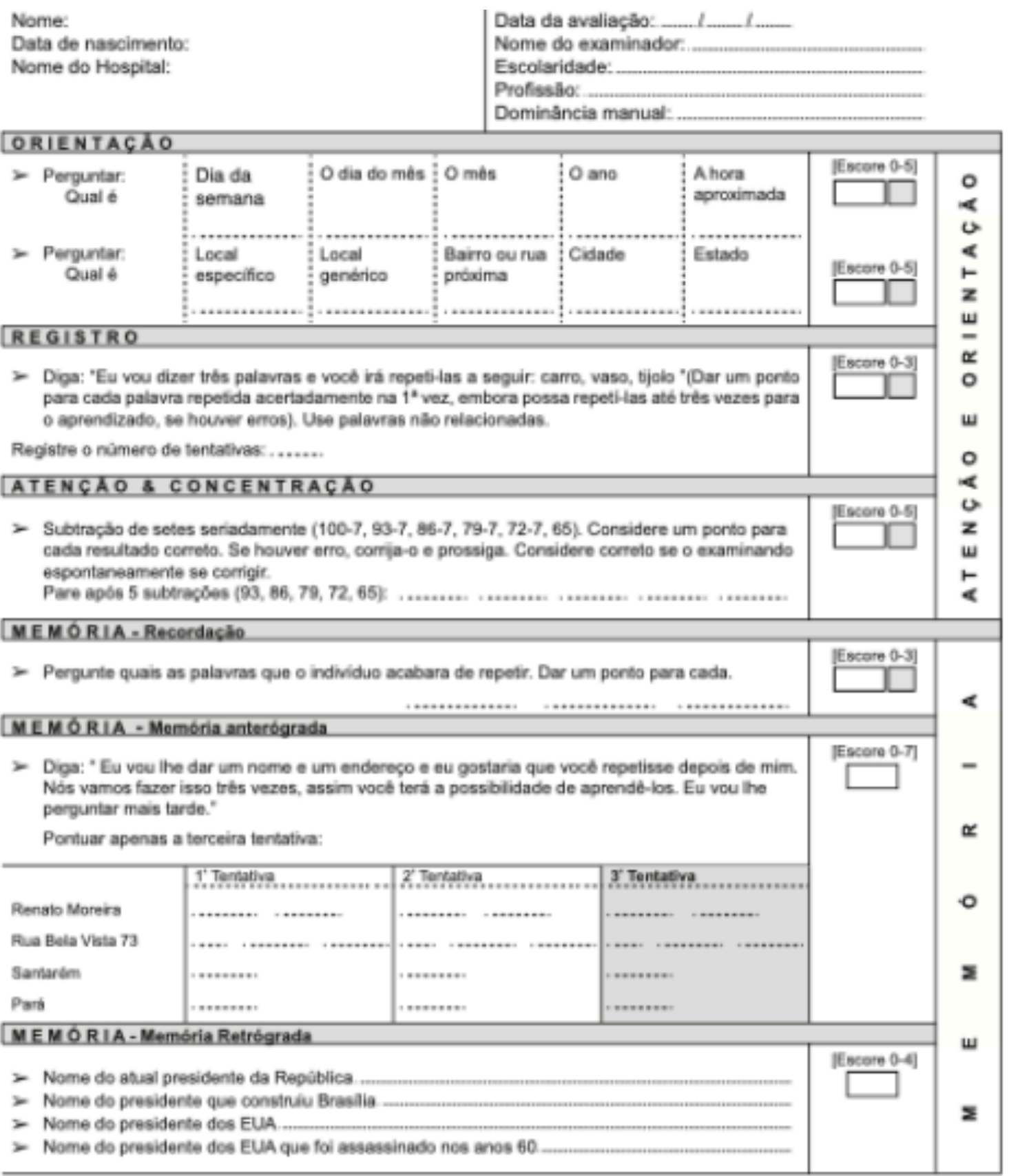




\section{FLUENCIA VERBAL-Lotra "p" Animais}

- Letras

Diga: "Eu vou the dizer uma letra do alfabelo e eu gostaria que vock dissesse o maior número de palayras que puder comecando com a letra. mas näo diga nomes de pessoas ou lugares. Vock esta pronte(a) ? Vock tem um minuto e a letra A "P"
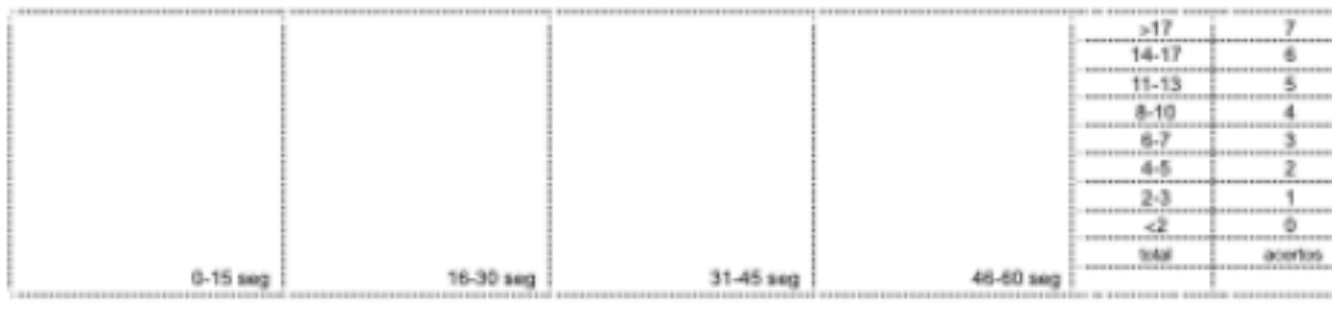

Animais

Diga: "Agora vocé poderia dizer o maior nímero de animais que conseguir, começando

com qualquer letra?

\section{Escare 0.T]}

\begin{tabular}{|c|c|c|c|c|c|}
\hline & & & & $\times 21$ & 7 \\
\hline & & & & 17.21 & 6 \\
\hline & & & & $14-16$ & 5 \\
\hline & & & & 11.13 & 4 \\
\hline & & & & $\theta-10$ & 3 \\
\hline & & & & 7.8 & 2 \\
\hline & & & & 56 & 1 \\
\hline & & & & -5 & 0 \\
\hline & & & & me & wens \\
\hline $0.15 \mathrm{seg}$ & $16-30 \mathrm{seg}$ & $31-45=60$ & $46-60$ sey & & \\
\hline
\end{tabular}

\section{LINGUAGEM - Compreensio}

- Mostrar a hstruclo escrita e pedir ao individuo para fazer o que esta sendo mandado (nß̄o auxilie se ele pecir ajuda ou se so ler a frase sem realizar o comande)

\section{Feche os olhos}

- Comando:

"Pegue este papel com a mbo direita, dobre-o ao meio e celeque -o ne chlio." Dar um ponto para cada acerto. Se o incividuo pecir ajuda no meio da tarefa naso de dicas.

\section{LINGUAGEM-ESCTIA}

> Peça ao individuo para escrever uma frase: Se nào compreender o significado, ajude com: alguma frase que fenha começo, meio o fim; aiguma coisa que acanteceu hgie; algume caisa gta queira dizer. Para a correça nâ sâo considerados erros gramaticais cu

[Escore 0-1] ortografices. Dar um ponte 

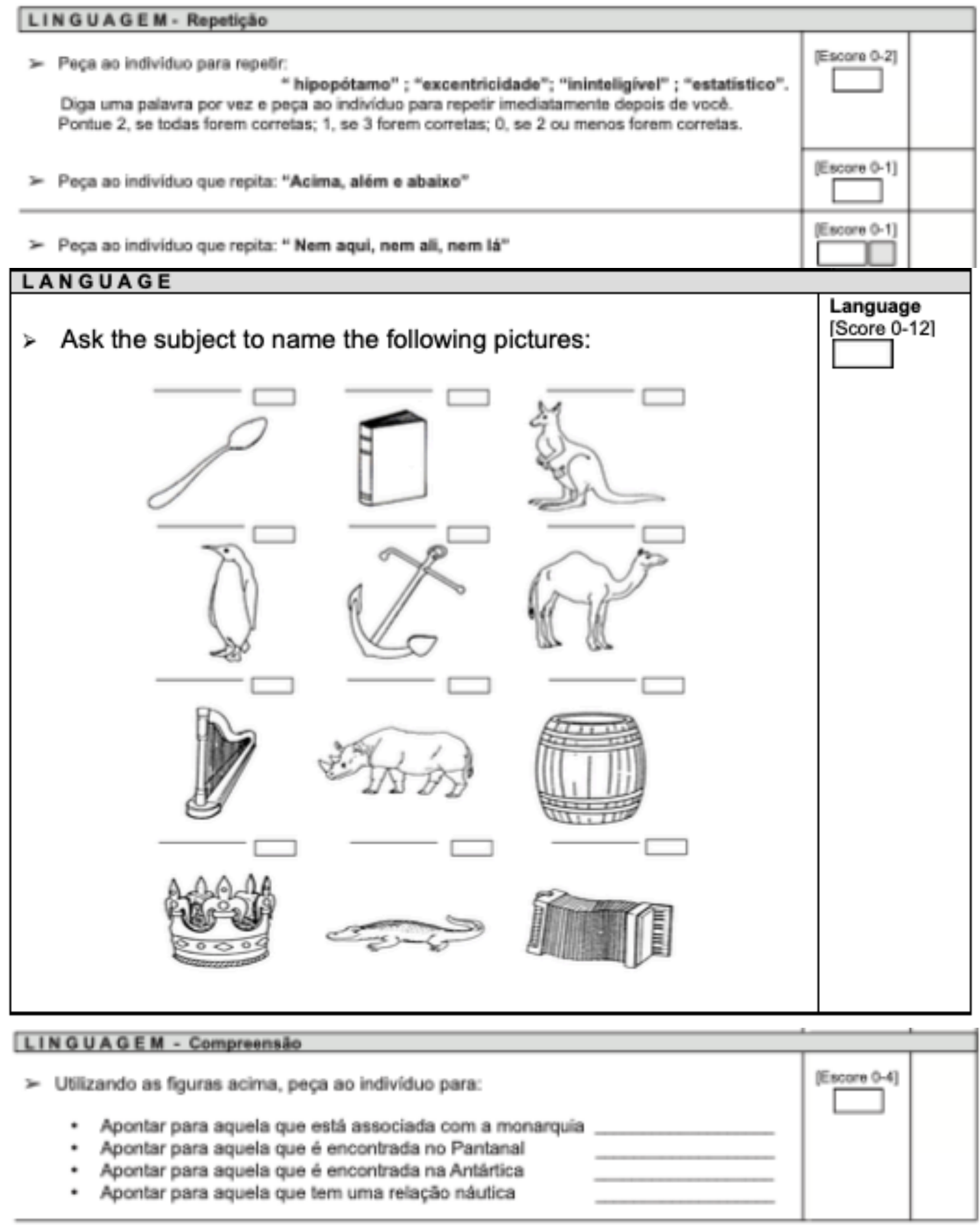


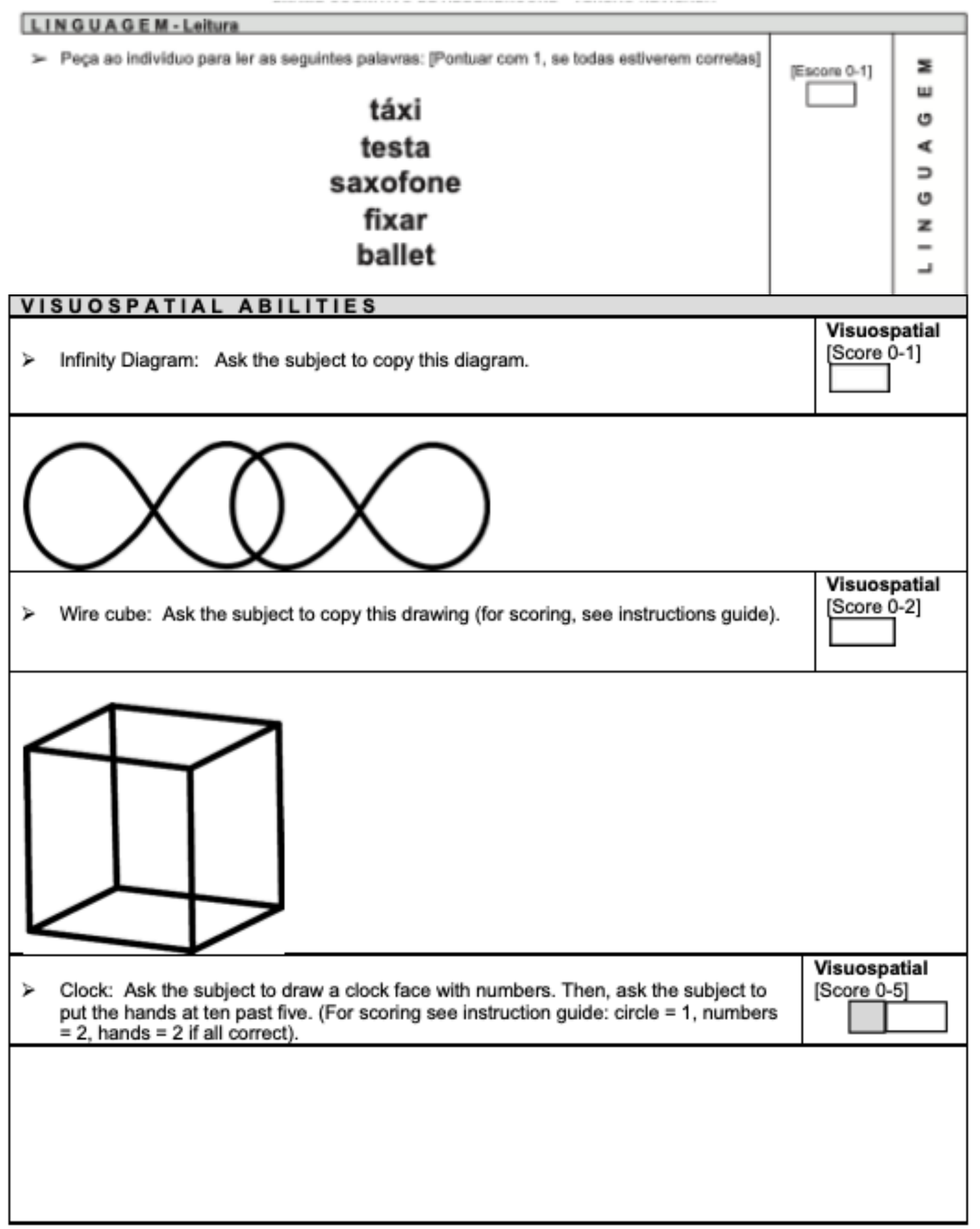




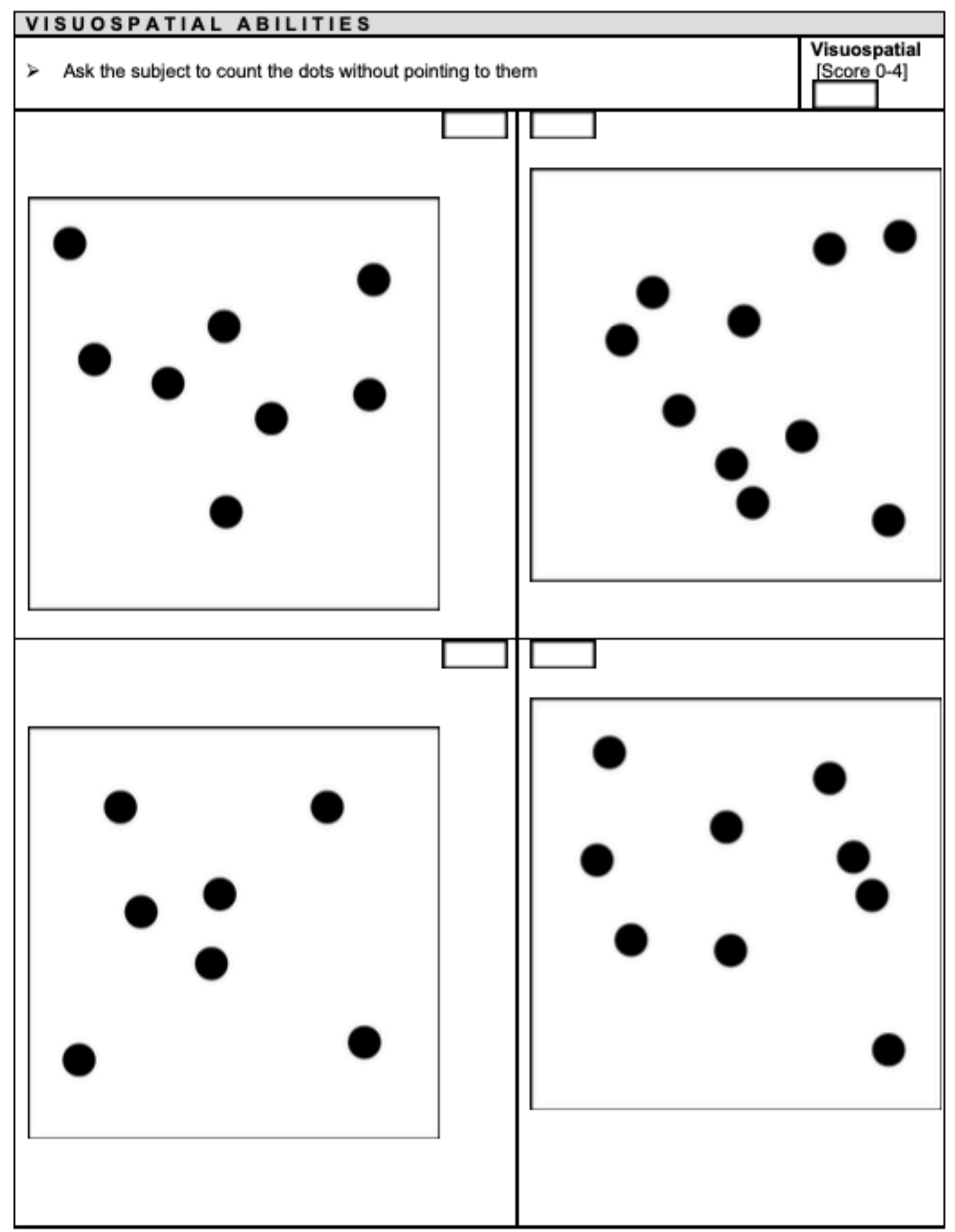




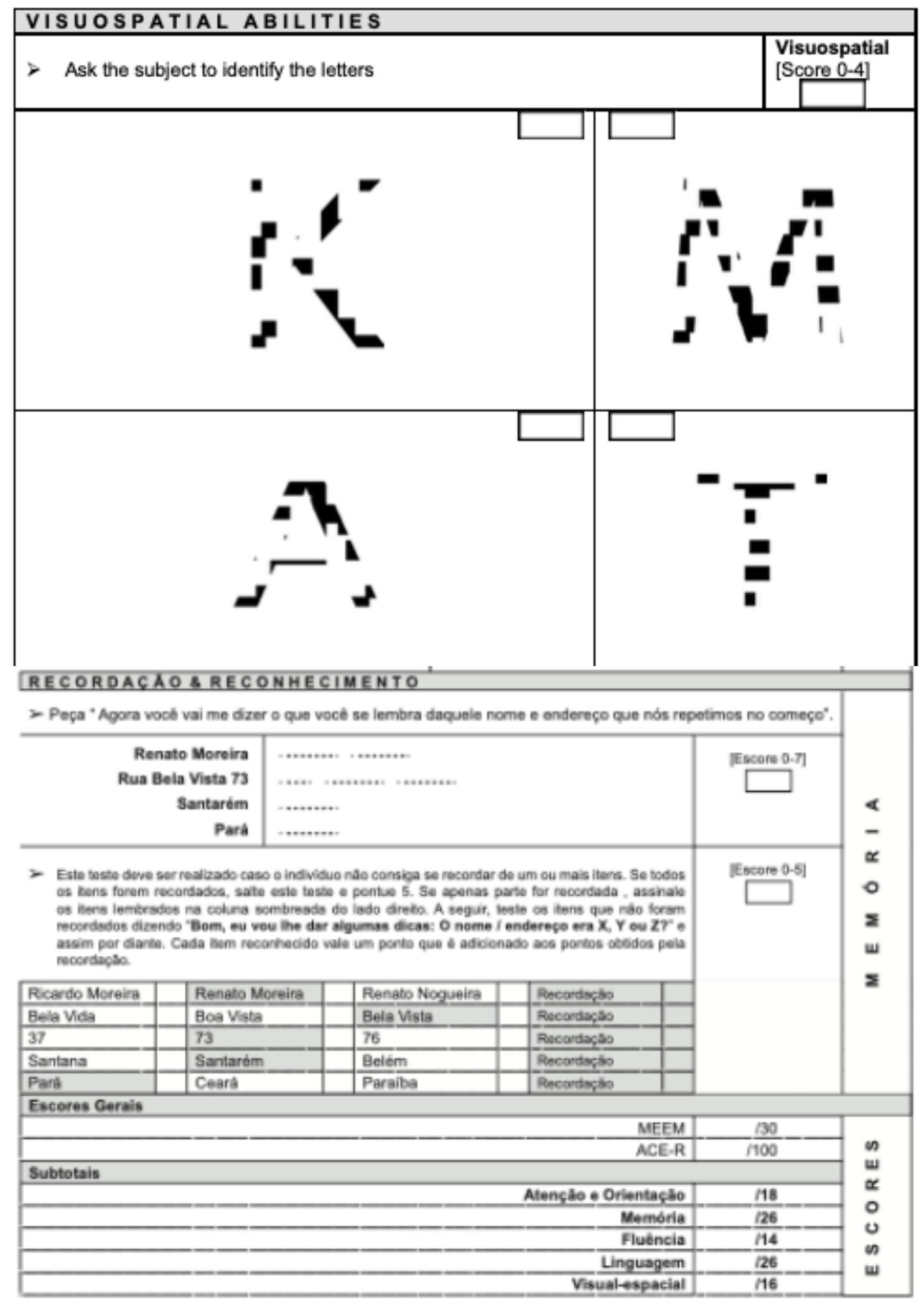




\section{Anexo E - Inventário Beck de Depressão - BDI}

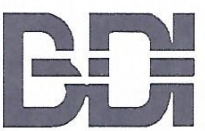

Nome:

Ocupação:
Estado Civil:

Escolaridade:
Data:

Idade: Sexo:

Este questionário consiste em 21 grupos de afirmações. Depois de ler cuidadosamente cada grupo, faça um círculo em torno do número $(0,1,2$ ou 3) próximo à afirmação, em cada grupo, que descreve mellhor a maneira que você tem se sentido na última semana, incluindo hoje. Se várias afirmações num grupo parecerem se aplicar igualmente bem, faça um círculo em cada uma. Tome o cuidado de ler todas as afirmações, em cada grupo, antes de fazer a sua escollha.

10 Não me sinto triste.

Eu me sinto triste.

2 Estou sempre triste e não consigo sair disto.

3 Estou tão triste ou infeliz que não consigo suportar.

2 Não estou especialmente desanimado quanto ao futuro.

1 Eu me sinto desanimado quanto ao futuro.

2 Acho que nada tenho a esperar.

3 Acho o futuro sem esperança e tenho a impressão de que as coisas não podem melhorar.

3 Não me sinto um fracasso.

1 Acho que fracassei mais do que uma pessoa comum.

2 Quando olho para trás, na minha vida, tudo o que posso ver é um monte de fracassos.

3 Acho que, como pessoa, sou um completo fracasso.

40 Tenho tanto prazer em tudo como antes.

1 Não sinto mais prazer nas coisas como antes.

2 Não encontro um prazer real em mais nada.

3 Estou insatisfeito ou aborrecido com tudo.

5 - Não me sinto especialmente culpado

1 Eu me sinto culpado grande parte do tempo.

2 Eu me sinto culpado na maior parte do tempo.

3 Eu me sinto sempre culpado.

6 N Não acho que esteja sendo punido.

1 Acho que posso ser punido.

2 Creio que vou ser punido.

3 Acho que estou sendo punido.

7 Não me sinto decepcionado comigo mesmo.

1 Estou decepcionado comigo mesmo.

2 Estou enojado de mim.

3 Eu me odeio.
80 Não me sinto de qualquer modo pior que os outros. 1 Sou crítico em relação a mim por minhas fraquezas ou erros.

2 Eu me culpo sempre por minhas falhas.

3 Eu me culpo por tudo de mal que acontece.

90 Não tenho quaisquer idéias de me matar.

1 Tenho idéias de me matar, mas não as executaria.

2 Gostaria de me matar.

3 Eu me mataria se tivesse oportunidade.

10 Não choro mais que o habitual.

1 Choro mais agora do que costumava.

2 Agora, choro o tempo todo.

3 Costumava ser capaz de chorar, mas agora não consigo, mesmo que o queira.

110 Não sou mais irritado agora do que já fui.

1 Fico aborrecido ou irritado mais facilmente do que costumava.

2 Agora, eu me sinto irritado o tempo todo.

3 Não me irrito mais com coisas que costumavam me irritar.

12 Não perdi o interesse pelas outras pessoas.

1 Estou menos interessado pelas outras pessoas do que costumava estar.

2 Perdi a maior parte do meu interesse pelas outras pessoas.

130 Tomo decisões tão bem quanto antes.

1 Adio as tomadas de decisões mais do que costumava.

2 Tenho mais dificuldades de tomar decisões do que antes.

3 Absolutamente não consigo mais tomar decisões.
3 Perdi todo o interesse pelas outras pessoas.

Subtotal da Página 1 CONTINUAÇÃO NO VERSO

"Traduzido e adaptado por permissāo de The Psychological Corporation, U.S.A. Direitos reservados ${ }^{1991, ~ a ~ A a r o n ~ T . ~ B e c k . ~}$

Tradução para a língua portuguesa. Direitos reservados ${ }^{\circ} 1993$ a Aaron T. Beck. Todos os direitos reservados."

Tradução e adaptação brasileira, 2001, Casa do Psicólogo ${ }^{\circledast}$ Livraria e Editora Ltda

BDI é um logotipo da Psychological Corporation. 
14 Não acho que de qualquer modo pareço pior do que antes.

1 Estou preocupado em estar parecendo velho ou sem atrativo.

2 Acho que há mudanças permanentes na minha aparência, que me fazem parecer sem atrativo.

3 Acredito que pareço feio.

15 Posso trabalhar tão bem quanto antes.

1 É preciso algum esforço extra para fazer alguma coisa.

2 Tenho que me esforçar muito para fazer alguma coisa.

3 Não consigo mais fazer qualquer trabalho.

16 Consigo dormir tão bem como o habitual.

1 Não durmo tão bem como costumava.

2 Acordo 1 a 2 horas mais cedo do que habitualmente e acho difícil voltar a dormir.

3 Acordo várias horas mais cedo do que costumava e não consigo voltar a dormir.

17 Não fico mais cansado do que o habitual.

1 Fico cansado mais facilmente do que costumava.

2 Fico cansado em fazer qualquer coisa.

3 Estou cansado demais para fazer qualquer coisa.

180 O meu apetite não está pior do que o habitual.

1 Meu apetite não é tão bom como costumava ser.

2 Meu apetite é muito pior agora.

3 Absolutamente não tenho mais apetite.
19 - Não tenho perdido muito peso se é que perdi - algum recentemente.

1 Perdi mais do que 2 quilos e meio.

2 Perdi mais do que 5 quilos.

3 Perdi mais do que 7 quilos.

Estou tentando perder peso de propósito, comendo menos: Sim__Não

200 Não estou mais preocupado com a minha saúde do que o habitual.

1 Estou preocupado com problemas físicos, tais como dores, indisposição do estômago ou constipação.

2 Estou muito preocupado com problemas físicos e é difícil pensar em outra coisa.

3 Estou tão preocupado com meus problemas físicos que não consigo pensar em qualquer outra coisa.

21 Não notei qualquer mudança recente no meu interesse por sexo.

1 Estou menos interessado por sexo do que costumava.

2 Estou muito menos interessado por sexo agora.

3 Perdi completamente o interesse por sexo.

Subtotal da Página 2

Subtotal da Página 1

Escore Total. 


\section{Anexo F - Inventário Beck de Ansiedade - BAI}

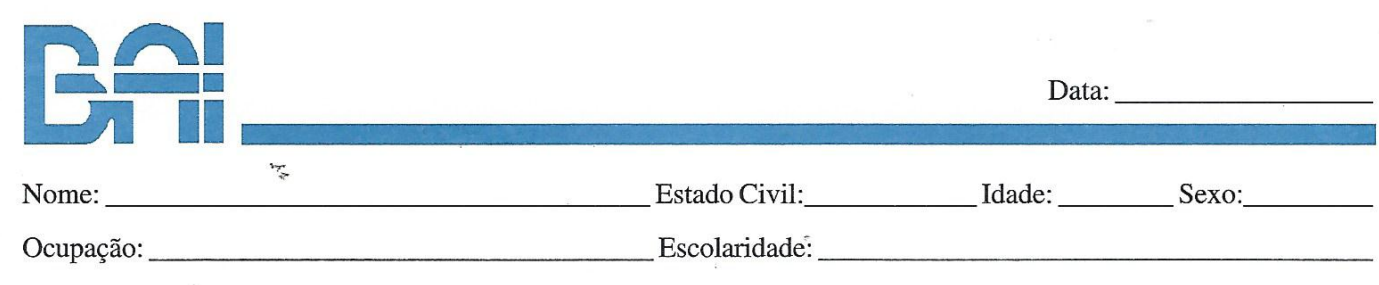

Abaixo está uma lista de sintomas comuns de ansiedade. Por favor, leia cuidadosamente cada item da lista. Identifique o quanto você tem sido incomodado por cada sintoma durante a última semana, incluindo hoje, colocando um " $x$ " no espaço correspondente, na mesma linha de cada sintoma.

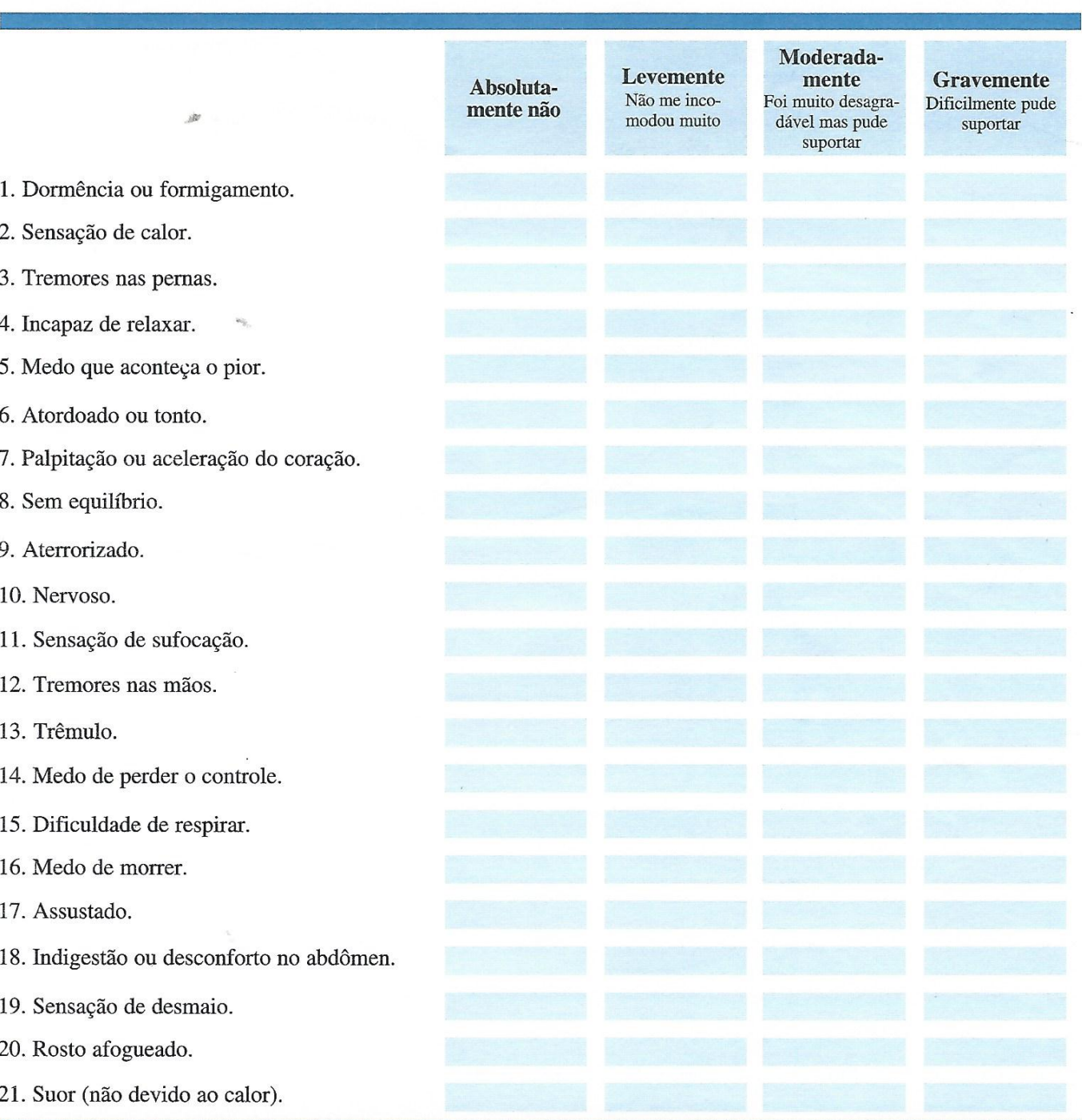

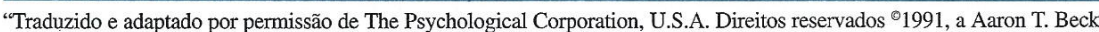
Tradução para a língua portuguesa. Direitos reservados ${ }^{\circledR} 1993$ a Aaron T. Beck. Todos os direitos reservados."

Tradução e adaptação brasileira, 2001, Casa do Psicólogo ${ }^{\circledR}$ Livraria e Editora Ltda. BAI é um logotipo da Psychological Corporation. 


\section{Anexo G - Questionário de Atividades Funcionais de Pfeffer (QAF)}

1) Ele (Ela) manuseia seu próprio dinheiro?
$0=$ Normal
$1=$ Faz, com dificuldade
$2=$ Necessita de Ajuda
$0=$ Nunca $o$ fez, mas poderia fazê-lo agora
$3=$ Não é capaz
$1=$ Nunca o fez e agora teria dificuldade
2) Ele (Ela) é capaz de comprar roupas, comida, coisas para casa sozinho(a)?
$0=$ Normal
$1=$ Faz, com dificuldade
$0=$ Nunca $\circ$ fez, mas poderia fazê-lo agora
$1=$ Nunca o fez e agora teria dificuldade
$2=$ Necessita de ajuda
$3=$ Não é capaz
3) Ela (Ela) é capaz de esquentar a água para o café e apagar o fogo?
$0=$ Normal
1= Faz, com dificuldade
2= Necessita de ajuda
$0=$ Nunca o fez, mas poderia fazê-lo agora
$1=$ Nunca $o$ fez e agora teria dificuldade

$3=$ Não é capaz

4) Ele (Ela) é capaz de preparar uma comida?

$0=$ Normal

$1=$ Faz, com dificuldade

$2=$ Necessita de ajuda

$0=$ Nunca $\mathrm{ofez}$, mas poderia fazê-lo agora

$3=$ Não é capaz

$1=$ Nunca o fez e agora teria dificuldade

5) Ele (Ela) é capaz de manter-se em dia com as atualidades, com os acontecimentos da Comunidade ou da vizinhança?

$0=$ Normal

$1=$ Faz, com dificuldade

$2=$ Necessita de ajuda

$0=$ Nunca o fez, mas poderia fazê-lo agora

$3=$ Não é capaz

$1=$ Nunca o fez e agora teria dificuldade

6) Ele (Ela) é capaz de prestar atenção, entender e discutir um programa de rádio ou televisão, um jornal ou uma revista?

$0=$ Normal

$1=$ Faz, com dificuldade

$2=$ Necessita de ajuda

$0=$ Nunca o fez, mas poderia fazê-lo agora

$3=$ Não é capaz

$1=$ Nunca o fez e agora teria dificuldade

7) Ele (Ela) é capaz de lembrar-se de compromissos, acontecimentos familiares, feriados?

$0=$ Normal

$1=$ Faz, com dificuldade

$2=$ Necessita de ajuda

$0=$ Nunca o fez, mas poderia fazê-lo agora

$3=$ Não é capaz

$1=$ Nunca o fez e agora teria dificuldade

8) Ele (Ela) É capaz de manusear seus próprios remédios?

$0=$ Normal

$1=$ Faz, com dificuldade

$2=$ Necessita de ajuda

$0=$ Nunca o fez, mas poderia fazê-lo agora

$3=$ Não é capaz

$1=$ Nunca o fez e agora teria dificuldade

9) Ele (Ela) é capaz de passear pela vizinhança e encontrar o caminho de volta para casa?

$0=$ Normal

$1=$ Faz, com dificuldade

$2=$ Necessita de ajuda

$0=$ Nunca $\mathrm{ofez}$, mas poderia fazê-lo agora

$3=$ Não é capaz

$1=$ Nunca o fez e agora teria dificuldade

10) Ele (Ela) pode ser deixado(a) em casa sozinho(a) de forma segura?

$0=$ Normal

1= Sim, mas com precauções

2= Sim, por períodos curtos

$0=$ Nunca ficou, mas poderia ficar agora

$3=$ Não poderia

ESCORE = 


\section{Anexo H - Mini-Exame do Estado Mental}

MINI-EXAME DO ESTADO MENTAL

(Folstein, Folstein \& McHugh, 1.975)

Paciente:

Data da Avaliação:

Avaliador:

ORIENTAÇÃOO

- Dia da semana (1 ponto)

- Dia do mês (1 ponto)

- Mês (1 ponto)

- Ano (1 ponto)

- Hora aproximada (1 ponto).

- Local especifico (andar ou setor) (1 ponto)

- Instituiçáo (residéncia, hospital, clinica) (1 ponto)

- Bairro ou rua próxima (1 ponto)

- Cidade (1 ponto)

- Estado (1 ponto).

MEMÓRIA IMEDIATA

- Fale 3 palavras nấo relacionadas: Posteriormente pergunte ao paciente pelas 3 palavras. Dê 1 ponto

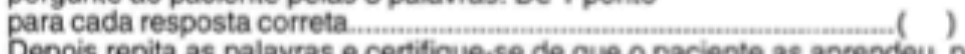

Depois repita as palavras e certifique-se de que o paciente as aprendeu, pois mais adiante você irá perguntá-las novamente.

ATENÇĂO E CÁLCULO

- $(100-7)$ sucessivas, 5 vezes sucessivamente

(1 ponto para cada calculo correto)

(alternativamente soletrar MUNDO de trás para frente)

\section{EVOCAČ̃o}

- Pergunte pelas 3 palavras ditas anteriormente

(1 ponto por palavra).

LINGUAGEM

- Nomear um relogio e uma caneta (2 pontos).

- Repetir (nem aqui, nem ali, nem la) (1 ponto)

- Comando: "pegue este papel com a máo direita

dobre ao meio e coloque no chlio (3 pontos)

- Ler e obedecer: "leche os olhos" (1 ponto).

- Escrever uma frase (1 ponito).

- Copiar um desenho (1 ponto)

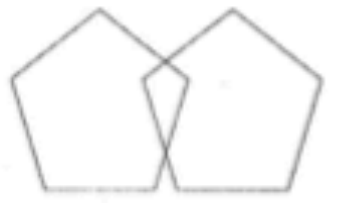




\section{Anexo I - Bateria Breve do Rastreio Cognitivo}

Teste de figuras da Bateria Breve do Rastreio Cognitivo
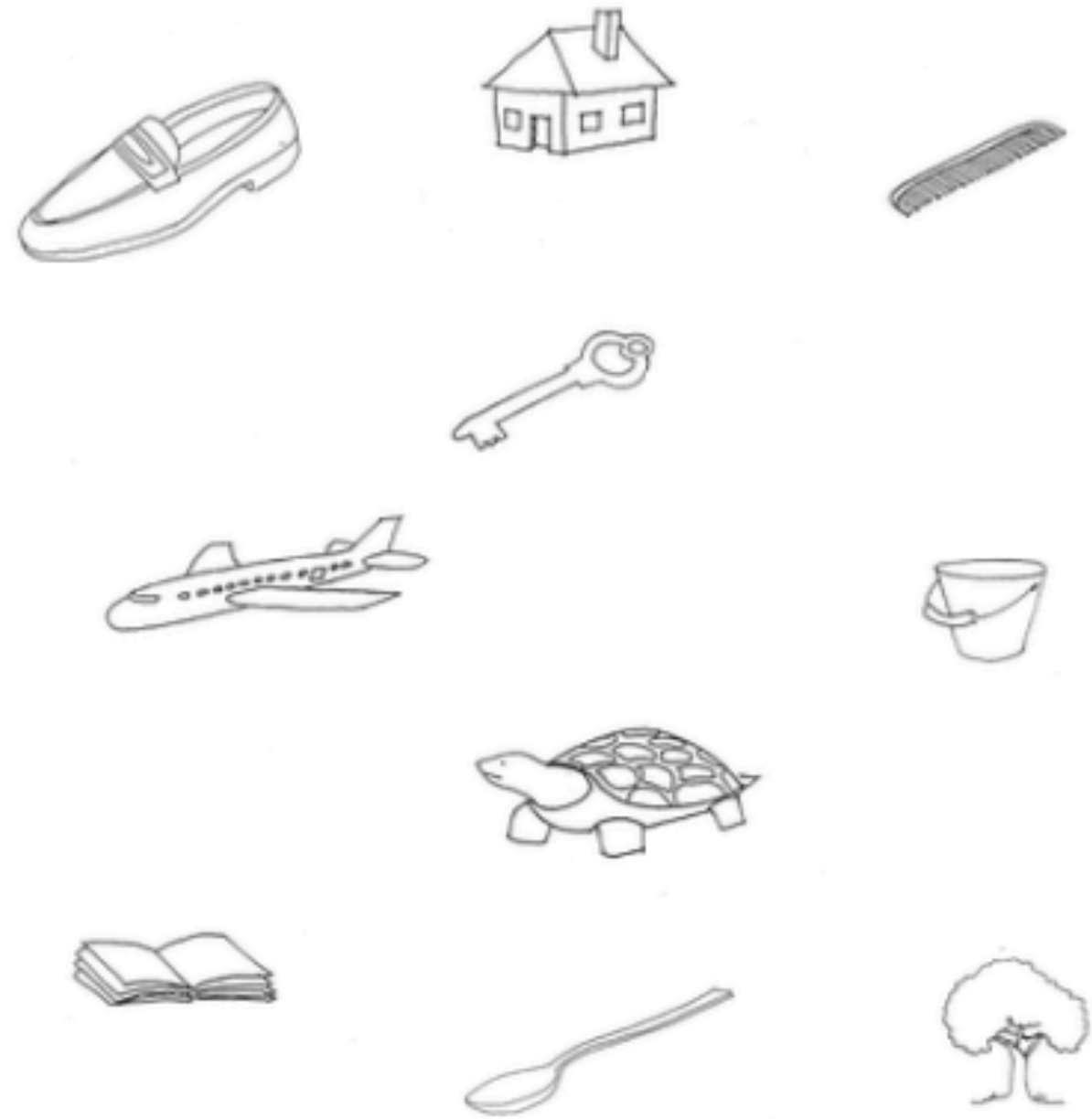
Reconhecimento das figuras da Bateria Breve do Rastreio Cognitivo
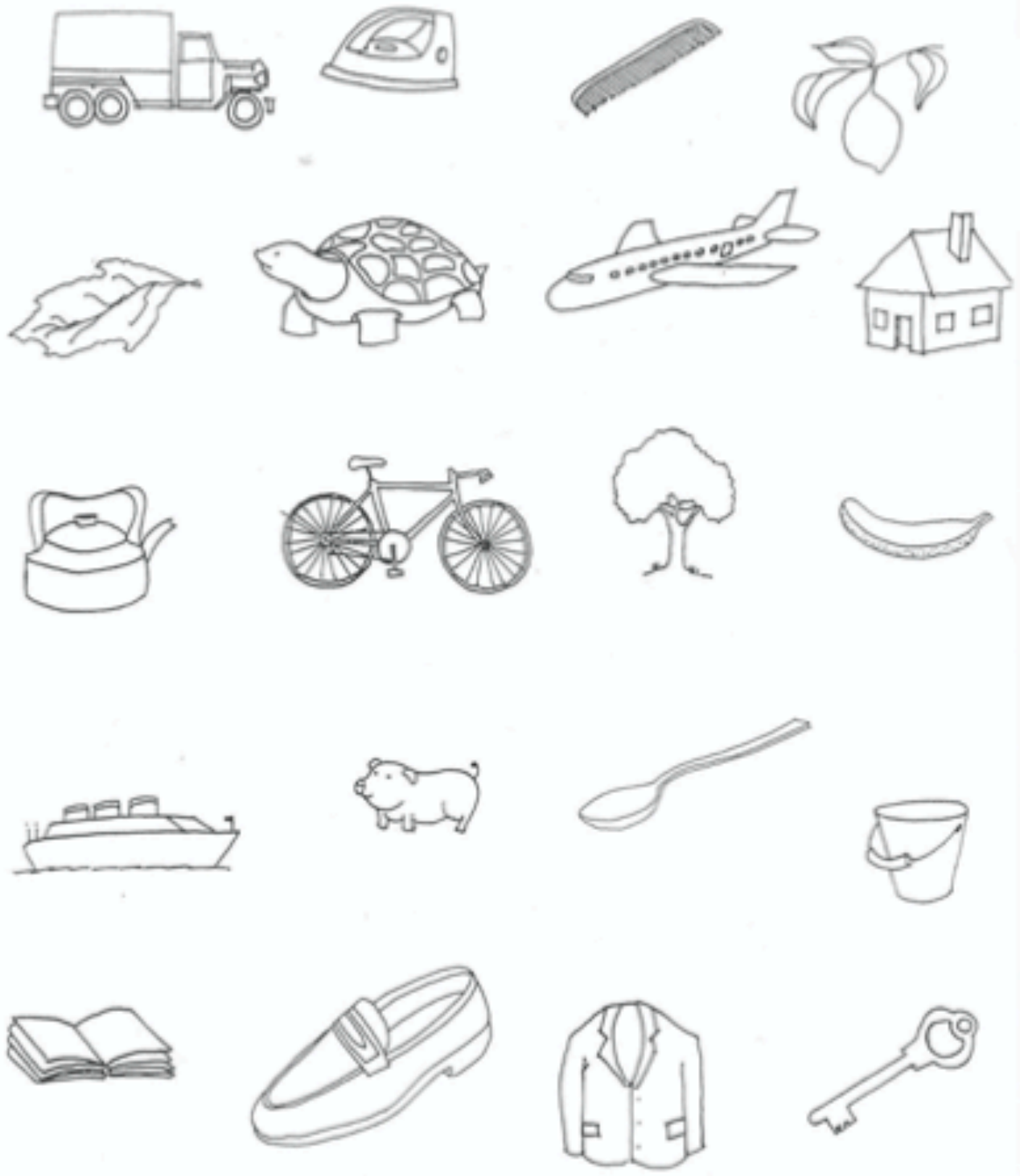


\section{Anexo J - Questionário sobre o Declínio Cognitivo do Idoso (IQCODE)}

\section{Questionário sobre o declínio cognitivo do idoso (IQCODE)}

Agora nós queremos que você se lembre como o seu amigo ou familiar estava há 10 anos atrás e compare com o estado $\mathrm{cm}$ que ele está agora. 10 anos eram 19.... Abaixo são situações em que esta pessoa usa sua memória ou inteligência e nós queremos que voce indique se estas situaçôes melhoraram, permaneceram do mesmo jeito ou se pioraram nos últimos 10 anos. Observe a importância de comparar a sua performance presente com há de 10 anos atrás. Então, se há 10 anos atrás esta pessoa sempre se esquecia onde ela guardava as coisas, e ela ainda se esquece, então isto seria considerado "não muito alterado". Por favor, indique as alterações que você observou, marcando com um "X"na resposta apropriada.

\begin{tabular}{|c|c|c|c|c|c|}
\hline $\begin{array}{l}\text { Comparada há } 10 \text { anos atrás, como está a pessoa nas } \\
\text { situações: }\end{array}$ & $\begin{array}{l}\text { Muito } \\
\text { melhor }\end{array}$ & $\begin{array}{l}\text { Um } \\
\text { pouco } \\
\text { melhor }\end{array}$ & \begin{tabular}{|l} 
Não \\
muito \\
alterado
\end{tabular} & $\begin{array}{l}\text { Um } \\
\text { pouco } \\
\text { pior }\end{array}$ & $\begin{array}{l}\text { Muito } \\
\text { pior }\end{array}$ \\
\hline \multicolumn{6}{|l|}{$\begin{array}{l}\text { 1. Lembrar-se de coisas sobre a familia e amigos, p. } \\
\text { ex. ocupações, aniversários, endereços }\end{array}$} \\
\hline \multicolumn{6}{|l|}{$\begin{array}{l}\text { 2. Lembrar-se de coisas que aconteceram } \\
\text { recentemente }\end{array}$} \\
\hline \multicolumn{6}{|l|}{ 3. Lembrar-se do que conversou nos últimos dias } \\
\hline \multicolumn{6}{|l|}{ 4. Lembrar-se de seu endereço e telefone } \\
\hline \multicolumn{6}{|l|}{ 5. Lembrar-se do dia e mês correntes } \\
\hline \multicolumn{6}{|l|}{$\begin{array}{l}\text { 6. Lembrar-se onde as coisas sâo guardadas } \\
\text { usualmente }\end{array}$} \\
\hline \multicolumn{6}{|l|}{$\begin{array}{l}\text { 7. Lembrar-se onde foram guardadas coisas que } \\
\text { foram colocadas em locais diferentes do usual }\end{array}$} \\
\hline \multicolumn{6}{|l|}{ 8. Saber como os aparelhos da casa funcionam } \\
\hline \multicolumn{6}{|l|}{ 9. Aprender como usar novos aparelhos da casa } \\
\hline \multicolumn{6}{|l|}{ 10. Aprender coisas novas $\mathrm{em}$ geral } \\
\hline \multicolumn{6}{|l|}{$\begin{array}{l}\text { 11. Acompanhar uma história } \mathrm{em} \text { um livro ou na } \\
\text { televisão }\end{array}$} \\
\hline \multicolumn{6}{|l|}{ 12. Tomar decisões em problemas do dia-a-dia } \\
\hline \multicolumn{6}{|l|}{ 13. Manusear dinheiro para as compras } \\
\hline \multicolumn{6}{|l|}{$\begin{array}{l}\text { 14. Lidar com problemas financeiros, como por } \\
\text { exemplo, pensão, coisas de banco }\end{array}$} \\
\hline \multicolumn{6}{|l|}{$\begin{array}{l}\text { 15. Lidar com outros problemas matemáticos do dia- } \\
\text { a-dia, como por exemplo, saber quanta comida } \\
\text { comprar, saber quanto tempo transcorreu entre as } \\
\text { visitas de familiares e amigos }\end{array}$} \\
\hline \multicolumn{6}{|l|}{$\begin{array}{l}\text { 16.Usar sua inteligência para entender qual o sentido } \\
\text { das coisas }\end{array}$} \\
\hline & $\mathrm{xl}$ & $\mathrm{x} 2$ & $\mathrm{x} 3$ & $\mathrm{x} 4$ & $\times 5$ \\
\hline
\end{tabular}

Escore $=$ Total/ número de questões respondidas 


\section{Anexo K - Escala Hoehn and Yahr - H\&Y}

\section{ESTADIAMENTO DE HOEHN E YAHR}

0: Assintomático.

1: Apenas envolvimento unilateral.

2: Envolvimento bilateral sem alteração do equilíbrio.

3: Envolvimento ligeiro a moderado, alguma instabilidade postural mas independente fisicamente; necessita de ajuda para recuperar-se do teste do puxão.

4: Incapacidade grave; ainda consegue andar ou ficar de pé sem ajuda.

5: Confinado a cadeira de rodas ou acamado, se não for ajudado. 


\title{
Anexo L - Termo de Consentimento Livre e Esclarecido
}

\author{
TERMO DE CONSENTIMENTO LIVRE E ESCLARECIDO
}

Projeto de Pesquisa - Uso do Addenbrooke's Cognitive Examination (ACE-III) em pacientes com Doença de Parkinson Idiopática.

Você está sendo convidado(a) a participar voluntariamente de um estudo que tem como objetivo avaliar a utilidade do teste Addenbrooke's Cognitive Examination (ACE-III) para a detecção de alteração cognitiva em pacientes com doença de Parkinson.

As alteraçēes cognitivas são uma importante causa de incapacidade funcional, sendo importante a utilização de testes de screening cognitivo, de fácil administração, sensibilidade e especificidade suficientes para detectar as alteraçōes cognitivas precoces e/ou iniciais.

Esta análise será realizada através de entrevista e execuçâo de testes neuropsicológicos.

Fui esclarecido que para esta pesquisa precisarei fornecer algumas informaçōes, que todas os dados colhidos serão mantidos em segredo e que não passarei por nenhum risco fisico e/ou psicológico, porém caso ocorra serāo fornecidas abordagens necessárias; que é inteiramente "gratuito", e que poderei recusar ou interromper a minha participação em qualquer momento, sem sofrer nenhum tipo de constrangimento.

Além disto, estou ciente que:

- Ajudarei no estudo sobre a utilidade do teste Addenbrooke's Cognitive Examination para detecção de alteração cognitiva em pacientes com doença de Parkinson, permitindo beneficios futuros para mim e para outras pessoas com esta condiçāo neurológica;

- Os objetivos e procedimentos que serão seguidos na pesquisa foram explicados de forma simplificada;

- Serei mantido atualizado sobre os resultados da pesquisa;

- Os resultados da pesquisa serão utilizados somente para fins cientificos, em meio adequado. Os dados serão utilizados SEM constar o nome e o endereço do participante.

- Em qualquer etapa do estudo, posso ter acesso aos profissionais responsáveis pela pesquisa para esclarecimento de eventuais dúvidas. 
Qualquer dúvida ou complicaçāo que ocorra no transcurso deste estudo, poderei ter acesso à profissional responsável (Nariana Mattos Figueiredo Sousa, CRP: 03/8002, Av. Tancredo Neves, 2782, Caminho das Árvores, Salvador/BA, CEP: 41820-900).

Declaro que minha participação no estudo é voluntária e que a minha assinatura garante que recebi uma cópia deste termo de consentimento de igual teor.

Salvador, de de 2017.

Assinatura do participante ou representante legal

Declaro que obtive de forma apropriada e voluntária o Consentimento Livre e Esclarecido deste paciente ou representante legal para a participação neste estudo.

Assinatura do responsável pelo estudo 


\section{Anexo M - Aprovação pela Rede SARAH de Hospitais de Reabilitação}

ASSOCIAÇÃO DAS PIONEIRAS
SOCIAIS-DF/ REDE SARAH
PARECER CONSUBSTANCIADO DO CEP
Plotoformo
Profil

Titulo da Pesquisa: Uso da Addenbrooke's Cognitive Examination, terceira revis\&o (ACE-AI) em pacientes com Doença de Parkinson Idiopatica.

Pesquisador: NARIANA MATTOS FIGUEIREDO SOUSA

Area Temática:

Versào: 3

CAAE: 57521316.8 .0000 .0022

Instituiçăo Proponente:Associaça das Pioneiras Sociais-DF / Rede Sarah

Patrocinador Principal: Financiamento Propprio

DADOS DO PARECER

Número do Parecer: 1.880 .391

Apresentaçào do Projeto:

Trata-se de estudo quantitativo - descritivo, na qual participarabo pacientes da Rede Sarah de Hosplais de Reabilitaça com diagnostico de Doença de Parkinson Idiopatica, segundo criterios do UK Parkinson's Disease Society Brain Bank, $O$ estudo consiste na aplicaçăo da bateria de avaliaçào cognitiva breve Addenbrooke's Cognitive Examination (ACE) para o diagnóstico de demencia inicial e diagnostico diferencial dos quadros demenciais com objetivo de avaliar a aplicabilidade desta ferramenta nos pacientes com đoença de Parkinson. Os pacientes seráo avaliados individualmente pelo esquisador em sessalo constituida de dois "niveis", Para a avaliaçao de nivel L, serb utlizado o Exame Cognitivo de Addenbrooke,terceira revisâo. A avaliaçâo nivel II seré feta mediante realizaçbo de avaliaçbo neuropsicolbgica.contemplando as funçøes cognitivas e habilidades funcionais. O pesquisador preencherd questionárie com informaçles clinicas, radiológicas (tempo de evoluç̄o da doença, dados de neuroimagem estruturalRessonância Magnética de Encófalo, medicamentos - dosagem e horarios de uso) e sociodemográficas, cujos dados serào obtidos do prontuário eletrónico.

Objetivo da Pesquisa:

Objetivo Primário:

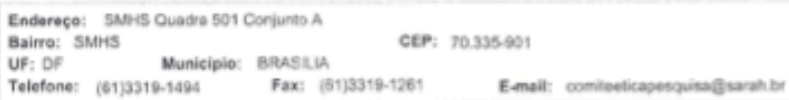




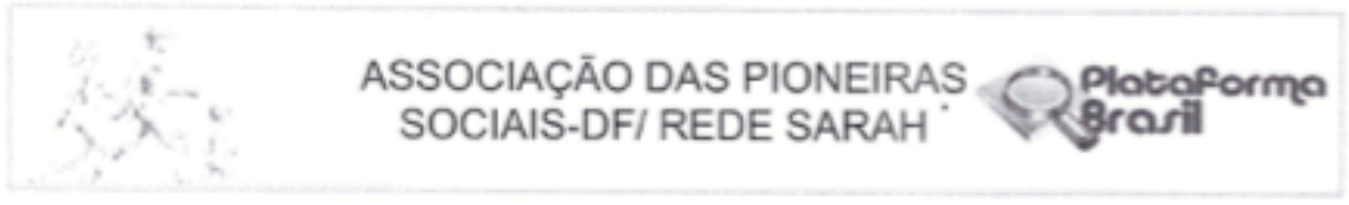

Conthuchos do Farecer 1 , 680.391

Investigar a acurácia diagnóstica (sensibildade e especificidade) do Exame Cognitivo de Addenbrooke (ACE -III) como ferramenta de rastreio cognitivo em pacientes com diagnostico de Doença de Parkinson Idiopática.Objetivo Secundário:

- Avaliar a adequaço do uso do referido teste para auxiliar no diagnóstico de comprometimento cognitivo leve e sindrome demencial na Doença de Parkinson Idiopática.

- Correlacionar o desempenho dos pacientes na ACE-lli com outros instrumentos úlilizados nesta populacalo para investigaçlo de demincia.

\section{Avaliaça dos Riscos e Beneficios:}

Riscos:

Segundo o pesquisador, o estudo nâo apresenta nenhum risco fisico elou psicologico para os participantes. Beneficios:

Colaborar oom o estudo sobre a utilidade do teste Addenbrooke's Cognitive Examination para detecsab de alteraçlo cognitiva em pacientes com doença de Parkinson, permitindo beneficios futuros para o paciente e para outras pessoas com a mesma condiçáo neurologica.

\section{Comentários e Consideraçঠes sobre a Pesquisa:}

O objetivo e metodologia do projeto foram descritos. Foram citados trabalhos experimentais anteriores sobre o tema da propesiço do pesquisador.

EMENDA:

Trata-se de uma correça do titulo da pesquisa no projeto inserido na Platalorma Brasil nos itens "Projeto de Pesquisa" e "Titulo Público da Pesquisa* e Substiluiça da Foltha de Rosto.

\section{Consideraçø̄es sobre os Termos de apresentaçăo obrigatória:}

Foram corrigidos de forma adequada.

Recomendaçöes:

Sem novas recomendap̧es.

Conclusóes ou Pendencias e Lista de Inadequaçóes:

Projeto aprovado.

Considerạ̧ōes Finais a critério do CEP:

Tendo em vista a legislaçăo vigente (Resoluçä̀ CNS 466/12), o CEP.APS recomenda aos

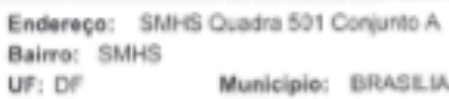




\section{ASSOCIAÇÃO DAS PIONEIRAS SOCIAIS-DF/ REDE SARAH \\ Q Plotoformo}

$i^{3}, 4-6$

Condinascas do Parecer 1, abs 391

Pesquisadores:

Comunicar toda e qualquer alteraçăo do projeto e do termo de consentimento via emenda na Plataforma Brasil, Informar imediatamente qualquer evento adverso ocomido durante o desenvolvimento da pesquisa (via documental encaminhada em papel), apresentar na forma de notificaça relatorios parciais do andamento do mesmo a cada 06 (seis) meses e ao termino da pesquise encaminhar a este Comite um sumário dos resultados do projeto (relatorio final).

Este parecer foi elaborado baseado nos documentos abaixo relacionados:

\begin{tabular}{|c|c|c|c|c|}
\hline Tipo Documento & Arquivo & Postagem & Autor & Stuaça \\
\hline $\begin{array}{l}\text { Informaç̧os Basicas } \\
\text { de Projeto }\end{array}$ & $\begin{array}{l}\text { PB_INFOFIMACOES_BASICAS_808845 } \\
\text { E1] }\end{array}$ & $\begin{array}{c}19 / 12 / 2016 \\
094420\end{array}$ & & Acento \\
\hline Folha do Rosto & folnaDeRosto PDF & $\begin{array}{l}19 / 12 / 2016 \\
09.4306\end{array}$ & $\begin{array}{l}\text { NARIAWA MATTOS } \\
\text { FIGUEIREDO }\end{array}$ & Aceito \\
\hline $\begin{array}{l}\text { Projeto Detalhado I } \\
\text { Brochura } \\
\text { Investgader }\end{array}$ & PROJETO.dOC & $\begin{array}{c}2906 / 2016 \\
13: 18.55\end{array}$ & $\begin{array}{l}\text { NARIANA MATTOS } \\
\text { FIGUEIREDO } \\
\text { SQUSA }\end{array}$ & Aceito \\
\hline $\begin{array}{l}\text { TCLE / Termos de } \\
\text { Assentimento / } \\
\text { Justificativa de } \\
\text { Avselneda. }\end{array}$ & TCLE.doC & $\begin{array}{c}27 / 06 / 2016 \\
15.12 .20\end{array}$ & $\begin{array}{l}\text { NARIANA MATTOS } \\
\text { FIGUEIREDO } \\
\text { SOUSA }\end{array}$ & Aceito \\
\hline
\end{tabular}

Situaçbo do Parecer:

Aprovado

Necessita Aprociaçăo da CONEP:

Nå

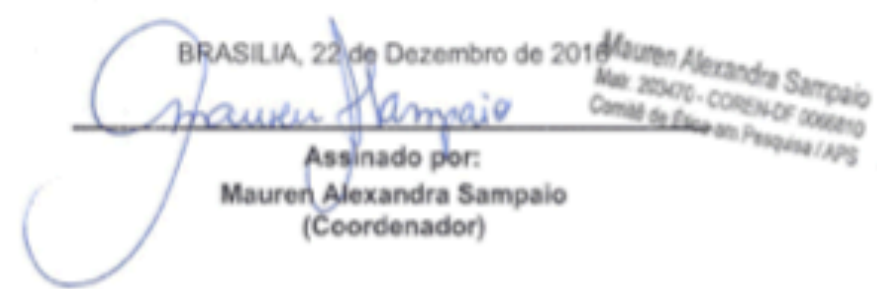

Enderese: SMeis Quadra SO1 Conuntes A Bairro: SMHS

UF: DF Municipio: Bresstid

CEP: $70.395-90$ \%
Telefone:
(61) $9319-1494$
Fax: (51)3319-1201

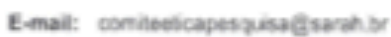




\title{
Anexo N - Aprovação pela Faculdade de Medicina da Universidade de São Paulo/FMUSP
}
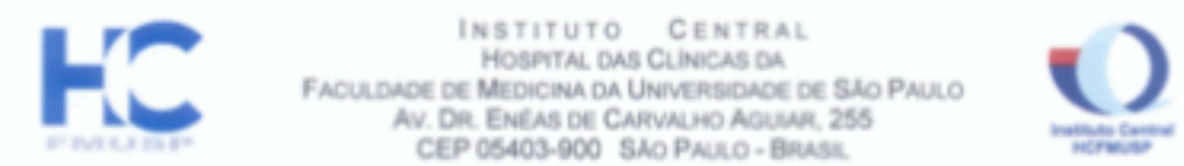

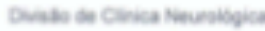

Slo Paulo, 13 de maryo de 2017

\author{
À Profa.Dra. Maria Aparecida Anevedo Koike Folgueira \\ DD. Coondenadora \\ CEPFMUSP
}

laformo que o CEP da FMUSP seŕ́ co-participante da pesquisa para admisslo no doutorado da aluna NARIANA MATTOS FIGUEIREDO SOTSA intitulada "Uso do

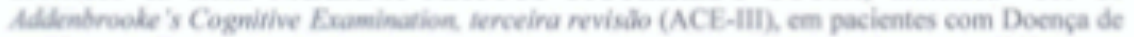
Parkinson Idiopatica" destina-se a investigar as propriedades diagnobticas (sensibilidade e especificidade) deste instrumento como uma ferramenta de rastreio cognitivo nesta populaclo. Para tal finalidade, serla incluidos 100 pacientes $e 60$ controles saodiveis, pareados quanto as sevo, idade, escolaridade, $e$ conforme critérios de incluslo pre-estabelecidos para cada grupos que serlo submetidos à avaliaclo neuropsicológica, constituida pelo ACE-III e demais testes cognitivos padronizados para esta populaclo, bem como aplicaclo de escalas de humor. ansiedade e funcionais. Os pacientes favem parte do programa da rede Sarah de Hospitais de Reabilitaclor/Unidade Salvadoe BA.

O trabalho supracitado ji foi autorizado pela instituiçlo Sarah/Brasilia (conforme parecer do comine de ética enviado em anesol. Bem como cadastrado e aprovado pela Plataforma Brasil. No momento, foi finalizado o estudo piloto (40 pacientes $e 10$ controles), obtendo - assim - os resultados preliminares desta etape do estudo.

Atenciosamente,

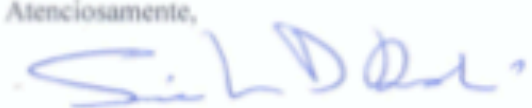

Profa.Dra. Sonia Maria Dowzi Brucki Orientadora

APRONADO PELO CONSELHO DO DEPARTAMENTO

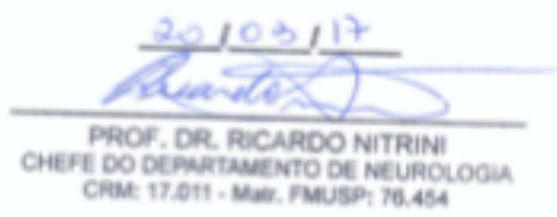




\section{REFERÊNCIAS}

Aarsland, D. et al. (2017) 'Cognitive decline in Parkinson disease', Nature Reviews Neurology. Nature Publishing Group, pp. 217-231. doi: 10.1038/nrneurol.2017.27.

Aarsland, D. and Kurz, M. W. (2010a) 'The Epidemiology of Dementia Associated with Parkinson's Disease', Brain Pathology, 20(3), pp. 633-639. doi: 10.1111/j.1750-3639.2009.00369.x.

Aarsland, D. and Kurz, M. W. (2010b) 'The epidemiology of dementia associated with Parkinson disease', Journal of the Neurological Sciences, 289(1-2), pp. 18-22. doi: 10.1016/j.jns.2009.08.034.

Amaral-Carvalho, V. and Caramelli, P. (2012) 'Normative Data for Healthy Middle-Aged and Elderly Performance on the Addenbrooke Cognitive Examination-Revised', Cognitive And Behavioral Neurology, 25(2), pp. 72-76. doi: 10.1097/WNN.0b013e318259594b.

American Psychiatric Association (2014) DSM-5 Manual diagnóstico e estatístico de transtornos mentais. 5. Porto Alegre, RS: Artmed.

Bajpai, S. et al. (2020) 'Hindi Version of Addenbrooke's Cognitive Examination III: Distinguishing Cognitive Impairment Among Older Indians at the Lower CutOffs', Clinical Interventions in Aging. Dove Medical Press Ltd., 15, pp. 329-339. doi: $10.2147 /$ CIA.S244707.

Bak, T. H. et al. (2005) 'Cognitive bedside assessment in atypical parkinsonian syndromes.', Journal of neurology, neurosurgery, and psychiatry, 76(3), pp. 420-2. doi: 10.1136/jnnp.2003.029595.

Barbosa, M. T. et al. (2006) 'Parkinsonism and Parkinson's disease in the elderly: A community-based survey in Brazil (the Bambuí study)', Movement Disorders, 21(6), pp. 800-808. doi: 10.1002/mds.20806.

Bastide, L. et al. (2012) 'The Addenbrooke's Cognitive Examination Revised Is as Effective as the Original to Detect Dementia in a French-Speaking Population', Dementia and Geriatric Cognitive Disorders. Dement Geriatr Cogn Disord, 34(5-6), pp. 337-343. doi: 10.1159/000345562.

Benazzouz, A. et al. (2014) 'Involvement of dopamine loss in extrastriatal basal ganglia nuclei in the pathophysiology of Parkinson's disease', Frontiers in Aging Neuroscience, 6, p. 87. doi: 10.3389/fnagi.2014.00087.

Benge, J., Phillips-Sabol, J. and Phenis, R. (2014) 'The neuropsychological assessment battery categories test as a measure of executive dysfunction in patients with Parkinson's disease and essential tremor: an exploratory study', The Clinical Neuropsychologist, 28(6), pp. 1008-1018. doi: 10.1080/13854046.2014.950985.

Berankova, D. et al. (2015) 'Addenbrooke's Cognitive Examination and Individual Domain Cut-Off Scores for Discriminating between Different Cognitive Subtypes of Parkinson's Disease', Parkinson's Disease, 2015, pp. 1-7. doi: 


\section{$10.1155 / 2015 / 579417$.}

Bernadotte, A. and Aarsland, D. (2015) 'Epidemiology of dementia associated with Parkinson's disease', in Emre M. (ed.) Cognitive Impairment and Dementia in Parkinson's Disease. 2nd edn. Oxford: Oxford University Press, pp. 5-16.

Bier, J. C. et al. (2004) 'Is the Addenbrooke's cognitive examination effective to detect frontotemporal dementia?', Journal of neurology, 251(4), pp. 428-31. doi: 10.1007/s00415-004-0345-z.

Biundo, R. et al. (2013) 'Anatomical Correlates of Cognitive Functions in Early Parkinson's Disease Patients', PLoS ONE. Edited by B. Draganski, 8(5), p. e64222. doi: 10.1371/journal.pone.0064222.

Bocanegra, Y., Trujillo-Orrego, N. and Pineda, D. (2014) '[Dementia and mild cognitive impairment in Parkinson's disease: a review]', Revista de Neurologia, 59(12), pp. 555-569.

Bonelli, R. M. and Cummings, J. L. (2008) 'Frontal-subcortical dementias', Neurologist, 14(2), pp. 100-107. doi: 10.1097/NRL.0b013e31815b0de2.

Bovolenta, T. and Felício, A. (2017) 'How do demographic transitions and public health policies affect patients with Parkinson's disease in Brazil?', Clinical Interventions in Aging, 12, pp. 197-205. doi: 10.2147/CIA.S123029.

Braak, H. et al. (2003) 'Staging of brain pathology related to sporadic Parkinson's disease', Neurobiology of Aging, 24(2), pp. 197-211. doi: 10.1016/S0197-4580(02)00065-9.

Breder, R. et al. (2017) 'Low Sensitivity of the Mini-Mental State Examination for Cognitive Assessment of Brazilian Patients With Parkinson Disease', Journal of Geriatric Psychiatry and Neurology. SAGE Publications Inc., 30(6), pp. 311315. doi: $10.1177 / 0891988717731826$.

Brønnick, K. (2015) 'Cognitive profile in Parkinson's disease dementia', in Emre, M. (ed.) Cognitive impairment and dementia in Parkinson's disease. 2nd ed. Oxford: Oxford University Press, pp. 27-46.

Brucki, S. M. D. et al. (2003) 'Sugestões para o uso do mini-exame do estado mental no Brasil', Arquivos de Neuro-Psiquiatria, 61(3B), pp. 777-781. doi: 10.1590/S0004-282X2003000500014.

Bruno, D. et al. (2020) 'Validación argentino-chilena de la versión en español del test Addenbrooke's Cognitive Examination III para el diagnóstico de demencia', Neurología. Spanish Society of Neurology, 35(2), pp. 82-88. doi: 10.1016/j.nrl.2017.06.004.

Camargos, A. C. R. et al. (2004) 'O impacto da doença de parkinson na qualidade de vida: uma revisão de literatura', Revista Brasileira de Fisioterapia, 8(3), pp. 267-272.

Campos, L. S. et al. (2015) 'Clinical predictors of cognitive impairment and psychiatric complications in Parkinson's disease', Arquivos de NeuroPsiquiatria, 73(5), pp. 390-395. doi: 10.1590/0004-282X20150016.

Carod-Artal, F. J. et al. (2008) 'Psychometric attributes of the SCOPA-COG 
Brazilian version', Movement Disorders, 23(1), pp. 81-87. doi: 10.1002/mds.21769.

Carvalho, V. A., Barbosa, M. T. and Caramelli, P. (2010) 'Brazilian version of the Addenbrooke Cognitive Examination-revised in the diagnosis of mild Alzheimer disease', Cognitive and Behavioral Neurology, 23(1), pp. 8-13. doi: 10.1097/WNN.0b013e3181c5e2e5.

Caspell-Garcia, C. et al. (2017) 'Multiple modality biomarker prediction of cognitive impairment in prospectively followed de novo Parkinson disease', PLoS ONE. Public Library of Science, 12(5). doi: 10.1371/journal.pone.0175674.

Caviness, J. N. et al. (2007) 'Defining mild cognitive impairment in Parkinson's disease', Movement Disorders. Mov Disord, 22(9), pp. 1272-1277. doi: 10.1002/mds.21453.

Cerasa, A. et al. (2014) 'Neurofunctional correlates of attention rehabilitation in Parkinson's disease: an explorative study', Neurological Sciences, 35(8), pp. 1173-1180. doi: 10.1007/s10072-014-1666-z.

César, K. G. et al. (2017) 'Addenbrooke's cognitive examination-revised: normative and accuracy data for seniors with heterogeneous educational level in Brazil', International Psychogeriatrics. Cambridge University Press, 29(8), pp. 1345-1353. doi: 10.1017/S1041610217000734.

Chade, A. et al. (2008) 'Detecting cognitive impairment in patients with Parkinson's disease using a brief cognitive screening tool: Addenbrooke's Cognitive Examination (ACE)', Dementia \& Neuropsychologia. FapUNIFESP (SciELO), 2(3), pp. 197-200. doi: 10.1590/s1980-57642009dn20300006.

Charernboon, T. and Chompookard, P. (2019) 'Detecting cognitive impairment in patients with schizophrenia with the Addenbrooke's Cognitive Examination', Asian Journal of Psychiatry. Elsevier B.V., 40, pp. 19-22. doi: 10.1016/j.ajp.2019.01.006.

Chow, T. and Cummings, J. (1999) 'Frontal : subcortical circuits', in Miller, B. and Cummings, J. (eds) The Human Frontal Lobes: Functions and Disorders. New York: Guilford Publications, pp. 3-26.

Crawford, S. et al. (2012) 'A systematic review of the accuracy and clinical utility of the Addenbrooke's Cognitive Examination and the Addenbrooke's Cognitive Examination-Revised in the diagnosis of dementia', International Journal of Geriatric Psychiatry, 27(7), pp. 659-669. doi: 10.1002/gps.2771.

Cunha, J. (2001) Manual da versão em português das escalas Beck. São Paulo: Casa do Psicólogo.

Dalrymple-Alford, J. C. et al. (2010) 'The MoCA: Well-suited screen for cognitive impairment in Parkinson disease', Neurology, 75(19), pp. 1717-1725. doi: 10.1212/WNL.0b013e3181fc29c9.

Dinda, B. et al. (2019) 'Therapeutic potentials of plant iridoids in Alzheimer's and Parkinson's diseases: A review.', European journal of medicinal chemistry, 169, pp. 185-199. doi: 10.1016/j.ejmech.2019.03.009. 
Dudas, R. B. (2005) 'The Addenbrooke's Cognitive Examination (ACE) in the Differential Diagnosis of Early Dementias Versus Affective Disorder', American Journal of Geriatric Psychiatry. Elsevier BV, 13(3), pp. 218-226. doi: 10.1176/appi.ajgp.13.3.218.

Dujardin, K. et al. (2007) 'Characteristics of apathy in Parkinson's disease', Movement Disorders, 22(6), pp. 778-784. doi: 10.1002/mds.21316.

Elamin, M. et al. (2016) 'The Utility of the Addenbrooke's Cognitive Examination Version Three in Early-Onset Dementia', Dementia and Geriatric Cognitive Disorders, 41(1-2), pp. 9-15. doi: 10.1159/000439248.

Emre, M. (2003) 'Dementia associated with Parkinson's disease', Lancet Neurology, 2(4), pp. 229-237. doi: 10.1016/S1474-4422(03)00351-X.

Fang, R. et al. (2014) 'Validation of the Chinese version of Addenbrooke's cognitive examination-revised for screening mild Alzheimer's disease and mild cognitive impairment.', Dementia and geriatric cognitive disorders, 37(3-4), pp. 223-31. doi: 10.1159/000353541.

Fernandes, I. and Andrade Filho, A. de S. (2018) 'Estudo clínico-epidemiológico de pacientes com doença de Parkinson em Salvador-Bahia', Revista Brasileira de Neurologia e Psiquiatria, 22(1), pp. 45-59.

Galtier, I. et al. (2017) 'Mild Cognitive Impairment in Parkinson's Disease: Clustering and Switching Analyses in Verbal Fluency Test', Journal of the International Neuropsychological Society: JINS, 23(6), pp. 511-520. doi: 10.1017/S1355617717000297.

Galton, C. J. et al. (2005) 'A comparison of the Addenbrooke's Cognitive Examination (ACE), conventional neuropsychological assessment, and simple MRI-based medial temporal lobe evaluation in the early diagnosis of Alzheimer's Disease', Cognitive and Behavioral Neurology, 18(3), pp. 144-150. doi: 10.1097/01.wnn.0000182831.47073.e9.

García-Caballero, A. et al. (2006) 'Validation of the Spanish version of the Addenbrooke's Cognitive Examination in a rural community in Spain', International Journal of Geriatric Psychiatry, 21(3), pp. 239-245. doi: 10.1002/gps. 1450.

Geurtsen, G. J. et al. (2014) 'Parkinson's disease mild cognitive impairment: Application and validation of the criteria', Journal of Parkinson's Disease, 4(2), pp. 131-137. doi: 10.3233/JPD-130304.

Goldman, J. G. et al. (2018) 'Evolution of diagnostic criteria and assessments for Parkinson's disease mild cognitive impairment.', Movement Disorders, 33(4), pp. 503-510. doi: $10.1002 / \mathrm{mds} .27323$.

Goldman, J. G. and Weintraub, D. (2015) 'Advances in the treatment of cognitive impairment in Parkinson's disease', Movement Disorders, 30(11), pp. 1471-1489. doi: 10.1002/mds.26352.

Goldman, L. and Bennett, J. (2001) Cecil - Tratado de Medicina Interna. 21st edn. Edited by J. C. Bennett and L. Gooldman. Rio de Janeiro: Guanabara Koogan. 
Hall, J. M. and Lewis, S. J. G. (2019) 'Neural Correlates of Cognitive Impairment in Parkinson's Disease: A Review of Structural MRI Findings', International review of neurobiology, 144, pp. 1-28. doi: 10.1016/bs.irn.2018.09.009.

Hoehn, M. M. and Yahr, M. D. (1967) 'Parkinsonism: onset, progression, and mortality', Neurology, 17(5), pp. 427-427. doi: 10.1212/WNL.17.5.427.

Hoogland, J. et al. (2017) 'Mild cognitive impairment as a risk factor for Parkinson's disease dementia', Movement Disorders, 32(7), pp. 1056-1065. doi: 10.1002/mds.27002.

Hoops, S. et al. (2009) 'Validity of the MoCA and MMSE in the detection of $\mathrm{MCl}$ and dementia in Parkinson disease', Neurology. Lippincott Williams and Wilkins, 73(21), pp. 1738-1745. doi: 10.1212/WNL.0b013e3181c34b47.

Hsieh, S. et al. (2013) 'Validation of the Addenbrooke's Cognitive Examination III in Frontotemporal Dementia and Alzheimer's Disease', Dementia and Geriatric Cognitive Disorders. S. Karger AG, 36(3-4), pp. 242-250. doi: 10.1159/000351671.

Hsieh, Y.-H. et al. (2008) 'Cognitive and Motor Components of Response Speed in the Stroop Test in Parkinson's Disease Patients', The Kaohsiung Journal of Medical Sciences, 24(4), pp. 197-203. doi: 10.1016/S1607$551 \times(08) 70117-7$.

$\mathrm{Hu}$, M. T. M. et al. (2014) 'Predictors of cognitive impairment in an early stage Parkinson's disease cohort', Movement Disorders. United States, 29(3), pp. 351-359. doi: 10.1002/mds.25748.

Hughes, T. et al. (2000) 'A 10-year study of the incidence of and factors predicting dementia in Parkinson's disease', Neurology, 54(8), pp. 1596-602. doi: 10.1212/WNL.54.8.1596.

Irwin, D. J. et al. (2012) 'Neuropathologic substrates of Parkinson disease dementia', Annals of Neurology, 72(4), pp. 587-598. doi: 10.1002/ana.23659.

Jankovic, J. and Tolosa, E. (2015) Parkinson's disease and movement disorders. 6th edn. Edited by J. Jankovic and Eduardo Tolosa. Philadelphia: Wolters Kluwer.

Janvin, C. C. et al. (2006) 'Subtypes of mild cognitive impairment in parkinson's disease: Progression to dementia', Movement Disorders, 21(9), pp. 1343-1349. doi: $10.1002 / m d s .20974$.

Jubb, M. T. and Evans, J. J. (2015) 'An Investigation of the Utility of the Addenbrooke's Cognitive Examination III in the Early Detection of Dementia in Memory Clinic Patients Aged over 75 Years', Dementia and Geriatric Cognitive Disorders, 40(3-4), pp. 222-232. doi: 10.1159/000433522.

Kan, K. C. et al. (2019) 'Validation of the Malay Version of Addenbrooke's Cognitive Examination III in Detecting Mild Cognitive Impairment and Dementia.', Dementia and geriatric cognitive disorders extra. S. Karger AG, 9(1), pp. 66-76. doi: 10.1159/000495107.

Kaszás, B. et al. (2012) 'Sensitivity and specificity of Addenbrooke's Cognitive 
Examination, Mattis Dementia Rating Scale, Frontal Assessment Battery and Mini Mental State Examination for diagnosing dementia in Parkinson's disease', Parkinsonism \& Related Disorders, 18(5), pp. 553-556. doi: 10.1016/j.parkreldis.2012.02.010.

Kim, J.-S. et al. (2018) 'Hemispherotomy and Functional Hemispherectomy: Indications and Outcomes.', Journal of epilepsy research. Korean Epilepsy Society, 8(1), pp. 1-5. doi: 10.14581/jer.18001.

Komadina, N. C. et al. (2011) 'Utility and Limitations of Addenbrooke's Cognitive Examination-Revised for Detecting Mild Cognitive Impairment in Parkinson's Disease', Dementia and Geriatric Cognitive Disorders, 31(5), pp. 349-357. doi: 10.1159/000328165.

Kourtesis, P. et al. (2020) 'A Comparison of the Greek ACE-III, M-ACE, ACE-R, MMSE, and ECAS in the Assessment and Identification of Alzheimer's Disease', Journal of the International Neuropsychological Society. Cambridge University Press, 26(8), pp. 825-834. doi: 10.1017/S1355617720000314.

Krajcovicova, L., Klobusiakova, P. and Rektorova, I. (2019) 'Gray Matter Changes in Parkinson's and Alzheimer's Disease and Relation to Cognition', Current Neurology and Neuroscience Reports, 19(11), p. 85. doi: 10.1007/s11910-019-1006-z.

Kudlicka, A., Clare, L. and Hindle, J. V (2011) 'Executive functions in Parkinson's disease: Systematic review and meta-analysis', Movement Disorders, 26(13), pp. 2305-2315. doi: 10.1002/mds.23868.

Kulisevsky, J. and Pagonabarraga, J. (2009) 'Cognitive impairment in Parkinson's disease: Tools for diagnosis and assessment', Movement Disorders, 24(8), pp. 1103-1110. doi: 10.1002/mds.22506.

Kwak, Y. T., Yang, Y. and Kim, G. W. (2010) 'Korean Addenbrooke's Cognitive Examination Revised (K-ACER) for differential diagnosis of Alzheimer's disease and subcortical ischemic vascular dementia', Geriatrics \& Gerontology International, 10(4), pp. 295-301. doi: 10.1111/j.1447-0594.2010.00624.x.

Larner, A. J. (2005) 'An audit of the Addenbrooke's Cognitive Examination (ACE) in clinical practice', International Journal of Geriatric Psychiatry, 20(6), pp. 593-594. doi: 10.1002/gps.1336.

Larner, A. J. (2007) 'Addenbrooke's Cognitive Examination-Revised (ACE-R) in day-to-day clinical practice', Age and Ageing, 36(6), pp. 685-6. doi: 10.1093/ageing/afm112.

Larner, A. J. and Mitchell, A. J. (2014) 'A meta-analysis of the accuracy of the Addenbrooke's Cognitive Examination (ACE) and the Addenbrooke's Cognitive Examination-Revised (ACE-R) in the detection of dementia', International Psychogeriatrics. Cambridge University Press, 26(4), pp. 555-563. doi: 10.1017/S1041610213002329.

Lau, L. M. L. de et al. (2006) 'Subjective complaints precede Parkinson disease: The Rotterdam study', Archives of Neurology, 63(3), pp. 362-365. doi: 10.1001/archneur.63.3.noc50312. 
Lees, A. J., Hardy, J. and Revesz, T. (2009) 'Parkinson's disease', The Lancet, 373(9680), pp. 2055-2066. doi: 10.1016/S0140-6736(09)60492-X.

Lezak, M. D., Howieson, D. B. and Loring, D. W. (2004) Neuropsychological Assessment. 4th edn. New York: Oxford University Press.

$\mathrm{Li}$, X. et al. (2019) 'Validation Study of the Chinese Version of Addenbrooke's Cognitive Examination III for Diagnosing Mild Cognitive Impairment and Mild Dementia', Journal of Clinical Neurology. Korean Neurological Association, 15(3), p. 313. doi: 10.3988/jcn.2019.15.3.313.

Litvan, I. et al. (2003) 'SIC task force appraisal of clinical diagnostic criteria for parkinsonian disorders', Movement Disorders. Mov Disord, 18(5), pp. 467-486. doi: $10.1002 / \mathrm{mds} .10459$.

Litvan, I. et al. (2012) 'Diagnostic criteria for mild cognitive impairment in Parkinson's disease: Movement Disorder Society Task Force guidelines.', Movement disorders : official journal of the Movement Disorder Society, 27(3), pp. 349-56. doi: 10.1002/mds.24893.

Lucza, T. et al. (2015) 'Screening Mild and Major Neurocognitive Disorders in Parkinson's Disease', Behavioural Neurology. Hindawi Limited, pp. 1-10. doi: $10.1155 / 2015 / 983606$.

Lucza, T. et al. (2018) 'Comparing Sensitivity and Specificity of Addenbrooke's Cognitive Examination-I, III and Mini-Addenbrooke's Cognitive Examination in Parkinson's Disease', Behavioural Neurology, (ID 5932028), pp. 1-9. doi: 10.1155/2018/5932028.

Mader, M. J. and Anjos, M. A. dos (2003) 'Neuropsicologia: contribuições para a investigação das funções cognitivas na doença de Parkinson', in Meneses, M. and Teive, H. (eds) Doença de Parkinson. Rio de Janeiro: Guanabara Koogan, pp. 112-116.

Malloy-Diniz, L. F. et al. (2007) 'The Rey Auditory-Verbal Learning Test: applicability for the Brazilian elderly population', Revista Brasileira de Psiquiatria (São Paulo), 29(4), pp. 324-329. doi: 10.1590/S1516-44462006005000053.

Martinez-Horta, S., Horta-Barba, A. and Kulisevsky, J. (2019) 'Cognitive and behavioral assessment in Parkinson's disease.', Expert review of neurotherapeutics, 19(7), pp. 613-622. doi: 10.1080/14737175.2019.1629290.

Mathuranath, P. S. et al. (2000) 'A brief cognitive test battery to differentiate Alzheimer's disease and frontotemporal dementia', Neurology, 55(11), pp. 1613-1620. doi: 10.1212/01.wnl.0000434309.85312.19.

Mathuranath, P. S. et al. (2004) 'Adaptation of the ACE for a Malayalam speaking population in southern India', International Journal of Geriatric Psychiatry, 19(12), pp. 1188-1194. doi: 10.1002/gps.1239.

Matias-Guiu, J. A. et al. (2015) 'Validación de la versión española del test Addenbrooke's Cognitive Examination III para el diagnóstico de demencia', Neurología, 30(9), pp. 545-551. doi: 10.1016/j.nrl.2014.05.004.

Matias-Guiu, J. A. et al. (2017) 'Addenbrooke's cognitive examination III: Diagnostic utility for mild cognitive impairment and dementia and correlation 
with standardized neuropsychological tests', International Psychogeriatrics. Cambridge University Press, 29(1), pp. 105-113. doi: 10.1017/S1041610216001496.

Matías-Guiu, J. A. et al. (2016) 'Normative Data for the Spanish Version of the Addenbrooke's Cognitive Examination III.', Dementia and geriatric cognitive disorders, 41(5-6), pp. 243-50. doi: 10.1159/000445799.

Matías-Guiu, J. A. et al. (2017) 'Comparative Diagnostic Accuracy of the ACEIII, MIS, MMSE, MoCA, and RUDAS for Screening of Alzheimer Disease', Dementia and Geriatric Cognitive Disorders, 43(5-6), pp. 237-246. doi: 10.1159/000469658.

McColgan, P. et al. (2012) 'Addenbrooke's Cognitive Examination-Revised for mild cognitive impairment in Parkinson's disease', Movement Disorders, 27(9), pp. 1172-1176. doi: 10.1002/mds.25084.

Mekala, S. et al. (2020) 'Dementia Diagnosis in Seven Languages: The Addenbrooke's Cognitive Examination-III in India', Archives of Clinical Neuropsychology. Oxford University Press, 35(5), pp. 528-538. doi: 10.1093/arclin/acaa013.

Merrit, R. (2007) Tratado de Neurologia. 11. ed. Edited by L. Rowland. Rio de Janeiro: Guanabara Koogan.

Mioshi, E. et al. (2006) 'The Addenbrooke's Cognitive Examination Revised (ACE-R): a brief cognitive test battery for dementia screening', International Journal of Geriatric Psychiatry, 21(11), pp. 1078-1085. doi: 10.1002/gps. 1610.

Muslimović, D. et al. (2005) 'Cognitive profile of patients with newly diagnosed Parkinson disease', Neurology. Lippincott Williams and Wilkins, 65(8), pp. 1239-1245. doi: 10.1212/01.wnl.0000180516.69442.95.

Muslimović, D. et al. (2007) 'Course of cognitive decline in Parkinson's disease: A meta-analysis', Journal of the International Neuropsychological Society. Cambridge University Press, 13(6), pp. 920-932. doi: 10.1017/S1355617707071160.

Nardone, R. et al. (2017) 'Cortical afferent inhibition abnormalities reveal cholinergic dysfunction in Parkinson's disease: a reappraisal', Journal of Neural Transmission, 124(11), pp. 1417-1429. doi: 10.1007/s00702-017-1775-y.

Newman, J. P. (2005) 'Brief assessment of cognitive mental status in Hebrew: Addenbrooke's Cognitive Examination', Israel Medical Association Journal, 7(7), pp. 451-452.

Nitrini, R. et al. (1994) 'Testes neuropsicológicos de aplicações simples para o diagnóstico de demência', Arquivos de Neuro-Psiquiatria, 52(4), pp. 457-465. doi: 10.1590/S0004-282X1994000400001.

Nitrini, R. et al. (2004) 'Performance of illiterate and literate nondemented elderly subjects in two tests of long-term memory', Journal of the International Neuropsychological Society, 10(4), pp. 634-638. doi: 10.1017/S1355617704104062.

Noone, P. (2015) 'Addenbrooke's Cognitive Examination-III', Occupational 
Medicine, 65(5), pp. 418-420. doi: 10.1093/occmed/kqv041.

Ozdilek, B. and Kenangil, G. (2014) 'Validation of the turkish version of the montreal cognitive assessment scale (MoCA-TR) in patients with parkinsons disease', Clinical Neuropsychologist, 28(2), pp. 333-343. doi: 10.1080/13854046.2014.881554.

Papagno, C. and Trojano, L. (2018) 'Cognitive and behavioral disorders in Parkinson's disease: an update. I: cognitive impairments.', Neurological Sciences, 39(2), pp. 215-223. doi: 10.1007/s10072-017-3154-8.

Peixoto, B. et al. (2018) 'Validation of the Portuguese version of Addenbrooke's Cognitive Examination III in mild cognitive impairment and dementia', Advances in Clinical and Experimental Medicine. Wroclaw University of Medicine, 27(6), pp. 781-786. doi: 10.17219/acem/68975.

Peralta, C. et al. (2019) 'Recent Advancement and Clinical Implications of 18FDG-PET in Parkinson's Disease, Atypical Parkinsonisms, and Other Movement Disorders', Current Neurology and Neuroscience Reports, 19(8), p. 56. doi: 10.1007/s11910-019-0966-3.

Petrelli, A. et al. (2015) 'Cognitive training in Parkinson's disease reduces cognitive decline in the long term', European Journal of Neurology, 22(4), pp. 640-647. doi: 10.1111/ene.12621.

Pfeffer, R. I. et al. (1982) 'Measurement of functional activities in older adults in the community', Journal of Gerontology, 37(3), pp. 323-329. doi: 10.1093/geronj/37.3.323.

Pigliautile, M. et al. (2019) 'Italian version and normative data of Addenbrooke's Cognitive Examination III', International Psychogeriatrics. Cambridge University Press, 31(2), pp. 241-249. doi: 10.1017/S104161021800073X.

Pigott, M. et al. (2015) 'Longitudinal study of normal cognition in Parkinson disease', Neurology, 85(15), pp. 1276-1282.

Piovezan, M. R. et al. (2007) 'Cognitive function assessment in idiopathic Parkinson's disease', Arquivos de Neuro-Psiquiatria, 65(4 A), pp. 942-946.

Portet, F., Gabelle, A. and Touchon, J. (2006) 'Parkinson's disease dementia and Lewy body dementia', Psychologie \& Neuropsychiatrie du Vleillissement, (Spec No 1), pp. S35-50.

Porto, C. S. et al. (2003) 'Brazilian version of the Mattis Dementia Rating Scale : Diagnosis of mild dementia in Alzheimer's Disease', Arq Neuropsiquiatr, 61(2b), pp. 339-345.

Pringsheim, T. et al. (2014) 'The prevalence of Parkinson's disease: a systematic review and meta-analysis', Movement Disorders, 29(13), pp. 158390. doi: $10.1002 / \mathrm{mds} .25945$.

Qassem, T. et al. (2020) 'Validation of the Addenbrooke's Cognitive Examination-III in Mild Cognitive Impairment in Arabic Speakers in Egypt', Dementia and Geriatric Cognitive Disorders. S. Karger AG, pp. 1-5. doi: $10.1159 / 000510952$. 
Reich, E. (1997) 'Demencias subcorticales en enfermidades extrapiramidales', in Mangone, C. et al. (eds) Demencia - Enfoque Multidisciplinario. Buenos Aires: Bayer, pp. 157-182.

Reyes, M. A. et al. (2009) 'Addenbrooke's Cognitive Examination validation in Parkinson's disease', European Journal of Neurology, 16(1), pp. 142-147. doi: 10.1111/j.1468-1331.2008.02384.x.

Rocha, M. S. G. et al. (2014) 'Addenbrooke's Cognitive Examination-Revised is accurate for detecting dementia in Parkinson's disease patients with low educational level', Dementia \& Neuropsychologia. Associação de Neurologia Cognitiva e do Comportamento, 8(1), pp. 20-25. doi: 10.1590/S198057642014DN81000004.

Rolinski, M. et al. (2012) 'Cholinesterase inhibitors for dementia with Lewy bodies, Parkinson's disease dementia and cognitive impairment in Parkinson's disease', The Cochrane Database of Systematic Reviews, (3), p. CD006504. doi: 10.1002/14651858.CD006504.pub2.

Salazar, R. D. et al. (2017) 'Dual tasking in Parkinson's disease: Cognitive consequences while walking', Neuropsychology, 31(6), pp. 613-623. doi: 10.1037/neu0000331.

Sanchez, M. A. dos S. and Lourenço, R. A. (2009) 'Informant Questionnaire on Cognitive Decline in the Elderly (IQCODE): cross-cultural adaptation for use in Brazil', Cadernos de Saude Publica, 25(7), pp. 1455-1465. doi: 10.1590/S0102311X2009000700003.

Sarasola, D. et al. (2005) 'Validity of the Spanish version of the Addenbrooke's Cognitive Examination for the diagnosis of dementia and to differentiate Alzheimer's disease and frontotemporal dementia', Revista de Neurologia. Revista de Neurologia, 41(12), pp. 717-721. doi: 10.33588/rn.4112.2004625.

Schrag, A. et al. (2007) 'Rate of clinical progression in Parkinson's disease. A prospective study', Movement Disorders, 22(7), pp. 938-945. doi: 10.1002/mds.21429.

Senda, M. et al. (2020) 'Diagnostic utility of the Addenbrooke's Cognitive Examination - III (ACE-III), Mini-ACE, Mini-Mental State Examination, Montreal Cognitive Assessment, and Hasegawa Dementia Scale-Revised for detecting mild cognitive impairment and dementia', Psychogeriatrics. Blackwell Publishing Ltd, 20(2), pp. 156-162. doi: 10.1111/psyg.12480.

Sobreira, E. et al. (2015) 'Rastreio de comprometimento cognitivo em pacientes com doença de parkinson: Validade diagnóstica das versões brasileiras da montreal cognitive assessment e do addenbrooke's cognitive examinationrevised', Arquivos de Neuro-Psiquiatria. Associacao Arquivos de NeuroPsiquiatria, 73(11), pp. 929-933. doi: 10.1590/0004-282X20150156.

Sollinger, A. B. et al. (2010) 'Mild cognitive impairment in Parkinson's disease: Subtypes and motor characteristics', Parkinsonism and Related Disorders. Parkinsonism Relat Disord, 16(3), pp. 177-180. doi: 10.1016/j.parkreldis.2009.11.002.

Steidl, E. M. dos S., Ziegler, J. R. and Ferreira, F. V. (2007) 'Doença de 
Parkinson: revisão bibliográfica', Revista Eletrônica Disciplinarum scientia. Ciências da Saúde, 8(1), pp. 115-129. Available at: https://periodicos.ufn.edu.br/index.php/disciplinarumS/article/view/921 (Accessed: 20 November 2020).

Stella, F. et al. (2007) 'Early impairment of cognitive functions in Parkinson's disease', Arquivos de Neuro-Psiquiatria, 65(2B), pp. 406-410.

Stokholm, J. et al. (2009) 'Validation of the danish addenbrooke's cognitive examination as a screening test in a memory clinic', Dementia and Geriatric Cognitive Disorders, 27(4), pp. 361-365. doi: 10.1159/000209271.

Straus, E., Sherman, E. M. S. and Spreen, O. (2006) A compendium of neuropsychological tests: administration, norms, and commentary. 3rd edn. New York: Oxford University Press.

Takenoshita, S. et al. (2019) 'Validation of Addenbrooke's cognitive examination III for detecting mild cognitive impairment and dementia in Japan', BMC Geriatrics. BioMed Central Ltd., 19(1), p. 123. doi: 10.1186/s12877-019-1120-4.

Taylor, A. E., Saint-Cyr, J. A. and Lang, A. E. (1988) 'Idiopathic Parkinson's disease: revised concepts of cognitive and affective status.', The Canadian journal of neurological sciences, 15(2), pp. 106-113. doi: 10.1017/s031716710002744x.

Tedrus, G. M. A. S., Fonseca, L. C., Letro, G. H., Bossoni, A. S. and Bastos, S. A. (2009) 'Dementia and mild cognitive impairment in Parkinson's disease', Arquivos de Neuro-Psiquiatria, 67(4), p. 1164. doi: S0004-282X2009000600038 [pii].

Tedrus, G. M. A. S., Fonseca, L. C., Letro, G. H., Bossoni, A. S. and Samara, A. B. (2009) 'Dementia and mild cognitive impairment in patients with Parkinson's disease', Arquivos de Neuro-Psiquiatria, 67(2 B), pp. 423-427. doi: 10.1590/S0004-282X2009000300010.

Teive, H. A. G. (2000) Doença de Parkinson: um guia prático para pacientes e familiares.

Teive, H. A. G. and Meneses, M. S. (2003) Doenca de parkinson. Rio de Janeiro: Guanabara Koogan.

Terpening, Z. et al. (2011) 'Utility of the Addenbrooke's Cognitive Examination Revised for the diagnosis of dementia syndromes', Australasian Journal on Ageing, 30(3), pp. 113-118. doi: 10.1111/j.1741-6612.2010.00446.x.

Todorova, A., Jenner, P. and Ray Chaudhuri, K. (2014) 'Non-motor Parkinson's: integral to motor Parkinson's, yet often neglected', Practical Neurology, 14(5), pp. 310-322. doi: 10.1136/practneurol-2013-000741.

Wakabayashi, K. et al. (2007) 'The Lewy body in Parkinson's disease: Molecules implicated in the formation and degradation of a-synuclein aggregates', in Neuropathology, pp. 494-506. doi: 10.1111/j.14401789.2007.00803.x.

Wang, B.-R. et al. (2019) 'Comparative diagnostic accuracy of ACE-III and MoCA for detecting mild cognitive impairment.', Neuropsychiatric disease and 
treatment. Dove Medical Press Ltd., 15, pp. 2647-2653. doi: 10.2147/NDT.S212328.

Wang, B. R. et al. (2017) 'Validation of the Chinese version of Addenbrooke's Cognitive Examination III for diagnosing dementia', International Journal of Geriatric Psychiatry. John Wiley and Sons Ltd, 32(12), pp. e173-e179. doi: $10.1002 / g p s .4680$.

Weschsler, D. (1987) Manual for Weschsler Memory Scale-revised. San Antonio, TX: The Psychological Corporation.

Williams-Gray, C. H. et al. (2007) 'Evolution of cognitive dysfunction in an incident Parkinson's disease cohort', Brain, 130(7), pp. 1787-1798. doi: 10.1093/brain/awm111.

Williams-Gray, C. H. et al. (2009) 'The distinct cognitive syndromes of Parkinson's disease: 5 year follow-up of the CamPalGN cohort', Brain, 132(11), pp. 2958-2969. doi: 10.1093/brain/awp245.

Winer, J. R. et al. (2018) 'Associations Between Tau, $\beta$-Amyloid, and Cognition in Parkinson Disease', JAMA neurology, 75(2), pp. 227-235. doi: 10.1001/jamaneurol.2017.3713.

Wirdefeldt, K. et al. (2011) 'Epidemiology and etiology of Parkinson's disease: a review of the evidence.', European journal of epidemiology, 26 Suppl 1, pp. S158. doi: 10.1007/s10654-011-9581-6.

Wolters, A. F. et al. (2019) 'Resting-state fMRI in Parkinson's disease patients with cognitive impairment: A meta-analysis.', Parkinsonism \& related disorders, 62, pp. 16-27. doi: 10.1016/j.parkreldis.2018.12.016.

Yoshida, H. et al. (2012) 'Validation of the revised Addenbrooke's Cognitive Examination (ACE-R) for detecting mild cognitive impairment and dementia in a Japanese population', International Psychogeriatrics, 24(1), pp. 28-37. doi: 10.1017/S1041610211001190.

Zgaljardic, D. J. et al. (2003) 'A Review of the Cognitive and Behavioral Sequelae of Parkinson's Disease: Relationship to Frontostriatal Circuitry', Cognitive and Behavioral Neurology. Cogn Behav Neurol, 16(4), pp. 193-210. doi: 10.1097/00146965-200312000-00001.

Zhu, K., van Hilten, J. J. and Marinus, J. (2014) 'Predictors of dementia in Parkinson's disease; findings from a 5-year prospective study using the SCOPA-COG', Parkinsonism \& related disorders. England, 20(9), pp. 980-985. doi: 10.1016/j.parkreldis.2014.06.006. 


\section{APÊNDICE}

\section{Trabalhos apresentados no período da pós-graduação}

1 Uso da Addenbrooke's Cognitive Examination III (ACE-III) em pacientes com doença de Parkinson idiopática

\subsection{Eventos (congressos, jornadas e conferências)}

Jornada Científica, Unidade SARAH Salvador (2017), como apresentação oral.

Congresso Brain, Behavior and Emotions (2019), como apresentação oral.

Apresentado na The 15th International Conference on Alzheimer's \& Parkinson's Diseases (e-pôster com gravação de vídeo de 5 minutos), 914/03/2021.

\section{Trabalhos científicos relacionados ao estudo vigente}

\section{1 Grupo de treino cognitivo na doença de Parkinson (CCL-DP)}

2.1.1 Eventos (congressos, jornadas e conferências)

Ano 2018:

Apresentação Oral (agosto): Congresso Brasileiro de Medicina Física e Reabilitação - Salvador/BA (apresentado o projeto, delineamento do grupo de intervenção cognitiva).

2.1.2 Trabalhos apresentados em eventos e divulgados em periódicos ou anais:

Pôster com Apresentação Oral (novembro): $3^{\circ}$ Congresso Internacional e de Neuropsicologia e $17^{\circ}$ Congresso Brasileiro de Neuropsicologia da SBNp - São Paulo/SP. "Treino da atenção e funções executivas na doença de Parkinson: Um estudo piloto". https://sbnpbrasil.com.br/wpcontent/uploads/2019/03/Anais-do-XVII-Congresso-da-SBNp.pdf

Ano 2019 (após aumento da casuística, grupo clínico):

Apresentação Oral (junho): Congresso Brain, Behavior and Emotions Brasília/DF. "Treino Cognitivo (TC) na doença de Parkinson: Experiência em um hospital de reabilitação". 
Pôster com Apresentação Oral (setembro): Congresso Internacional de Doença de Parkinson e Desordens do Movimento (Movement Disorder Society) - Nice/França. "Cognitive training in Parkinson's disease: Experience in a rehabilitation hospital in Brazil". https://www.mdsabstracts.org/abstract/cognitive-training-in-parkinsonsdisease-experience-in-a-rehabilitation-hospital-from-brazil/

Pôster com Apresentação Oral (outubro): IX Congresso Brasileiro de Alzheimer e VII Congresso Brasileiro de Neuropsiquiatria Geriátrica São Paulo/SP. "Cognitive training in Parkinson's disease: Experience in a rehabiliation hospital".

Ano 2020 (ajuste metodológico - estudo controlado e randomizado): "The impact of cognitive intervention on cognitive symptoms and quality of life in idiopathic Parkinson's disease: a randomized and controlled study".

Jornada Científica (SARAH): Apresentação oral (agosto).

Apresentação como vídeo (setembro): Congresso Internacional e Brasileiro de Neuropsicologia.

Aceito para o Congresso Brain, Behavior and Emotions, apresentação pôster eletrônico (novembro).

Ano 2021:

Aceito para The 15th International Conference on Alzheimer's \& Parkinson's Diseases (e-pôster com gravação de vídeo de 5 minutos), 9$14 / 03 / 2021$.

\subsubsection{Publicação:}

Aceito para publicação na Revista Dementia \& Neuropsychologia, em outubro/2020, após ajuste metodológico (controlado e randomizado).

\subsection{Associação entre desempenho de marcha e cognição da doença de Parkinson}

2.2.1 Eventos (congressos, jornadas e conferências):

Jornadas científicas em 2017 (apresentação oral) e 2019 (pôster eletrônico), Unidade SARAH Salvador.

2.2.2 Trabalhos apresentados em eventos e divulgados em periódicos ou anais: 
Junho de 2018: Congresso Brain, Behavior and Emotions (Modalidade Pôster - com tamanho amostral de 35 pacientes). Trabalho premiado, Jovem Pesquisador. "Relação entre desempenho cognitivo e parâmetros de marcha em pacientes com doença de Parkinson".

Junho de 2019: Congresso Brain, Behavior and Emotions (Apresentação Oral - com tamanho amostral de 65 pacientes). Trabalho premiado, Jovem Pesquisador. "Relação entre desempenho cognitivo e mobilidade em pacientes com doença de Parkinson: Um estudo transversal".

Agosto de 2019: NEURODC (Apresentação como Pôster - com tamanho amostral de 65 pacientes). "Relashionship between cognitive performance and obility in patients with Parkinson's disease: A crosssectional study".

Setembro de 2019: Apresentação (Modalidade Pôster com Apresentação Oral, tamanho amostral de 65 pacientes) - Congresso Internacional de Doença de Parkinson e Desordens do Movimento (Movement Disorder Society) - Nice/França. "Relationship between cognitive performance and motor dysfunction in patients with Parkinson's disease: A cross-sectional study".

https://www.mdsabstracts.org/abstract/relationship-between-cognitiveperformance-and-mobility-in-patients-with-parkinsons-disease-a-crosssectional-study $/$

Ano 2020: (versão final, casuística total de 107 pacientes):

Jornada Científica SARAH (agosto - apresentação oral). "Associações transversais entre cognição e mobilidade em pacientes com a doença de Parkinson".

$X V$ Congresso Internacional e Brasileiro de Neuropsicologia (apresentação com gravação de vídeo). "Cross-sectional associations between cognition and mobility in Parkinson's disease".

Congresso Brain, Behavior and Emotions (aceito na modalidade pôster eletrônico). Trabalho premiado, Jovem Pesquisador. "Cognitive associations with mobility in patients with mild cognitive impairment in Parkinson's disease".

Ano 2021:

Aceito para The 15th International Conference on Alzheimer's \& Parkinson's Diseases (e-pôster com gravação de vídeo de 5 minutos), 9$14 / 03 / 2021$. 


\subsubsection{Publicações:}

Dezembro de 2019: Revista Dementia \& Neuropsychologia, quando o estudo tinha o tamanho amostral de 65 pacientes.

Nariana Mattos Figueiredo Sousa and Roberta Correa Macedo "Relationship between cognitive performance and mobility in patients with Parkinson's Disease: A cross-sectional study". Dement Neuropsychol. 2019 Oct-Dec; 13(4): 403-409. doi: 10.1590/198057642018dn13-040006

https://www.ncbi.nlm.nih.gov/pmc/articles/PMC6907702/

Ano 2020: Publicação na revista Dementia \& Neuropsychologia (aceito em outubro). "Cross-sectional associations between cognition and mobility in Parkinson's disease". 